\title{
S3-Leitlinie der Deutschen Gesellschaft für Gastroenterologie, Verdauungs- und Stoffwechselkrankheiten (DGVS) zur Prophylaxe, Diagnostik und Therapie der Hepatitis-B-Virusinfektion
}

\author{
(AWMF-Register-Nr. 021-11)
}

Markus Cornberg', ${ }^{1}$, Lisa Sandmann², Ulrike Protzer ${ }^{3}$, Claus Niederau $^{4}$, Frank Tacke ${ }^{5}$, Thomas Berg ${ }^{6}$, Dieter Glebe ${ }^{7}$, Wolfgang Jilg ${ }^{8}$, Heiner Wedemeyer ${ }^{2}$, Stefan Wirth ${ }^{9}$, Christoph Höner zu Siederdissen ${ }^{2}$, Petra Lynen-Jansen ${ }^{10}$, Pia van Leeuwen ${ }^{10}$, jörg Petersen ${ }^{11}$

Collaborators:

Sandra Ciesek, Jörg Timm, Viola Knop, Peter Schirmacher, Christian Schüttler, Peter Buggisch, Andrea Tannapfel, Christoph Jochum, Holger Hinrichsen, Achim Kautz ${ }^{12}$, Kai-Henrik Peiffer, Christoph Sarrazin, Eckart Schott, Nektarios Dikopoulos, Daniela Kroy, Martin Sprinzl, Florian van Bömmel, Ingo van Thiel12, Johannes Vermehren, Karsten Wursthorn, Stefan Zeuzem, Michael P. Manns, Christoph Berg, Kerstin Herzer, Benjamin Maasoumy, Martina Sterneck, Niklas Aehling, Egbert Trowe ${ }^{13}$, Christian Strassburg ${ }^{14}$, Wolfram Gerlich, Birgit Kallinowski, Julian Schulze zur Wiesch, Jens Verheyen, Sabine Wicker, Anika Wranke, Hartwig Klinker, Patrick Ingiliz, Stefan Christensen, Patrick Gerner, Gunter Flemming, Jan de Laffolie, Thomas Lang, Michael Melter, Wolf-Dietrich Huber

Institute

1 Deutsches Zentrum für Infektionsforschung (DZIF), Klinik

für Gastroenterologie, Hepatologie und Endokrinologie,

Medizinische Hochschule Hannover, Hannover; Centre for individualised infection Medicine (CiiM), Hannover

2 Klinik für Gastroenterologie, Hepatologie und Endokrinologie, Medizinische Hochschule Hannover, Hannover

3 Institut für Virologie, Technische Universität München/ Helmholtz Zentrum München, München

4 Oberhausen

5 Medizinische Klinik m. S. Hepatologie und Gastroenterologie, Charité Universitätsmedizin Berlin, Berlin

6 Klinik und Poliklinik für Gastroenterologie und Rheumatologie, Universitätsklinikum Leipzig, Leipzig

7 Institut für Medizinische Virologie, Nationales Referenzzentrum für Hepatitis-B-Viren und Hepatitis-DViren, Justus-Liebig-Universität Gießen, Gießen

8 Institut für Medizinische Mikrobiologie und Hygiene, Universität Regensberg, Regensburg

9 Zentrum für Kinder- und Jugendmedizin, Helios Universitätsklinikum Wuppertal, Wuppertal
10 Deutsche Gesellschaft für Gastroenterologie, Verdauungsund Stoffwechselkrankheiten (DGVS), Berlin

11 IFI Institut für Interdisziplinäre Medizin an der Asklepios Klinik St. Georg, Hamburg

12 Deutsche Leberhilfe e. V.

13 Lebertransplantierte Deutschland e. V.

14 Bonn, Deutsche Transplantationsgesellschaft (DTG)

Bibliografie

Z Gastroenterol 2021; 59: 691-776

DOI 10.1055/a-1498-2512

ISSN 0044-2771

(C) 2021. Thieme. All rights reserved.

Georg Thieme Verlag KG, Rüdigerstraße 14,

70469 Stuttgart, Germany

Korrespondenzadresse

Prof. Dr. Markus Cornberg

Klinik für Gastroenterologie, Hepatologie und Endokrinologie Medizinische Hochschule Hannover, Carl-Neuberg-Str. 1,

30625 Hannover, Deutschland

Tel.: +49/5 11/5326821

cornberg.markus@mh-hannover.de 


\begin{tabular}{|c|c|c|c|c|c|}
\hline \multicolumn{2}{|c|}{ Inhaltsverzeichnis } & Seite & \multicolumn{2}{|c|}{ Inhaltsverzeichnis } & Seite \\
\hline \multicolumn{2}{|c|}{ Vorwort } & 693 & \multirow[t]{2}{*}{3.5} & \multirow{2}{*}{$\begin{array}{l}\text { Wie sind Therapieansprechen und Resistenz bei } \\
\text { NA-Therapie definiert und wie wird das Therapie- } \\
\text { ansprechen einer NA-Therapie überprüft? }\end{array}$} & \multirow[t]{2}{*}{721} \\
\hline \multicolumn{2}{|c|}{ Zielorientierung der Leitlinie } & 694 & & & \\
\hline \multicolumn{2}{|c|}{$\begin{array}{l}\text { Zusammensetzung der Leitliniengruppe und Beteiligung von } \\
\text { Interessengruppen }\end{array}$} & 694 & 3.6 & $\begin{array}{l}\text { Wie ist das Vorgehen bei nicht ausreichendem } \\
\text { Therapieansprechen oder Resistenzentwicklung? }\end{array}$ & 722 \\
\hline \multicolumn{2}{|c|}{ Grundlagen der Methodik } & 695 & \multirow{2}{*}{3.7} & \multirow{2}{*}{$\begin{array}{l}\text { Was ist bei Langzeittherapie mit Nukleosid- oder } \\
\text { Nukleotidanaloga zu beachten? }\end{array}$} & \multirow{2}{*}{723} \\
\hline Exte & Begutachtung und Verabschiedung & 697 & & & \\
\hline \multicolumn{2}{|c|}{ Verbreitung und Implementierung } & 698 & \multirow{3}{*}{3.8} & \multirow{3}{*}{$\begin{array}{l}\text { Wann kann eine antivirale Therapie der Hepatitis B } \\
\text { mit Nukleosid- oder Nukleotidanaloga beendet } \\
\text { werden? }\end{array}$} & \multirow[t]{3}{*}{725} \\
\hline 1 & Diagnostik der Hepatitis-B-Virusinfektion & 699 & & & \\
\hline \multirow{2}{*}{1.1} & \multirow{2}{*}{$\begin{array}{l}\text { Wie und bei wem soll eine Diagnostik auf eine } \\
\text { HBV-Infektion erfolgen? }\end{array}$} & \multirow{2}{*}{699} & & & \\
\hline & & & 3.9 & $\begin{array}{l}\text { Wie sollen HBV-Patienten mit Leberzirrhose antiviral } \\
\text { behandelt werden? }\end{array}$ & 727 \\
\hline \multirow[t]{2}{*}{1.2} & \multirow{2}{*}{$\begin{array}{l}\text { Wie ist das weitere Vorgehen nach initialer } \\
\text { HBV-Diagnostik (HBsAg/Anti-HBc)? }\end{array}$} & \multirow[t]{2}{*}{700} & & & \\
\hline & & & 3.10 & $\begin{array}{l}\text { Wie sollen Patienten mit extrahepatischen } \\
\text { Manifestationen behandelt werden? }\end{array}$ & 728 \\
\hline 1.3 & $\begin{array}{l}\text { Welche ergänzende Diagnostik ist bei Erstdiagnose } \\
\text { einer HBV-Infektion erforderlich? }\end{array}$ & 702 & 3.11 & Wie sollen Patienten mit eingeschränkter Nieren- & 728 \\
\hline \multirow{2}{*}{1.4} & \multirow{2}{*}{$\begin{array}{l}\text { Wann ist eine Hepatitis-Delta-Virus-Diagnostik indi- } \\
\text { ziert? Wie wird eine Hepatitis Delta diagnostiziert? }\end{array}$} & 702 & & ehandelt werden? & \\
\hline & & & 3.12 & Welche Behandlungsempfehlungen werden für & 729 \\
\hline 1.5 & Wie soll die Verlaufsdiagnostik von Patienten ohne & 703 & & scnwangere HBsAg-positive Patientinnen gegeden? & \\
\hline & antivirale Therapie erfolgen? & & 3.13 & Wie kann eine Hepatitis-B-Reaktivierung unter & 731 \\
\hline 1.6 & Wie sollte das Therapie-Monitoring bei chronischer & 704 & & Infoltion & \\
\hline & Hepatitis B aussehen? & & 4 & $\begin{array}{l}\text { Infektionen mit Hepatitis-B-Viren im Zusammen- } \\
\text { hang mit Organtransplantationen }\end{array}$ & 734 \\
\hline 1.7 & $\begin{array}{l}\text { Welche Patienten mit chronischer Hepatitis B sollten } \\
\text { in ein HCC-Früherkennungsprogramm aufgenom- } \\
\text { men werden und wie sollte dieses durchgeführt }\end{array}$ & 705 & 4.1 & $\begin{array}{l}\text { Wie ist das Management von Patienten mit } \\
\text { HBV-Infektion vor LTx? }\end{array}$ & 734 \\
\hline & werden? & & 4.2 & Was versteht man unter einer HBV-Reinfektion? & 735 \\
\hline 1.8 & $\begin{array}{l}\text { Bei welchen Patienten ist eine Leberbiopsie indiziert, } \\
\text { bei welchen Patienten eine nichtinvasive Fibrose- } \\
\text { Diagnostik? }\end{array}$ & 707 & 4.3 & $\begin{array}{l}\text { Wie ist das Management von Patienten mit HBV-In- } \\
\text { fektion nach LTx? Wie erfolgt die Reinfektionspro- } \\
\text { phylaxe? }\end{array}$ & 735 \\
\hline 2 & $\begin{array}{l}\text { Indikationsstellung zur Therapie der } \\
\text { Hepatitis-B-Virusinfektion }\end{array}$ & 708 & 4.4 & $\begin{array}{l}\text { Wie ist das therapeutische Vorgehen bei } \\
\text { nachgewiesener HBV-Reinfektion? }\end{array}$ & 738 \\
\hline 2.1 & $\begin{array}{l}\text { Akute Hepatitis B: Kann die klinische Heilungsrate } \\
\text { durch eine antivirale Therapie erhöht werden? Kann } \\
\text { durch eine antivirale Therapie die Krankheitsdauer }\end{array}$ & 708 & 4.5 & $\begin{array}{l}\text { Wie ist das Management von HBV-infizierten } \\
\text { Patienten mit kombinierter Organtransplantation } \\
\text { (z. B. Leber plus Niere)? }\end{array}$ & 738 \\
\hline & $\begin{array}{l}\text { verkürzt und die Schwere der Erkrankung reduziert } \\
\text { werden? }\end{array}$ & & 4.6 & Wie ist das Management von Patienten, die für eine & 739 \\
\hline 2.2 & Chronische Hepatitis-B-Virusinfektion (Monoinfek- & 709 & & evaluiert werden? & \\
\hline & tion): Welche Patienten sollen therapiert werden? & & 4.7 & Wie ist das Management von Patienten mit positiver & 740 \\
\hline 2.3 & $\begin{array}{l}\text { Sollen Patienten mit hoch virämischer chronischer } \\
\text { HBV-Infektion (früher als „immuntolerante“ } \\
\text { Patienten bezeichnet) behandelt werden? }\end{array}$ & 712 & & $\begin{array}{l}\text { HBV-Serologie nach Transplantation anderer solider } \\
\text { Organe (nicht Leber)? Wann, wie und bei wem wird } \\
\text { eine Prophylaxe durchgeführt? }\end{array}$ & \\
\hline 2.4 & $\begin{array}{l}\text { Sollen Patienten mit niedrig virämischer chronischer } \\
\text { HBV-Infektion (früher als „inaktive Träger“ bezeich- } \\
\text { net) behandelt werden? }\end{array}$ & 712 & 4.8 & $\begin{array}{l}\text { Wie ist das Management von Patienten vor und nach } \\
\text { Stammzelltransplantation (SZT)? Wann, wie und bei } \\
\text { wem wird eine antivirale Therapie bzw. Prophylaxe }\end{array}$ & 740 \\
\hline 3 & Therapie der chronischen Hepatitis-B-Virusinfektion & 713 & & durchgeführt? & \\
\hline 3.1 & $\begin{array}{l}\text { Was sind die Ziele der Therapie der chronischen } \\
\text { Hepatitis B? }\end{array}$ & 713 & 4.9 & $\begin{array}{l}\text { Wie ist das Management von Patienten mit } \\
\text { De-novo-HBV-Infektion nach Organtransplantation? }\end{array}$ & 742 \\
\hline 3.2 & $\begin{array}{l}\text { Welche grundsätzlichen Fragen sind bei der Thera- } \\
\text { pieplanung der Hepatitis B in der Primärtherapie zu }\end{array}$ & 714 & 4.10 & $\begin{array}{l}\text { Wie ist das Management von Patienten, die ein } \\
\text { Organ eines Anti-HBc-positiven Spenders erhalten? }\end{array}$ & 742 \\
\hline & berücksichtigen? & & 4.11 & Wie ist das Management von Patienten, die ein & 744 \\
\hline 3.3 & Wie soll eine Therapie mit pegyliertem Interferon & 718 & & Organ eines HBsAg-positiven Spenders erhalten? & \\
\hline & alfa durchgeführt werden? & & 4.12 & Wer sollte vor einer Organtransplantation gegen & 745 \\
\hline 3.4 & Wie ist der Stellenwert einer Kombinationstherapie & 719 & & HBV geimpft werden & \\
\hline & mit pegyliertem Interferon alfa und einem Nukleos & & 5 & Immunprophylaxe der Hepatitis-B-Virusinfektion & 746 \\
\hline & & & 5.1 & Wer soll gegen Hepatitis B geimpft werden? & 746 \\
\hline
\end{tabular}




\begin{tabular}{|c|c|c|}
\hline \multicolumn{2}{|c|}{ Inhaltsverzeichnis } & \multirow{2}{*}{$\begin{array}{l}\text { Seite } \\
746\end{array}$} \\
\hline 5.2 & $\begin{array}{l}\text { Wann sollte die Impfung gegen Hepatitis B } \\
\text { durchgeführt werden? }\end{array}$ & \\
\hline 5.3 & $\begin{array}{l}\text { Ist es vor einer Hepatitis-B-Impfung notwendig zu } \\
\text { testen, ob bereits Kontakt mit dem Hepatitis-B-Virus } \\
\text { stattgefunden hat? }\end{array}$ & 747 \\
\hline 5.4 & $\begin{array}{l}\text { Ist es nach einer Hepatitis-B-Impfung notwendig zu } \\
\text { testen, ob die Impfung erfolgreich war? }\end{array}$ & 748 \\
\hline 5.5 & $\begin{array}{l}\text { Ist nach erfolgreicher Impfung gegen Hepatitis B } \\
\text { eine Auffrischimpfung notwendig? }\end{array}$ & 749 \\
\hline 5.6 & $\begin{array}{l}\text { Wie ist bei Nichtansprechen auf die Hepatitis-B- } \\
\text { Impfung (Anti-HBs nach } 3 \text { Impfungen < } 10 \text { IU/I) zu } \\
\text { verfahren? }\end{array}$ & 751 \\
\hline 5.7 & $\begin{array}{l}\text { Wie ist bei Personen zu verfahren, deren Anti-HBs- } \\
\text { Konzentration } 4-8 \text { Wochen nach Grundimmunisie- } \\
\text { rung 10-99 IU/I beträgt (gesunde Lowresponder)? }\end{array}$ & 751 \\
\hline 5.8 & $\begin{array}{l}\text { Was ist bei der Impfung von Immunsupprimierten } \\
\text { generell zu beachten? }\end{array}$ & 751 \\
\hline 5.9 & $\begin{array}{l}\text { Wie ist die Postexpositionsprophylaxe bei } \\
\text { Neugeborenen durchzuführen? }\end{array}$ & 752 \\
\hline 5.10 & $\begin{array}{l}\text { Wie ist bei nicht gegen Hepatitis B Immunen im } \\
\text { Falle eines Kontakts mit HBV-haltigem Material zu } \\
\text { verfahren? }\end{array}$ & 753 \\
\hline 5.11 & $\begin{array}{l}\text { Gibt es Sicherheitsbedenken oder Kontraindika- } \\
\text { tionen gegen eine Hepatitis-B- Impfung? }\end{array}$ & 753 \\
\hline 5.12 & $\begin{array}{l}\text { Gibt es Tätigkeitseinschränkungen von HBV-Infizier- } \\
\text { ten im Gesundheitswesen (HCW, healthcare worker)? }\end{array}$ & 754 \\
\hline 6 & Management der relevanten HBV-Koinfektionen & 755 \\
\hline 6.1 & $\begin{array}{l}\text { Bei welchen Patienten mit HBV/HDV-Infektion soll } \\
\text { eine Therapie durchgeführt werden? Wie soll die } \\
\text { antivirale Therapie durchgeführt werden? }\end{array}$ & 755 \\
\hline 6.2 & $\begin{array}{l}\text { Bei welchen Patienten mit HBV/HCV-Koinfektion soll } \\
\text { eine Therapie durchgeführt werden? Wie soll die } \\
\text { antivirale Therapie durchgeführt werden? }\end{array}$ & 757 \\
\hline 6.3 & $\begin{array}{l}\text { Wie sollte die antivirale Therapie bei HBV/HCV/HDV- } \\
\text { Dreifachinfektionen durchgeführt werden? }\end{array}$ & 759 \\
\hline 6.4 & $\begin{array}{l}\text { Bei welchen Patienten mit HBV/HIV-Koinfektion soll } \\
\text { eine Therapie durchgeführt werden? Wie soll die } \\
\text { antivirale Therapie bei Patienten mit HBV/HIV-Koin- } \\
\text { fektion durchgeführt und überwacht werden? }\end{array}$ & 759 \\
\hline 7 & $\begin{array}{l}\text { Hepatitis-B-Virusinfektionen im Kindes- und } \\
\text { Jugendalter }\end{array}$ & 760 \\
\hline 7.1 & Wie wird die Diagnose gestellt? & 761 \\
\hline 7.2 & $\begin{array}{l}\text { Welche Therapiemöglichkeiten und -ziele bestehen } \\
\text { bei einer Hepatitis B im Kindes- und Jugendalter? }\end{array}$ & 762 \\
\hline 7.3 & Welche prophylaktischen Maßnahmen sind sinnvoll? & 764 \\
\hline
\end{tabular}

\section{Besonderer Hinweis}

Die Medizin unterliegt einem fortwährenden Entwicklungsprozess, sodass alle Angaben, insbesondere zu diagnostischen und therapeutischen Verfahren, immer nur dem Wissensstand zur Zeit der Drucklegung der Leitlinie entsprechen können. Hinsichtlich der angegebenen Empfehlungen zur Therapie und der Auswahl sowie Dosierung von Medikamenten wurde die größtmögliche Sorgfalt beachtet. Gleichwohl werden die Benutzer aufgefordert, die Beipackzettel und Fachinformationen der Hersteller zur Kontrolle heranzuziehen und im Zweifelsfall einen Spezialisten zu konsultieren. Fragliche Unstimmigkeiten sollen bitte im allgemeinen Interesse der Redaktion mitgeteilt werden. Der Benutzer selbst bleibt verantwortlich für jede diagnostische und therapeutische Applikation, Medikation und Dosierung.

In dieser Leitlinie sind eingetragene Warenzeichen (geschützte Warennamen) nicht besonders kenntlich gemacht. Es kann also aus dem Fehlen eines entsprechenden Hinweises nicht geschlossen werden, dass es sich um einen freien Warennamen handelt.

Das Werk ist in allen seinen Teilen urheberrechtlich geschützt. Jede Verwertung außerhalb der Bestimmungen des Urhebergesetzes ist ohne schriftliche Zustimmung der DGVS unzulässig und strafbar. Kein Teil des Werkes darf in irgendeiner Form ohne schriftliche Genehmigung reproduziert werden. Dies gilt insbesondere für Vervielfältigungen, Übersetzungen, Mikroverfilmungen und die Einspeicherung, Nutzung und Verwertung in elektronischen Systemen, Intranets und dem Internet.

\section{Vorwort}

Die Entwicklung und Implementierung von nationalen, hochwertigen, evidenz- und konsensbasierten Leitlinien ist eine wesentliche Grundlage für eine optimierte und sichere Versorgung unserer Patienten.

Hepatitis B ist eine potenziell lebensbedrohliche Lebererkrankung, die durch das Hepatitis-B-Virus (HBV) verursacht wird. Die akute HBV-Infektion kann in seltenen Fällen ein Leberversagen verursachen oder zu einer chronischen Infektion führen, die mit dem Risiko einer Leberzirrhose und der Entstehung von Leberkrebs (hepatozelluläres Karzinom) verbunden ist. Es steht ein sicherer und wirksamer Impfstoff zur Verfügung, der bei Immungesunden einen > 90 \%igen Schutz vor Hepatitis B bietet. Dennoch ist die HBV-Infektion ein globales Problem des öffentlichen Gesundheitswesens, da weltweit insgesamt 257 Millionen Menschen mit einer chronische HBV-Infektion leben. Die WHO berichtet von 887000 Menschen, die im Jahr 2015 an einer Hepatitis B verstorben sind [1]. Die Epidemiologie ändert sich aufgrund verschiedener Faktoren wie Impfpolitik und Migration. In Deutschland war die Zahl der an das Robert Koch-Institut gemeldeten Personen mit Hepatitis-B-Virusinfektion im Zeitraum von 2001 bis 2009 rückläufig. Seit 2015 nimmt die Zahl der gemeldeten Patienten jedoch wieder deutlich zu. 2018 wurden insgesamt 4507 Neuinfektionen in Deutschland erfasst. Gründe hierfür können u.a. neue Kriterien für den Nachweis der Hepatitis-B-Virusinfektion sowie eine erhöhte Testung bei Asylsuchenden sein [2]. Die Gesamtkosten einer leitliniengerechten Versorgung von Hepatitis-B-Pa- 
tienten in Deutschland sind hoch. Dabei muss berücksichtigt werden, dass lediglich etwa $25 \%$ der mit dem Hepatitis-B-Virus Infizierten erfasst werden. Somit führt die Erkrankung Hepatitis B zu hohen Versorgungskosten. [3].

Um eine evidenzbasierte und einheitliche Prophylaxe, Diagnostik und Therapie bei der Hepatitis-B-Virusinfektion zu gewährleisten, wurde 2007 die erste Leitlinie publiziert [4], gefolgt von einem Update 2011 [5]).

Inzwischen wurden weitere wichtige Leitlinien, Metaanalysen und randomisierte Studien veröffentlicht, die eine erneute Überarbeitung der Leitlinie erforderten. Insbesondere wurden Leitlinienadaptationen der internationalen EASL- und AASLD-Leitlinien zur Hepatitis B [6-8], der DGVS-S3-Leitlinie zum hepatozellulären Karzinom [9], der EASL-Leitlinie zur nichtinvasiven Fibrosebestimmung [10] sowie der DGVS-S3-Leitlinie zur Hepatitis C [11, 12] vorgenommen.

Die Leitlinie ist eine systematisch entwickelte ärztliche Orientierungshilfe mit Handlungs- und Entscheidungsvorschlägen, von denen in begründeten Fällen abgewichen werden kann oder sogar muss. Die Entscheidung, ob einer bestimmten Empfehlung gefolgt wird, trifft der behandelnde Arzt unter Berücksichtigung der individuellen Situation seines Patienten.

\section{Zielorientierung der Leitlinie}

Die Etablierung von Standards in der Prophylaxe, Diagnostik und Therapie von Hepatitis-B-Virusinfektionen, die die rationalen und evidenzbasierten Handlungsmöglichkeiten für behandelnde Ärzte aufzeigen, zählt zu den Zielen der Leitlinienaktualisierung.

Ein weiteres Ziel ist, die Diagnose und die Darstellung diagnostischer Fallstricke zu verbessern. Darüber hinaus werden neue Therapieoptionen und Perspektiven dargestellt, die die Sicherstellung einer angemessenen Therapie der Hepatitis-B-Virusinfektion gewährleisten.

Um einen bestmöglichen Behandlungserfolg zu erzielen, werden folgende Aspekte bei der Leitlinienaktualisierung kritisch betrachtet:

- klinische, klinisch-chemische, histologische und virologische Diagnostik

- transparente Stadieneinteilung und Risikobewertung

- Empfehlung einer risikoadaptierten antiviralen Therapie mit optimalen Erfolgsaussichten.

Auch eine Reduktion der Neuinfektionen soll durch adäquates Handeln entsprechend der Leitlinie sichergestellt werden.

Zu Beginn dieser vollständigen Leitlinienaktualisierung wurde daher zunächst der Überarbeitungsbedarf der Leitlinie in folgenden Schritten analysiert und festgelegt.

Festlegung des inhaltlichen Überarbeitungsbedarfs:

- Orientierende Literaturrecherche insbesondere nach Quellen aggregierter Evidenz

- Aufarbeitung der Kommentare und Korrekturvorschläge zur alten Leitlinie

- Expertenbefragung der Leitliniengruppe zum Änderungs- und Ergänzungsbedarf
- Priorisierung des Überarbeitungsbedarfs der alten Leitlinienempfehlung, Festlegung der Evidenzgrundlage und Ergänzung neuer Schlüsselfragen

- Konsentierung durch die Steuergruppe (Koordinator, AG-Leiter und Mandatsträger der eingeladenen Fachgesellschaften)

Die Methodik der Leitlinie beruht auf dem zurzeit gültigen Regelwerk der AWMF, dem gemeinsamen Manual von Cochrane, Ärztlichem Zentrum für Qualität in der Medizin und dem AWMF-Institut für Medizinisches Wissensmanagement für die Erstellung von Leitlinien und dem Leitlinienprogramm der DGVS [13-15]; hierbei ergaben sich einige Änderungen insbesondere in der Darstellung der angewandten Methodik.

Festlegung des methodischen Überarbeitungsbedarfs:

1. Suche nach existierenden Leitlinien seit 2011

2. Recherche/Klassifizierung von Studien und Empfehlungen nach den Kriterien der evidenzbasierten Medizin, Erstellen von Evidenztabellen

3. Dokumentation der Evidenzrecherche (Suchstrategien, Trefferquoten, Auswahl der Evidenz und Dokumentation der Ausschlussgründe)

4. Änderung der Empfehlungsgraduierung nach $A$ („soll“), B (,sollte“) und 0 (,kann“)

5. Formulierung von Qualitätszielen für die Versorgung

6. Dokumentation und Bewertung potenzieller Interessenkonflikte im Leitlinienreport, Offenlegung im Leitlinienreport

\section{Patientenzielgruppe}

Die Leitlinie richtet sich an Ärzte und betrifft sowohl Kinder und Jugendliche als auch Erwachsene mit einer Hepatitis-B-Virusinfektion sowie Patienten mit Koinfektionen.

\section{Versorgungsbereich}

Die Leitlinie umfasst als Versorgungsbereich die ambulante und stationäre medizinische Versorgung sowie die Diagnostik und die Therapie in der haus- und fachärztlichen Betreuung.

\section{Anwenderzielgruppe}

Die Leitlinie richtet sich an folgende an der Diagnostik und Therapie beteiligten Berufsgruppen: Gastroenterologen, Internisten, Infektiologen, Kinder- und Jugendärzte, Pathologen und Virologen sowie an Betroffene, Angehörige und Leistungserbringer (Krankenkassen, Rentenversicherungsträger). Die Leitlinie dient zur Information auch für Allgemeinmediziner, Krankenpflegekräfte und Mitarbeiter, die in anderen Bereichen des Gesundheitswesens in der Betreuung von Patienten mit Hepatitis-B-Virusinfektionen tätig sind.

\section{Zusammensetzung der Leitliniengruppe und Beteiligung von Interessengruppen}

Die Leitlinie wurde federführend durch die Deutsche Gesellschaft für Gastroenterologie, Verdauungs- und Stoffwechselkrankheiten (DGVS) erstellt. 
Die Koordination wurde von Herrn Prof. Dr. Cornberg, Hannover, und die Co-Koordination von Herrn Prof. Dr. Petersen, Hamburg, übernommen. Dr. Lisa Sandmann und Dr. Christoph Höner zu Siederdissen unterstützten die Koordinatoren als Sekretär*in.

Frau PD Dr. Lynen Jansen war für die methodische Betreuung der Leitlinie verantwortlich und übernahm organisatorische Aufgaben. Das Leitlinienportal (Dienstleister: Clinical Guideline Services) diente zur Vernetzung von allen Mandatsträgern und zur digitalen Unterstützung bei der Erstellung der Leitlinie. Eric Wohlfarth und Torsten Karge standen für das Leitlinienportal zur Verfügung.

Die Aktualisierung der Leitlinie wurde bei der AWMF am 01.03.2016 angemeldet und auf deren Website veröffentlicht. Zum selben Zeitpunkt fand die Ausschreibung des Leitlinienvorhabens in der Zeitschrift für Gastroenterologie (ZFG) statt. Interessierte konnten sich zur Mitarbeit bewerben. Darüber hinaus wurden die für das Fachgebiet relevanten Fachgesellschaften im Juli 2016 angeschrieben und gebeten, Mandatsträger ihrer Organisation für die Mitarbeit an der Leitlinie zu benennen.

Folgende Fachgesellschaften/Organisationen nahmen teil:

- Deutsche Arbeitsgemeinschaft niedergelassener Ärzte in der Versorgung HIV-Infizierter e. V. (dagnä)

- Deutsche Gesellschaft für Infektiologie (DGI)

- Deutsche Gesellschaft für Pathologie e. V./Bundesverband deutscher Pathologen e. V. (DGP/BDP)

- Deutsche Gesellschaft für Innere Medizin e. V. (DGIM)

- Deutsche Gesellschaft für Transplantationsmedizin (DTG)

- Deutsches Zentrum für Infektionsforschung (DZIF)

- Gesellschaft für Virologie e. V. (GfV)

- Gesellschaft für Pädiatrische Gastroenterologie \& Ernährung e. V. (GPGE) in Abstimmung mit der Deutschen Gesellschaft für Kinder- und Jugendmedizin (DGKJ)

- Deutsche Leberhilfe e. V. als Patientenorganisation

- Deutsche Leberstiftung (DLS)

- Helmholtz Zentrum für Infektionsforschung (HZI) e. V.

- Nationales Referenzzentrum HBV/HDV

- Lebertransplantierte Deutschland e. V. als Patientenorganisation

- Ständige Impfkommission (STIKO)

Repräsentativität der Leitliniengruppe: Beteiligung von Patienten

- Deutsche Leberhilfe e. V.

Achim Kautz, Claus Niederau, Ingo van Thiel

- Lebertransplantierte Deutschland e. V.

Egbert Trowe

Bei der personellen Besetzung der einzelnen Arbeitsgruppen wurden, wenn möglich, Fachkompetenz, eine interdisziplinäre Verteilung und der jeweilige Tätigkeitsbereich (niedergelassen und stationär) berücksichtigt (s. > Tab. 1).

Da sich die Versorgung in Deutschland von der in der Schweiz und in Österreich unterscheidet, wurden die Schweizerische Gesellschaft für Gastroenterologie (SGG) und die Österreichische Gesellschaft für Gastroenterologie und Hepatologie (ÖGGH) nicht beteiligt.

\section{Teilnehmer der Konsensuskonferenz waren:}

Niklas Aehling, Christoph Berg, Thomas Berg, Peter Buggisch, Stefan Christensen, Sandra Ciesek, Markus Cornberg, Nektarios Dikopoulos, Wolfram Gerlich, Dieter Glebe, Kerstin Herzer, Holger Hinrichsen, Christoph Höner zu Siederdissen, Patrick Ingiliz, Wolfgang Jilg, Christoph Jochum, Birgit Kallinowski, Daniela Kroy, Thomas Lang, Petra Lynen Jansen, Benjamin Maasoumy, Michael P. Manns, Claus Niederau, Kai-Henrik Peiffer, Jörg Petersen, Ulrike Protzer, Christoph Sarrazin, Eckart Schott, Julian Schulze zur Wiesch, Christian Schüttler, Martin Sprinzl, Christian P. Strassburg, Frank Tacke, Jörg Timm, Egbert Trowe, Florian van Bömmel, Ingo van Thiel, Jens Verheyen, Johannes Vermehren, Heiner Wedemeyer, Sabine Wicker, Stefan Wirth, Erik Wohlfarth, Anika Wranke, Karsten Wursthorn

\section{Grundlagen der Methodik}

Das methodologische Vorgehen ist im Leitlinienreport dargelegt. Dieser ist im Internet z. B. unter www.dgvs.de/wissen-kompakt/ leitlinien/leitlinien-dgvs/ oder https://www.awmf.org/leitlinien/ detail/II/021-011.html frei verfügbar.

\section{Schema der Evidenzbewertung}

Die Literaturbewertung wurde nach der Evidenzklassifizierung des Oxford Centre for Evidence-based Medicine 2009 ( $\triangleright$ Tab. 2) durchgeführt und in den Kommentartexten entsprechend angegeben. In den Empfehlungen wird für die Übersichtlichkeit auf die detaillierte Klassifizierung verzichtet und lediglich von 1 bis 5 angegeben. Die Details zur Suche und Auswahl und Bewertung der Evidenz sind im Leitlinienreport dargestellt.

\section{Schema der Empfehlungsgraduierung}

Bei der Überführung der Evidenzstärke in die Empfehlungsstärke konnte der Empfehlungsgrad gegenüber dem Evidenzgrad aufoder abgewertet werden (s. - Abb. 1). Die Graduierung der Empfehlungen erfolgte außerdem über die Formulierung soll, sollte, kann ( Tab. 3).

Negative Empfehlungen werden entsprechend formuliert. Die Konsensusstärke wurde gemäß > Tab. 4 festgelegt.

\section{Statements}

Als Statements werden Darlegungen oder Erläuterungen von spezifischen Sachverhalten oder Fragestellungen ohne unmittelbare Handlungsaufforderung bezeichnet. Sie werden entsprechend der Vorgehensweise bei den Empfehlungen im Rahmen eines formalen Konsensusverfahrens verabschiedet und können entweder auf Studienergebnissen oder auf Expertenmeinungen beruhen.

Bei allen Statements wurde auf die Vergabe des Empfehlungslevels verzichtet. Hintergrundinformationen wurden im Erläuterungstext dargestellt.

\section{Expertenkonsens}

Als Expertenkonsens werden Empfehlungen bezeichnet, zu denen keine systematische Recherche nach Literatur durchgeführt wurde. Teilweise wurde der Expertenkonsens auch angewandt, wenn 
- Tab. 1 Mitglieder der Leitliniengruppe.

AG 1: Definition der Hepatitis B und Hepatitis Delta und Empfehlungen zur Diagnostik

AG 2: Indikationsstellung zur Therapie der Hepatitis B

\section{AG-Leiter}

AG-Mitglieder

AG-Leiter

AG-Mitglieder
Claus Niederau (DGVS, Deutsche Leberhilfe e. V.)

Ulrike Protzer (GfV, DZIF)

Peter Buggisch (DGVS)

Sandra Ciesek (DGVS, GfV)

Viola Knop (DGVS)

Peter Schirmacher (DGP/BDP)

Christian Schüttler (Nationales Referenzzentrum HBV/HDV)

Andrea Tannapfel (DGP/BDP)

Jörg Timm (DGVS, GfH)

Jörg Petersen (DGVS)

Holger Hinrichsen (DGVS)

Christoph Jochum (DGVS)

Achim Kautz (Deutsche Leberhilfe e. V.)

Kai-Henrik Peiffer (DGVS)

Christoph Sarrazin (DGVS)

Eckart Schott (DGVS)

\begin{tabular}{|c|c|c|}
\hline \multirow[t]{2}{*}{ AG 3: Therapie der Hepatitis B } & AG-Leiter & $\begin{array}{l}\text { Markus Cornberg (DGVS, DLS, DGIM, HZI) } \\
\text { Frank Tacke (DGVS) }\end{array}$ \\
\hline & AG-Mitglieder & $\begin{array}{l}\text { Nektarios Dikopoulos (DGVS) } \\
\text { Christoph Höner zu Siederdissen (DGVS, DGIM) } \\
\text { Daniela Kroy (DGVS) } \\
\text { Michael P. Manns (DGVS, DLS, DGIM) } \\
\text { Martin Sprinzl (DGVS) } \\
\text { Florian van Bömmel (DGVS) } \\
\text { Ingo van Thiel (Deutsche Leberhilfe e. V., arbeitsübergreifend) } \\
\text { Johannes Vermehren (DGVS) } \\
\text { Karsten Wursthorn (DGVS) } \\
\text { Stefan Zeuzem (DGVS) }\end{array}$ \\
\hline \multirow{2}{*}{$\begin{array}{l}\text { AG 4: Infektionen mit Hepatitis-B-Viren im } \\
\text { Zusammenhang mit Organtransplantationen }\end{array}$} & AG-Leiter & Thomas Berg (DGVS) \\
\hline & AG-Mitglieder & $\begin{array}{l}\text { Christoph Berg (DGVS) } \\
\text { Kerstin Herzer (DGVS) } \\
\text { Benjamin Maasoumy (DGVS) } \\
\text { Niklas Aehling (DGVS) } \\
\text { Martina Sterneck (DGVS) } \\
\text { Christian P. Strassburg (DGVS, DTG) } \\
\text { Egbert Trowe (Lebertransplantierte Deutschland e. V.) }\end{array}$ \\
\hline \multirow[t]{2}{*}{ AG 5: Immunprophylaxe der Hepatitis B } & AG-Leiter & $\begin{array}{l}\text { Dieter Glebe (GF/Nationales Referenzzentrum HBV/HDV) } \\
\text { Wolfgang Jilg (GFV) }\end{array}$ \\
\hline & AG-Mitglieder & $\begin{array}{l}\text { Wolfram Gerlich (GfV) } \\
\text { Birgit Kallinowski (DGVS) } \\
\text { Julian Schulze zur Wiesch (DGVS) } \\
\text { Jens Verheyen } \\
\text { Sabine Wicker (STIKO) }\end{array}$ \\
\hline \multirow[t]{2}{*}{ AG 6: HBV-Koinfektionen } & AG-Leiter & Heiner Wedemeyer (DGVS, DLS) \\
\hline & AG-Mitglieder & $\begin{array}{l}\text { Stefan Christensen (DAGNÄ) } \\
\text { Patrick Ingiliz (DGVS) } \\
\text { Hartwig Klinker (DGI) } \\
\text { Anika Wranke (DGVS) }\end{array}$ \\
\hline \multirow[t]{2}{*}{ AG 7: Hepatitis B im Kindes- und Jugendalter } & AG-Leiter & Stefan Wirth (GPGE) \\
\hline & AG-Mitglieder & $\begin{array}{l}\text { Jan de Laffolie (GPGE) } \\
\text { Gunter Flemming (GPGE) } \\
\text { Patrick Gerner (GPGE) } \\
\text { Wolf-Dietrich Huber (GPGE) } \\
\text { Thomas Lang (GPGE) } \\
\text { Michael Melter (GPGE) }\end{array}$ \\
\hline
\end{tabular}


- Tab.2 Evidenzklassifizierung des Oxford Centre for Evidence-based Medicine 2009.

\begin{tabular}{|c|c|c|c|}
\hline Klasse & Therapie & Diagnostik & Prognose \\
\hline 1a & $\begin{array}{l}\text { Systematische Übersicht (SR)* } \\
\text { von randomisierten klinischen } \\
\text { Studien (RCTs) }\end{array}$ & $\begin{array}{l}\text { SR* von diagnostischen Klasse-1-Studien; CDR\# } \\
\text { von Klasse-1b-Studien aus verschiedenen Zentren }\end{array}$ & $\begin{array}{l}\text { SR* von Inzeptionskohortenstudien; CDR } \\
\text { validiert in verschiedenen Populationen }\end{array}$ \\
\hline $1 b$ & Einzelne RCTs & $\begin{array}{l}\text { Validierungskohortenstudie mit gutem Referenz- } \\
\text { standard; oder CDR getestet in einem Zentrum }\end{array}$ & $\begin{array}{l}\text { Inzeptionskohortenstudie mit } \geq 80 \% \text { Follow-up; } \\
\mathrm{CDR}^{\#} \text {, validiert in einer Population }\end{array}$ \\
\hline $1 c$ & Alles oder nichts & Absolute SpPins und SnNouts ${ }^{\circ}$ & Alles-oder-nichts-Fallserien \\
\hline $2 a$ & SR* von Kohortenstudien & $\mathrm{SR}^{*}$ von diagnostischen Klasse-2-Studien & $\begin{array}{l}\text { SR* von retrospektiven Kohortenstudien oder } \\
\text { Placebo-Gruppen in RCTs }\end{array}$ \\
\hline $2 b$ & $\begin{array}{l}\text { Einzelne Kohortenstudie oder } \\
\text { RCTs minderer Qualität }\end{array}$ & $\begin{array}{l}\text { explorative Kohortenstudien mit gutem Referenz- } \\
\text { standard; CDR }{ }^{\#} \text { nach Ableitung, oder validiert nur } \\
\text { an Teilgruppen oder Datenbanken }\end{array}$ & $\begin{array}{l}\text { Retrospektive Kohortenstudie oder Follow-up } \\
\text { der Placebogruppe in einem RCT; CDR\# nach } \\
\text { Ableitung, oder validiert an Teilgruppen }\end{array}$ \\
\hline $2 c$ & $\begin{array}{l}\text { Outcome-Studien, Ökologische } \\
\text { Studien }\end{array}$ & & Outcomes-Research-Studien \\
\hline $3 a$ & SR* von Fall-Kontrollstudien & SR* von Klasse-3-Studien & \\
\hline $3 b$ & Einzelne Fall-Kontrollstudie & $\begin{array}{l}\text { Nicht konsekutive Studie; oder ohne konsistent } \\
\text { angewandten Referenzstandard }\end{array}$ & \\
\hline 4 & $\begin{array}{l}\text { (Fallserien oder) Kohorten-/ } \\
\text { Fall-Kontrollstudien minderer } \\
\text { Qualität }\end{array}$ & $\begin{array}{l}\text { Fall-Kontrollstudien, schlechter oder nicht } \\
\text { unabhängiger Referenzstandard }\end{array}$ & $\begin{array}{l}\text { Fallserien oder prognostische Kohortenstudien } \\
\text { mäßiger Qualität }\end{array}$ \\
\hline 5 & $\begin{array}{l}\text { Expertenmeinung ohne explizite } \\
\text { Bewertung der Evdenz oder } \\
\text { basierend auf physiologischen } \\
\text { Modellen, Laborforschung oder } \\
\text { Definitionen }\end{array}$ & $\begin{array}{l}\text { Expertenmeinung ohne explizite Bewertung der } \\
\text { Evdenz, oder basierend auf physiologischen } \\
\text { Modellen, Laborforschung oder Definitionen }\end{array}$ & $\begin{array}{l}\text { Expertenmeinung ohne explizite Bewertung der } \\
\text { Evdenz, oder basierend auf physiologischen } \\
\text { Modellen, Laborforschung oder Definitionen }\end{array}$ \\
\hline \multicolumn{4}{|c|}{$\begin{array}{l}\text { * Systematisches Review mit Homogenität. } \\
\text { \# Clinical Decision Rule (Algorithmen oder Punktesysteme, die helfen, eine Prognose oder diagnostische Kategorie abzuschätzen). } \\
\text { SpPins haben eine so hohe Spezifität, dass sie die definitive Diagnose stellen; SnNouts haben eine so hohe Sensitivität, dass ein negatives Ergebnis die } \\
\text { Diagnose ausschließt. }\end{array}$} \\
\hline
\end{tabular}

nach ausführlicher Recherche keine Literatur vorlag. Diese Empfehlungen adressieren z. T. Vorgehensweisen der guten klinischen Praxis, zu denen keine wissenschaftlichen Studien notwendig sind bzw. erwartet werden können. Für die Graduierung des Expertenkonsenses wurden keine Symbole verwendet, die Stärke der Empfehlung ergibt sich aus der verwendeten Formulierung (soll/sollte/kann) entsprechend der Abstufung in $>$ Tab. $\mathbf{3}$.

\section{Externe Begutachtung und Verabschiedung}

\section{Verabschiedung durch die Vorstände der herausge- benden Fachgesellschaften/Organisationen}

Die vollständige Leitlinie wurde von allen beteiligten Fachgesellschaften begutachtet und konsentiert. Darüber hinaus stand die Leitlinie als Konsultationsfassung zur Kommentierung für 5 Wochen auf der DGVS- und der AWMF-Website zur Verfügung. Über den DGVS Newsletter wurde um Kommentierung gebeten. Die Änderungsvorschläge sind im Leitlinienreport dargestellt.

\section{Redaktionelle Unabhängigkeit und Finanzierung der Leitlinie}

Die Reisekosten und die Nutzung des Leitlinienportals wurden von der DGVS finanziert. Die Deutsche Leberstiftung unterstützte die Ausrichtung der Konsensuskonferenz. Eine finanzielle Beteiligung weiterer Institutionen erfolgte nicht. Mandatsträger und Experten arbeiteten ausschließlich ehrenamtlich.

\section{Darlegung von und Umgang mit Interessenkonflikten}

Im Einklang mit dem AWMF-Regelwerk zum Umgang mit Interessenkonflikten gaben alle Teilnehmenden zu Beginn der Leitlinienarbeit und erneut im Februar 2021 Erklärungen auf dem entsprechenden AWMF-Formular (Formblatt 2010) ab. Die Interessenkonflikte wurden von den Koordinatoren und P. Lynen Jansen vor der Konsensuskonferenz auf thematischen Bezug zur Leitlinie gesichtet, gemäß den AWMF-Kriterien als keine, gering, moderat oder hoch bezüglich der individuellen Empfehlung kategorisiert. Die Mandatsträger der Leitlinie gaben eine Vielzahl potenzieller, direkter Interessenkonflikte an. Nach Einschätzung der Leitliniengruppe stellt die interdisziplinäre Besetzung der Leitliniengruppe eine wichtige Maßnahme zum Ausgleich dieser potenziellen Interessenkonflikte dar. Mandatsträ- 


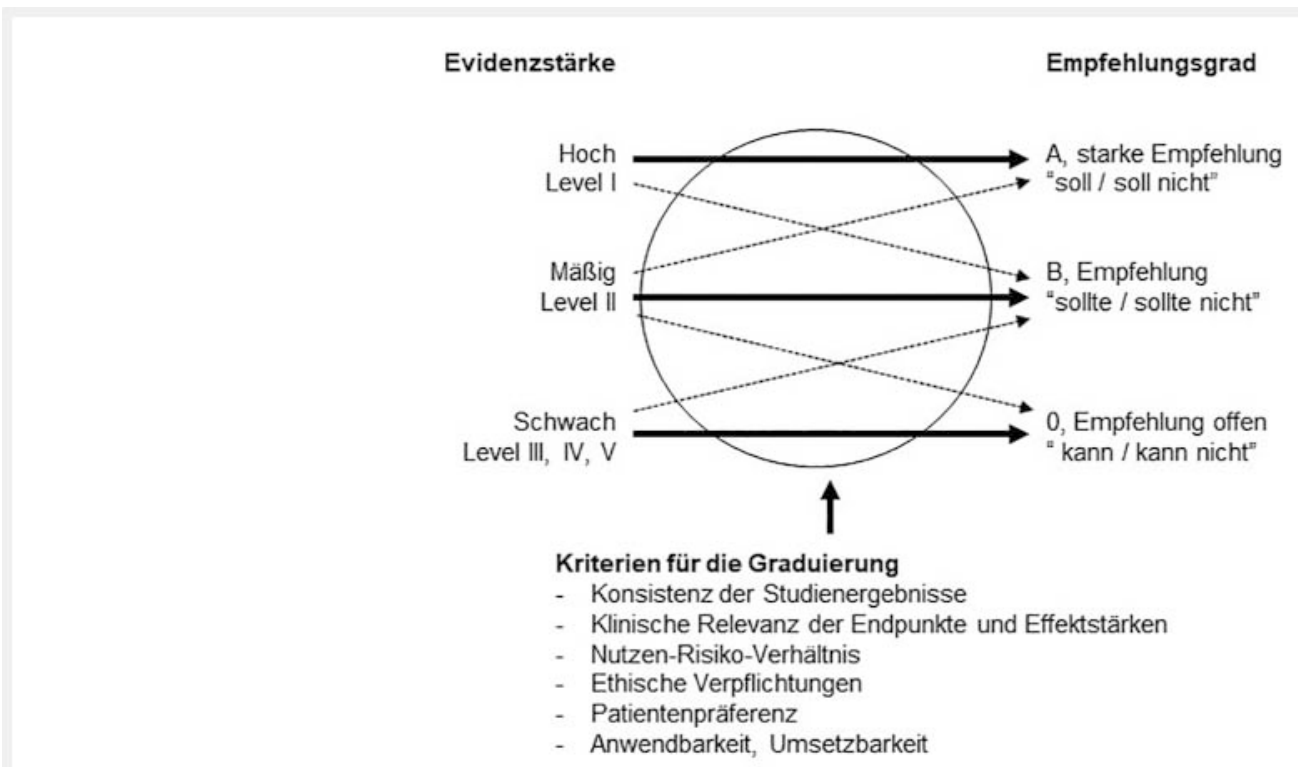

- Abb. 1 Schema der Empfehlungsgraduierung. [rerif]

- Tab.3 Schema zur Graduierung von Empfehlungen.

\begin{tabular}{|l|l|l|}
\hline $\begin{array}{l}\text { Empfehlungsgrad } \\
\text { (nur S3) }\end{array}$ & Beschreibung & Syntax \\
\hline A & starke Empfehlung & soll \\
\hline B & Empfehlung & sollte \\
\hline 0 & offen & kann \\
\hline
\end{tabular}

ger mit personenbezogenen Zuwendungen (Zugehörigkeit zu Advisory Boards, Gutachter- und Vortragstätigkeit) wurden daher nach kritischer Bewertung durch die Leitliniengruppe nicht von den Abstimmungen ausgeschlossen, wenn die Art der Zuwendungen nicht einseitig (z. B. Zugehörigkeit zu mehreren Advisory Boards) und die wissenschaftliche Expertise nicht verzichtbar war. Finanzielle Zuwendungen, die ausschließlich wissenschaftlichen Institutionen zugeordnet werden konnten, führten nicht zu einer Stimmenthaltung (Drittmittel, Studienbeteiligung). Mandatsträger, deren Interessenkonflikte nicht vorlagen, oder Mandatsträger mit Eigentümerinteressen (z. B. Patente, Aktienbesitz, Firmenzugehörigkeit) erhielten kein Stimmrecht. Es wurden keine Interessenkonflikte festgestellt, die eine Stimmenthaltung erforderlich gemacht hätten. Die 2021 aktualisierten Interessenkonflikte sind im Leitlinienreport dargestellt.

\section{Lernziele für Studierende der Medizin}

Die entsprechend mit „NKLM“ markierten Empfehlungen stellen den Bezug zu dem Nationalen Kompetenzbasierten Lernzielkatalog Medizin (NKLM) dar.
Tab. 4 Konsensfindung

\begin{tabular}{|l|l|}
\hline Konsens & \% Zustimmung \\
\hline Starker Konsens & $>95$ \\
\hline Konsens & $>75-95$ \\
\hline Mehrheitliche Zustimmung & $>50-75$ \\
\hline Kein Konsens & $<50$ \\
\hline
\end{tabular}

\section{Verbreitung und Implementierung}

Die Leitlinie wird neben der Zeitschrift für Gastroenterologie bei AMBOSS und auf den Homepages der DGVS (www.dgvs.de) und der AWMF (www.awmf.de) veröffentlicht.

\section{Gültigkeitsdauer und Aktualisierungsverfahren}

Die Gültigkeit wird auf 5 Jahre geschätzt (2026). Die Überarbeitung wird durch den Leitlinienbeauftragten der DGVS initiiert werden.

Ein Addendum zu den 2020 zugelassenen Medikamenten zur Therapie der Hepatitis D ist derzeit in Vorbereitung. Die Steuergruppe der Leitlinie prüft jährlich den Aktualisierungbedarf der Leitlinie. Als Ansprechpartner steht Ihnen Frau van Leeuwen (van leeuwen@dgvs.de) von der DGVS-Geschäftsstelle zur Verfügung.

\section{Diagnostik der Hepatitis-B-Virusinfektion}

U. Protzer, C. Niederau , S. Böhm, S. Ciesek, J. Timm, V. Knop, P. Schirmacher, C. Schüttler 


\subsection{Wie und bei wem soll eine Diagnostik auf eine} HBV-Infektion erfolgen?

\section{EMPFEHLUNG 1.1.1}

Zur initialen Diagnostik einer HBV-Infektion soll HBsAg und in der Regel Anti-HBc bestimmt werden [2, A].

Konsens: $100 \%$ (Konsensuskonferenz)

Geprüft 2020

\section{Kommentar:}

Für das initiale Screening ist die Bestimmung von HBsAg und Anti-HBc erforderlich. HBsAg wird durch Immunoassays mit hoher Sensitivität und Spezifität bestimmt. Obwohl das HBsAg ein exzellenter Parameter für das Screening ist, können falsch negative und falsch positive Befunde die Diagnostik erschweren. In der Frühphase der Infektion kann die Menge an HBsAg so gering sein, dass auch empfindliche Tests es nicht nachweisen. Diese Phase kann mehrere Wochen dauern. Zu geringe Mengen an HBsAg unter der Nachweisgrenze werden auch bei gering ausgeprägter akuter oder persistierender okkulter HBV-Infektion beobachtet. Ein Nachweis der Infektion ist in diesen Fällen durch eine hochempfindliche Bestimmung der HBV-DNA möglich. Für das initiale Screening ist die Bestimmung von $\mathrm{HBsAg}$ und Anti-HBc ausreichend.

Ein falsch negativer HBsAg-Test kann durch Escape-Variationen in den $\mathrm{HBsAg}$-Epitopen bedingt sein, da solche Varianten u. U. nicht oder nur schlecht an die zur Detektion benutzten Antikörper binden (Evidenz 2b). [16]

Da unterschiedliche HBsAg-Tests verschiedene Antikörper zum Nachweis verwenden, können diskrepante Ergebnisse entstehen (Evidenz 4). Eine Klärung kann durch den HBV-DNA-Nachweis mittels PCR erfolgen [17, 18].

Ein falsch positives HBsAg-Testergebnis (gehäuft beobachtet bei Dialysepatienten oder post mortem bei Organspendern) kann in der Regel durch Neutralisation mit Anti-HBs (vom Hersteller empfohlener Bestätigungstest/Neutralisationstest) ausgeschlossen werden. Die Einbeziehung des Anti-HBc-Antikörper-Befundes und unter Umständen ein Nachweis von HBV-DNA können notwendig und sinnvoll sein.

Während ein positives HBsAg eine Viruspersistenz oder eine Integration von HBV-DNA in Hepatozyten anzeigt, findet man Anti-HBc-Antikörper nach fast jedem Viruskontakt. Der Nachweis von Anti-HBc IgG erlaubt keine Aussage, ob eine Infektion persistiert oder ausgeheilt ist.

\section{EMPFEHLUNG 1.1.2}

Bei allen Schwangeren soll ein HBsAg-Screening erfolgen [2, A]. Konsens: $100 \%$ (Konsensuskonferenz)

Modifiziert 2020

Evidenztabelle siehe Leitlinienreport Anhang III

NKLM

\section{Kommentar:}

Da auch in Niedrig-Endemie-Gebieten 0,4 bis 1,5\% der Schwangeren HBsAg-Träger sind und damit ein Risiko der Übertragung der HBV-Infektion auf das Kind besteht, ist ein generelles HBsAg-Screening in der Schwangerschaft in Deutschland seit 1994 vorgeschrieben. Dieses Screening sollte so früh wie möglich durchgeführt werden, um mit der Therapie - falls erforderlich - nach dem ersten Trimester, aber idealerweise vor der 28. Schwangerschaftswoche beginnen zu können (siehe 3.12). Die aktuelle Mutterschaftsrichtlinie sieht abweichend hiervon vor, bei allen Schwangeren nach der 32. Schwangerschaftswoche, möglichst nahe am Geburtstermin, einen Test auf eine Hepatitis-B-Virus(HBV)-Infektion der Mutter durchzuführen (HBsAg-Test) (https://www.g-ba.de/downloads/ 62-492-2130/Mu-RL_2020-02-20_iK_2020-04-28.pdf).

Ist die Mutter HBsAg-positiv, soll das Neugeborene unmittelbar (innerhalb der ersten 12 Stunden) post partum gegen Hepatitis $B$ aktiv und passiv immunisiert werden, um eine Mutter-KindÜbertragung des HBV zu verhindern (siehe 5.9).

Eine vertikale HBV-Transmission (Mutter-Kind-Übertragung) kann trotz adäquat durchgeführter aktiv-passiver Impfung des Neugeborenen allerdings nicht komplett verhindert werden [19-22].

In verschiedenen Kohorten betrug das Übertragungsrisiko bis zu $32 \%$, wenn die Mütter eine sehr hohe HBV-Viruslast hatten $\left(\geq 10^{7}\right.$ $10^{8} \mathrm{IU} / \mathrm{ml}$ ). Durch eine Reduktion der Viruslast $(<200000 \mathrm{IU} / \mathrm{ml})$ mittels antiviraler Therapie (z. B. Tenofovir, TDF) lässt sich dieses Risiko reduzieren (siehe 3.12). Bislang gibt es keine Evidenz, dass bei einer HBV-DNA $<200000 \mathrm{IU} / \mathrm{ml}$ eine vertikale Transmission auftritt [19, 20, 22].

Daher empfehlen aktuelle internationale Leitlinien (EASL, AASLD, WHO), dass bei Vorliegen einer HBV-DNA-Konzentration $>200000 \mathrm{IU} / \mathrm{ml}$ eine antivirale Therapie mit Tenofovir (TDF) erfolgen sollte, um das Risiko einer vertikalen Transmission (MutterKind-Übertragung) zu reduzieren. [6, 7, 23] (siehe 3.12).

Wird eine Therapie zur Reduzierung des vertikalen Transmissionsrisikos durchgeführt, sollte die Therapie möglichst frühzeitig begonnen werden, um die HBV-DNA zum Zeitpunkt der Geburt auf $<200000 \mathrm{IU} / \mathrm{ml}$ zu reduzieren. In den meisten Studien wurde die Therapie vor der 28. bis 32. Schwangerschaftswoche gestartet. [19-22, 24, 25] Die WHO-Leitlinie empfiehlt, die Therapie - wenn erforderlich - vor der 28. Schwangerschaftswoche zu beginnen [23].

Erfolgt das Screening auf HBsAg gemäß der Mutterschaftsrichtlinie erst nach der 32. Schwangerschaftswoche, werden Mütter mit einer Indikation für eine antivirale Therapie jedoch viel zu spät diagnostiziert. Deshalb wird ein früheres Screening empfohlen. Durch eine Bestimmung des HBsAg zu Beginn der Schwangerschaft kann die infizierte Mutter rechtzeitig einem Experten zugewiesen, therapiert und eine Infektion des Neugeborenen verhindert werden.

Anmerkung zu den Neugeborenen HBsAg-positiver Mütter: Um Impfversagen bzw. Virusdurchbrüche bei Neugeborenen HBV-infizierter Mütter zu erkennen, sollen Anti-HBs plus HBsAg/ Anti-HBc 4-8 Wochen nach der Grundimmunisierung, also 12 Monate nach insgesamt 6 Monaten der Grundimmunisierung (bei Reifgeborenen) getestet werden. Bei Frühgeborenen gilt ein etwas anderes Impfschema bis Monat 12 (Details siehe 5.9.1).

In Ausnahmefällen kann auch eine HBsAg-negative, isoliert Anti-HBc-positive Mutter das Virus auf ihre Kinder (wenn nicht 
geimpft) übertragen. Da hieraus aber im Regelfall keine chronischen Infektionen resultierten, entstehen keine Konsequenzen für das Schwangeren-Screening [26].

\section{EMPFEHLUNG 1.1.3}

Eine HBV-Diagnostik soll erfolgen bei [2, A]:

- Personen mit erhöhten Leberwerten und/oder klinischen Zeichen einer Hepatitis

- allen Personen mit vorbestehender Erkrankung oder Immunsuppression, bei denen ein schwerer Verlauf einer Hepatitis B zu erwarten ist.

- Patienten mit Leberzirrhose/-fibrose

- Patienten mit Hepatozellulärem Karzinom

- Dialysepatienten

- HIV- und/oder HCV-Infizierten

- Patienten vor bzw. während einer immunsuppressiven Therapie, einer Therapie mit B-Zell depletierenden Antikörpern (Rituximab) oder Chemotherapie

- Patienten mit einer angeborenen Immunschwäche

- allen Personen mit erhöhtem Expositionsrisiko für eine Hepatitis B

- Personen mit Migrationshintergrund aus Regionen mit erhöhter HBsAg-Prävalenz

- Familien- oder Haushaltsangehörige, insbesondere Kinder von HBsAg-positiven Müttern und Geschwister sowie Eltern von (aktuell oder ehemals) HBV-Infizierten

- Sexualpartner von HBV-Infizierten

- medizinisches Personal

- Patienten oder Personen in psychiatrischen Einrichtungen, Fürsorgeeinrichtungen für Zerebralgeschädigte oder Verhaltensgestörte, Justizvollzugsanstalten

- Personen mit häufig wechselnden Sexualkontakten

- aktive und ehemalige i. v. Drogenbenutzer

- Screening zur Vermeidung einer Transmission auf gesunde Empfänger von Knochenmark- oder Organtransplantaten vor und nach Transplantation

- Blut-, Gewebe-, Samen- und Organspender

- Schwangere (siehe 1.1.2)

Konsens: $100 \%$ (Delphi-Runde)

Geprüft 2020

NKLM

\section{Kommentar:}

Aufgrund der Prävalenz einer persistierenden, $\mathrm{HBsAg-positiven}$ HBV-Infektion von 0,4-0,8\% und einer Prävalenz von Anti-HBc von ca. $7 \%$ in Deutschland und der schwerwiegenden Folgen einer chronischen HBV-Infektion (Evidenz 2a) ist es gerechtfertigt, die Indikation zur HBV-Diagnostik großzügig zu stellen [27-29].

Obwohl das Hepatitis-B-Virus weltweit vorkommt, gibt es Hochendemie-Gebiete (> 50\% der Bevölkerung Anti-HBc-positiv) in Asien, dem Südpazifik, in Afrika südlich der Sahara, in Südamerika und im Mittleren Osten. Gebiete mit mittlerer Prävalenz (10$50 \%$ Anti-HBc-positiv) sind der Mittelmeerraum und Osteuropa.
Personen, die in diesen Gebieten geboren sind oder deren Mütter aus diesen Regionen stammen, haben ein erhöhtes Risiko, HBVTräger zu sein.

Das Screening von Migranten aus diesen Regionen hilft, die Infektion früh genug zu diagnostizieren, um eine Progression von Lebererkrankungen zu vermindern, und ist kosteneffizient (Evidenz 2b) [30].

Das HBV wird perinatal, perkutan durch Blut-zu-Blut-Kontakt oder durch Sexualkontakte übertragen. Da bereits geringste Mengen des Virus für eine Infektion ausreichen, kann es auch zur Übertragung bei engem Kontakt, z. B. innerhalb einer Familie, kommen. Ein weiterer, wichtiger Risikofaktor sind Handlungen oder Maßnahmen mit potenziellem Blutkontakt (z. B. Drogenkonsum, Doping, Piercing, Blutprodukte, Hämodialyse etc.). Auch Übertragungen bei operativen medizinischen oder zahnmedizinischen Eingriffen sind beschrieben [5].

Da viele HBV-Infektionen inapparent verlaufen und eine HBVInfektion den Verlauf und die Prognose einer nicht HBV-bedingten Lebererkrankung erheblich beeinflussen kann, soll bei Patienten mit einer Lebererkrankung grundsätzlich eine HBV-Diagnostik erfolgen [5].

Unter Immunsuppression verlaufen HBV-Infektionen gehäuft chronisch, und es kann zu einer Reaktivierung durchgemachter HBV-Infektionen kommen (siehe auch 3.13).

\subsection{Wie ist das weitere Vorgehen nach initialer HBV-Diagnostik (HBsAg/Anti-HBc)?}

\section{EMPFEHLUNG 1.2.1}

Bei Personen der oben genannten Risikogruppen, die HBsAgund Anti-HBc-negativ sind und über keinen ausreichenden Impfschutz verfügen, soll eine Impfung angeboten werden (siehe 5.1) [EK].

Konsens: $100 \%$ (Konsensuskonferenz)

Geprüft 2020

NKLM

\section{Kommentar:}

Für den unter 1.1.3 genannten Personenkreis besteht gemäß den Empfehlungen der Ständigen Impfkommission am Robert Koch-Institut eine eindeutige Indikation zur Impfung (siehe auch 5.1.4). Diese soll daher bei negativem HBsAg und Anti-HBc umgehend eingeleitet werden. Eine Impfindikation während der Schwangerschaft muss streng geprüft werden.

\section{EMPFEHLUNG 1.2.2}

Bei HBsAg-positiven Personen soll die Diagnostik komplettiert und das Ausmaß der Leberkrankung bestimmt werden, um eine Therapieindikation abzuklären [EK].

Konsens: $100 \%$ (Konsensuskonferenz)

Geprüft 2020

NKLM 


\section{Kommentar:}

Wird HBsAg-positiv getestet, kann eine akute oder eine chronische HBV-Infektion vorliegen. Die klinische Untersuchung und die Bestimmung biochemischer Parameter (Aminotransferasen [AST und ALT], Gamma-Glutamyl-Transpeptidase [GGT], alkalische Phosphatase [AP], Bilirubin und Serumalbumin und Gammaglobulin, Vollblutbild und Prothrombinzeit) sind wichtig, um das Ausmaß der Leberkrankung zu bestimmen [6].

\section{EMPFEHLUNG 1.2.3}

Bei Verdacht auf eine akute Hepatitis B sollten zusätzlich zu $\mathrm{HBsAg}$ und Anti-HBc der Nachweis von Anti-HBc-lgM erfolgen, die HBV-DNA bestimmt sowie die ALT und die Leberfunktion im Verlauf kontrolliert werden [3, B]. (siehe Stufenschema 1.2.3).

Konsens: $100 \%$ (Konsensuskonferenz)

Geprüft 2020

NKLM

\section{Kommentar:}

Nach einer kürzlich stattgehabten HBV-Infektion und während einer akuten Hepatitis B kann man Anti-HBc-IgM in hoher Konzentration nachweisen. Es fällt mit der Ausheilung ab. Allerdings kann ein positives Anti-HBc-IgM in niedrigerer Konzentration auch bei Exazerbation einer chronischen Hepatitis B nachgewiesen werden (Evidenz 3b) [31].

Der alleinige Nachweis von Anti-HBc-IgM hat daher eine begrenzte Aussagekraft und eine Quantifizierung des Anti-HBc-IgM zur Differenzierung einer akuten von einer chronischen Hepatitis B mit akutem Schub kann sinnvoll sein.

Anti-HBs-Antikörper zeigen eine Immunität nach Impfung oder nach durchgemachter Infektion an. Bei einer frischen HBVInfektion im Jugendlichen- oder Erwachsenenalter ist in den meisten Fällen eine funktionale Ausheilung zu erwarten. Um diese nachzuweisen, sollen Anti-HBs-Antikörper bestimmt werden (s. Stufenschema 1.2.3). Die Bestimmung der Anti-HBs-Antikörper sollte ggf. alle 3 bis 12 Monate wiederholt werden, bis der Titer $>10 \mathrm{IU} / \mathrm{l}$ ist [5].

\section{STUFENSCHEMA 1.2.3: SEROLOGISCHE DIAGNOSTIK} BEI V. A. AKUTE HBV-INFEKTION:

\section{Initial: HBsAg und Anti-HBc;}

- falls HBsAg bestätigt: HBeAg, Anti-HBe; Anti-HBc IgM; ggf. HBV-DNA quantitativ

- falls HBsAg isoliert positiv: HBsAg-Bestätigungstest (Ausschluss einer falsch positiven Reaktion);

- falls bestätigt positiv: HBeAg, HBV-DNA; nach 2-4 Wochen Kontrolle: HBsAg, Anti-HBc und Anti-HBc lgM

- falls nur Anti-HBc positiv: Anti-HBs
- falls Anti-HBs positiv: durchgemachte HBV-Infektion mit klinischer Ausheilung; evtl. Kontrolle im Verlauf bis Anti-HBs $\geq 10 \mathrm{IU} / \mathrm{I}$

- falls Anti-HBs negativ oder ALT erhöht: Anti-HBc-IgM; HBV-DNA quantitativ (DD: frische HBV-Infektion/HBV-Escape-Variante/ „Anti-HBc only“);

\section{EMPFEHLUNG 1.2.4}

Bei Verdacht auf eine chronische Hepatitis B:

- sollen die HBV-Viruslast (HBV-DNA) und der HBeAg/AntiHBe-Status bestimmt werden [EK] (siehe Stufenschema 1.2.4).

- kann quantitatives HBsAg zur besseren Differenzierung der Phase und zur Beurteilung der Prognose der HBV-Infektion bestimmt werden [EK] (siehe 3.5.3).

Konsens: 96,7\% (Konsensuskonferenz)

Modifiziert 2020

NKLM

\section{Kommentar:}

Als Marker einer HBV-Virämie wird die HBV-DNA-Konzentration im Serum angesehen. Diese wird in der Regel mittels PCR nachgewiesen. Die meisten auf dem Markt verfügbaren Tests erlauben einen quantitativen Nachweis der HBV-DNA. Da dies keine wesentlichen Mehrkosten verursacht, das Ausmaß der HBV-Virämie aber große prognostische Bedeutung hat, ist der quantitative HBV-DNA-Nachweis (standardisiert in $\mathrm{IU} / \mathrm{ml}$ ) der Goldstandard [5, 6, 32-34].

Das $\mathrm{HBeAg}$ ist als prognostischer Marker etabliert und ist (bei HBeAg-positiven HBV-Stämmen) ein Surrogat-Marker für die Aktivität der viralen RNA-Transkription in Hepatozyten [35].

Die Bestimmung des HBeAg/Anti-HBe-Serostatus ist sinnvoll, um die Prognose des weiteren Erkrankungsverlaufs sowie des Therapieansprechens eines Patienten abzuschätzen (Evidenz 3a) [5].

Die quantitative Bestimmung des HBsAg kann die Quantifizierung der HBV-DNA nicht ersetzen, kann aber z. B. bei der Differenzierung zwischen einer akuten versus chronischen Hepatitis B zusätzliche Hilfestellung leisten und die Differenzierung der unterschiedlichen Phasen einer chronischen HBV-Infektion unterstützen. Die quantitative Bestimmung des HBsAg kann insbesondere helfen, die niedrig virämische Phase der HBeAg-negativen chronischen HBV-Infektion gegenüber der HBeAg-negativen chronischen Hepatitis besser abzugrenzen. Bei einer HBV-Viruslast $<2000 \mathrm{IU} / \mathrm{ml}$ und einem $\mathrm{HBsAg}>1000 \mathrm{IU} / \mathrm{ml}$ liegt ein höheres Risiko einer Reaktivierung vor [6, 36].

Eine asiatische Studie berichtete bei Patienten mit einer Viruslast $<2000 \mathrm{lU} / \mathrm{ml}$ über ein 2 \%iges HCC-Risiko nach 20 Jahren, wenn das $\mathrm{HBsAg}<1000 \mathrm{IU} / \mathrm{ml}$ ist, aber ein $8 \%$ iges Risiko bei einem $\mathrm{HBsAg}>1000 \mathrm{IU} / \mathrm{ml}$ [37]. 
Um die Prognose zu beurteilen und eine Therapieindikation zu überprüfen, ist eine ergänzende Diagnostik notwendig (s. unten).

\section{STUFENSCHEMA 1.2.4: SEROLOGISCHE DIAGNOSTIK} BEI V. A. CHRONISCHE HBV-INFEKTION:

Initial: HBsAg und Anti-HBC;

- falls beide positiv:

HBeAg, Anti-HBe;

Anti-HBc-IgM (bei Differenzialdiagnose akute Hepatitis B);

HBV-DNA quantitativ;

Anti-HDV

- falls HBsAg isoliert positiv:

HBsAg-Bestätigungstest (Ausschluss einer falsch positiven

Reaktion);

ggf. HBV-DNA (bei Differenzialdiagnose akute/okkulte

HBV-Infektion)

nach 2-4 Wochen: Kontrolle Anti-HBc

- falls nur Anti-HBc positiv:

Anti-HBs

- falls positiv: ausgeheilte Hepatitis B,

- falls negativ: Anti-HBc bestätigen,

- wenn bestätigt: „Anti-HBc only“-Status, bei klinischen Symptomen oder Frage der Infektiosität: HBV-DNA quantitativ

- wenn HBV-DNA positiv: okkulte HBV-Infektion

1.3 Welche ergänzende Diagnostik ist bei Erstdiagnose einer HBV-Infektion erforderlich?

\section{EMPFEHLUNG 1.3}

Bei Erstdiagnose einer HBV-Infektion sollen zusätzlich folgende Maßnahmen durchgeführt werden [EK]:

- Anamnese (inkl. Risikofaktoren, Familien-, Partneranamnese), körperliche Untersuchung

- Ausschluss einer Koinfektion mit HCV, HDV und HIV

- Hepatitis-A-Immunstatus (Frage Impfung)

- Ausschluss einer Hepatitis-E-Virusinfektion

- Klinisch-chemische Labortests

- Ultraschall des Abdomens

Konsens: 96,7\% (Konsensuskonferenz)

Modifiziert 2020

NKLM

\section{Kommentar:}

Um das Ausmaß der entzündlichen Veränderungen sowie eine mögliche Einschränkung der Leberfunktion einschätzen zu können, sind verschiedene klinisch-biochemische Labortests (z. B. Leberentzündungs- und Lebersynthese-Parameter, Gesamtbilirubin), ein Vollblutbild sowie ein Gerinnungsstatus erforderlich. Bei Verdacht auf eine fortgeschrittene Lebererkrankung sollten zur Bestimmung der Syntheseleistung der Leber zusätzliche
Tests (Prothrombinzeit [Quick-Wert], Albumin) durchgeführt werden. Ein Ultraschall des Abdomens soll erfolgen, um evtl. Raumforderungen in der Leber und Begleiterkrankungen (z. B. Gallensteine, Fettleber) zu entdecken und ggf. Anhaltspunkte für Umbauprozesse des Lebergewebes zu gewinnen [6].

Um eine weitere Schädigung der Leber zu vermeiden, soll der Hepatitis-A-Immunstatus erhoben und eine Impfung erwogen werden. Aufgrund der hohen Verbreitung der Hepatitis-E-Infektion muss bei einem unklaren Anstieg der Transaminasen eine HEV-Koinfektion ausgeschlossen werden.

Ebenso sollen Koinfektionen mit dem Hepatitis-C-Virus und dem Hepatitis-D-Virus (s. unten) sowie bei Risikopatienten auch eine Infektion mit HIV ausgeschlossen werden [6].

Familienmitgliedern bzw. Partnern sowie engen Kontaktpersonen HBV-Infizierter sollen eine HBV-Diagnostik und eine Impfung angeboten werden (siehe 5.1.4).

1.4 Wann ist eine Hepatitis-Delta-Virus-Diagnostik indiziert? Wie wird eine Hepatitis Delta diagnostiziert?

\section{EMPFEHLUNG 1.4.1}

Eine Hepatitis-Delta-Virus(HDV)-Diagnostik soll bei allen Hepatitis-B-Patienten sowohl bei neu diagnostizierter HBV-Infektion als auch bei fehlender HDV-Testung bei bekannter HBV-Infektion durchgeführt werden. Insbesondere bei Exazerbation einer chronischen Hepatitis B soll eine HDV-Superinfektion ausgeschlossen werden [EK].

Konsens: 97,9\% (Delphi-Runde)

Modifiziert 2020

NKLM

\section{Kommentar:}

Das HDV ist ein natürliches Satelliten-Virus des HBV, das weltweit vorkommt. Die Übertragung des HDV erfolgt parenteral. Freisetzung und Weitergabe des HDV hängen vom HBV ab, da HBV die Hüllproteine des HDV liefert. Eine HDV-Infektion kann somit nicht isoliert auftreten, sie kann nur bei HBsAg-positiven Patienten vorkommen.

Eine chronische HDV-Infektion ist durch die Persistenz der HDVRNA über mindestens 6 Monate definiert. Die Quantifizierung der HDV-RNA dient der Therapieüberwachung der chronischen Hepatitis D. Es gibt 2 Formen der HDV-Infektion: die simultane Infektion mit HBV und HDV sowie die HDV-Superinfektion von HBsAg-Trägern. Beide Formen können sowohl akut als auch chronisch verlaufen. Eine Koinfektion mit dem HDV findet man in Ost- und Westeuropa bei 5-12\% der Patienten mit einer chronischen Hepatitis B.

Die HBV-Richtlinien der AASLD 2016 empfehlen die Testung auf HDV (Anti-HDV) von HBsAg-positiven Personen, die einem Risiko für HDV ausgesetzt sind, einschließlich HIV-Infizierter, Personen, die Drogen injizieren, Männern, die Sex mit Männern haben, und Immigranten aus Gebieten mit hoher HDV-Prävalenz. Darüber hinaus empfiehlt die AASLD-Leitlinie, dass HBsAg-positive Patienten mit niedriger oder nicht nachweisbarer HBV-DNA, aber hohem ALT-Werten auf HDV getestet werden sollten [7]. 
- Tab.5 Diagnostische Kriterien einzelner Verlaufsformen der Hepatitis B/D.

\section{Akute Hepatitis B:}

\section{Chronische Hepatitis B:}

HBeAg-positive chronische Hepatitis $B$

HBeAg-negative chronische Hepatitis B

HBsAg-Träger-Status:

HBeAg-positive chronische HBV-Infektion

HBeAg-negative chronische HBV-Infektion
- HBsAg positiv und Anti-HBc-IgM hoch positiv;

- bei fehlendem HBsAg: HBeAg, HBV-DNA

- Verlauf $\leq 6$ Monate

- HBsAg positiv > 6 Monate

- HBeAg positiv oder HBeAg negativ

- persistierend oder intermittierend erhöhte ALT/GPT-Werte

- HBV-DNA initial > $2000 \mathrm{lU} / \mathrm{ml}$

- wenn vorhanden: Leberhistologie mit Zeichen der chronischen Hepatitis

- HBsAg positiv >6 Monate

- persistierend normale ALT/GPT-Werte

- Leberbiopsie (optional) ohne wesentliche Hepatitis (Grading 0-1 nach Desmet)

- hochvirämisch: HBeAg positiv; HBV-DNA > $2000 \mathrm{IU} / \mathrm{ml}$ (selten: HBeAg negativ bei HBeAg-negativen HBV-Varianten)

- inaktiv: HBeAg negativ; HBV-DNA $\leq 2000 \mathrm{IU} / \mathrm{ml}$

\begin{tabular}{|c|c|}
\hline Ausgeheilte Hepatitis B: & $\begin{array}{l}\text { - Nachweis von Anti-HBc und Anti-HBs } \geq 10 \mathrm{IU} / \mathrm{I} \\
\text { " HBsAg negativ } \\
\text { " HBV-DNA negativ* }\end{array}$ \\
\hline Sonderfall: „Anti-HBc only“ & $\begin{array}{l}\text { - Nachweis von Anti-HBc (bestätigt) } \\
\text { " HBsAg negativ, Anti-HBs negativ oder < } 10 \text { IU/I } \\
\text { " HBV-DNA negativ* } \\
\text { " normale ALT/GPT-Werte }\end{array}$ \\
\hline Okkulte HBV-Infektion & $\begin{array}{l}\text { - Nachweis von Anti-HBc (bestätigt) } \\
\text { - HBsAg negativ } \\
\text { - HBV-DNA positiv ( } \geq 20 \mathrm{IU} / \mathrm{ml})^{*}\end{array}$ \\
\hline Hepatitis Delta: & $\begin{array}{l}\text { - HBsAg positiv } \\
\text { " Anti-HDV positiv } \\
\text { " falls HDV-RNA positiv: aktive Infektion }\end{array}$ \\
\hline
\end{tabular}

Die Empfehlungen der AASLD-Leitlinie sind sehr komplex und können zu Fehlinterpretationen führen. Aufgrund der hohen Morbidität und Mortalität sollte keine HDV-Koinfektion übersehen werden [38].

Daher wurde mit einem starken Konsens die Testung aller HBsAg-positiven Patienten in Deutschland empfohlen.

\section{EMPFEHLUNG 1.4.2}

Im Screening-Test werden Anti-HDV-Antikörper bestimmt. Da der Nachweis von Anti-HDV nicht zwischen einer persistierenden und einer ausgeheilten Hepatitis D unterscheiden kann, soll bei positivem Anti-HDV ein Virusnachweis im Blut mittels HDV-RNA erfolgen [EK].

Konsens: 95,7\% (Delphi-Runde)

Modifiziert 2020

NKLM

\section{Kommentar:}

Der Nachweis von Anti-HDV-Antikörpern erfolgt durch Immunoassays (keine Änderung zu [5]).

Der Virusnachweis und damit der Nachweis der Infektiosität erfolgen durch den Nachweis von HDV-RNA (keine Änderung zu [5]).
Vor und während der Therapie einer HDV-Infektion z. B. mit Interferon alfa sollte ein Monitoring der HDV-RNA erfolgen (keine Änderung zu [5]).

Es sollte ein CE-zertifizierter HDV-RNA-Nachweistest nach Angaben des Herstellers verwendet werden (Expertenmeinung). Wichtig ist die Beachtung der Extraktionsmethode, die bei inkorrekter Anwendung zu Schwankungen der Nachweisgrenze führen kann (Evidenz 3b) [39].

\subsection{Wie soll die Verlaufsdiagnostik von Patienten ohne antivirale Therapie erfolgen?}

\section{EMPFEHLUNG 1.5 .}

Eine akute HBV-Infektion soll überwacht werden, bis ein HBsAg-Verlust erreicht ist [EK] (s. Algorithmus, > Tab. 6).

Konsens: $100 \%$ (Konsensuskonferenz)

Modifiziert 2020

NKLM

\section{Kommentar:}

Die Ausheilung einer Hepatitis B wird serologisch diagnostiziert, eine Bestimmung der HBV- DNA ist nur bei gezielten Frage- 
stellungen erforderlich (z. B. unklare serologische Befundkonstellation, Infektiosität) (s. > Tab. 6).

Bei Ausheilung einer akuten Hepatitis B kommt es häufig erst verzögert zum Auftreten von Anti-HBs-Antikörpern, in ca. $25 \%$ der Patienten sind diese auch nach 24 Monaten noch nicht nachweisbar (keine Änderung zu [5]).

Daher kann nach Negativierung des HBsAg je nach klinischem Bild die Verlaufskontrolle in großen Intervallen erfolgen (keine Änderung zu [5]).

\section{EMPFEHLUNG 1.5.2}

Patienten mit chronischer HBV-Infektion ohne antivirale Therapie sollen regelmäßige Verlaufskontrollen erhalten [EK]. Diese umfasst die Bestimmung der ALT-Aktivität im Serum, die Bestimmung der HBV-Viruslast, einen Ultraschall des Abdomens und ggf. Fibrosediagnostik. Die Frequenz sollte sich nach dem klinischen Verlauf richten [EK] (s. Algorithmus, Tab. 7).

Konsens: $100 \%$ (Konsensuskonferenz)

Modifiziert 2020

NKLM

\section{Kommentar:}

Die Intervalle der Verlaufsuntersuchungen einer chronischen HBV-Infektion, für die keine Therapieindikation vorliegt, hängen vom klinischen Verlauf ab und müssen individuell festgelegt werden (entzündliche Aktivität? Höhe der Virämie? Vorliegen einer Leberzirrhose? Risiko für die Entwicklung eines HCC?) (siehe - Tab. 7). Wichtig ist eine Regelmäßigkeit der ärztlichen Kontrolle, um eine evtl. Zunahme der entzündlichen Aktivität bzw. ein Fortschreiten der Lebererkrankung rechtzeitig zu diagnostizieren (keine Änderung zu [5]).

Eine einmalige quantitative Bestimmung des $\mathrm{HBsAg}$ in Kombination mit der Virämie (HBV-DNA $<2000 \mathrm{IU} / \mathrm{ml}$ und $\mathrm{HBsAg}$ $<1000 \mathrm{IU} / \mathrm{ml}$ ) kann mit einem prädiktiven Wert von $90 \%$ einen inaktiven HBsAg-Träger identifizieren (siehe 1.2.4). Eine quantitative HBsAg-Bestimmung kann daher in bestimmten Situationen sinnvoll sein. [6]

\subsection{Wie sollte das Therapiemonitoring bei chronischer} Hepatitis B aussehen?

\section{EMPFEHLUNG 1.6.1}

Bei Therapie mit direkt wirksamen antiviralen Medikamenten (z. B. Nukleos(t)idanaloga) werden vor Therapie bzw. zum Therapiemonitoring folgende Untersuchungen empfohlen [EK]:

\section{Vor Therapie:}

- HBV-DNA quantitativ,

- klinisch-chemische Labortests,

- HBeAg/Anti-HBe,

- quantitative Bestimmung des HBsAg
- Tab. 6 Algorithmus zur Verlaufskontrolle einer akuten HBV-Infektion.

- Transaminasenaktivität und Prothrombinzeit nach klinischem Bedarf und Verlauf (cave: fulminantes Leberversagen!) wiederholen bis zur Normalisierung

- HBsAg/Anti-HBs alle 3-12 Monate bis zur Anti-HBs-Serokonversion

- Immunität kann bei Anti-HBs > $10 \mathrm{IU} / \mathrm{I}$ angenommen werden, wenn HBsAg negativ ist

- bei HBsAg negativ/Anti-HBs < 10 IU/I: HBV-DNA; Kontrolle nach 12 Monaten

- Tab.7 Algorithmus zur Verlaufskontrolle einer chronischen HBV-Infektion.

Kontrollintervall: Bei allen Patienten im ersten Jahr mind. $3 \times$, anschließend je nach klinischer Aktivität der Erkrankung alle 3-12 Monate Transaminasenaktivität und HBV-DNA quantitativ bestimmen

- bei Vorliegen einer Leberfibrose oder -zirrhose Kontrolle alle 6 Monate

- Ultraschall des Abdomens und ggf. AFP zur HCC-Surveillance bei erhöhtem HCC-Risiko (siehe auch 1.8)

Bei Patienten mit chronischer Hepatitis B alle 6 Monate:

- Klinische Chemie (Leberentzündungs- und LebersyntheseParameter, Blutbild, Prothrombinzeit)

- HBV-DNA (quantitativ)

- HBeAg (sofern initial positiv), wenn negativ: Anti-HBe

- HBsAg (ggf. quantitativ), wenn negativ: Anti-HBs (Frage: Ausheilung?)

Bei Patienten mit chronischer HBV-Infektion

- HBV-DNA < 2000 und HBsAg < $1000 \mathrm{IU} / \mathrm{ml}$ : alle 12 Monate

- HBV-DNA < 2000 und HBsAg > $1000 \mathrm{IU} / \mathrm{ml}$ : alle 6 Monate

- HBeAg, wenn negativ: Anti-HBe, HBsAg kontrollieren (ggf. quantitativ)

- wenn HBsAg negativ: Anti-HBs (Frage: Ausheilung?)

- bei Anstieg der Transaminasenaktivität über den Normwert: siehe chronische Hepatitis B

Während der Therapie (s. auch 3.5 und 3.6):

- HBV-DNA quantitativ:

- im ersten Jahr alle 3 Monate;

- nach dem 1. Jahr kann bei virologischem Ansprechen das Intervall auf alle 6 Monate verlängert werden.

- Resistenzvarianten bei nicht ausreichendem Therapieansprechen oder Verdacht auf Resistenzentwicklung

- HBeAg (falls positiv) alle 6-12 Monate, bei Verlust Anti-HBe.

- HBsAg quantitativ.

- klinisch-chemische Labortests alle 3 Monate
Modifiziert 2020 


\section{EMPFEHLUNG 1.6.2}

Bei Therapie mit Interferon oder Immunmodulatoren werden vor Therapie bzw. zum Therapiemonitoring folgende Untersuchungen empfohlen [EK]:

\section{Vor Therapie:}

- HBV-DNA quantitativ

- klinisch-chemische Labortests

- HBeAg/Anti-HBe

- quantitative Bestimmung des HBsAg

- HBV-Genotypisierung

Während der Therapie (siehe auch 3.3):

- HBV-DNA quantitativ alle 3 Monate

- klinisch-chemische Labortests alle 3 Monate

- quantitative Bestimmung des HBsAg nach 12 und 24 Wochen

- Anti-HBs bei HBsAg-Verlust

- HBeAg (falls positiv) alle 3 Monate, bei Verlust Anti-HBe

Konsens: $100 \%$ (Delphi-Runde)

Modifiziert 2020

\section{Kommentar:}

Vor Einleitung einer antiviralen Therapie ist v. a. die Bestimmung der HBV-DNA und der Transaminasen wichtig, um den Therapieerfolg zu beurteilen. So zeigt z. B. ein erneuter Anstieg der HBV-DNA nach initialem Abfall ein Therapieversagen während einer NA-Therapie an. Hier sollte sichergestellt werden, dass die Medikamente regelmäßig eingenommen wurden, bevor ein Therapieversagen diagnostiziert wird. In zahlreichen Studien ist belegt, dass ein Jahr nach Beginn einer Therapie mit Lamivudin 15-30\% der Patienten Mutationen im Polymerase-Gen des HBV, vorwiegend im YMDD-Motiv, aufweisen (siehe 3.5). Auch für Adefovir, Entecavir und Telbivudin sind Resistenzmutationen beschrieben, die evtl. bereits vor Therapie vorliegen können. Sie vermitteln zum Teil Kreuzresistenzen gegenüber mehreren Nukleosid-/Nukleotidanaloga. Für Tenofovir stellt die Entstehung von Resistenzvarianten klinisch bislang kein klinisch relevantes Problem dar (siehe 3.5). Sowohl bei Versagen einer laufenden Therapie als auch bei primärem Nichtansprechen sollte daher eine Resistenzbestimmung des HBV erfolgen (i.d. Regel genotypisch), um einen gezielten Therapiewechsel vornehmen zu können [6].

HBeAg/Anti-HBe vor und während (alle 3-6 Monate) der Therapie sind wichtig, um bei initial HBeAg-positiven Patienten im Verlauf der Therapie eine Anti-HBe-Serokonversion zu dokumentieren. Das ist wichtig für die Beurteilung des Therapieerfolgs einer Interferontherapie oder zur Entscheidung der Therapiedauer (Therapiebeendigung) einer NA-Therapie (siehe 3.3).

Die HBsAg-Serumkonzentration kann als Surrogatmarker für die Menge an intrahepatischer cccDNA dienen (siehe 1.2.4). Die quantitative Bestimmung erfolgt in IU/ml mittels geeichter Immunassays $(1 \mathrm{lU} / \mathrm{ml}$ entspricht etwa $0,88 \pm 0,20 \mathrm{ng} / \mathrm{ml}$ nativem HBsAg-Protein je nach HBV-Genotyp). Ein kontinuierlicher Abfall der HBsAg-Konzentration kann als prädiktiver Marker für ein Ansprechen auf eine Interferon-alfa-Therapie (siehe 3.3) oder eine $\mathrm{HBsAg-Elimination} \mathrm{unter} \mathrm{Nukleos(t)idanaloga} \mathrm{(NA)} \mathrm{dienen} \mathrm{[6].}$

Da das Therapieansprechen auf Interferon alfa u. a. vom HBVGenotyp abhängig sein kann, kann vor Einleitung einer solchen Therapie die Bestimmung des Genotyps sinnvoll sein. (keine Änderung zu [5]).

1.7 Welche Patienten mit chronischer Hepatitis B sollten in ein HCC-Früherkennungsprogramm aufgenommen werden, und wie sollte dieses durchgeführt werden?

\section{EMPFEHLUNG 1.7.1}

Bei erhöhtem HCC-Risiko sollte mindestens alle 6 Monate ein abdomineller Ultraschall durch einen erfahrenen Untersucher durchgeführt werden. Dieses soll insbesondere bei Patienten mit Leberzirrhose erfolgen [EK].

Konsens: $100 \%$ (Konsensuskonferenz)

Modifiziert 2020

Leitlinienadaptation DGVS HCC Leitlinie

NKLM

\section{Kommentar:}

Ein hohes HCC-Risiko (s. auch $>$ Tab. 8) haben Patienten mit fortgeschrittener Leberfibrose oder Leberzirrhose, Patienten mit langjähriger, hoher Virämie (> $2000 \mathrm{IU} / \mathrm{ml}$ ), Patienten mit erhöhten Transaminasen und Patienten mit positivem HBeAg und/oder HBV-Genotyp-C-Virusinfektion (Evidenz 2b, (keine Änderung zu [5]). Weitere Risikofaktoren sind männliches Geschlecht, Alter > 40 Jahre, positive HCC-Familienanamnese, Migrationshintergrund aus hyperendemischen Gebieten, Alkoholkonsum oder Aflatoxinexposition (keine Änderung zu [5]).

Die EASL- und DGVS-Leitlinien zum HCC empfehlen, dass die sonografische Früherkennung durch einen qualifizierten Untersucher erfolgen sollte. Die deutschen S3-Leilinien zum HCC empfehlen zudem den Gebrauch der Geräteklasse DEGUM Stufe II durch Ärzte mit einer Qualifikation der DEGUM-Stufe II (oder höher) [9].

Die DEGUM-Einstufung der Untersucherqualität wird begründet mit einer unkontrollierten Studie, die zeigt, dass Ärzte der DEGUM-III-Qualifikation eine bessere HCC-Erkennungsrate hatten als die mit einer DEGUM-I- und -II-Qualifikation. Diese Studie hat erhebliche methodische Mängel (Evidenzgrad IIIb) und untersucht zudem auch nicht, ob Ärzte mit DEGUM-II-Qualifikation eine höhere HCC-Erkennungsrate haben als die mit einer DEGUM-IQualifikation oder Ärzte ohne DEGUM-Qualifikation [40].

Die DEGUM-Qualifikation wird deshalb nicht in die Leitlinienempfehlung aufgenommen. Ursprünglich wurde ein Vorsorgeintervall von 6 Monaten empfohlen, da die Verdopplungszeit des HCC im Mittel zwischen 140 und 200 Tagen liegt [41-43].

Eine Studie aus Taiwan verglich den Wert einer Sonografie alle 4 versus alle 12 Monate bei Patienten mit chronischer Hepatitis B oder C. Obwohl in der 4-Monats-Gruppe mehr Frühkarzinome erkannt wurden als in der 12-Monatsgruppe, waren die Überlebensraten über 4 Jahre nicht unterschiedlich [44]. 
- Tab. 8 HCC-Inzidenz/100 Personen-Jahre bei Subgruppen von Patienten mit chronischer HBV-Infektion (adaptiert und modifiziert nach [50].

\begin{tabular}{|l|l|l|}
\hline $\begin{array}{l}\text { Variable } \\
\text { (therapienaive Patienten) }\end{array}$ & $\begin{array}{l}\text { HCC-Inzidenzl } \\
\mathbf{1 0 0} \text { Personen- } \\
\text { Jahre }\end{array}$ & $\begin{array}{l}\text { 95\%-Konfi- } \\
\text { denzinter- } \\
\text { vall }\end{array}$ \\
\hline alle & 0,88 & $0,76-0,99$ \\
\hline Zirrhose & 3,16 & $2,58-3,74$ \\
\hline keine Zirrhose & 0,10 & $0,02-0,18$ \\
\hline HBeAg positiv & 1,47 & $0,40-2,55$ \\
\hline HBeAg negativ & 0,72 & $0,21-1,23$ \\
\hline HCV-Koinfektion & 3,73 & $1,59-5,86$ \\
\hline Männer & 0,63 & $0,40-0,86$ \\
\hline Frauen & 0,29 & $0,04-0,53$ \\
\hline$\geq 50$ Jahre & 3,92 & $2,72-5,11$ \\
\hline$<50$ Jahre & 0,82 & $0,69-0,95$ \\
\hline $\begin{array}{l}\text { Studien mit }>50 \% \text { Patienten } \\
\text { mit erhöhter ALT }\end{array}$ & 1,86 & $1,30-2,42$ \\
\hline $\begin{array}{l}\text { Studies mit }>50 \% \text { Patienten } \\
\text { mit normaler ALT }\end{array}$ & 0,32 & $0,21-0,43$ \\
\hline
\end{tabular}

Die NICE-Leitlinie enthält ein systematisches Review und eine Metaanalyse zur Häufigkeit der Vorsorge (in diesem Fall mit Ultraschall + AFP-Messung); nach diesen Analysen kommt NICE zu dem Schluss, dass das auch in den anderen 3 Leitlinien empfohlene Intervall von 6 Monaten optimal ist (Evidenzgrad Ila); ein kürzeres Intervall von 3-4 Monaten hatte keine Vorteile, und längere Intervalle von 9-12 Monaten hatten eher Nachteile für die Früherkennung [45].

Eine weitere Metaanalyse zeigte, dass die Sensitivität der 6-monatlichen Untersuchung um $20 \%$ besser war als die der 12-monatlichen [46].

In asiatischen Leitlinien wird für Hochrisikogruppen eine Verkürzung des Untersuchungsintervalls auf 3-4 Monate empfohlen, auch dies aufgrund der Evidenz der Expertenmeinung [47-49].

\section{EMPFEHLUNG 1.7.2}

Das Kontrollintervall kann je nach Risikoabschätzung ( $\triangleright$ Tab.9) auf 12 Monate verlängert werden. Optional kann zusätzlich zum Ultraschall eine AFP-Bestimmung zur Früherkennung eines HCC durchgeführt werden [EK].

Konsens: $100 \%$ (Konsensuskonferenz)

Modifiziert 2020

Leitlinienadaptation DGVS HCC Leitlinie
Tab.9 Früherkennungsempfehlungen in tabellarischer Form.

Ultraschall alle 6 Monate durch einen erfahrenen Untersucher (A) optional zusätzlich AFP-Bestimmung (0)

dringend empfohlen (A): HCC-Risiko hoch

Zirrhose

empfohlen (B): HCC- $\quad$ nicht notwendig (B): Risiko mäßig hoch HCC-Risiko niedrig

ausgeprägte Fibrose keine/wenig Fibrose (Metavir F2-F3) (Metavir F0-F1) erhöhte ALT/GPT normale ALT/GPT HBV-DNA $>$ HBV-DNA < $2000 \mathrm{IU} / \mathrm{ml} \quad 2000 \mathrm{IU} / \mathrm{ml}$ positive HCC- negative HCCFamilienanamnese Familienanamnese Männer, $\geq 40$ Jahre Frauen, $<40$ Jahre

Genotyp C

zusätzliche hepatotoxische Faktoren: Fettleber, Diabetes mellitus Typ 2, hohe Aufnahme an Aflatokein Genotyp C keine zusätzlichen hepatotoxischen Faktoren (s. Spalte links) xin oder Alkohol, Koinfektion mit HDV, HIV und HCV

\section{Kommentar:}

Patientengruppen mit relativ niedrigem HCC-Risiko ( $\triangleright$ Tab. 9) kann man auch eine Sonografie nur alle 12 Monate anbieten; dies entspricht in der aktuellen Leitlinie einer Expertenmeinung. Ein kombiniertes HCC-Screening mittels Ultraschalls des Abdomens und Bestimmung des Alpha-Fetoproteins (AFP) kann aufgrund der begrenzten Sensitivität und Spezifität der einzelnen Untersuchungen gerechtfertigt sein.

Als ergänzendes Verfahren ist die Bestimmung des AFP-Spiegels zwar etabliert, eine Empfehlung zur Durchführung im Rahmen der Früherkennung wird allerdings von aktuellen Leitlinien nicht mehr gegeben. Die Bestimmung der AFP-Konzentration im Serum hat für die Früherkennung eine schlechte Spezifität [9, 51].

Dennoch hatte sich die Expertengruppe für eine „kann“-Empfehlung für die ergänzende AFP-Bestimmung ausgesprochen, da die Kombination Ultraschall plus Serum-AFP-Bestimmung die Sensitivität erhöhen kann (in einer Studie z. B. von 63\% auf 69\%). Ein Effekt auf die Mortalität konnte bislang nicht klar gezeigt werden $[9,52]$.

Nur bei nachgewiesener Raumforderung hat das AFP eine konkrete diagnostische Relevanz; es hilft die Prognose des HCC einzuschätzen und kann für die Verlaufsbeobachtung sinnvoll sein [9].

Sowohl im Screening als auch im Rahmen der Diagnostik ist eine Reihe von weiteren Serummarkern für das HCC in der Evaluierung, z. B. Des-Gamma-Carboxyprothrombin (DCP), $\alpha$-Fukosidase, Glypikan 3 sowie das Verhältnis zwischen glykosiliertem AFP und Gesamt-AFP. Bislang gibt es zum Einsatz dieser Marker aber keine Empfehlung [9]. 


\section{EMPFEHLUNG 1.7.3}

Patienten sollen während und nach einer antiviralen Therapie weiterhin eine HCC-Vorsorge erhalten, da das HCC-Risiko reduziert, aber nicht eliminiert wird. Das Untersuchungsintervall kann während bzw. nach erfolgreicher Therapie der Hepatitis B individuell angepasst werden [EK]. Konsens: $100 \%$ (Konsensuskonferenz)

Modifiziert 2020

\section{Kommentar:}

Eine nachhaltige HBV-DNA-Suppression mit Interferon alfa oder dauerhafte HBV-DNA-Suppression mit Nukleosidanaloga bzw. Nukleotidanaloga (NA) ist mit einer Reduktion des HCC-Risikos (Evidenz 1a, siehe 3.1.1) assoziiert. Allerdings bleibt ein Restrisiko bestehen, was abhängig von verschiedenen virologischen und klinischen Faktoren ist. Patienten mit kompensierter Zirrhose und niedriger, aber quantifizierbarer HBV-DNA < $2000 \mathrm{lU} / \mathrm{ml}$ haben ein höheres HCC-Risiko als Patienten mit nicht nachweisbarer bzw. nicht quantifizierbarer HBV-DNA (siehe 3.1.1). Risikoscores zu Einschätzung des HCC-Risikos unter NA-Therapie können hilfreich sein, um die Überwachungsintervalle festzulegen. Bei asiatischen Patienten wurden folgende Risikoscores validiert: GAGHCC, CU-HCC, REACH-B. Bei europäischen Patienten scheint nur der PAGE-B-Score einen ausreichenden prädiktiven Wert zu besitzen. In den asiatischen Risikoscores spielen das Alter und die Viruslast sowie das Vorhandensein einer Zirrhose eine Rolle (siehe 3.1). Beim PAGE-B-Score sind neben dem Alter das männliche Geschlecht und die Thrombozyten gewichtet $[6,53]$.

\subsection{Bei welchen Patienten ist eine Leberbiopsie indiziert, bei welchen Patienten eine nichtinvasive Fibrosediagnostik?}

\section{EMPFEHLUNG 1.8.1}

Die Leberbiopsie ist eine hilfreiche Maßnahme zur Einstufung der entzündlichen Aktivität, der Leberfibrose und von Komorbiditäten. Sie kann bei Patienten mit chronischer HBV-Infektion durchgeführt werden, wenn sich daraus Konsequenzen für Diagnose, Verlaufsbeurteilung und/oder Therapie ableiten lassen [EK].

Konsens: $100 \%$ (Konsensuskonferenz)

Modifiziert 2020

NKLM

\section{Kommentar:}

Maßgebliche Grundlage der Entscheidung für eine Leberbiopsie ist die Frage, ob das diagnostische Ergebnis der Biopsie für das therapeutische Vorgehen von Bedeutung ist. Die histopathologische Diagnostik dient zur Klärung folgender Fragen:

1. Bestimmung der entzündlichen Aktivität (Grading);

2. Bestimmung des Fibroseausmaßes (Staging);

3. Aussagen zur Ätiologie (insbes. Komorbidität).
Da alle o.g. Parameter Einfluss auf die Prognose und Therapie (-entscheidung) bei einer Hepatitis B haben können, ist zu jedem Punkt pathologisch-diagnostisch explizit Stellung zu beziehen (keine Änderung zu [5]).

Bei jeder chronischen Hepatitis dient die Leberbiopsie in erster Linie der Bestimmung der entzündlichen Aktivität (Grading) und des Fibroseausmaßes (Staging) und ist in der Beurteilung dieser Parameter nach wie vor der „Goldstandard“ (keine Änderung zu [5]).

Bei fortgeschrittener Leberzirrhose muss eine sorgfältige RisikoNutzen-Abwägung erfolgen, da ein erhöhtes Blutungsrisiko besteht und die Therapieindikation bereits aus dem klinischen Befund der Leberzirrhose abgeleitet werden kann. Es sollten nichtinvasive Parameter ausgeschöpft werden, um das Risiko abschätzen zu können.

Die Beurteilung der Ätiologie ist insbesondere bei unklaren oder negativen serologischen Parametern und in Bezug auf relevante Begleiterkrankungen von Bedeutung. Bei unklarer Anamnese und fehlenden biochemischen und serologischen Vorbefunden kann die Leberbiopsie auch dazu dienen, die Chronizität einer Lebererkrankung zu beurteilen. Untersuchungen an Biopsien, die ausschließlich zum Grading/Staging gewonnen wurden, zeigen eine relevante Komorbidität in etwa 20 \% der Fälle (keine Änderung zu [5]).

\section{EMPFEHLUNG 1.8.2}

Für die Beurteilung der Leberfibrose zur Therapieindikationsstellung können nichtinvasive Verfahren zum Einsatz kommen [EK].

Konsens: $100 \%$ (Konsensuskonferenz)

Neu 2020

NKLM

\section{Kommentar:}

Nichtinvasive Verfahren für die Beurteilung der Leberfibrose werden von anderen Leitlinien empfohlen (Evidenz 2b) $[6,10]$.

Allerdings sind die nichtinvasiven Verfahren bei der Hepatitis B weniger gut evaluiert als bei der Hepatitis C. Insbesondere kann die Interpretation nichtinvasiver Verfahren (Elastografie) bei hohen Transaminasen (z. B. bei Flares) erschwert sein [6, 10].

\section{EMPFEHLUNG 1.8.3}

Für die Beurteilung der Leberfibrose sollte die transiente Elastografie anderen nichtinvasiven Verfahren vorgezogen werden [EK].

Konsens: 85,7\% (Konsensuskonferenz)

Modifiziert

Leitlinienadaptation EASL Clinical Practice Guideline Non-invasive Tests

NKLM 


\section{Kommentar:}

Sowohl für die fortgeschrittene Fibrose/Zirrhose als auch für fehlende Fibrose hat die transiente Elastografie (TE) eine höhere Prädiktionsgenauigkeit als Serumbiomarker. So kann bei Patienten mit normwertiger ALT und einer Lebersteifigkeit von $9 \mathrm{kPa}$ und Patienten mit erhöhter ALT (aber $<5 \times$ ULN) und einer Lebersteifigkeit von $12 \mathrm{kPa}$ von einer fortgeschrittenen Leberfibrose oder -zirrhose ausgegangen werden (Evidenz 3b) [10, 54, 55].

\section{EMPFEHLUNG 1.8.4}

Eine nichtinvasive Fibrosebestimmung zur Erfassung einer Fibroseverbesserung während oder nach einer antiviralen Therapie kann erfolgen. Komorbidität und Transaminasenverlauf sollen bei der Interpretation berücksichtigt werden [EK]. Konsens: $100 \%$ (Konsensuskonferenz)

Modifiziert 2020

Leitlinienadaptation EASL Clinical Practice Guideline Non-invasive Tests

\section{Kommentar:}

Bei Patienten mit erhöhten Transaminasen ist die Interpretation der Steifigkeit oftmals nicht eindeutig. Nach akuter Exazerbation können bis 3-6 Monate nach Normalisierung der Leberwerte die Steifigkeitswerte fehlgedeutet werden (Evidenz 3b) [10, 56].

Die nichtinvasive Fibrosemessung (statt Leberpunktion) bei HBeAg-negativen Patienten empfiehlt sich bei einer HBV-DNA $<20000$ U/I und normalen ALT-Werten, da das Risiko einer fortgeschrittenen Fibrose/Zirrhose bei dieser Konstellation $<10 \%$ beträgt (Evidenz 3a) [10, 57].

\section{Indikationsstellung zur Therapie der Hepatitis-B-Virusinfektion}

J. Petersen, C. Jochum, H. Hinrichsen, A. Kautz (Leberhilfe), K.H. Peiffer, C. Sarrazin, E. Schott

\subsection{Akute Hepatitis B: Kann die klinische Heilungsrate durch eine antivirale Therapie erhöht werden? Kann durch eine antivirale Therapie die Krankheitsdauer verkürzt und die Schwere der Erkrankung reduziert werden?}

\section{STATEMENT 2.1.1}

Aufgrund der hohen Spontanheilungsrate der akuten Hepatitis B beim Erwachsenen besteht in der Regel keine Therapieindikation für die aktuell verfügbaren antiviralen Medikamente. Konsens: 97,9\% (Delphi-Runde)

Geprüft 2020

NKLM

\section{Kommentar:}

Die akute Hepatitis B heilt bei Erwachsenen in 95-99\% der Fälle spontan aus (Evidenz 3a). (keine Änderung zu [5]).
Eine Verbesserung der Ausheilung durch eine antivirale Therapie wird kaum nachweisbar sein. Die Therapie der akuten Hepatitis B mit antiviralen Medikamenten bleibt daher umstritten. Eine randomisierte, placebokontrollierte Studie aus Indien hat keinen Vorteil einer Lamivudintherapie der akuten Hepatitis B gegenüber einer Placebobehandlung gezeigt (Evidenz 2b) [58].

Eine weitere Studie aus Asien ergibt Hinweise für eine verbesserte klinische Response unter Lamivudintherapie bei schwereren, aber nicht fulminanten Verläufen mit bereits eingeschränkter Spontangerinnung (Evidenz 2b) [59].

Eine placebokontrollierte Studie aus Europa (GAHB-Studie) konnte aufgrund unzureichender Patientenrekrutierung nicht beendet werden (Evidenz 2b). Hier deutete sich bei jedoch niedrigen Fallzahlen kein Vorteil hinsichtlich Überleben oder Transplantationsfreiheit an [60].

Auch auf der Basis einer Metaanalyse, die Studien bei Patienten mit verschiedenen Schweregraden einer akuten HBV-Infektion eingeschlossen hat, kann generell eine antivirale Therapie bei akuter HBV-Infektion derzeit nicht empfohlen werden (Evidenz 3a) [61].

\section{STATEMENT 2.1.2}

Sonderfälle sind Patienten mit schwerer akuter oder fulminanter Hepatitis B. Bei Anzeichen einer eingeschränkten Lebersynthese sollten diese Patienten mit einem Nukleos(t)idanalogon behandelt und frühzeitig in einem Transplantationszentrum betreut werden [3, B].

Konsens: $100 \%$ (Delphi-Runde)

Geprüft 2020

NKLM

\section{Kommentar:}

Mehrere Fallberichte und Fallserien haben dagegen gezeigt, dass Patienten mit fulminanter Hepatitis B (0,1-0,5\% der Fälle bei Erwachsenen), die frühzeitig antiviral behandelt werden, in der Regel keine Transplantation mehr benötigen, im Vergleich zu 50-80\% der unbehandelten Patienten aus historischen Kontrollen (Evidenz 3b) [62-64].

Es gibt allerdings Hinweise dafür, dass die Therapie frühzeitig erfolgen muss, da bei Patienten mit schon weit fortgeschrittenem Leberversagen eine Lebertransplantation oder der Tod mit einer antiviralen Therapie nicht mehr verhindert werden kann (Evidenz 3b) [63].

Bei Anzeichen einer Einschränkung der Lebersynthese im Rahmen der akuten Hepatitis B (Verlängerung der Prothrombinzeit, Quick-Wert $<50 \%$ ) erscheint daher eine sofortige orale antivirale Therapie gerechtfertigt, um einem fulminanten Leberversagen vorzubeugen. Patienten mit einer symptomatischen Hepatitis B sollten hinsichtlich der Lebersynthese engmaschig beobachtet werden, um eine Therapie frühzeitig einzuleiten. Die Ergebnisse einer asiatischen Studie zeigen allerdings, dass eine antivirale Therapie der akuten Hepatitis B die Serokonversionsrate möglicherweise reduziert (Evidenz 2b) [59]. 


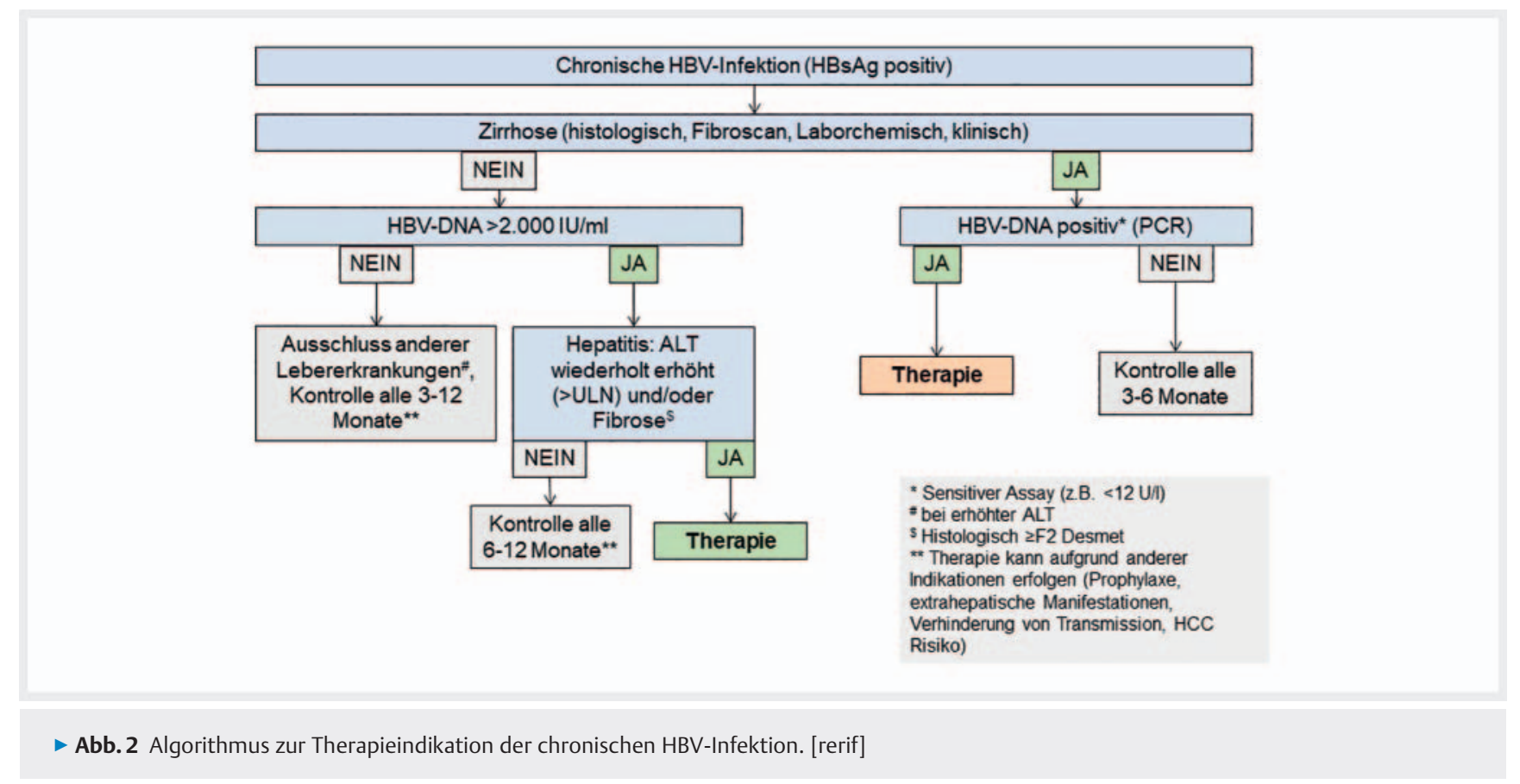

Diese Beobachtung konnte in anderen Studien nicht bestätigt werden (Evidenz 2b) [60, 63].

Das Risiko-Nutzen-Verhältnis für die Behandlung der akuten fulminanten Hepatitis B mit Nukleos(t)idanaloga (NA) spricht in Zusammenschau der Evidenz für die Behandlung. Patienten mit fulminanter Hepatitis B waren außerdem nicht ausreichend in der Metaanaylse von Mantzoukis repräsentiert [61].

Eine antivirale Therapie sollte bis zur HBsAg-Serokonversion oder bei fehlender Anti-HBs-Entwicklung bis 6 Monate nach HBsAg-Verlust fortgeführt werden. Auch wenn die meisten Untersuchungen mit Lamivudin durchgeführt worden sind, legen neuere Daten nahe, dass auch die neuen antiviralen Medikamente Entecavir und Tenofovir gleich effektiv und sicher sind (Evidenz 3b) [63].

Bei der Auswahl von NA sollen Komorbiditäten (v. a. Niereninsuffizienz und Knochendichteminderung) und Begleitumstände berücksichtigt werden (siehe 3.2.2).

\subsection{Chronische Hepatitis-B-Virusinfektion (Monoinfektion): Welche Patienten sollen therapiert werden?}

\section{STATEMENT 2.2.1}

Alle Patienten mit chronischer Hepatitis B sind grundsätzlich Kandidaten für eine antivirale Therapie. Die Indikationsstellung berücksichtigt in erster Linie die ALT-Aktivität im Serum (wiederholt erhöht), die Höhe der Virusreplikation (Grenzwert $2000 \mathrm{IU} / \mathrm{ml}$ ) und den Entzündungs- und Fibrosestatus in der Biopsie oder den Fibrosestatus in der nichtinvasiven Leberelastografie (siehe $>$ Abb. 2).

Konsens: 97,9\% (Delphi-Runde)

Geprüft 2020

NKLM

\section{Kommentar:}

Eine sichere Indikation zur antiviralen Behandlung besteht bei Patienten mit chronischer Hepatitis B, HBeAg-positiv oder HBeAgnegativ, die

- eine Virusreplikation von $\geq 2000 \mathrm{IU} / \mathrm{ml}$ zeigen und

- eine entzündliche Aktivität mit wiederholt erhöhter Transaminasenaktivität im Serum aufweisen und

- unter Berücksichtigung von Lebensalter und Begleiterkrankungen ein Risiko haben, eine Leberzirrhose und deren Komplikationen wie insbesondere ein HCC zu entwickeln.

Die Empfehlung entspricht auch den internationalen Leitlinien der EASL und AASLD [6-8].

Die Höhe der Transaminasen allein ist kein zuverlässiger Parameter für die Abschätzung der Krankheitsaktivität, insbesondere bei HBeAg-negativen Patienten, und ist daher für die Indikation zur Therapie nur eingeschränkt verwertbar (Evidenz 2b) [65].

Bei zunächst nicht eindeutiger Indikation sollten Viruslast und Transaminasen wiederholt in dreimonatigen Abständen kontrolliert werden. In unklaren Situationen (z. B. HBV-DNA im Serum $>2000 \mathrm{IU} / \mathrm{ml}$ und normalen oder nur minimal erhöhten bzw. fluktuierenden Transaminasen) kann eine Leberbiopsie erfolgen, um das Lebergewebe histologisch zu beurteilen (siehe auch 1.8.1 und 2.4). Das Ergebnis der Histologie kann in die Indikationsstellung mit einbezogen werden. Dies gilt insbesondere für Patienten jenseits des 30. Lebensjahres. Auch bei normalen oder nur minimal erhöhten Transaminasen im Serum kann eine Entzündung und/oder eine signifikante Fibrose (> minimale Fibrose) in der Leber vorliegen, die dann eine Therapieindikation begründen können (Evidenz 2b) [66-70].

Bei Patienten, die histologisch nur Minimalveränderungen aufweisen und deshalb zunächst nicht behandelt werden, kann die Histologie nach 3-5 Jahren kontrolliert werden. Alternativ können nichtinvasive sonografische Elastografieverfahren Informationen 
bezüglich einer bereits vorliegenden Zirrhose liefern oder für Verlaufsbeurteilungen herangezogen werden (siehe 1.8.2). Patienten mit einer Virämie $\geq 2000 \mathrm{IU} / \mathrm{ml}$ und wiederholt erhöhten Transaminasen sollten therapiert werden, auch ohne Vorliegen einer Leberbiopsie. Einige Studien zeigen allerdings auch für Patienten mit normalen Transaminasen in Abhängigkeit von der Viruslast ab etwa $2000 \mathrm{IU} / \mathrm{ml}$ ein signifikant erhöhtes Zirrhose- und Karzinomrisiko (Evidenz 2b) [32, 33, 71].

Diese Studien sind an asiatischen Patienten (Patienten waren alle über 25 Jahre, mehrheitlich HBeAg-negativ) mit den Genotypen $B$ und $C$ nach mehrheitlich vertikaler Transmission erhoben worden. Obwohl die Daten nicht direkt auf kaukasische Patienten mit Genotypen A und D und häufigerer horizontaler Transmission übertragbar sind, sollten diese Studienergebnisse in therapeutische Überlegungen mit einfließen, zumal ein nicht unerheblicher Anteil von HBV-Patienten in Deutschland aus asiatischen Ländern stammt. So sollten Patienten, die bei anhaltend normalen Transaminasen eine höhere Viruslast zeigen (> $2000 \mathrm{IU} / \mathrm{ml}$ ), regelmäßig überwacht (Kontrollen alle 6 Monate) und bei Hinweisen für eine Aktivierung der Erkrankung antiviral behandelt werden (siehe 2.4) [6].

\section{EMPFEHLUNG 2.2.2}

Patienten mit Leberzirrhose sollen bei HBV-DNA-Nachweis unabhängig von der Höhe der Virämie antiviral behandelt werden $[2, \mathrm{~A}]$.

Konsens: $100 \%$ (Konsensuskonferenz)

Modifiziert 2020

Leitlinienadaption EASL Clinical Practice Guideline HBV 2017, AASLD Practice Guideline HBV 2016

NKLM

(siehe auch 3.9.1)

\section{Kommentar:}

Zu den besonders therapiebedürftigen Patienten zählen Patienten mit deutlicher oder fortschreitender Leberfibrose oder -zirrhose. Letztere sind bereits durch relativ milde Schübe („Flares“) der chronischen Hepatitis bei mangelnder Leberreserve z. T. vital gefährdet. Zudem sind selbst niedrige HBV-DNA-Level $(<2000 \mathrm{IU} / \mathrm{ml})$ in dieser Patientengruppe mit einem erhöhten HCC-Risiko assoziiert (Evidenz 2b) [72-74].

Eine nachhaltige bzw. dauerhafte HBV-DNA-Suppression durch eine antivirale Therapie ist mit der Verhinderung von Leberzirrhose, hepatischen Dekompensationen, HCC (Evidenz 1a), Lebertransplantation und Tod (Evidenz 2a) assoziiert (siehe 3.1) $[75,76]$.

Analog zu den internationalen Leitlinien von EASL und AASLD sollen daher Patienten mit Leberzirrhose bei Nachweis jeglicher Virämie (über der Nachweisgrenze sensitiver Testsysteme) antiviral therapiert werden [6-8]. Die EASL-Leitlinie gibt hier einen stärkeren Empfehlungsgrad, ohne Primärquellen anzugeben. Die AASLD-Leitlinie unterscheidet zwischen kompensierter Leberzir- rhose (geringere Evidenz, offene Empfehlung) und dekompensierter Leberzirrhose (moderate Evidenz, starker Empfehhlungsgrad). Zur Vereinfachung haben wir analog der EASL-Leitline in unserer Empfehlungsstärke nicht zwischen kompensierter und dekompensierter Leberzirrhose unterschieden.

\section{EMPFEHLUNG 2.2.3}

Patienten mit HCC und positiver HBV-DNA sollten mit Nukleos (t)idanaloga behandelt werden [2, B].

Konsens: $100 \%$ (Konsensuskonferenz)

Neu 2020

Evidenztabelle siehe Leitlinienreport Anhang III

\section{Kommentar:}

Mehrere Studien belegen einen Nutzen einer antiviralen Therapie bei Patienten mit HBV-Infektion und hepatozellulärem Karzinom (HCC). Durch eine antivirale Therapie bei Patienten nach kurativer HCC-Resektion wird die Rate von HCC-Rezidiven vermindert sowie das Gesamtüberleben verbessert (Evidenz 2a). Auch bei Patienten mit primär nicht resezierbarem HCC zeigt sich ein Überlebensvorteil sowie eine verlangsamte Progression der Tumorerkrankung, wenn diese antiviral behandelt wird (Evidenz 2a) [77-85].

\section{STATEMENT 2.2.4}

Reaktivierungen der Hepatitis-B-Virusreplikation durch Immunsuppression sollen verhindert werden, da sie das Risiko von akuter Dekompensation und Zirrhose erhöhen (siehe 3.13).

Konsens: 95,7\% (Delphi-Runde)

Modifiziert 2020

\section{Kommentar:}

Die HBV-Infektion kann reaktivieren, sowohl bei inaktiven HBsAg-Trägern als auch nach klinisch durchgemachter Hepatitis B mit Verlust von HBsAg oder Ausbildung von Anti-HBs und/oder Anti-HBc-Antikörpern. Reaktivierungen der Hepatitis B erhöhen das Risiko von Zirrhose und HCC. Das Risiko der Reaktivierung der HBV-Infektion mit Gefahr der klinischen Dekompensation wird durch eine Immunsuppression (Chemotherapie, Transplantation u. a.) deutlich erhöht (siehe 3.13). (keine Änderung zu [5]).

Gemäß internationalen Leitlinien ist eine prophylaktische Therapie mit NA bei HBsAg-positiven Patienten, die immunsuppressiv behandelt werden, empfohlen, um Reaktivierungen zu verhindern (siehe 3.13) [6, 86, 87].

Aber auch bei lediglich Anti-HBc-positiven Patienten und auch in Einzelfällen bei Anti-HBs-positiven Personen kann eine präventive Therapie mit Nukleos(t)idanaloga notwendig sein (Einzelheiten siehe 3.13). 


\section{STATEMENT 2.2.5}

Eine Schwangerschaft stellt keine Kontraindikation für eine Therapie mit Tenofovir (TDF), Lamivudin oder Telbivudin dar. Die medizinische Indikation sowie die Verhinderung der Mutter-Kind-Übertragung sollen berücksichtigt werden (siehe 3.12).

Konsens: $100 \%$ (Konsensuskonferenz)

Neu 2020

Evidenztabelle siehe Leitlinienreport Anhang III

\section{Kommentar:}

Aus Tierversuchen lässt sich kein Hinweis auf eine Beeinträchtigung des Fötus durch Tenofovir oder Telbivudin ableiten. Ausreichende klinische Daten aus großen Schwangerschaftsregistern liegen aktuell für Lamivudin, Tenofovir (TDF) und Telbivudin vor. Hierbei zeigte sich für diese Substanzen kein erhöhtes Risiko für fötale Missbildungen, auch wenn die Substanzen bereits im ersten Trimenon eingesetzt wurden (Evidenz 2a) [19].

Die Empfehlungen zum Behandlungsbeginn richten sich nach den allgemeinen Therapieempfehlungen (siehe 3.12). Eine Therapieindikation zur Verhinderung der Mutter-Kind-Übertragung soll geprüft werden, da eine antivirale Therapie mit Tenofovir (TDF), Telbivudin oder Lamivudin bei Schwangeren mit hoher Viruslast (> $200000 \mathrm{IU} / \mathrm{ml}$ ) das Risiko der vertikalen Übertragung senkt (siehe 3.12) (Evidenz 1b) [19-22, 24, 25, 88].

Die Empfehlungen entsprechen den internationalen Leitlinien von AASLD, EASL und WHO [6, 7, 23].

\section{STATEMENT 2.2.6}

Berufliche und soziale Aspekte können eine antivirale Therapie begründen, insbesondere mit dem Ziel, die Transmission an Dritte zu verhindern (siehe 2.3, 3.12).

Konsens: $100 \%$ (Delphi-Runde)

Geprüft 2020

\section{Kommentar:}

Eine antivirale Therapie kann im Einzelfall erwogen werden, um z. B. einem HBV-Infizierten die weitere Berufsausübung zu ermöglichen, falls ihm aufgrund einer replikativen HBV-Infektion ein Berufsverbot droht. Die Übertragung von HBV an Dritte durch z. B. im Gesundheitswesen tätige Personen ist ab einer Virämie von $<200 \mathrm{IU} / \mathrm{ml}$ nicht bekannt, aber denkbar. Übertragungen sind bisher vorwiegend bei verletzungsträchtigen Prozeduren berichtet worden (z. B. bei Thoraxchirurgen, Kieferchirurgen und Gynäkologen) und sind fast immer von HBV-Infizierten mit $>20000 \mathrm{IU} / \mathrm{ml}$ ausgegangen [89].

Auch soziale Aspekte wie eine Stigmatisierung des Infizierten oder sexuelle Praktiken (u. a. häufig wechselnde Sexualpartner), die mit einem erhöhten Übertragungsrisiko einhergehen, können eine Therapie begründen.

\section{EMPFEHLUNG 2.2.7}

Patienten mit extrahepatischen Komplikationen sollten behandelt werden [3, B] (siehe 3.10).

Konsens: 97,9\% (Delphi-Runde)

Modifiziert 2020

Leitlinienadaption EASL Clinical Practice Guideline HBV 2017

\section{Kommentar:}

Zu den extrahepatischen Komplikationen einer HBV-Infektion zählen z. B. eine HBV-assoziierte Polyarteriitis nodosa und eine HBV-assoziierte Nephropathie (v. a. membranöse Glomerulonephritis). Einzelne Fallberichte und Fallserien berichten, dass eine antivirale Therapie die Progression der extrahepatischen Komplikationen stoppen und ggf. zu einer Regression führen kann. So wurde z. B. in einer Fallserie von 17 Patienten mit HBV-assoziierter Vaskulitis bei Kryglobulinämie mittels antiviraler NA-Therapie in allen behandelten Patienten sowohl eine weitere Progression der Vaskulitis verhindert als auch in den überwiegenden Fällen eine Besserung der Symptomatik erreicht (Evidenz 3b) [90].

Mehrere Metaanalysen berichten zudem von einem Nutzen einer antiviralen Therapie bei HBV-assoziierter Nephropathie hinsichtlich einer verminderten Proteinausscheidung, einer stabilisierten Nierenfunktion sowie einer erhöhten Remissionsrate (Evidenz 3a) [91, 92].

\section{STATEMENT 2.2.8}

Alkohol- oder Drogenkonsum stellt keine Kontraindikation gegen eine Therapie mit Nukleos(t)idanaloga dar.

Konsens: 95,7\% (Delphi-Runde)

Geprüft 2020

\section{Kommentar:}

Die Abstinenz vor Therapiebeginn stellt keine absolute Voraussetzung zur Indikationsstellung dar. Die zu erwartende Compliance sollte vor Therapiebeginn abgeschätzt und während der Therapie klinisch überprüft werden. Therapieindikation, -dauer und -überwachung sind abhängig von der Höhe der Transaminasen, der HBV-DNA, ggf. histologischen Veränderungen in der Leber und dem $\mathrm{HBeAg} /$ Anti-HBe-Status und sind daher nicht grundsätzlich anders als bei Patienten ohne Alkohol- bzw. Drogenabhängigkeit. Aufgrund des Nebenwirkungsprofils einer Therapie mit (PEG-) Interferon alfa wird als Primärtherapie eine orale antivirale Therapie empfohlen (keine Änderung zu [5]). 


\subsection{Sollen Patienten mit hochvirämischer chronischer HBV-Infektion (früher als „immuntolerante“ Patienten bezeichnet) behandelt werden?}

\section{STATEMENT 2.3.1}

Bei hochvirämischer chronischer HBV-Infektion mit wiederholt normaler ALT besteht keine dringende medizinische Indikation für eine antivirale Behandlung. Konsens: 92,9\% (Konsensuskonferenz)

Neu 2020

Da die Höhe der HBV-DNA als unabhängiger Risikofaktor für die Entwicklung einer Leberzirrhose und/oder eines HCC identifiziert wurde (u. a. in der REVEAL-Studie), liegt die Überlegung nahe, dass auch Patienten mit einer HBeAg-positiven chronischen HBVInfektion (früher „immuntolerante“ Patienten) von einer antiviralen Therapie profitieren könnten. Bis dato gibt es jedoch keine Evidenz, dass eine antivirale Therapie in dieser Patientengruppe die Inzidenz einer Leberzirrhose und/oder eines HCCs vermindert bzw. einen Überlebensvorteil bringt. Die Studienkohorte in der REVEAL-Studie war nicht repräsentativ für die HBeAg-positive chronische HBV-Infektion. Alle Patienten waren älter als 30 Jahre, $67 \%$ sogar älter als 40 Jahre und $95 \%$ der Patienten waren HBeAgnegativ (Evidenz 2b) [32, 33].

Histologische Untersuchungen von jungen Patienten mit einer $\mathrm{HBeAg-positiven} \mathrm{chronischen} \mathrm{HBV-Infektion} \mathrm{mit} \mathrm{niedrig} \mathrm{normaler}$ ALT zeigen zudem, dass nur in einer Minderheit dieser Patienten signifikante histologische Veränderungen bestehen (Evidenz 3b) [67, 93, 94].

Daher empfehlen die internationalen Leitlinien der EASL und AASLD, dass keine medizinische Therapieindikation für diese Patienten vorliegt $[6,7]$.

\section{EMPFEHLUNG 2.3.2}

Patienten $>30$ Jahre oder Patienten mit hoch normalen ALT-Werten (Männer > 30 U/I, Frauen > 19U/I) können antiviral behandelt werden [3, 0]. Konsens: 96,6\% (Konsensuskonferenz)

Neu 2020

Leitlinienadaption EASL Clinical Practice Guideline HBV 2017, AASLD Practice Guideline HBV 2016

\section{Kommentar:}

Patienten mit einer $\mathrm{HBeAg-positiven} \mathrm{chronischen} \mathrm{Infektion}$ können eine spontane HBeAg-Serokonversion erreichen. Im Alter von ca. 31 Jahren hatten $85 \%$ aller Studienteilnehmer (in einer prospektiven Studie mit 240 Teilnehmern) Anti-HBe entwickelt. Bei $15 \%$ dieser Patienten kam es im weiteren Verlauf allerdings zu einer HBeAg-negativen chronischen Hepatitis B (Evidenz 2b) [95].

Ältere Patienten (> 30 Jahre) mit fortbestehender, chronischer HBeAg-positiver Infektion (irrtümlich in Studien oft als „immunto- lerante“ Patienten bezeichnet) weisen vermehrt signifikante histologische Veränderungen auf und zeigen im Vergleich zu HBeAg-negativen Patienten ein deutlich erhöhtes Risiko für die Entwicklung eines HCC (Evidenz 3b). Subgruppenanalysen belegen zudem, dass auch HBeAg-positive Patienten mit hoch normaler ALT (Männer > $30 \mathrm{U} / \mathrm{I}$, Frauen > 19 U/I) bereits häufiger signifikante histologische Veränderungen aufweisen, die eine antivirale Therapie begründen können [66, 93, 96].

Aus diesem Grund empfehlen auch die AASLD-Leitlinien bei HBeAg-positiver Infektion eine antivirale Therapie bei älteren Patienten (> 40 Jahre) sowie bei hoch normalen ALT-Werten (Frauen > 19 IU/I, Männer > $30 \mathrm{IU} / \mathrm{I}$ ). [7] Die EASL-Leitlinien haben hier die Altersgrenze bei $>30$ Jahren gesetzt [6].

\section{EMPFEHLUNG 2.3.3}

Eine antivirale Therapie zur Verhinderung einer Transmission an Dritte kann erfolgen [EK].

Konsens: $100 \%$ (Delphi-Runde)

Neu 2020

\section{Kommentar:}

Da das Transmissionsrisiko von der Höhe der Viruslast abhängt, kann eine antivirale Therapie zur Verhinderung der Transmission v. a. bei Schwangeren und Berufstätigen im Gesundheitswesen erfolgen. Details siehe 2.2.6 und 3.12.

\subsection{Sollen Patienten mit niedrig virämischer chronischer HBV-Infektion (früher als „inaktive Träger“ bezeichnet) behandelt werden?}

\section{EMPFEHLUNG 2.4.1}

Bei niedrig virämischer chronischer HBV-Infektion (HBeAg negativ, HBV-DNA < $2000 \mathrm{IU} / \mathrm{ml}$, wiederholt normale ALT, kein Hinweis für eine moderate bis fortgeschrittene Leberfibrose) braucht i. d. R. keine antivirale Behandlung zu erfolgen [3, 0]. Konsens: 96,6\% (Konsensuskonferenz)

Neu 2020

Leitlinienadaption EASL Clinical Practice Guideline HBV 2017, AASLD Practice Guideline HBV 2016

\section{Kommentar:}

Diese Empfehlung entspricht den Empfehlungen von EASL und AASLD [6, 7].

Zu den Patienten, die in der Regel nicht behandelt werden sollten, zählen Patienten mit niedrig virämischer chronischer HBVInfektion (früher: inaktive HBsAg-Träger; anhaltend niedrige Virämie $<2000 \mathrm{lU} / \mathrm{ml}$ und anhaltend normale ALT), da diese Personen eine geringe HBV-assoziierte Morbidität und Sterblichkeit aufweisen (Evidenz 3b) [97].

Niedrig virämische HBsAg-Träger (mit normalen ALT-Werten) aus Asien haben im Vergleich zu HBsAg-negativen Patienten ein erhöhtes HCC-Risiko (Evidenz 2b). Das Risiko kann durch die Be- 
stimmung von HBsAg stratifiziert werden. Ein HBsAg-Wert $>1000 \mathrm{IU} / \mathrm{ml}$ war bei HBeAg-negativen Patienten mit HBV-DNA $<2000 \mathrm{IU} / \mathrm{ml}$ sowie bei Patienten mit HBV-DNA-Werten von 2000-20000 IU/ml mit einem höheren HCC-Risko assoziiert. Dabei ist allerdings nicht klar, ob diese Patienten wiederholt normale Transaminasen aufweisen (siehe unten) (Evidenz 2b) [71, 98, 99].

Zudem wurde diese Assoziation bislang nicht bei europäischen Patienten dokumentiert (Evidenz 3b) [97].

HBeAg-negative Patienten mit einer HBV-DNA zwischen 2000 und $20000 \mathrm{lU} / \mathrm{ml}$, die wiederholt normale ALT aufweisen (Zeitraum von mindestens 3 Jahren), haben i. d. R. keinen Hinweis auf einen signifikanten Leberschaden (Fibrose) (Evidenz 3a) [57].

Patienten, die diese Kriterien erfüllen, brauchen zunächst nicht antiviral behandelt zu werden. Die Kontrollen (HBV-DNA, ALT) sollten aber häufiger als bei Patienten mit HBV-DNA < $2000 \mathrm{IU} / \mathrm{ml}$ erfolgen (siehe 1.2.4).

HBeAg-negative Patienten mit HBV-DNA > $20000 \mathrm{IU} / \mathrm{ml}$ und normaler ALT können behandelt werden. Die Daten der REVEALStudie aus Asien belegen die Assoziation von HBV-DNA und HCC bzw. Zirrhoserisiko, insbesondere bei $\mathrm{HBeAg}$-negativen Patienten mit einer HBV-DNA > $20000 \mathrm{lU} / \mathrm{ml}$ (Evidenz 2b) [32, 33].

In unklaren Situationen (fluktuierende ALT- oder HBV-DNAWerte) kann eine Leberbiopsie sinnvoll sein, um die entzündliche Aktivität und das Ausmaß der Leberfibrose histologisch zu beurteilen (siehe 1.8.1).

\section{EMPFEHLUNG 2.4.2}

Eine antivirale Therapie zur Verhinderung einer Transmission an Dritte kann erwogen werden [EK].

Konsens: 96,6\% (Konsensuskonferenz)

Neu 2020

\section{Kommentar:}

Auch in dieser Patientengruppe kann eine antivirale Therapie zur Verhinderung der Transmission an Dritte erwogen werden. Details siehe 2.2.6.

\section{Therapie der chronischen Hepatitis-B-Virusinfektion}

M. Cornberg, F. Tacke , N. Dikopoulos, C. Höner zu Siederdissen, D. Kroy, M. Sprinzl, F. van Bömmel, I. van Thiel, J. Vermehren, K. Wursthorn, S. Zeuzem

\subsection{Was sind die Ziele der Therapie der chronischen Hepatitis B?}

\section{STATEMENT 3.1.1}

Ziele der Therapie der chronischen Hepatitis B sind, die Morbidität (Leberzirrhose, Leberdekompensation, hepatozelluläres Karzinom, extrahepatische Manifestationen) und Mortalität der HBV-Infektion zu senken. Ein weiteres Ziel ist die Verbesserung und, idealerweise, die Reversion einer Leberfibrose oder Zirrhose. Um diese Ziele zu erreichen, werden Surrogat- marker während und nach der Behandlung zur Überprüfung des Therapieerfolgs herangezogen:

- Langfristiges Therapieziel ist der Verlust des HBsAg. Idealerweise kommt es zu einer Serokonversion von HBs-Antigen zu Anti-HBs-Antikörpern.

- Bei Patienten ohne Leberzirrhose soll eine dauerhafte Suppression der HBV-DNA (mindestens < $2000 \mathrm{IU} / \mathrm{ml}$, idealerweise unterhalb der Nachweisgrenze bzw. nicht quantifizierbar) erreicht werden. Bei Patienten mit Leberzirrhose soll die HBV-DNA unterhalb der Nachweisgrenze bzw. nicht quantifizierbar sein.

- Ein HBeAg-Verlust und eine Serokonversion zu Anti-HBe kann ein Therapieendpunkt sein, wenn die HBV-DNA dauerhaft supprimiert ist (mindestens $<2000 \mathrm{IU} / \mathrm{ml}$, idealerweise unterhalb der Nachweisgrenze bzw. nicht quantifizierbar).

- Die Normalisierung der ALT kann ein zusätzlicher Endpunkt sein.

Konsens: 93,8\% (Delphi-Runde)

Modifiziert 2020

NKLM

\section{Kommentar:}

Analog zu den Daten im natürlichen Verlauf ist der HBsAg-Verlust der optimale Therapieendpunkt, da er mit einer funktionellen Heilung gleichzusetzen ist [6-8, 100].

Eine NA-Therapie kann nach HBsAg-Verlust beendet werden (siehe 3.8). Ein HBsAg-Verlust während einer NA-Therapie ist meist dauerhaft und war in asiatischen Studien mit einem geringeren HCC-Risiko assoziiert (Evidenz 3b) [101-103].

Eine HBV-DNA > $2000 \mathrm{lU} / \mathrm{ml}$ ist mit dem Risiko für die Entstehung einer Leberzirrhose und eines hepatozellulären Karzinoms (HCC) assoziiert (Evidenz 2b) [32, 33, 100].

Eine nachhaltige HBV-DNA-Suppression mit Interferon alfa (IFN) oder dauerhafte HBV-DNA-Suppression mit Nukleosidanaloga bzw. Nukleotidanaloga (NA) ist mit der Verhinderung von Leberzirrhose, hepatischen Dekompensationen, HCC (Evidenz 1a), Lebertransplantation und Tod (Evidenz 2a) assoziiert. Die stärkste Evidenz für die Verhinderung von HCC und Tod durch eine effektive NA-Behandlung liegt bei Patienten mit Leberzirrhose vor [75, 76].

Für Patienten ohne Leberzirrhose waren die Nachbeobachtungszeiten (5 Jahre) vermutlich zu kurz, und es wurden zu wenige Patienten untersucht, um die Verhinderung von HCC und Tod nachzuweisen [104].

Aufgrund der Datenlage, die einen positiven Effekt der antiviralen Therapie bei Patienten mit einer Viruslast > $2000 \mathrm{IU} / \mathrm{ml}$ zeigt, sind placebokontrollierte Studien als unethisch zu betrachten und nicht mehr durchführbar. Der Nutzen einer antiviralen Therapie kann anhand von Surrogatparametern (HBV-DNA, Anti-HBe-Serokonversion, HBsAg-Verlust, ALT-Normalisierung und Fibroseverbesserung) beurteilt werden [6].

Ein bestimmter HBV-DNA-Grenzwert, der im Verlauf der Therapie unterschritten werden sollte, ist allerdings nicht genau 
definiert. Bei einer Therapie mit IFN bzw. PEG-IFN wurde eine HBV-DNA < $2000 \mathrm{IU} / \mathrm{ml}$ (meist 6 Monate nach Ende der Therapie) als Endpunkt definiert [6-8, 100].

Analog zu den Daten im natürlichen Verlauf sollte daher die HBV-DNA auch mit NA auf jeden Fall $<2000 \mathrm{IU} / \mathrm{ml}$ abfallen. Ideal ist in jedem Fall ein Abfall der HBV-DNA unterhalb der Nachweisgrenze bzw. Quantifizierungsgrenze hochsensitiver Assays $(<20 \mathrm{IU} / \mathrm{ml})$ (Expertenmeinung). Denn bei nur partieller Unterdrückung der HBV-DNA (aufgrund von Nichtansprechen oder von Resistenzen) steigt das Risiko für die Entwicklung eines HCC (Evidenz 2a) [105, 106].

Vor allem bei Patienten mit Leberzirrhose ist eine komplette virologische Kontrolle (Suppression der HBV-DNA unter die Nachweisgrenze bzw. in den nicht quantifizierbaren Bereich eines hochsensitiven Assays) wichtig. Patienten mit kompensierter Zirrhose und quantifizierbarer HBV-DNA $<2000 \mathrm{lU} / \mathrm{ml}$ haben ein höheres HCC-Risiko als Patienten mit nicht nachweisbarer bzw. nicht quantifizierbarer HBV-DNA. Dies gilt auch für Patienten unter antiviraler Therapie (Evidenz 2b) [72-74].

Das frühe Erreichen des kompletten virologischen Ansprechens (nicht quantifizierbar) nach 1 Jahr Therapie ist ebenfalls für das HCC-Risiko bedeutsam. Dies bestätigt sich auch in einer anderen Studie, in der eine nachweisbare HBV-DNA (> $20 \mathrm{lU} / \mathrm{ml}$ ) nach 1 Jahr Therapie mit ETV mit einem höheren HCC-Risiko bei Patienten mit dekompensierter Zirrhose verbunden war (Evidenz 2b) [107].

Eine dauerhafte Suppression der HBV-DNA ist mit einer Verbesserung der Leberhistologie assoziiert. Nach 5 Jahren Therapie mit Entecavir bzw. Tenofovir wurde bei den meisten Patienten eine Verbesserung der Leberfibrose und bei einigen Patienten sogar eine Reversion einer F6-Fibrose nach Ishak (= Zirrhose) dokumentiert (Evidenz 2b) [108, 109].

Der Endpunkt „Verbesserung der Leberfibrose oder Leberzirrhose" kann mit der nichtinvasiven transienten Elastografie bestimmt werden (siehe 1.8.2).

Ein $\mathrm{HBeAg}$-Verlust und eine Anti-HBe-Serokonversion bei initial HBeAg-positiven Patienten (ohne das Vorliegen von Pre-Core oder BCP (basal-core-promoter)-Mutanten) sind mit einer Immunkontrolle gleichzusetzen. Eine dauerhafte HBeAg-Serokonversion nach PEG-IFN-Behandlung kann mit einer guten Prognose assoziiert sein, vergleichbar mit der von inaktiven HBsAg-Trägern (bzw. HBeAg-negativer chronischer Infektion) (Evidenz 2b) [110].

In einer asiatischen Kohortenstudie mit einer Langzeitbeobachtung von 15 Jahren zeigte sich eine geringere Inzidenz von Zirrhose und HCC nach IFN-induzierter HBeAg-Serokonversion sowohl im Vergleich zu Patienten, die keine HBeAg-Serokonversion unter IFN-Behandlung erreicht hatten, als auch im Vergleich zu nicht therapierten Kontrollen (Evidenz 3b) [111].

Allerdings gibt es auch Studien, in denen eine HBeAg-Serokonversion nach IFN-Behandlung nicht mit einem verbesserten Verlauf gegenüber unbehandelten Kontrollen assoziiert war. In einer dieser Studien waren $89 \%$ der Patienten nach HBeAg-Serokonversion noch HBV-DNA-positiv. Die HBV-DNA wurde allerdings nicht quantifiziert und Precore/BCP-Mutationen wurden nicht analysiert (Evidenz 3b) [112].

Um dem Grenzwert gerecht zu werden, ab dem im natürlichen Verlauf der HBV-Infektion die Rate von Komplikationen ansteigt, sollte die HBV-DNA nach HBeAg-Serokonversion dauerhaft auf $<2000 \mathrm{lU} / \mathrm{ml}$, bei Patienten mit Leberzirrhose auf $<20 \mathrm{IU} / \mathrm{ml}$ supprimiert sein. Die HBeAg-Serokonversion während einer NA-Behandlung kann analog zur IFN-Behandlung ein Kriterium für einen Therapiestopp darstellen (siehe 3.8). Analog zu internationalen Leitlinien von EASL und AASLD sollte nach einer HBeAg-Serokonversion, die während der Behandlung mit NA entstanden ist, die Behandlung für weitere 12 Monate fortgeführt werden [6-8].

Im Fall einer dauerhaften virologischen Response wird in der Regel auch eine dauerhafte ALT-Normalisierung erreicht. Falls die ALT weiterhin erhöht bleibt, sollten andere Ursachen hierfür ausgeschlossen werden (z. B. Fettleberhepatitis). Bei Patienten mit virologischer Response, bei denen die Leberwerte jedoch weiterhin erhöht sind, ist die Wahrscheinlichkeit einer Fibroseregression geringer (Evidenz 2b) [113].

\section{STATEMENT 3.1 .2}

Weitere Ziele der Therapie sind die Senkung der Infektiosität des Patienten bzw. die Senkung der Transmissionsrate (z. B. Mutter-Kind-Übertragung), die Verhinderung einer HBV-Reaktivierung und/oder die Verbesserung von extrahepatischen Manifestationen.

Konsens: 97,9\% (Delphi-Runde)

Neu 2020

NKLM

\section{Kommentar:}

Bei Personen, die im medizinischen Bereich arbeiten, soll eine Suppression der HBV-DNA $<2000 \mathrm{lU} / \mathrm{ml}$ und bei Personen, die verletzungsträchtigen Tätigkeiten nachgehen, $<200 \mathrm{IU} / \mathrm{ml}$ erreicht werden (siehe 5.12). Um die vertikale Transmission (Mutter-KindÜbertragung) zu verhindern, soll die HBV-DNA zum Zeitpunkt der Geburt $<200000 \mathrm{IU} / \mathrm{ml}$ liegen (siehe 3.12). Es sind keine Grenzwerte für HBV-Marker bekannt, die mit einer Verbesserung von extrahepatischen Manifestationen assoziiert sind. Ideal ist die Suppression der HBV-DNA unter die Nachweisgrenze (Expertenmeinung).

\subsection{Welche grundsätzlichen Fragen sind bei der Therapieplanung der Hepatitis B in der Primärtherapie zu berücksichtigen?}

Für die Therapie der chronischen HBV-Infektion stehen mit pegyliertem Interferon alfa (PEG-IFN) und Nukleosid- bzw. Nukleotidanaloga zwei unterschiedliche Therapiekonzepte zur Verfügung ( $\triangleright$ Tab. 10). 


\section{EMPFEHLUNG 3.2.1}

Bei der Therapieauswahl sollte geprüft werden, ob eine Therapie mit PEG-IFN möglich und sinnvoll ist [EK].

Konsens: 89,7\%* (Konsensuskonferenz)

Modifiziert 2020

$N K L M$

\section{Kommentar:}

Die Therapie mit pegyliertem Interferon alfa (IFN) ist für HBVInfektionen zeitlich begrenzt (siehe 3.3). Für die Therapie sowohl der HBeAg-positiven als auch der HBeAg-negativen chronischen Hepatitis B mit IFN konnte in einer Metaanalyse bzw. in mehreren Langzeitverlaufsstudien eine Verbesserung klinischer Endpunkte, der Leberwerte, der HBV-DNA-Konzentration und der Leberhistologie sowie der Häufigkeit des Leberzellkarzinoms im Vergleich zu nicht therapierten Patienten dokumentiert werden (Evidenz 1a) (keine Änderung zu [5]).

In einer aktuellen retrospektive Kohortenstudie aus einem einzelnen Studienzentrum in Asien war während eines Beobachtungszeitraums von 5 Jahren die kumulative Rate an HCC bei Patienten, die eine Therapie mit PEG-IFN erhielten, signifikant geringer als bei Patienten, die eine Therapie mit NAs erhielten, insbesondere im Vergleich zu Patienten mit einer Entecavir-Therapie. Die Studie hat allerdings Limitationen, da es sich um asiatische Patienten handelt und wichtige Informationen zur Nachbeobachtungszeit und zum Stadium der Leberzirrhose nicht sehr detailliert dargestellt sind (Evidenz 2b) [114].

Die serologischen Surrogatparameter HBeAg-Serokonversion und HBsAg-Verlust (auch bei HBeAg-negativen Patienten) werden mit einer IFN- bzw. PEG-IFN-basierten Therapie häufiger erreicht als mit einer gleich langen (meist 48-wöchigen) NA-Therapie (Evidenz 1b) [115-117].

Allerdings ist die Rate an HBsAg-Verlusten insgesamt sehr gering ( $\triangleright$ Tab. 10). Bei Langzeittherapie mit NAs können kumulative HBeAg-Serokonversionsraten erreicht werden, die mit der HBeAgSerokonversionsrate von zeitlich begrenzter PEG-IFN-Therapie vergleichbar sind. Die HBeAg-Serokonversionsrate unter einer IFN-Therapie scheint im Vergleich zu einer zeitlich begrenzen Lamivudintherapie aber nachhaltiger zu sein (Evidenz 3b) [118].

Aufgrund der Nebenwirkungen der IFN- bzw. PEG-IFN-Therapie sollen Patienten über die Vor- und Nachteile der Therapie besonders aufgeklärt werden. Kontraindikationen gegen eine PEG-IFNTherapie sollen berücksichtigt werden. Positiv prädiktive Faktoren für ein Therapieansprechen auf PEG-IFN wie eine hohe ALT, mäßig hohe HBV-DNA und ein Genotyp A können berücksichtigt werden. Bei der Durchführung einer IFN enthaltenden Therapie sollten die definierten (vgl. Abschnitt 3.3.1) STOP-Kriterien (HBVDNA-Abfall, HBsAg-Abfall) zur Therapiesteuerung angewendet werden, um bei abzusehendem Nichtansprechen die Therapie vorzeitig beenden zu können (siehe 3.3).

* Bei der Abstimmung gab es Personen, die sowohl eine stärkere Empfehlung als auch eine schwächere (offene) Empfehlung gefordert haben. Aufgrund des Nebenwirkungsprofils von Interferon alfa wurde die „soll“Empfehlung der 2011er-Leitlinie in eine „sollte“-Empfehlung geändert.

\section{ANMERKUNG}

Die Herstellerfirma des PEG-Interferon alfa-2a hat im Juli 2020 angekündigt, dieses weltweit vom Markt zu nehmen. Aktuelle Projektionen gehen von einer Verfügbarkeit in Deutschland bis zum Jahresende 2022 aus. Der Marktrückzug betrifft alle Handelsformen; es besteht kein Zusammenhang mit der Sicherheit oder Wirksamkeit des Produktes. Bis zur letzten Lieferung ist die bekannte Qualität gewährleistet. Der aktuelle Bestand des Arzneimittels wird abverkauft, eine Produktion findet nicht mehr statt (https://www.roche.de/medien/mel dungen/Mittelfristig-laeuft-Pegasys-aus-Alle-1-5163.html). Wir werden rechtzeitig ein Addendum veröffentlichen.

\section{EMPFEHLUNG 3.2.2}

Bei der Therapie mit Nukleos(t)idanaloga sollen Entecavir (ETV) oder Tenofovir (TDF oder TAF) bevorzugt werden $[1, A]$. Bei der Auswahl von NA sollen das Stadium der Lebererkrankung, Komorbiditäten (v. a. Niereninsuffizienz und Knochendichteminderung) und Begleitumstände (z. B. Schwangerschaft, Kinderwunsch, Transplantation), die Höhe der HBV-DNA sowie eventuelle Vortherapien berücksichtigt werden [EK].

Konsens: $100 \%$ (Konsensuskonferenz)

Neu 2020

Leitlinienadaption EASL Clinical Practice Guideline HBV 2017, AASLD Practice Guideline HBV 2016

NKLM

\section{Kommentar:}

Die antivirale Wirksamkeit von NA wurde in Phase-III-Studien belegt (Evidenz 1a) [76].

Mittlerweile liegen auch Langzeitdaten über 5 Jahre für Entecavir und Tenofovir (TDF) vor ( $\triangleright$ Tab. 10). Das virologische Ansprechen bei naiven Patienten liegt mit Entecavir oder Tenofovir (TDF) bei > 92-100\% (Evidenz 1a) (> Tab. 10).

Im Langzeitverlauf sind die Ansprechraten für Entecavir u. a. aufgrund des Auftretens von Resistenzen, v. a. bei mit Lamivudin vorbehandelten bzw. gegen Lamivudin resistenten Patienten, graduell schlechter als für Tenofovir. Die HBsAg-Verlust- bzw. Serokonversionsrate ist gering ( $\triangleright$ Tab. 10) und steigt im Verlauf nur mäßig an ( $5 \%$ bzw. 9,8\% nach 5 Jahren Therapie mit ETV und TDF).

NA haben keinen wesentlichen direkten Effekt auf die Menge der cccDNA im Zellkern der Leberzellen, von der das HBsAg unabhängig von der HBV-DNA-Polymerase exprimiert wird. In einer kürzlich publizierten Studie wurde nach einjähriger NA-Therapie ein geringer Rückgang der cccDNA beobachtet, der unabhängig vom eingesetzten NA ist und somit auf einen NA-unabhängigen Mechanismus schließen lässt. Infrage kommt hier die (allmähliche) Verdünnung des cccDNA-Pools durch Zellteilung. Umgekehrt eignet sich das Serum-HBsAg nicht als Surrogatparameter für die Menge der cccDNA in den Leberzellkernen, da die Produktion des HBsAg nicht nur von der Menge der cccDNA, sondern auch von deren transkrip- 
- Tab. 10a Antivirale Wirksamkeit der zugelassenen Substanzen zur Therapie der chronischen Hepatitis B bei HBeAg-positiven Patienten nach 48 Wochen [6, 76, 137]. b Antivirale Wirksamkeit der zugelassenen Substanzen zur Therapie der chronischen Hepatitis B bei HBeAg-negativen Patienten nach 48 Wochen $[6,76,136]$. c Antivirale Wirksamkeit von TDF und ETV im Langzeitverlauf. $\mathbf{d}$ Kumulative Inzidenz von Resistenzentwicklung gegen verschiedenen NA $[6,135]$.

a

\begin{tabular}{|l|l|l|l|l|l|l|l|}
\hline & $\begin{array}{l}\text { Peg-IF- } \\
\text { Na-2a }\end{array}$ & LAM & TBV & ETV & ADV & TDF & TAF \\
\hline Dosis* & $180 \mu \mathrm{g}$ & $100 \mathrm{mg}$ & $600 \mathrm{mg}$ & $0,5 \mathrm{mg}$ & $10 \mathrm{mg}$ & $245 \mathrm{mg}$ & $25 \mathrm{mg}$ \\
\hline \begin{tabular}{l} 
Anti-HBe-Serokonversion \\
\hline HBV-DNA
\end{tabular} & $32 \%$ & $16-18 \%$ & $22 \%$ & $21 \%$ & $12-18 \%$ & $21 \%$ & $10 \%$ \\
\hline$<29-80 \mathrm{IU} / \mathrm{ml}$ & $14 \%$ & $36-44 \%$ & $60 \%$ & $67 \%$ & $13-21 \%$ & $76 \%$ & $64 \%$ \\
\hline ALT normal\# & $41 \%$ & $41-72 \%$ & $77 \%$ & $68 \%$ & $48-54 \%$ & $68 \%$ & $72 \%$ \\
\hline HBsAg Verlust & $3 \%$ & $0-1 \%$ & $0,5 \%$ & $2 \%$ & $0 \%$ & $3 \%$ & $1 \%$ \\
\hline
\end{tabular}

*PEG-IFN wird einmal pro Woche subkutan als Injektion verabreicht; NA täglich oral als Tablette. \# Die Definition „ALT normal“ variiert zwischen verschiedenen Studien [z. B. Abfall der ALT $\leq 1,25$-fach der Norm in ETV-Studien oder $\leq 1,3$-fach der Norm in TDF-Studien]. Die untere Nachweisgrenze der HBVDNA-Assays variiert zwischen verschiedenen Studien: z. B. $<29 \mathrm{IU} / \mathrm{ml}$ für TAF-Studien.

b

\begin{tabular}{|l|l|l|l|l|l|l|l|}
\hline & $\begin{array}{l}\text { Peg-IF- } \\
\text { Na-2a }\end{array}$ & LAM & TBV & ETV & ADV & TDF & TAF \\
\hline Dosis* & $180 \mu \mathrm{gg}$ & $100 \mathrm{mg}$ & $600 \mathrm{mg}$ & $0,5 \mathrm{mg}$ & $10 \mathrm{mg}$ & $245 \mathrm{mg}$ & $25 \mathrm{mg}$ \\
\hline $\begin{array}{l}\text { HBV-DNA } \\
<29-80 \mathrm{IU} / \mathrm{ml}\end{array}$ & $19 \%$ & $72-73 \%$ & $88 \%$ & $90 \%$ & $51-63 \%$ & $93 \%$ & $94 \%$ \\
\hline ALT normal\# & $59 \%$ & $71-79 \%$ & $74 \%$ & $78 \%$ & $72-77 \%$ & $76 \%$ & $83 \%$ \\
\hline HBsAg Verlust & $4 \%$ & $0 \%$ & $0 \%$ & $0 \%$ & $0 \%$ & $0 \%$ & $0 \%$ \\
\hline
\end{tabular}

*PEG-IFNa-2a wird einmal pro Woche subkutan als Injektion verabreicht; NA täglich oral als Tablette. \# Die Definition „ALT normal“ variiert zwischen verschiedenen Studien [z. B. Abfall der ALT $\leq 1,25$-fach der Norm in ETV-Studien oder $\leq 1,3$-fach der Norm in TDF Studien]. Die Nachweisgrenze der HBV-DNAAssays variiert zwischen verschiedenen Studien: z. B. <29IU/ml für TAF-Studien.

c

\begin{tabular}{|l|l|l|}
\hline & ETV (5 Jahre) & TDF (5 Jahre) \\
\hline Dosis* & $0,5 / 1,0 \mathrm{mg}$ & $245 \mathrm{mg}$ \\
\hline $\begin{array}{l}\text { HBV-DNA } \\
<300 \text { (ETV) bzw. }<69 \text { (TDF) IU/ml }\end{array}$ & $93 \%$ & $98,3 \%$ \\
\hline ALT normal\# & $80 \%{ }^{*}$ & $81,3 \%$ \\
\hline HBsAg Verlust & $5 \% * *$ & $9,8 \%$ \\
\hline HBeAg Verlust & $31 \% * *$ & $49,7 \%$ \\
\hline
\end{tabular}

TDF: cirrhosis and no cirrhosis [142]; ETV: [143, 144] *HBeAg-positive **HBeAg-positive; $5 \%$ after 2 years.

d

\begin{tabular}{|l|l|l|l|l|l|l|}
\hline & LAM & TBV & ETV & ADV & TDF & TAF \\
\hline Jahr 1 & $24 \%$ & $4 \%$ & $0,2 \%$ & $0 \%$ & $0 \%$ & $0 \%$ \\
\hline Jahr 2 & $38 \%$ & $17 \%$ & $0,5 \%$ & $3 \%$ & $0 \%$ & $0 \%$ \\
\hline Jahr 3 & $49 \%$ & & $1,2 \%$ & $11 \%$ & $0 \%$ & \\
\hline Jahr 4 & $67 \%$ & & $1,2 \%$ & $18 \%$ & $0 \%$ & \\
\hline Jahr 5 & $70 \%$ & & $1,2 \%$ & $29 \%$ & $0 \%$ & \\
\hline
\end{tabular}

tioneller Aktivität oder der Produktion von HBsAg aus in die WirtsDNA integrierter viraler HBV-DNA abhängt. Eine HBsAg-Reduktion unter NA-Therapie ist deshalb mit Ausnahme des frühen Abfalls (bis Monat 6 nach Start der NA-Therapie) wenig prädiktiv [36].

Die Langzeitsuppression der HBV-DNA durch die Therapie mit NA führt zu einer Verbesserung von wichtigen Endpunkten:
Risiko der HCC-Entstehung: Vor allem bei Patienten mit Leberzirrhose sinkt unter NA-Behandlung das Risiko der Entwicklung eines HCC. Dieser Effekt wird ab einer Dauer der Suppression der HBV-DNA von einem Jahr deutlich (Evidenz 1a) [75, 76, 119].

Der Einfluss der langfristigen Virussuppression mit NA bei Patienten ohne Leberzirrhose auf die Entstehung eines HCC ist eben- 
falls messbar, aber geringer als bei Patienten mit Zirrhose. Frühere Untersuchungen bei Patienten mit nur partieller Suppression der HBV-DNA aufgrund von Resistenzen zeigten eine Assoziation zwischen dem Auftreten von HCC und dem Auftreten von Resistenzen bzw. dem Einsatz von NA mit niedriger Resistenzschwelle (siehe 3.1). Ein HBsAg-Verlust ist ebenfalls mit einem geringeren HCC-Risiko assoziiert (Evidenz 3b) [100, 101].

In jüngster Zeit gab es Metaanalysen mit adjustierten Risikoanalysen, die einen möglichen Unterschied zwischen ETV und TDF in Bezug auf das HCC-Risiko bzw. die Effektivität einer Reduktion des HCC-Risikos untersucht haben. Hier wurde in 2 Metaanalysen, in die 14 Studien (mit 263947 Personenjahre) bzw. 15 Studien (mit 61787 Patienten) vor allem aus asiatischen Kohorten eingegangen sind, eine statistisch signifikant geringere Rate von HCC bei Patienten mit TDF- gegenüber ETV-Langzeittherapie dokumentiert. [120, 121] Bislang ergibt sich aus diesen Daten allerdings keine Konsequenz für die Therapie in Deutschland bzw. bei europäischen Patienten. Eine große multizentrische europäische Kohortenanalyse (unter Einbezug deutscher Patienten) zeigte eine gleich niedrige HCC-Rate unter Langzeitbehandlung mit TDF oder ETV [122].

Risikoscores zu Einschätzung des HCC-Risikos unter NA-Therapie können hilfreich sein, um die Überwachungsintervalle festzulegen (siehe 1.7). Bei asiatischen Patienten wurden folgende Risikoscores validiert: GAG-HCC, CU-HCC, REACH-B. Bei europäischen Patienten scheint nur der PAGE-B-Score einen ausreichenden prädiktiven Wert zu besitzen. Aktuelle Daten stützen die Anwendung des CAGE-B- und SAGE-B-Scores in europäischen Patienten; diese Arbeit wurde jedoch nicht im Rahmen der Konsenuskonferenz bewertet, da sie zu einem späteren Zeitpunkt erschien. In den asiatischen Risikoscores spielen das Alter und die Viruslast sowie das Vorhandensein einer Zirrhose eine Rolle (siehe 3.1). Beim PAGE-B-Score sind neben dem Alter das männliche Geschlecht und die Thrombozyten gewichtet [53, 123].

Histologische Verbesserung: Eine Reversion einer histologisch nachgewiesenen Leberzirrhose kann mit längerfristiger (3-5 Jahre) NA-Therapie (z. B. ETV oder TDF) erreicht werden (Evidenz 2b) [108, 109].

Rekompensation: Die Therapie bei Patienten mit dekompensierter Leberzirrhose kann zu einer deutlichen klinischen Verbesserung und Reduktion des HCC-Risikos führen. Eine Reduktion des MELD-Scores bzw. des CHILD-Pugh-Scores und eine Verbesserung des Überlebens sind gezeigt worden (Evidenz 1b) [124-126].

Verbesserung des Überlebens: Mehrere Studien (zusammengefasst in einer Metaanalyse) konnten für Patienten mit einer Leberzirrhose eine Reduktion der Mortalität zeigen. Die durchschnittliche Risikoreduktion in dieser Population lag bei $50 \%$ (Evidenz 2a) [76].

Bei der Therapie mit NA soll die Entwicklung von Resistenzen des HBV vermieden werden, da insbesondere bei Patienten mit fortgeschrittener Fibrose oder Zirrhose eine Resistenzentwicklung mit erhöhter Morbidität und Mortalität assoziiert ist (Evidenz 1b) $[127,128]$.

Die Resistenz des HBV gegen NA beruht auf der Selektion von HBV-Varianten und ist bei Patienten mit inkomplettem Ansprechen auf eine NA-Behandlung wahrscheinlicher als bei Patienten mit raschem und komplettem Ansprechen. Die Art des Resistenz- mechanismus sowie eine bereits stattgehabte Resistenzentwicklung gegen andere NA sind ebenfalls entscheidend für die Häufigkeit und Ausprägung der Resistenz [129, 130].

Entecavir und Tenofovir besitzen gegenüber den anderen NA die günstigsten Eigenschaften gegen Resistenzentwicklung. Resistenzvarianten gegen Tenofovir scheinen mit Resistenzvarianten gegen Adefovir identisch zu sein, bewirken aber (anders als bei Adefovir) keinen Durchbruch der HBV-DNA unter Behandlung mit Tenofovir [131, 132].

Entecavir hat eine hohe genetische Resistenzbarriere, d. h., das Vorhandensein nicht nur einer, sondern einer Vielzahl von Resistenzvarianten, einschließlich Varianten mit Resistenz gegen Lamivudin, ist Voraussetzung für einen Durchbruch der HBV-DNA unter Behandlung mit ETV ( $\triangleright$ Tab. 10) [133].

Die Seltenheit von Resistenzen gegen Entecavir sowie die starke antivirale Aktivität von Entecavir und Tenofovir sind der Grund für die höchste Rate an virologischer Response beider Substanzen im Langzeitverlauf im Vergleich mit den übrigen NA ( $\triangleright$ Tab. 10). Im Detail liegt die Resistenzentwicklung nach 5 Jahren Therapie bei $0 \%$ für TDF und bei $1,2 \%$ für ETV.

Für Tenofovir Alafenamid (TAF) liegen bezüglich einer möglichen Resistenzentwicklung Daten über 96 Wochen vor, wo auch bei Patienten mit quantifizierbarer HBV-DNA keine genotypische Resistenz gefunden wurde (Evidenz 1b) [134, 135].

Die Suppression der HBV-DNA war nicht unterschiedlich bei Patienten, die über 48 bzw. 96 Wochen entweder mit TDF oder mit TAF behandelt wurden. Die Rate an ALT-Normalisierung war nach 48 und 96 Wochen mit TAF höher als mit TDF. Welche Bedeutung dieses offenbar stärkere biochemische Ansprechen für die Langzeitmorbidität der Patienten hat, ist unklar. Die Reduktion der glomerulären Filtrationsrate (GFR) war signifikant geringer unter TAF als unter TDF. Auch die Knochendichte fiel während 48 bzw. 96 Wochen Behandlung signifikant geringer unter TAF als unter TDF ab (Evidenz 1b) [135-137].

Die klinische Bedeutung dieser Beobachtungen ist allerdings nicht belegt. Aufgrund der vorliegenden Daten empfiehlt die EASL-Leitlinie, dass TAF (oder ETV, wenn möglich) bei Patienten mit Osteopenie/Osteoporose sowie bei Niereninsuffizienz gegenüber TDF bevorzugt eingesetzt werden kann. Risikofaktoren für Nephrotoxizät in der Behandlung von Tenofovir (TDF) sind dekompensierte Zirrhose, GFR $<60 \mathrm{ml} / \mathrm{min}$, schlecht kontrollierter arterieller Hypertonus, Proteinurie, schlecht kontrollierter Diabetes mellitus, Glomerulonephritis, nephrotoxische Begleittherapie sowie Organtransplantation [6].

Ein systematisches Review, das ETV und TDF in Bezug auf Nephrotoxizität verglich, konnte in kontrollierten, randomisierten Studien keinen Unterschied zwischen den Substanzen feststellen. Die Beobachtungszeit in den randomisierten Studien ist allerdings relativ kurz. In Kohortenstudien traten Nierenschäden unter TDFTherapie jedoch häufiger auf. Im Regelfall waren dann auch Kofaktoren entsprechend den o. g. vorhanden (Evidenz 2a) [138].

Entecavir kann bei Patienten mit den o. g. Risikofaktoren ebenso bevorzugt gegenüber TDF eingesetzt werden. Beim Einsatz von Entecavir ist zu berücksichtigen, dass bei einer stattgehabten Vorbehandlung mit Lamivudin die Wahrscheinlichkeit des Auftretens von Resistenzen gegen Entecavir erhöht ist ( $\downarrow$ Tab. 10). Entecavir soll nicht in der Schwangerschaft eingesetzt werden (siehe 3.12) [6]. 
Eine andere wichtige, aber seltene Nebenwirkung einer NA-Therapie bei Patienten mit fortgeschrittener Leberzirrhose sind Laktatazidosen. Ab einem MELD von > 20 Punkten ist empfohlen, hierauf zu achten (Evidenz 3b) [5, 138].

Die Verwendung von Entecavir bzw. Tenofovir in der Primärbehandlung ist eine wichtige Maßnahme zur Vorbeugung einer Resistenzentwicklung. Aufgrund der Resistenzdatenlagen ( $\vee$ Tab. 10) und der nunmehr zahlreichen Langzeitdaten zu TDF und ETV gibt es prinzipiell keine medizinischen Gründe mehr, Lamivudin, Telbivudin oder Adefovir in der Primärtherapie einzusetzen. Die Empfehlung entspricht den Empfehlungen der EASL- und AASLD-Leitlinien. Generika für ETV und TDF sind verfügbar. Randomisierte Studien zur Effektivität und Sicherheit der Generika liegen nicht vor [6-8].

Ein möglicher Vorteil von Telbivudin* gegenüber anderen NA kann ein positiver Effekt auf die glomeruläre Filtrationsrate sein (Evidenz 2b) [139, 140].

Eine Therapie mit Lamivudin braucht daher bei Patienten mit Therapieansprechen, bei bestehender Möglichkeit einer engmaschigen Kontrolle der HBV-DNA (mindestens alle 6 Monate), der Möglichkeit einer resistenzadaptierten Therapieumstellung und ohne fortgeschrittene Leberfibrose beim zu behandelnden Patienten (um im Falle einer Resistenz die Wahrscheinlichkeit eines Leberversagens zu vermindern) nicht umgestellt zu werden.

\section{EMPFEHLUNG 3.2.3}

Adefovir soll nicht mehr eingesetzt werden* [EK]. Konsens: $100 \%$ (Konsensuskonferenz)

Neu 2020

\section{Kommentar:}

Adefovir hat eine geringere antivirale Wirksamkeit nach 48 Wochen Therapie im Vergleich zu Entecavir oder Tenofovir ( $\triangleright$ Tab. 10). Die Wahrscheinlichkeit der Resistenzentwicklung im Langzeitverlauf ist höher als bei Entecavir oder Tenofovir ( $\vee$ Tab. 10). Die Therapie mit Adefovir ist mit einer höheren Rate an Nephrotoxizität und Knochendichteminderung verbunden als bei Tenofovir (Evidenz 3b) (siehe 3.11) [141].

Daher soll Adefovir generell nicht mehr eingesetzt werden.

\subsection{Wie soll eine Therapie mit pegyliertem Interferon alfa durchgeführt werden?}

\section{EMPFEHLUNG 3.3.1}

Die Therapie mit pegyliertem Interferon alfa (PEG-IFN) sollte gegenüber Interferon alfa bevorzugt werden [EK].

Konsens: $100 \%$ (Delphi-Runde)

Modifiziert 2020

* Anmerkung zu Telbivudin: Das Medikament ist in Deutschland mittlerweile vom Markt genommen worden.

* $\quad$ Falls ein Patient mit Adefovir erfolgreich behandelt wird und die Umstellung auf ein anderes NA problematisch ist (z. B. Unverträglichkeit), kann die Therapie mit Adefovir weitergeführt werden.

\section{Kommentar:}

Die Therapie mit PEG-IFN ist seit vielen Jahren Standard. Eine bessere antivirale Wirksamkeit gegenüber nicht pegyliertem Interferon alfa konnte allerdings nicht gezeigt werden. Dauer und Dosis der PEG-IFN (PEG-IFN a-2a) sind mittlerweile aber besser definiert als die Therapie mit Standardinterferon alfa (Evidenz 1a) [145, 146].

Stoppregeln (siehe 3.3.3) sind nur für die Therapie mit PEG-IFN untersucht worden. Neben der günstigeren Pharmakokinetik von PEG-IFN (Injektion nur einmal pro Woche im Vergleich zu 3-mal pro Woche bei nicht pegylierten Interferonen) ist damit auch eine Optimierung der Therapie (Individualisierung) möglich.

* Der Repräsentant der Patientenvertreter hat sich für eine stärkere Empfehlung [soll] pro PEG-IFN versus Alfa-Interferon ausgesprochen.

\section{EMPFEHLUNG 3.3.2}

Die Therapiedauer mit PEG-IFN sollte i.d.R. 48 Wochen betragen $[1, \mathrm{~B}]$.

Konsens: $100 \%$ (Delphi-Runde)

Neu 2020

Leitlinienadaption EASL Clinical Practice Guideline HBV 2017, AASLD Practice Guideline HBV 2016

\section{Kommentar:}

Daten einer prospektiven, randomisierten Studie zeigen, dass eine 48-wöchige Therapie mit $180 \mu \mathrm{g}$ PEG-IFN alfa-2a einmal pro Woche (zugelassene Therapiedauer und -dosis) einer kürzeren Therapie (24 Wochen) oder einer niedrigeren Dosierung (90 $\mathrm{\mu g}$ einmal pro Woche) in Bezug auf eine dauerhafte Anti-HBe-Serokonversion überlegen war (Evidenz 1b) [146].

Diese Studie hatte allerdings nur wenige Patienten aus Europa eingeschlossen.

Diese Empfehlung entspricht auch den EASL- und AASLD-Leitlinien [6, 7].

Für HBeAg-negative Patienten ist die optimale Therapiedauer nicht gut untersucht. Bei HBeAg-negativen Patienten scheint eine längere Therapiedauer (z. B. 72 Wochen) mit höheren langfristigen Ansprechraten assoziiert zu sein (Evidenz 2a) (keine Änderung zu [5]).

\section{EMPFEHLUNG 3.3.3}

Prädiktive Faktoren sollten als Entscheidungshilfe für die vorzeitige Beendigung einer PEG-IFN-Therapie herangezogen werden [EK]. Die quantitativen Bestimmungen der HBV-DNA und des HBsAg als Prädiktoren für das Therapieansprechen sollten bei Therapiestart, Woche 12 und Woche 24 bestimmt werden [EK]. In den Entscheidungsprozess, die Therapie mit PEG-IFN vorzeitig zu beenden, soll zusätzlich die Beurteilung der mit PEG-IFN assoziierten Nebenwirkungen und der Therapiewunsch des Patienten berücksichtig werden [EK]. Konsens: 97,9\% (Delphi-Runde)

Neu 2020 


\section{Kommentar:}

Nachfolgend wird zwischen HBeAg-positiven und HBeAg-negativen Patienten unterschieden:

HBeAg-positive chronische Hepatitis B: Eine kombinierte retrospektive Kohorte von HBeAg-positiven Hepatitis-B-Patienten ( $n=803$ ) identifizierte $\mathrm{HBsAg-Serumkonzentrationen}>20000 \mathrm{lU} / \mathrm{ml}$ bzw. einen fehlenden Abfall des HBsAg-Spiegels nach 12 bzw. 24 Wochen PEG-IFN-Therapie als robusten negativen Prädiktor für ein Therapieansprechen (Evidenzgrad IIb) ( $\triangleright$ Tab. 11) [147].

In der Studie wurde das Ansprechen als kombinierter Endpunkt aus HBeAg-Serokonversion und HBV-DNA < 10000 Kopien/ml (entspricht < $2000 \mathrm{lU} / \mathrm{ml}$ ) 24 Wochen nach dem Ende der PEGIFN-Behandlung definiert. Diese Ergebnisse wurden sowohl für Patienten mit PEG-IFN-Monotherapie als auch für Patienten mit einer Kombination aus PEG-IFN und NA bestätigt. Durch den Einschluss vorwiegend kaukasischer und asiatischer HBV-Kohorten konnte der identifizierte Prädiktor auf Patientensubgruppen mit einem HBV-Genotyp A, B, C und D erfolgreich angewendet werden. Für den Entscheidungsprozess sollten die Evaluation der mit PEG-IFN assoziierten Nebenwirkungen und der Patientenwunsch berücksichtigt werden. Ebenfalls kann das „Baseline Prediciton Tool“ zur Abschätzung eines Therapieerfolgs genutzt werden, das allerdings nur bei asiatischen Patienten mit Genotyp B/C evaluiert wurde. Ein Alter < 40 Jahre, weibliches Geschlecht, eine ALT $>4 \times$ oberhalb der Norm, ein HBsAg < $25000 \mathrm{IUI} / \mathrm{ml}$ und eine HBVDNA <6 log IU/ml sind prädiktiv für ein Therapieansprechen [148].

HBeAg-negative chronische Hepatitis B: Die aktuellen Studien zur Evaluation von Prädiktoren des Therapieansprechens bestätigten einen hohen negativen prädiktiven Wert (>95\%) für das Therapieansprechen. In der größten retrospektiven Studie ( $n=262$ ) wurde das Therapieansprechen als kombinierter Endpunkt aus Normalisierung der Transaminasen (ALT) und HBV-Viruslast $<2000 \mathrm{IU} / \mathrm{ml} 24$ Wochen nach dem Ende der PEG-IFN-Behandlung definiert. Der NPV für fehlenden Abfall der HBV-DNA $>2$ log und fehlenden Abfall des HBsAg nach 12 Wochen Therapie war in Patienten mit HBV-Genotyp D mit $100 \%$ am höchsten ausgefallen (Evidenzgrad IIb) [149].

Der einzige Patient, der trotz Erreichens der Stopp-Regel ein Therapieansprechen erzielte, war mit HBV-Genotyp A infiziert. Daher sind die identifizierten Prädiktoren besonders bei Patienten mit HBV-Genotyp-D-Infektion als Entscheidungskriterium für die vorzeitige Beendigung einer PEG-IFN-Therapie zur Woche 24 empfohlen [6].

Für den Entscheidungsprozess sollten die Evaluation der aktuellen mit IFN assoziierten Nebenwirkungen und der Patientenwunsch berücksichtigt werden.

\section{EMPFEHLUNG 3.3.4}

Während und nach der Therapie mit PEG-IFN sollen regelmäßige sicherheitsrelevante Blutuntersuchungen durchgeführt sowie interferontypische Nebenwirkungen eruiert werden [EK]. Konsens: 97,9\% (Delphi-Runde)

Neu 2020

NKLM

\section{Kommentar:}

Ein Abfall der Leukozyten und Thrombozyten ist während einer IFN-basierten Therapie häufig [150].

Eine Kontrolle des Blutbildes und eine Dosisanpassung der IFNDosis sollten gemäß Fachinformation erfolgen. Eine IFN-Therapie kann eine autoimmune Thyreopathie induzieren. Dies ist insbesondere bei Patienten mit chronischer Hepatitis $\mathrm{C}$ gezeigt worden (Evidenz 2a) [151].

Es sollte daher eine Kontrolle des TSH vor und während der Therapie (alle 8 Wochen) erfolgen. Während der Therapie kann es auch trotz Suppression der HBV-DNA zu ALT-Flares kommen, insbesondere in der frühen Behandlungsphase (Evidenz 2b) [152].

ALT-Bestimmungen sollten alle 4 Wochen durchgeführt werden.

\subsection{Wie ist der Stellenwert einer Kombinationstherapie mit pegyliertem Interferon alfa und einem Nukleos(t)idanalogon?}

\section{EMPFEHLUNG 3.4.1}

Eine primäre Kombinationstherapie mit pegyliertem Interferon alfa (PEG-IFN) und einem Nukleos(t)idanalogon (NA) kann derzeit nicht empfohlen werden [EK]. Eine zusätzliche Therapie mit PEG-IFN zu einer NA-Therapie („Add-on“) oder eine Umstellung einer NA-Therapie auf PEG-IFN („Switch“) kann nicht empfohlen werden [EK].

Konsens: $100 \%$ (Delphi-Runde)

Neu 2020

\section{Kommentar:}

Die bisher gültige DGVS-Leitlinie sah keinen Vorteil einer Kombinationstherapie mit IFN bzw. PEG-IFN und Nukleos(t)idanaloga (NA) im Vergleich zu einer PEG-IFN-Monotherapie und empfahl daher, außerhalb von klinischen Studien keine Kombinationstherapie durchzuführen [5].

Auch die aktuelle AASLD-Leitlinie zur Therapie der chronischen Hepatitis B empfiehlt keine Kombinationstherapie mit PEG-IFN und NA und beruft sich auf eine systematische Übersichtsarbeit, die keine signifikanten Vorteile der PEG-IFN/NA-Kombinationstherapie gegenüber einer PEG-IFN-Monotherapie zeigen konnte (Evidenz 1a) [7, 153].

Allerdings wurden die meisten Studien mit Lamivudin durchgeführt. Die aktuellste randomisierte, kontrollierte Studie bei $\mathrm{HBeAg}$-positiven und HBeAg-negativen Patienten untersuchte die primäre Kombinationstherapie mit PEG-IFN-2a und Tenofovir (TDF) für 48 Wochen gegen eine PEG-IFN-2a-Monotherapie für 48 oder eine Therapie mit TDF für 120 Wochen. Der primäre Endpunkt der Studie war ein HBsAg-Verlust zur Woche 72 und wurde insgesamt bei relativ wenigen Patienten erreicht. In der PEG-IFN/ TDF-Kombinationsgruppe war die Rate an HBsAg-Verlust nach 48 Wochen signifikant höher als in der PEG-IFN Monotherapie $(9,1$ vs. $2,8 \%, p=0,003)$. Der Unterschied war auch in dieser Studie bei HBV-Genotyp-A-Patienten und HBeAg-positiven Patienten am höchsten, allerdings waren die Patientenzahlen in den jeweiligen Subgruppen sehr klein (Evidenz 1b) [154]. 
- Tab. 11 Prädiktoren des Therapieansprechens unter PEG-IFN.

\begin{tabular}{|c|c|c|c|c|c|c|c|}
\hline Intervention & $\mathbf{n}$ & Endpunkt & Prädiktor & HBVGT & PPV & NPV & Reference \\
\hline Gesamtkohorte & 803 & \multirow{18}{*}{$\begin{array}{l}\text { HBeAg Verlust } \\
+ \text { HBV-DNA }<10000 \\
\text { Kopien/mL zur } \\
\text { Woche } 78\end{array}$} & \multirow{5}{*}{$\begin{array}{l}\mathrm{HBsAg} \geq 20000 \mathrm{IU} / \mathrm{ml} \text { zur } \\
\text { Therapiewoche } 12\end{array}$} & $A$ & & $83 \%$ & \multirow[t]{18}{*}{ [147] } \\
\hline - PEG-IFN alfa-2b mono (52 Wo) & 104 & & & & & & \\
\hline - PEG-IFN alfa-2b + LAM (52 Wo) & 100 & & & B & & $92 \%$ & \\
\hline \multirow[t]{2}{*}{ - PEG-IFN alfa-2a mono (48 Wo) } & \multirow[t]{2}{*}{361} & & & C & & $99 \%$ & \\
\hline & & & & $\mathrm{D}$ & & $96 \%$ & \\
\hline \multirow[t]{4}{*}{ - PEG-IFN alfa-2a + LAM (48 Wo) } & \multirow[t]{4}{*}{238} & & \multirow{4}{*}{$\begin{array}{l}\mathrm{HBsAg} \geq 20000 \mathrm{IU} / \mathrm{ml} \text { zur } \\
\text { Therapiewoche } 24\end{array}$} & A & & $94 \%$ & \\
\hline & & & & B & & $100 \%$ & \\
\hline & & & & C & & $100 \%$ & \\
\hline & & & & $\mathrm{D}$ & & $97 \%$ & \\
\hline Subkohorte (PEG-IFN mono) & 465 & & \multirow{2}{*}{$\begin{array}{l}\text { Kein HBsAg-Abfall zur } \\
\text { Therapiewoche } 12\end{array}$} & \multirow[t]{2}{*}{ A } & & \multirow[t]{2}{*}{$100 \%$} & \\
\hline - PEG-IFN alfa-2b mono (52 Wo) & 104 & & & & & & \\
\hline \multirow{7}{*}{ - PEG-IFN alfa-2a mono (48 Wo) } & \multirow[t]{7}{*}{361} & & \multirow{2}{*}{$\begin{array}{l}\mathrm{HBsAg} \geq 20000 \mathrm{IU} / \mathrm{ml} \text { zur } \\
\text { Therapiewoche } 12\end{array}$} & B & & $92 \%$ & \\
\hline & & & & C & & $98 \%$ & \\
\hline & & & $\begin{array}{l}\text { Kein HBsAg-Abfall zur } \\
\text { Therapiewoche } 12\end{array}$ & $\mathrm{D}$ & & $97 \%$ & \\
\hline & & & \multirow{4}{*}{$\begin{array}{l}\mathrm{HBsAg} \geq 20000 \mathrm{IU} / \mathrm{ml} \text { zur } \\
\text { Therapiewoche } 24\end{array}$} & A & & $96 \%$ & \\
\hline & & & & B & & $100 \%$ & \\
\hline & & & & C & & $100 \%$ & \\
\hline & & & & $\mathrm{D}$ & & $100 \%$ & \\
\hline \multicolumn{8}{|l|}{ HBeAg-negative Hepatitis B } \\
\hline Testkohorte & & \multirow{10}{*}{$\begin{array}{l}\text { HBV-DNA }<2000 \text { IU/ } \\
\text { ml und normale } \\
\text { GPT } 24 \text { Wochen } \\
\text { nach Therapieende }\end{array}$} & \multirow{10}{*}{$\begin{array}{l}\text { HBsAg-Abfall und HBV- } \\
\text { DNA-Abfall > 2log zur } \\
\text { Therapiewoche } 12\end{array}$} & \multirow[t]{2}{*}{ Alle } & \multirow[t]{2}{*}{$30 \%$} & \multirow[t]{2}{*}{$100 \%$} & \multirow[t]{11}{*}{ [149] } \\
\hline - PEG-IFN alfa-2a mono (48 Wo) & 102 & & & & & & \\
\hline Validierungskohorte & 160 & & & Alle & $41 \%$ & $95 \%$ & \\
\hline - PEG-IFN alfa-2a mono (48 Wo) & 85 & & & & & & \\
\hline - PEG-IFN alfa-2a mono (48/93 Wo) & 75 & & & & & & \\
\hline Subkohorte (HBV GT D) & & & & $\mathrm{D}$ & $36 \%$ & $100 \%$ & \\
\hline - PEG-IFN alfa-2a mono (48 Wo) & 81 & & & & & & \\
\hline Subkohorte (HBV GT D) & 91 & & & \multirow[t]{3}{*}{ D } & \multirow[t]{3}{*}{$34 \%$} & \multirow[t]{3}{*}{$100 \%$} & \\
\hline - PEG-IFN alfa-2a mono (48 Wo) & 21 & & & & & & \\
\hline - PEG-IFN alfa-2a mono (48/96 Wo) & 70 & & & & & & \\
\hline $\begin{array}{l}\text { Validierungskohorte } \\
\text { - PEG-IFN alfa-2a mono (48 Wo) }\end{array}$ & 37 & $\begin{array}{l}\text { HBV-DNA }<2000 \mathrm{IU} / \\
\text { ml und normale } \\
\text { GPT } 48 \text { Wochen } \\
\text { nach Therapieende }\end{array}$ & $\begin{array}{l}\text { HBsAg-Abfall und HBV- } \\
\text { DNA-Abfall > 2log zur } \\
\text { Therapiewoche } 12\end{array}$ & Alle & $16 \%$ & $83 \%$ & \\
\hline
\end{tabular}

d, Tag, LAM, Lamivudin; NPW, negativer prädiktiver Wert; HBV GT, Hepatitis-B-Virus-Genotyp; PEG-IFN alfa-2a, pegyliertes Interferon alpha 2a; PEG-IFN alfa-2b, pegyliertes Interferon alpha 2b; PPW, positiv prädiktiver Wert; Wo, Wochen.

Basierend auf dieser Studie kann daher keine generelle Empfehlung für eine De-novo-Kombinationstherapie ausgesprochen werden. In Einzelfällen kann bei HBeAg-positiven Patienten, bei denen eine Therapie mit PEG-IFN sinnvoll erscheint (Genotyp A, Vorliegen weiterer für ein PEG-IFN-Ansprechen günstiger prädiktiver Faktoren, vgl. 3.2 und 3.3), eine primäre Kombinationstherapie mit PEG-IFN und TDF für 48 Wochen diskutiert werden, mit dem Ziel, die Rate eines HBsAg-Verlustes und damit einer dauer- haften immunologischen Kontrolle der HBV-Infektion zu erhöhen. Da eine Zulassung für die primäre Kombinationstherapie nicht vorliegt, sollte basierend auf der o.g. randomisierten, kontrollierten Studie [154] und der aktuellen Leitlinie in diesen speziellen Einzelfällen vorher eine Kostenanfrage über einen „Off-LabelUse“ der Kombinationstherapie erfolgen.

Zahlreiche Studien untersuchen die Frage nach der Effektivität einer Umstellung („Switch“) einer laufenden Therapie mit NA auf 
PEG-IFN für 48-52 Wochen oder einer zusätzlichen („Add-on“) Therapie mit PEG-IFN (meist für 24 Wochen) zu einer laufenden Therapie mit NA vs. einer fortgeführten NA-Monotherapie. Die HBsAg-Verlustraten können durch die PEG-IFN-Therapie verbessert werden. Allerdings liegen die HBsAg-Verlustraten nur bei $8 \%$ für die „Add-on“-Therapie und bei 14\% für die „Switch“-Therapie. Höhere HBsAg-Verlustraten in den „Switch“-Studien können durch Selektion von Patienten mit günstigeren Voraussetzungen zu erklären sein, sodass ein Vergleich der Therapiekonzepte schwierig ist (Evidenz 2a) [155].

Momentan reicht die Evidenz nicht aus, um eine Empfehlung auszusprechen. Weitere Studienergebnisse zu diesem Thema werden erwartet. Eine Aktualisierung der Empfehlung wird bei Änderung der Evidenz zeitnah vorgenommen.

3.5 Wie sind Therapieansprechen und Resistenz bei NA-Therapie definiert und wie wird das Therapieansprechen einer NA-Therapie überprüft?

Definition Therapieansprechen:

- Ein optimales virologisches Ansprechen auf NA liegt vor, wenn die HBV-DNA unterhalb der Nachweisgrenze liegt oder nicht quantifizierbar ist.

- Ein partielles Therapieansprechen auf NA liegt vor, wenn die HBV-DNA nicht kontinuierlich abfällt und ein Plateau $>2000 \mathrm{IU} / \mathrm{ml}$ nach 96 Wochen vorliegt.

- Eine Nichtansprechen (Nonresponse) ist definiert durch einen fehlenden Abfall > 1 log nach 6 Monaten antiviraler Therapie.

- Von einer Resistenz gegen NA wird ausgegangen, wenn nach primärem Ansprechen unter laufender Behandlung mit NA ein bestätigter Anstieg der HBV-DNA $\geq 1$ log-Stufe über dem Nadir auftritt.

\section{EMPFEHLUNG 3.5.1}

Die quantitative Bestimmung der HBV-DNA sollte im ersten Jahr der Therapie alle 3 Monate erfolgen [EK]. Nach dem ersten Jahr und bei virologischem Ansprechen kann das Kontrollintervall bei Therapie mit Entecavir oder Tenofovir (TDF oder TAF) auf 6 Monate verlängert werden [EK].

Konsens: 97,9\% (Delphi-Runde)

Geprüft 2020

\section{Kommentar:}

Unabhängig vom Stadium der Lebererkrankung und vom verabreichtem NA sollte die HBV-DNA im ersten Jahr der Therapie alle 3 Monate kontrolliert werden, um die Therapieadhärenz des Patienten zu überprüfen und im Fall einer Therapie mit Lamivudin, Telbivudin oder Zweitlinientherapie mit Entecavir das Risiko einer Resistenzentwicklung zu überprüfen. (keine Änderung zu [5])

Eine engmaschigere Kontrolle, beispielsweise nach 4-6 Wochen, kann bei Patienten mit Leberzirrhose oder Leberversagen sinnvoll sein, um die Compliance zu prüfen und das Therapiemanagement gegebenenfalls anzupassen. In klinischen Kohorten waren bis zu 40 \% aller virologischen Durchbrüche mutmaßlich nicht auf Resistenzen, sondern auf unregelmäßige Medikamenteneinnahmen zurückzuführen (Evidenz 3b) [156].

Bei guter Therapieadhärenz mit Entecavir und Tenofovir können die Kontrollintervalle verlängert werden, da eine Resistenzentwicklung in dieser Situation unwahrscheinlich ist ( $\bullet$ Tab. 10 d). Beim Einsatz von NA mit geringer Resistenzbarriere sollte das Kontrollintervall immer mindestens 3 Monate betragen, da die frühe Identifikation einer viralen Resistenz mit einer entsprechenden frühzeitigen Therapieanpassung notwendig ist (keine Änderung zu [5]).

\section{STATEMENT 3.5.2}

Bei Patienten mit Leberzirrhose sollte die HBV-DNA nach 48 Wochen unterhalb der Nachweisgrenze liegen oder nicht quantifizierbar sein.

Konsens: $100 \%$ (Konsensuskonferenz)

Neu 2020

\section{Kommentar:}

Das Ziel der Therapie mit NA ist die Suppression der HBV-DNA unter die Nachweisgrenze bzw. unter die Grenze der Quantifizierung. Bei Patienten mit einer Leberzirrhose sollte dies nach 12 Monaten erreicht sein, da sich hieraus ein vermindertes Risiko der HCC-Entwicklung ergibt (siehe 3.1). Bei Patienten ohne Leberzirrhose und Therapie mit Entecavir und Tenofovir gibt es allerdings keinen definierten HBV-DNA-Grenzwert unterhalb $2000 \mathrm{IU} / \mathrm{ml}$, der mit Morbidität oder Mortalität assoziiert ist. Bei sehr hoher Ausgangsviruslast kann es beim Einsatz von Entecavir und Tenofovir 2-3 Jahre dauern, bis eine komplette HBV-DNA-Suppression erreicht wird (HBV-DNA unterhalb der Nachweisgrenze). In diesen Fällen ist das Therapieansprechen nicht ausreichend, wenn sich ein Plateau ohne fortgesetzten Abfall der HBV-DNA einstellt. Bei Therapie mit NA mit geringer Resistenzbarriere (Lamivudin, Telbivudin) ist ein langsamer Virusabfall mit der Entwicklung von Resistenzen assoziiert und sollte zu einem Wechsel der Therapie führen (keine Änderung zu [5]).

\section{EMPFEHLUNG 3.5.3}

Die quantitative Bestimmung des HBsAg kann zur Vorhersage eines HBsAg-Verlustes sinnvoll sein [EK].

Konsens: $100 \%$ (Delphi-Runde)

Neu 2020

\section{Kommentar:}

Da die NA keinen direkten Effekt auf die cccDNA haben und $\mathrm{HBsAg}$ zusätzlich aus integrierter HBV-DNA produziert werden kann, fällt das HBsAg im Verlauf einer NA-Therapie i.d. R. nicht oder nur sehr langsam ab. Die jährliche Rate an HBsAg-Verlust liegt bei ca. $1 \%$. [157].

Die Kinetik des HBsAg hat primär keinen Einfluss auf Kontrollintervalle oder Umstellung der Therapie. Ein deutlicher Abfall des HBsAg-Werts im Verlauf der Therapie kann aber ein Indiz für einen 
späteren HBsAg-Verlust sein. Bislang ist die Evidenz für die Vorhersage basierend auf der Kinetik nicht ausreichend. Ein absoluter Wert $<100 \mathrm{IU} / \mathrm{ml}$ war bei asiatischen Patienten allerdings prädiktiv für eine funktionelle Heilung (HBsAg-Verlust) in den folgenden Jahren [36].

Die Kenntnis des quantitativen HBsAg kann daher hilfreich sein, um Patienten über die mögliche Therapiedauer aufzuklären oder über einen möglichen Therapiestopp nachzudenken (siehe 3.8). Ein Kontrollintervall ist bislang nicht etabliert. Eine Bestimmung einmal pro Jahr kann sinnvoll sein.

\subsection{Wie ist das Vorgehen bei nicht ausreichendem Therapie- ansprechen oder Resistenzentwicklung?}

\section{EMPFEHLUNG 3.6.1}

Bei persistierender HBV-DNA < $2000 \mathrm{lU} / \mathrm{ml}$ unter Behandlung mit Tenofovir (TDF oder TAF) oder ETV braucht keine Anpassung der Behandlung zu erfolgen, wenn keine Zirrhose und kein Anhalt für Resistenz oder Nichtansprechen vorliegt [EK]. Bei partiellem Therapieansprechen oder Nonresponse soll zunächst die Therapieadhärenz des Patienten überprüft werden [EK]. Konsens: $100 \%$ (Delphi-Runde)

Modifiziert 2020

\section{Kommentar:}

In klinischen Kohorten waren bis zu 30-40\% aller virologischen Durchbrüche mutmaßlich auf unregelmäßige Medikamenteneinnahme zurückzuführen. Bisher bekannte Risikofaktoren sind Vergessen der Medikamenteneinnahme länger als 1 Tag am Stück, kürzerer Zeitraum nach Diagnosestellung und jüngeres Patientenalter [156, 158, 159].

Bei Patienten ohne Leberzirrhose und Therapie mit Entecavir und Tenofovir gibt es keinen definierten HBV-DNA-Grenzwert unterhalb $2000 \mathrm{IU} / \mathrm{ml}$, der mit Morbidität oder Mortalität assoziiert ist (siehe 3.5.2).

\section{EMPFEHLUNG 3.6.2}

Eine Testung auf HBV-Varianten, die mit einer Nukleos(t)idanaloga-Resistenz assoziiert sind, kann erfolgen $[4,0]$. Konsens: 95,8\% (Delphi-Runde)

Geprüft 2020

\section{Kommentar:}

Die Bestimmung von Polymerase-Gen-Mutationen des HBV, die mit Resistenzen assoziiert sind, kann für die Therapieplanung mit einem Nukleosidanalogon erwogen werden, insbesondere bei Unklarheiten über eventuelle Vortherapien. Bei Vorliegen von gegen Lamivudin oder von bestimmten gegen Telbivudin resistenten Varianten ist z. B. das Risiko für eine Entecavir-Resistenz erhöht (keine Änderung zu [5]).

Der Durchbruch der HBV-DNA im Rahmen der Resistenzentwicklung des HBV tritt in der Regel einige Monate vor dem biochemischen Rückfall mit Anstieg der Transaminasen auf. Die Therapieanpassungen sind aber möglichst bereits bei Sicherung des virologischen Rückfalls durchzuführen (keine Änderung zu [5]).

Wird die Monotherapie trotz Resistenz des HBV fortgesetzt, können sich weitere, kompensatorische Mutationen ausbilden, die wiederum den Einsatz anderer Substanzen aufgrund von Kreuzresistenzen einschränken. Das Warten auf das Ergebnis der Resistenztestung sollte die Therapieumstellung allerdings nicht unnötig verzögern. Tenofovir ist auch bei komplexen Vortherapien i. d. R. effektiv [160].

Sollte die HBV-DNA unter Tenofovir und optimaler Therapieadhärenz dennoch wiederholt erhöht sein, können besondere HBV-Mutationen selektioniert worden sein, die mit einer verringerten Wirksamkeit der hochpotenten NA einhergehen können [161, 162].

\section{EMPFEHLUNG 3.6.3}

Bei partiellem Therapieansprechen oder Nichtansprechen (Nonresponse) oder Resistenz soll eine Therapieanpassung geprüft werden $[1, \mathrm{~A}]$ :

- Wurde ein Nukleosidanalogon (Lamivudin, Entecavir, Telbivudin) eingesetzt, soll eine Therapieumstellung auf Tenofovir (TDF oder TAF) erfolgen [1, A].

- Wurde Adefovir eingesetzt, soll eine Therapieumstellung auf Entecavir oder Tenofovir (TDF oder TAF) erfolgen [EK, modifiziert 2020].

- Wurde Tenofovir (TDF oder TAF) eingesetzt, kann eine Therapieumstellung auf Entecavir erfolgen oder ein Nukleosidanalogon (vorzugsweise ETV) zusätzlich gegeben werden $[4,0]$.

Konsens: $100 \%$ (Konsensuskonferenz)

Geprüft 2020

\section{Kommentar:}

Bei primärem Nichtansprechen oder Resistenz während der Therapie mit Nukleosidanaloga (Lamivudin, Telbivudin, Entecavir) soll die Behandlung auf Tenofovir (TDF oder TAF) umgestellt werden (keine Änderung zu [5]).

Eine Monotherapie mit Tenofovir (TDF oder TAF) reicht i. d. R. aus (Evidenz 1b) [160].

Gegen Entecavir resistente Virusvarianten sollten primär mit Tenofovir (TDF oder TAF) behandelt werden. Diese Entscheidung gründet sich auf In-vitro-Daten und klinische Erfahrung mit dem antiviral schwächeren Nukleotidanalogon Adefovir (keine Änderung zu [5]).

Eine Therapie mit Entecavir bei Lamivudin-Resistenz ist zwar häufig mit einem biochemischen Ansprechen assoziiert, birgt jedoch ein relativ hohes Risiko des Auftretens einer Entecavir-Resistenz mit mehr als 50 \% nach 5 Jahren (Evidenz 1b) (keine Änderung zu [5]).

Daher ist der Einsatz von Entecavir bei Patienten mit gesicherter Lamivudin-Resistenz nicht sinnvoll. Im Falle eines nicht ausreichenden primären Ansprechens von Lamivudin oder Telbivudin kann jedoch Entecavir eingesetzt werden, wenn das Vorhandensein von Varianten, die mit einer Resistenz gegen Nukleosidanalo- 
ga assoziiert sind, ausgeschlossen wurde und Tenofovir (TDF oder TAF) aus anderen Gründen nicht eingesetzt werden kann (Expertenmeinung).

Adefovir wird nicht mehr als Primärtherapie empfohlen (siehe 3.2). Sollte ein Patient dennoch mit Adefovir behandelt sein und nicht ausreichend auf die Therapie ansprechen, ist ein Wechsel auf Entecavir oder Tenofovir (TDF oder TAF) möglich. Die Daten zu Entecavir basieren auf Kohortenstudien von hoher Qualität (Evidenz 2b), während für Tenofovir Daten aus einer prospektiven, randomisierten Studie vorliegen (Evidenz 1b) (keine Änderung zu [5]).

Bei einer möglichen Vorbehandlung mit Lamivudin ist zu berücksichtigen, dass diese eine Resistenzentwicklung gegen Entecavir begünstigen kann (siehe oben). Liegt eine gesicherte Resistenz gegen Adefovir vor, so können ebenfalls verschiedene andere Nukleosidanaloga (Evidenz 2b) und Tenofovir eingesetzt werden (TDF, Evidenz 1b). Allerdings war in 2 Kohorten das Vorliegen von Adefovir-Resistenzen mit einem langsameren TDF-Ansprechen assoziiert (Evidenz 2b), während in anderen Fällen dennoch ein normales Ansprechen auf eine TDF-Monotherapie beschrieben wurde (Evidenz 3b) (keine Änderung zu [5]).

Die Selektion von Mutationen, die mit einer reduzierten antiviralen Wirksamkeit von Tenofovir assoziiert sind, ist beschrieben, aber selten [161, 162].

Sollten im Langzeitverlauf jedoch Resistenzen auftreten, so ist aufgrund von In-vitro-Daten zu erwarten, dass Nukleosidanaloga, insbesondere Entecavir, weiterhin wirksam sein sollten (Expertenmeinung).

Im Falle eines nicht ausreichenden Ansprechens auf eine Behandlung mit Tenofovir kann eine Umstellung auf Entecavir erfolgen (Expertenmeinung), wobei eine alleinige Umstellung nicht im Fall einer Lamivudin-Resistenz erfolgen sollte. Alternativ kann ein Nukleosidanalogon unter Beibehaltung von Tenofovir gegeben werden, womit sowohl in Fallserien und einer Kohortenstudie als auch bei einigen Patienten der Tenofovir-Zulassungsstudien (Evidenz 2b für die Aussage) eine Suppression der HBV-DNA unter die Nachweisgrenze erreicht wurde. (keine Änderung zu [5]).

\subsection{Was ist bei Langzeittherapie mit Nukleosid- oder Nuk- leotidanaloga zu beachten?}

\section{EMPFEHLUNG 3.7.1}

Bei der Auswahl der antiviralen Therapie sowie der Überwachungsintervalle sollen Komorbiditäten berücksichtigt werden $[2, A]$.

Konsens: $100 \%$ (Delphi-Runde)

Geprüft 2020

NKLM

\section{Kommentar:}

Da die Therapie der Hepatitis B in vielen Fällen eine Langzeittherapie darstellt, sind Komorbiditäten zu berücksichtigen. Ein gleichzeitig bestehender Diabetes mellitus kann das Risiko für die Entstehung eines hepatozellulären Karzinoms (HCC) bei Patienten mit Virushepatitis erhöhen (Evidenz 2b) (keine Änderung zu [5]).
Eine HBV-Infektion ist mit einem höheren Risiko für die Entwicklung einer terminalen Niereninsuffizienz bei Patienten mit Diabetes mellitus assoziiert (Evidenz 2b) (keine Änderung zu [5]).

Ältere Patienten über 60 Jahre mit chronischen Lebererkrankungen haben eine verringerte Knochendichte, was insbesondere Frauen betrifft (Evidenz 3b) (keine Änderung zu [5]).

Eine Knochendichtemessung ist daher bei postmenopausalen Frauen mit chronischer Hepatitis B sinnvoll, insbesondere wenn eine Langzeittherapie mit potenziell nephrotoxischen antiviralen Substanzen durchgeführt wird, die einen renalen Phosphatverlust induzieren können. Die NA zur Behandlung der chronischen Hepatitis B haben unterschiedliche Eigenschaften, die in bestimmten Situationen beachtet werden müssen. Bei einer Behandlung mit Adefovir und Tenofovir (TDF) ist zu beachten, dass die Substanzen zu Nierenfunktionseinschränkungen führen können [138].

Entecavir wird nicht für die Behandlung schwangerer Frauen empfohlen.

\section{EMPFEHLUNG 3.7.2}

Die Nierenfunktion soll vor Therapie und regelmäßig während der Therapie überwacht werden [I, A].

Konsens: 97,8\% (Delphi-Runde)

Geprüft 2020

NKLM

\section{Kommentar:}

Alle zur Therapie der HBV-Infektion zugelassenen NA werden renal ausgeschieden. Die Messung des Kreatininspiegels im Serum vor und während einer Behandlung mit Nukleos(t)idanaloga ist eine Voraussetzung für den sicheren Gebrauch dieser Substanzen, um ggf. eine Dosisanpassung gemäß der aktuellen Nierenfunktion durchzuführen ( $\vee$ Tab. 12). Grundsätzlich ist zu beachten, dass Serumkreatininveränderungen nur eingeschränkt Nierenfunktionseinschränkungen anzeigen können. Frühe tubuläre Schäden können durch eine Proteinurie, normoglykämische Glukosurie bzw. eine verminderte Phosphat-Reabsorption angezeigt werden (keine Änderung zu [5]).

\section{EMPFEHLUNG 3.7.3}

Eine Therapie mit Lamivudin oder Telbivudin (NA mit geringer Resistenzbarriere) kann bei optimalem Therapieansprechen fortgesetzt werden [EK].

Konsens: 97,8\% (Delphi-Runde)

Neu 2020

\section{Kommentar:}

Für Lamivudin und Telbivudin sind keine Studien bekannt, die über eine Einschränkung der Nierenfunktion durch die Therapie berichten. Telbivudin scheint sogar einen günstigen Effekt auf Kreatininwerte bzw. die Glomerulofiltrationsrate (GFR) zu haben (Evidenz 2b) [139, 140]. 
- Tab. 12 Dosisanpassung von antiviralen Substanzen (LAM, ETV, TDF, TAF) in der Therapie der Hepatitis B bei eingeschränkter Nierenfunktion gemäß Fachinformation.

\begin{tabular}{|c|c|c|c|c|c|c|c|}
\hline \multirow{2}{*}{\multicolumn{2}{|c|}{$\begin{array}{l}\text { Substanz } \\
\text { Lamivudin }\end{array}$}} & \multirow{3}{*}{$\begin{array}{l}\text { Standarddosis } \\
100 \mathrm{mg}\end{array}$} & \multicolumn{4}{|c|}{ Kreatininclearance $\mathrm{ml} / \mathrm{min}$} & \multirow{3}{*}{$\begin{array}{l}\text { Bemerkung } \\
\text { Lösung ( } 5 \mathrm{mg} / \mathrm{ml}) \\
\text { verfügbar zur } \\
\text { Dosisanpassung }\end{array}$} \\
\hline & & & $30-50$ & $15-30$ & $5-15$ & $<5$ & \\
\hline & & & $50 \mathrm{mg}$ & $25 \mathrm{mg}$ & $15 \mathrm{mg}$ & $10 \mathrm{mg}$ & \\
\hline \multirow[t]{3}{*}{ Entecavir } & \multirow{2}{*}{$\begin{array}{l}\text { Unbehandelte } \\
\text { Patienten }\end{array}$} & & $30-49$ & $10-29$ & \multicolumn{2}{|c|}{$<10 /$ Dialyse } & \multirow{3}{*}{$\begin{array}{l}\text { Lösung }(0,05 \mathrm{mg} / \mathrm{ml}) \\
\text { verfügbar zur } \\
\text { Dosisanpassung. } \\
\text { Bei Dialyse Einnahme } \\
\text { nach der Dialyse }\end{array}$} \\
\hline & & $0,5 \mathrm{mg}$ & $\begin{array}{l}0,25 \mathrm{mg} \text { oder } \\
0,5 \mathrm{mg} \text { alle } \\
48 \text { Stunden }\end{array}$ & $\begin{array}{l}0,15 \mathrm{mg} \\
\text { oder } \\
0,5 \mathrm{mg} \text { alle } \\
72 \text { Stunden }\end{array}$ & \multicolumn{2}{|c|}{$\begin{array}{l}0,05 \mathrm{mg} \text { oder } \\
0,5 \mathrm{mg} \text { alle } \\
5-7 \text { Tage }\end{array}$} & \\
\hline & $\begin{array}{l}\text { Mit Lamivudin vorbe- } \\
\text { handelte Patienten }\end{array}$ & $1 \mathrm{mg}$ & $0,5 \mathrm{mg}$ & $\begin{array}{l}0,3 \mathrm{mg} \\
\text { oder } \\
0,5 \mathrm{mg} \text { alle } \\
48 \text { Stunden }\end{array}$ & \multicolumn{2}{|c|}{$\begin{array}{l}0,1 \mathrm{mg} \text { oder } 0,5 \mathrm{mg} \\
\text { alle } 72 \text { Stunden }\end{array}$} & \\
\hline \multirow{2}{*}{$\begin{array}{l}\text { Tenofovir dis- } \\
\text { oproxil-fumarat }\end{array}$} & & & $30-49$ & $10-29$ & \multicolumn{2}{|l|}{ Dialyse } & \multirow{2}{*}{$\begin{array}{l}\text { Bei Dialyse Einnahme } \\
\text { nach der Dialyse }\end{array}$} \\
\hline & & $245 \mathrm{mg}$ & alle $48 \mathrm{~h}$ & $\begin{array}{l}\text { alle } \\
72-96 \mathrm{~h}\end{array}$ & alle $7 \mathrm{~T}$ & & \\
\hline \multirow{2}{*}{$\begin{array}{l}\text { Tenofovir alafe- } \\
\text { namid hemifu- } \\
\text { marat }\end{array}$} & & & & & \multicolumn{2}{|l|}{ Dialyse } & \multirow{2}{*}{$\begin{array}{l}{ }^{*} \text { Keine Dosierungsempf. } \\
\text { für Pat. mit einer } \mathrm{CrCl} \\
<15 \mathrm{ml} / \text { min ohne } \\
\text { Hämodialyse }\end{array}$} \\
\hline & & $25 \mathrm{mg}$ & & & \multicolumn{2}{|c|}{$\begin{array}{l}{ }^{*} \text { (Einnahme nach } \\
\text { Dialyse) }\end{array}$} & \\
\hline
\end{tabular}

Es gibt allerdings keine Evidenz, die zeigt, ob es sich hierbei um Laborkosmetik handelt oder ob ein klinischer Nutzen besteht. Eine Telbivudin-Therapie führte in den Zulassungsstudien in 7,5\% der Fälle zu deutlichen CK-Erhöhungen, die im Verlauf in der Regel reversibel und nicht mit klinischen Zeichen einer Myopathie assoziiert waren (Evidenz 2b) (keine Änderung zu [5]).

Patienten, die bereits mit Lamivudin oder Telbivudin erfolgreich behandelt werden (HBV-DNA negativ unter Therapie), brauchen nicht umgestellt zu werden (keine Änderung zu [5]).

* Anmerkung zu Telbivudin: Das Medikament ist in Deutschland mittlerweile vom Markt genommen worden.

Wie bereits unter 3.2 aufgeführt, soll Adefovir nicht mehr eingesetzt werden. Adefovir ist dosisabhängig nephrotoxisch. Für Adefovir sind Kreatininanstiege im Verlauf einer Behandlung in mehreren Studien und Real-World Kohorten beschrieben worden (Evidenz 2b), wobei ein Alter von über 50 Jahren und eine bereits bestehende verminderte Nierenfunktion bei Therapiebeginn prädiktive Parameter für das Auftreten einer renalen Dysfunktion waren. Eine tubuläre Dysfunktion (Fanconi-Syndrom) wurde bei Patienten mit ADV-Langzeittherapie beschrieben (Evidenz 4). [5, $141,163]$

Aufgrund der Alternativen ETV und TAF soll daher eine Therapieumstellung angeboten werden.

\section{EMPFEHLUNG 3.7.4}

Eine Therapie mit TDF sollte bei einem Abfall der glomerulären Filtrationsrate (GFR), beim Auftreten einer Tubulopathie, bei einer Hypophosphatämie $<1 \mathrm{mg} / \mathrm{dl}$ und bei Frakturrisiko auf ein anderes NA umgesetzt werden [2, B]. Vortherapien und Resistenzen sollen bei der Wahl des NA beachtet werden [EK]. Konsens: 97,8\% (Delphi-Runde)

Neu 2020

Leitlinienadaption EASL Clinical Practice Guideline HBV 2017

\section{Kommentar:}

In den Phase-III-Zulassungsstudien für Tenofovir (TDF) wurde kein Anstieg des Kreatinins im Serum um mehr als $\geq 0,5 \mathrm{mg} / \mathrm{dl}$ und kein Rückgang der GFR auf $<50 \mathrm{ml} / \mathrm{min}$ während der TDFTherapie von 144 Wochen beobachtet (Evidenz 1b) (keine Änderung zu [5]).

Bei Patienten mit einer TDF-Langzeittherapie und vorausgegangenem Therapieversagen anderer Nukleos(t)idanaloga wurde in einer retrospektiven Analyse über einen mittleren Zeitraum von ca. 30 Monaten ein mittlerer Rückgang der GFR von $5 \%$ beobachtet, der sich allerdings nicht von einer Kontrollgruppe mit unbehandelten HBV-Infizierten unterschied (Evidenz 2b). In einer prospektiven Studie führte die TDF-Therapie zu einem signifikanten Abfall der GFR um 3,2 mL/min/1,73 $\mathrm{m}^{2}$ nach 240 Monaten. Ebenso kam es in diesem Zeitraum zu einem signifikanten Abfall der Knochendichte am Femur um 2,5\%. Frauen waren häufiger von den Veränderungen betroffen als Männer (Evidenz 2b). In den TAF-Zulassungsstudien hatten Patienten, die mit TAF behandelt wurden, nach 96 Wochen einen geringeren Abfall der Knochendichte (Hüfte und Lendenwirbelsäule) und einen geringeren Abfall der GFR im Vergleich zu mit TDF behandelten Patienten (Evidenz 1b). Eine weitere randomisierte Studie bestätigte den geringeren Abfall der Knochendichte unter TAF. Eine Umstellung 
von TDF auf TAF führte in weiteren Kohorten zu einer Verbesserung der Knochendichtewerte.

Allerdings ist bislang nicht dokumentiert, dass klinische Endpunkte (Nierenversagen, Knochenbrüche) signifikant weniger mit TAF als mit TDF auftreten. [5, 135, 160, 164, 165]

Tubuläre Dysfunktionen sind im Zusammenhang von antiviralen Langzeittherapien der HIV-Infektion mit TDF beschrieben worden, die allerdings in den meisten Fällen reversibel waren, nachdem Tenofovir abgesetzt wurde (Evidenz 2b) (keine Änderung zu [5]).

Auch bei Patienten mit HBV-Infektion sind unter TDF FanconiSyndrome beschrieben. Eine erfolgreiche und sichere Fortführung der Therapie mit TAF ist beschrieben (Evidenz 4). [166]

\subsection{Wann kann eine antivirale Therapie der Hepatitis B mit Nukleosid- oder Nukleotidanaloga beendet werden?}

\section{EMPFEHLUNG 3.8.1}

Eine antivirale Therapie mit Nukleosid- oder Nukleotidanaloga soll nur nach Rücksprache mit einem in der Therapie der Hepatitis B erfahrenen Arzt und unter engmaschigen Kontrollen beendet werden [EK]. Dabei sollten HBsAg-, HBeAg-Statuts, Komorbidität (Immunsuppression), Dauer der HBV-DNA-Suppression und Stadium der Leberfibrose berücksichtigt werden [EK].

Konsens: 97,9\% (Delphi-Runde)

Neu 2020

\section{Kommentar:}

Die Therapie mit Nukleosid- oder Nukleotidanaloga (NA) führt zu einer HBV-DNA-Suppression, die nicht mit einer Heilung bzw. funktionalen Heilung gleichzusetzen ist. Daher kommt es bei Absetzen der Therapie i. d. R. zu einem Wiederanstieg der HBV-DNA und mit zeitlichem Abstand ggf. zu einem Anstieg der ALT und möglicherweise zu einer klinisch relevanten Reaktivierung der Hepatitis. Einzelne Fälle von fulminanten Reaktivierungen wurden beschrieben (Evidenz 4) [167].

Das Risiko für eine Reaktivierung hängt von verschiedenen Faktoren ab: HBsAg-Menge, HBeAg-Status, Immunsuppression, Dauer der Therapie bzw. der HBV-DNA-Suppression. Stadium der Leberfibrose, Alter (Evidenz 2a) [168, 169].

\section{EMPFEHLUNG 3.8.2}

Eine antivirale Therapie mit Nukleosid- oder Nukleotidanaloga kann beendet werden, wenn ein HBsAg-Verlust erreicht ist [EK]. Konsens: $100 \%$ (Delphi-Runde)

Neu 2020

NKLM

\section{Kommentar:}

Der Verlust des HBsAg entspricht einer immunologischen Kontrolle der Hepatitis-B-Virusinfektion mit der langfristig besten Prognose (siehe 3.1) [6-8, 100].
Zu beachten ist, dass es aufgrund der Persistenz der cccDNA in der Leber trotz HBsAg-Verlusts prinzipiell zu einer Reaktivierung kommen kann (siehe 3.13) [170, 171].

Der Verlust des HBsAg unter Therapie mit Nukleo(t)sidanaloga ist selten ( $\triangleright$ Tab. 10). Im Falle eines HBsAg-Verlustes (2-mal bestätigt innerhalb von 6 Monaten) scheint das Risiko einer HBsAgReversion sehr niedrig zu sein. In der größten asiatischen Studie mit 4080 Patienten blieben > 95\% HBsAg-negativ (2,9\% der mit NA behandelten Patienten), obwohl nur $38 \%$ der HBsAg-negativen Patienten einen nachweisbaren Anti-HBs-Titer hatten. Eine Anti-HBs-Serokonversion war auch in anderen Studien nicht bedeutend für einen dauerhaften HBsAg-Verlust (Evidenz 3b) [101, $172,173]$.

Die EASL-Leitlinie empfiehlt sogar, dass eine Therapie bei bestätigtem HBsAg-Verlust beendet werden sollte [6].

Wir haben die Empfehlungsstärke der EASL-Leitlinie zum Therapieende bei HBsAg-Verlust, die für alle Patienten gilt, herabgestuft, da für Subgruppen (Zirrhose, immunsupprimierte Patienten) die Datenlage unzureichend ist.

So sollte bei Patienten mit einer Leberzirrhose aus Sicherheitsgründen eine Therapiebeendigung erst mit Nachweis des AntiHBs erfolgen, wobei ein sensitiver Test verwendet werden sollte, oder nach einer Konsoliderungstherapie von 6-12 Monaten nach Therapieende und HBsAg-Verlust. Es gibt bislang allerdings sehr wenig Evidenz, ob eine Konsolidierungstherapie einen Nutzen hat. Bei Yip et al. hatte kein Patient eine HBs-Seroreversion, der eine 12-monatige Konsoliderungstherapie erhielt. Aufgrund von Sicherheitsaspekten und der geringen Risiken einer längeren NA-Therapie besteht hier eine starke Expertenempfehlung für die Konsolidierungstherapie bzw. die Therapie bis zur Anti-HBs-Serokonversion bei Patienten mit Zirrhose. Zu beachten ist, dass der Zeitraum bis zur Anti-HBs-Serokonversion nach HBsAg-Verlust mehrere Jahre in Anspruch nehmen kann (58\% Anti-HBs-Serokonversion nach 5 Jahren) $[172,174]$.

Daten zum Langzeitverlauf nach Verlust des HBsAg unter antiviraler Therapie fehlen. Im ersten Jahr nach Absetzen der antiviralen Therapie erscheinen Kontrollen (HBV-DNA und ALT) in 3-monatigen Abständen sinnvoll. Im weiteren Verlauf sollten Kontrollen in 6- bis 12-monatigen Abständen unter Berücksichtigung von Komorbiditäten, Alter, Geschlecht und Fibrosegrad der Leber erfolgen, insbesondere im Hinblick auf das Risiko der Entwicklung eines hepatozellulären Karzinoms (HCC). Wichtig ist, dass ein Absetzen der Therapie nicht bei Patienten erfolgt, bei denen aufgrund einer Immunsuppression die Indikation zur prophylaktischen Therapie besteht (siehe 3.13). Wir haben die Empfehlungsstärke der EASL-Leitlinie zum Therapieende bei HBsAgVerlust, die für alle Patienten gilt, herabgestuft, da für Subgruppen (Zirrhose, immunsupprimierte Patienten) die Datenlage unzureichend ist.

\section{EMPFEHLUNG 3.8.3}

Bei HBeAg-positiven Patienten kann eine antivirale Therapie mit Nukleosid- oder Nukleotidanaloga 12 Monate nach HBeAg-Verlust und Anti-HBe-Serokonversion beendet werden $\left[3,0^{*}\right]$. Vor Beendigung der Therapie sollte die HBV-DNA 
negativ bzw. nicht quantifizierbar sein $\left[3, \mathrm{~B}^{* *}\right]$. Eine Leberzirrhose sollte ausgeschlossen sein [EK].

Konsens: 97,8\% (Delphi-Runde)

* Neu 2020; Leitlinienadaptation AASLD Practice Guideline HBV 2016.

** Geprüft 2020.

\section{Kommentar:}

Die umfangreichsten Daten zur Therapiebeendigung in initial HBeAg-positiven Patienten nach HBeAg-Verlust und Anti-HBe-Serokonversion sind in einer Metaanalyse mit insgesamt 1.217 HBeAg-positiven Patienten erhoben worden. Die eingeschlossenen Studien weisen jedoch eine große Heterogenität auf und wurden nahezu ausschließlich in Asien durchgeführt, sodass die Übertragbarkeit auf Deutschland eingeschränkt ist (Evidenz 3a) [168].

Insgesamt zeigten 71,2\% der Patienten eine virologische Remission (HBV-DNA < $2000 \mathrm{IU} / \mathrm{ml}$ ) ein Jahr nach Beendigung einer antiviralen Therapie. Eine biochemische Remission wurde in $66,5 \%$ von 403 Patienten, zu denen entsprechende Daten vorlagen, erreicht. Die HBeAg-Serokonversion blieb in 91,9\% der Patienten ein Jahr nach Therapiebeendigung stabil. Nach 2 Jahren sank die Zahl der Patienten mit virologischer Remission auf 53,4\%, die Anti-HBe-Serokonversion zeigte sich stabil bei $88 \%$ der Patienten. Bei heterogener Datenlage zeigte sich eine erhöhte Wahrscheinlichkeit für eine dauerhafte Remission in jüngeren Patienten und Patienten mit niedrigerem HBsAg. Eine fortgeführte antivirale Therapie zeigte in vergleichenden Studien eine höhere Rate an virologischer und biochemischer Remission; eine HBeAg-Reversion trat unter antiviraler Therapie nicht auf (Evidenz 3a) [168].

Daten zum langfristigen Verlauf hinsichtlich Mortalität, Progress der Lebererkrankung und Risiko für ein hepatozelluläres Karzinom (HCC) oder hepatische Dekompensation im Vergleich zu einer fortgeführten Therapie liegen nicht vor.

Die Wahrscheinlichkeit einer virologischen Remission war in einigen Studien niedriger, wenn eine Suppression der HBV-DNA unter antiviraler Therapie kürzer als 12 Monate bestand, sodass eine Suppression der HBV-DNA unterhalb der Quantifizierungsgrenze für mindestens 12 Monate bestehen sollte, bevor eine Therapiebeendigung diskutiert wird $[175,176]$.

Im Einklang mit internationalen Leitlinien und der Praxis in den bisher durchgeführten Studien sollte eine Konsolidierungstherapie von mindestens 12 Monaten nach Anti-HBe-Serokonversion erfolgen, bevor die Therapie beendet wird [7].

In der systematischen Analyse konnte allerdings keine signifikante Unterlegenheit einer Konsolidierungstherapie < 12 Monate nach Anti-HBe-Serokonversion belegt werden, bei allerdings sehr kleinen Fallzahlen [168].

In den bisherigen Studien, in denen überwiegend der HBV Genotyp B und C vorlag, konnte kein Einfluss des Genotyps auf die Wahrscheinlichkeit einer dauerhaften Remission belegt werden. Weiterhin ergab sich kein Hinweis, dass bestimmte Nukleo(t)sidanaloga mit einer erhöhten Wahrscheinlichkeit für eine dauerhafte Remission assoziiert sind. Ein niedrigeres HBsAg-Level (<2,5 log $\mathrm{IU} / \mathrm{ml}$ ) ist mit einer dauerhaften Remission (bei asiatischen Patien- ten) assoziiert. Allerdings ist hier die Evidenz geringer als für HBeAg-negative Patienten (Evidenz 3b) [177].

Ein virologischer und biochemischer Relapse tritt in der Regel innerhalb des ersten Jahres auf, sodass nach Therapiebeendigung nach Anti-HBe-Serokonversion mindestens alle 3 Monate eine Kontrolle eines virologischen und biochemischen Rückfalls (HBVDNA und ALT) erfolgen sollte.

Die optimalen Kontrollintervalle nach Therapiebeendigung sind bislang nicht gut definiert und sollten bei fortgeschrittener Fibrose engmaschiger sein. Es sollte auf klinische Zeichen einer hepatischen Dekompensation geachtet werden. Aufgrund der Unsicherheit, welche Patienten für einen Therapiestopp geeignet sind, ist eine Fortführung der Therapie bis zum Erreichen eines $\mathrm{HBsAg}$-Verlusts als Alternative in der AASLD-Leitlinie empfohlen, insbesondere bei Patienten mit Leberzirrhose [7].

\section{EMPFEHLUNG 3.8.4}

Bei HBeAg-negativen Patienten ohne fortgeschrittene Leberfibrose kann eine Therapie mit Nukleosid- oder Nukleotidanaloga vor HBsAg-Verlust beendet werden, wenn die HBV-DNA mindestens 3 Jahre negativ bzw. nicht quantifizierbar war und eine engmaschige Kontrolle nach Therapiestopp gewährleistet ist $[3,0]$.

Konsens: 90,3\% (Konsensuskonferenz)

Neu 2020

Leitlinienadaption EASL Clinical Practice Guideline HBV 2017

\section{Kommentar:}

Die Empfehlung entspricht den EASI-Leitinien [6].

Erfahrungen zum Beenden einer antiviralen Therapie bei HBeAgnegativen Patienten wurden in 2 systematischen Reviews mit 1732 und 1115 Patienten zusammengefasst. Die untersuchten Studien überschneiden sich dabei zu großen Teilen und wurden überwiegend im asiatischen Raum durchgeführt, sodass die Übertragbarkeit auf Deutschland eingeschränkt ist (Evidenz 3a) [168, 169].

Die Wahrscheinlichkeit für eine virologische Remission ein Jahr nach Absetzen der antiviralen Therapie lag bei HBeAg-negativen Patienten bei $48 \%$. Eine stabile biochemische Remission bestand nach einem Jahr bei 57,4\% von 687 Patienten, bei denen entsprechende Ergebnisse vorlagen. Die Wahrscheinlichkeit einer dauerhaften virologischen Remission nach Absetzen war deutlich erhöht, wenn zuvor eine virologische Remission unter antiviraler Therapie für mindestens 24 Monate bestanden hatte. Eine Studie mit längerer Verlaufsbeobachtung zeigte eine weiter reduzierte Rückfallquote bei einer antiviralen Therapie von mindestens 3 Jahren gegenüber 2 Jahren in 59 Patienten (25\% vs. 54\%) (Evidenz 3b) [178].

In einzelnen Studien wurden weitere Parameter mit einer erhöhten Wahrscheinlichkeit für eine dauerhafte virologische Remission assoziiert. Hierzu zählen niedrigere Ausgangsviruslast bei Therapiebeginn ( $<200000 \mathrm{lU} / \mathrm{ml}$ ), niedrigere ALT, jüngeres Alter (<40 Jahre), weibliches Geschlecht und Fehlen einer Leberzirrhose. Ebenfalls war ein niedrigeres $\mathrm{HBsAg}$ zum Zeitpunkt des 
Absetzens mit einer erhöhten Wahrscheinlichkeit für eine dauerhafte Remission assoziiert (Evidenz 3a) [168, 169].

In der systematischen Analyse von Chang et al. zeigte sich ein niedriges HBsAg $(<200 \mathrm{IU} / \mathrm{ml})$ mit einer höheren Rate an dauerhafter Remission verknüpft (Evidenz 3a) [169].

Es liegen bislang nur wenige Langzeitdaten hinsichtlich klinischer Endpunkte nach Absetzen der Therapie im Vergleich zu einer fortgesetzten Therapie vor. Asiatische Studien dokumentierten keine höheren Raten an klinischen Endpunkten, inklusive HCC, nach Absetzen der Therapie gemäß APASL-Stoppregeln. Der Beobachtungszeitraum lag bei 12-60 Monaten. Eine Studie hatte sogar Patienten mit kompensierter Leberzirrhose untersucht (Evidenz 3b). [47, 179, 180] Weitere Langzeitdaten sind aber erforderlich.

Ein Relapse (HBV-DNA-Anstieg) erfolgt üblicherweise innerhalb der ersten 1-12 Monate Dabei scheint es aber nach Beendigung von TDF einen schnelleren Virusrückfall zu geben (70\% innerhalb der ersten 12 Wochen) im Vergleich zu ETV (<10\% innerhalb der ersten 12 Wochen) (Evidenz 2b). Initial (in den ersten 6 Monaten nach Absetzen der Therapie) sollten Kontrollen in mindestens 4-wöchentlichen Abständen erfolgen, danach alle 3 Monate (Expertenmeinung). Im Fall eines Rückfalls kommt es typischerweise erst zum Anstieg der HBV-DNA nach 4-24 Wochen (Evidenz 2b) und im Anschluss zu einem Anstieg der ALT. Entsprechend sollten HBV-DNA und ALT kontrolliert werden. Ebenfalls muss auf klinische Zeichen einer hepatischen Dekompensation geachtet werden [168, 169, 181-186].

Patienten mit weiteren Lebererkrankungen oder immunsuppressiv behandelte Patienten waren in den Studien regelhaft ausgeschlossen, sodass zu diesen Patienten keine belastbaren Daten vorlegen. Bei ausgeprägten Komorbiditäten oder Immunsuppression ist aufgrund der hohen Gefahr einer Reaktivierung ein Absetzen einer HBV-Therapie nicht zu empfehlen (siehe 3.13). Der Anteil an Patienten mit Leberzirrhose lag in den Studien, die in den systematischen Reviews erfasst wurden, bei 9,3 und 16,1\%. Insgesamt wurden in den Studien keine gehäuften schweren $\mathrm{Ne}$ benwirkungen einer Therapiebeendigung beschrieben. Allerdings kam es in Einzelfällen in Patienten mit Leberzirrhose zu einer hepatischen Dekompensation nach Beendigung einer antiviralen Therapie (Evidenz 4), die nicht in jedem Fall durch eine Re-Therapie erfolgreich behandelt werden konnten [182].

Deshalb soll unter Sicherheitsaspekten eine Therapiebeendigung bei Patienten mit Leberzirrhose vor Erreichen eines HBsAgVerlusts bzw. Anti-HBs-Serokonversion nicht erfolgen [6].

Eine ggf. erforderliche Re-Therapie sollte nach Empfehlungen zur Einleitung einer viralen Therapie der Hepatitis B erfolgen (siehe 2.2). Im Falle einer Re-Therapie konnte in den durchgeführten Studien unter Verwendung von Entecavir und Tenofovir (TDF) eine erneute virale Suppression erreicht werden (Evidenz 2b) [186].

In den zur Verfügung stehenden Daten ergeben sich keine Hinweise für ein schlechteres Ansprechen auf eine erneute antivirale Therapie bzw. Resistenzentwicklungen, allerdings liegen keine Daten zum langfristigen Verlauf vor. Eine Re-Therapie sollte nur mit Entecavir (unter Beachtung der Resistenzproblematik) oder Tenofovir (TDF oder TAF) erfolgen.
Interessant ist, dass nach Beendigung einer NA-Therapie eine relativ hohe Rate an $\mathrm{HBsAg-Verlust} \mathrm{in} \mathrm{der} \mathrm{Langzeitbeobachtung}$ festgestellt wurde. In europäischen Studien lag der HBsAg-Verlust bei 19-39\% (Evidenz 2b) [181, 186-188]. In der bis zu diesem Zeitpunkt größten randomisierten STOP-NUC-Studie, die in Deutschland durchgeführt wurde, lag die HBsAg-Verlustrate 2 Jahre nach Therapieende bei $10 \%$ und bei den Patienten mit einem HBsAg-Wert < $1000 \mathrm{IE} / \mathrm{ml}$ zum Zeitpunkt des Therapieabbruchs bei $28 \%$. Kein Patient, der die NA-Therapie fortführte, hat in dieser Zeit einen HBsAg-Verlust erreicht [189].

Die durch den HBV-DNA-Rückfall ausgelösten ALT-Flares können möglicherweise ein Indiz für eine induzierte Immunantwort sein und die ungewöhnlich hohe Rate an HBsAg-Verlusten nach Therapiestopp erklären [186, 190, 191]. Weitere Studien sind allerdings notwendig, um dieses Konzept als Behandlungsstrategie zu empfehlen.

\subsection{Wie sollen HBV-Patienten mit Leberzirrhose antiviral behandelt werden?}

\section{EMPFEHLUNG 3.9.1}

Alle Patienten mit Leberzirrhose und nachweisbarer HBV-DNA sollen antiviral behandelt werden [1, A].

Konsens: $100 \%$ (Delphi-Runde)

Geprüft 2020

NKLM

\section{Kommentar:}

Eine antivirale Therapie bei Patienten mit Leberzirrhose verringert das Risiko einer Dekompensation und für die Entstehung eines hepatozellulären Karzinoms (Evidenz 1a) [76].

Gelingt es, mit einer antiviralen Therapie die Virusreplikation dauerhaft zu supprimieren, ist das Überleben von Patienten mit Leberzirrhose verbessert (Evidenz 2a) [76].

Eine retrospektive Studie hat Patienten mit Zirrhose und einer nachweisbaren HBV-DNA < $2000 \mathrm{lU} / \mathrm{ml}$ mit und ohne Therapie analysiert und zeigte ein geringeres HCC-Risiko bei Patienten mit Therapie. Allerdings hatten die therapierten Patienten andere Eigenschaften und höhere HBV-DNA-Werte als die nicht behandelten Patienten (Evidenz 3b) [73].

Patienten mit Leberzirrhose, die nach 11-32 Monaten Therapie mit ETV weiterhin eine HBV-DNA > $80 \mathrm{IU} / \mathrm{ml}$ aufwiesen, hatten im weiteren Verlauf ein höheres Risiko für die Entwicklung eines HCC, Dekompensation oder Tod (Evidenz 3b) [74].

Bei Patienten mit dekompensierter Zirrhose war eine nachweisbare HBV-DNA (> $20 \mathrm{lU} / \mathrm{ml}$ ) nach einem Jahr Therapie mit ETV mit einem höheren HCC-Risiko verbunden. Eine „low level viremia“ (> 12, aber <2000 IU/ml) während einer Therapie mit Entecavir über 1-8,7 Jahre war in einer großen asiatischen Studie auch bei Patienten mit kompensierter Leberzirrhose mit einem höheren HCC-Risiko assoziiert (Evidenz 2b) [72, 107].

Auf der Basis dieser Daten empfehlen auch die EASL- und die AASLD-Leitlinien, dass Patienten mit Leberzirrhose bei positiver HBV-DNA, unabhängig von einem Grenzwert und unabhängig von der ALT, antiviral behandelt werden sollen, wobei die AASLD- 
Leitlinien einen höheren Empfehlungsgrad bei Patienten mit dekompensierter Lebverzirrhose aussprechen (siehe 2.2.2) [6-8].

\section{EMPFEHLUNG 3.9.2}

Als Nukleosid- oder Nukleotidanaloga sollen Entecavir oder Tenofovir (TDF oder TAF) eingesetzt werden [1, A*]. Bei der Auswahl der Nukleosid- oder Nukleotidanaloga sollen Vortherapien und Komorbidität (MELD-Score, Niereninsuffizienz, Osteopenie, Osteoporose) berücksichtigt werden [EK].

Eine PEG-IFN-Therapie kann bei Patienten mit Child-A-Zirrhose eingesetzt werden [EK]. Bei dekompensierter Zirrhose (Child-Pugh B und C) sollen Nukleosid- oder Nukleotidanaloga eingesetzt werden $\left[1, A^{* *}\right]$. (PEG-)Interferon alfa ist kontraindiziert [Statement].

Konsens: 97,9\% (Delphi-Runde)

* Neu 2020; Leitlinienadaption AASLD Practice Guideline HBV 2016.

** Geprüft 2020.

\section{Kommentar:}

Bei Patienten mit Leberzirrhose war das Auftreten einer antiviralen Resistenz gegen die NA-Therapie in einer asiatischen Studie mit einer höheren Rate klinischer Komplikationen (Evidenz 1b) und in einer italienischen Studie mit einem verminderten Gesamtüberleben assoziiert (Evidenz 2b) (keine Änderung zu [5]).

Daher soll gemäß intrenationalen Leitlinien das Risiko einer Resistenz durch die primäre Auswahl einer Substanz mit einer hohen Resistenzbarriere minimiert werden. [7] Die Auswahl von ETV, TDF oder TAF richtet sich nach Vortherapien und Komorbidität wie unter 3.2 .2 beschrieben.

Die Therapie mit PEG-IFN ist bei Patienten mit F4-6-Fibrose (fortgeschrittene Fibrose und kompensierte Leberzirrhose) möglich und nicht weniger effektiv als bei Patienten ohne fortgeschrittene Fibrose. Eine europäische Studie hatte sogar eine etwas bessere Ansprechrate bei HBeAg-positiven Patienten beobachtet (Evidenz 2b) [192, 193].

Bei Patienten mit dekompensierter Leberzirrhose im Stadium Child-Pugh B und $C$ kann die Behandlung mit Interferon alfa zu einer weiteren Verschlechterung der Leberfunktion führen (keine Änderung zu [5]).

Der Nutzen der Therapie mit NA bei Patienten mit dekompensierter Leberzirrhose ist unter 3.2.2 beschrieben.

\subsection{Wie sollen Patienten mit extrahepatischen Manifestationen behandelt werden?}

\section{EMPFEHLUNG 3.10.1}

Patienten mit extrahepatischen Manifestationen einer Hepatitis-B-Virusinfektion sollten mit Nukleosid- oder Nukleotidanaloga behandelt werden [4, B].

Konsens: $100 \%$ (Delphi-Runde)

Geprüft 2020

\section{Kommentar:}

Kontrollierte Studien zur Therapie von extrahepatischen Manifestationen einer Hepatitis-B-Virusinfektion sind nicht durchgeführt worden. Es gibt allerdings zahlreiche Fallberichte, die eine Besserung der Symptomatik durch eine erfolgreiche Therapie beschrieben haben (Evidenz 4) (keine Änderung zu [5]).

Da IFN bzw. PEG-IFN potenziell Autoimmunerkrankungen auch verschlechtern kann, wird primär der Einsatz von Nukleosidanaloga oder Nukleotidanaloga (NA) empfohlen (Evidenz 4) (keine Änderung zu [5]).

\section{EMPFEHLUNG 3.10.2}

Die Therapie sollte in diesem Fall mindestens bis 12 Monate nach Abklingen der Symptome fortgesetzt werden [4, B]. Generell sollen die Regeln zur Therapiebeendigung wie unter 3.8 angewendet werden.

Konsens: $100 \%$ (Konsensuskonferenz)

Geprüft 2020

Kommentar:

Die Behandlungsdauer mit NA ist nicht in klinischen Studien untersucht worden. Aufgrund von Erfahrungen der Experten wird aber eine Fortsetzung der Behandlung für mindestens 12 Monate nach Abklingen der Symptome empfohlen, wobei vielfach eine Dauertherapie notwendig ist (Evidenz 4) (keine Änderung zu [5]).

\subsection{Wie sollen Patienten mit eingeschränkter Nierenfunk-} tion und Dialysepatienten behandelt werden?

\section{EMPFEHLUNG 3.11.1}

Eine Therapie einer chronischen Hepatitis-B-Virusinfektion mit pegyliertem Interferon alfa bei Hämodialysepatienten soll aufgrund der erhöhten Nebenwirkungsrate und der geringen Studiendaten und verfügbarer Alternativen nicht erfolgen [EK].

Konsens: $100 \%$ (Delphi-Runde)

Modifiziert 2020

\section{Kommentar:}

Eine Therapie mit PEG-IFNa-2a ist prinzipiell möglich bei Patienten mit Niereninsuffizienz oder Dialyse. Allerdings liegen hier nur wenige Daten insbesondere bei Patienten mit chronischer Hepatitis C vor, und die Therapie war in diesen meist multimorbiden Kollektiven mit deutlich mehr Nebenwirkungen verbunden (Evidenz 4) [194, 195]. 
EMPFEHLUNG 3.11.2

Aufgrund der häufigen Komorbiditäten von Dialysepatienten soll eine antivirale Therapie mit Nukleosid- oder Nukleotidanaloga bevorzugt werden [3, A]. Bei allen NA soll konsequent die Dosisanpassung an die Nierenfunktion beachtet werden [3, A].

Konsens: $100 \%$ (Delphi-Runde)

Geprüft 2020

\section{Kommentar:}

Bisher liegen keine größeren kontrollierten Studien zur Therapie der chronischen HBV-Infektion mit NA bei Patienten mit Niereninsuffizienz oder Dialysepatienten vor. Alle NA werden renal eliminiert. Dennoch ist ein Einsatz bei Patienten mit eingeschränkter Nierenfunktion entsprechend den jeweils angegebenen Dosisanpassungen als sicher einzustufen (Evidenz 3a) [138, 196].

Eine Therapie mit Adefovir führte in einigen Studien zu einem Abfall der GFR und zu proximaler tubulärer Dysfunktion, die eine Hypophosphatämie zur Folge hatte (Evidenz 3b) [141].

Ebenso wurden Fälle von Osteomalazie beschrieben (vermehrt bei der höheren Dosis von $30 \mathrm{mg}$ ). Wie unter 3.2.3 empfohlen, soll Adefovir überhaupt nicht mehr zur Therapie der chronischen Hepatitis B eingesetzt werden, da Alternativen verfügbar sind.

Auch die Behandlung mit Tenofovir (TDF) war in einigen Kohorten mit einem Abfall der GFR assoziiert, und einige Fälle von Fanconi-Syndromen wurden beschrieben (siehe 3.7). Meist wurden die schweren renalen Nebenwirkungen bei HIV-koinfizierten Patienten beschrieben. Ein möglicher Grund können Komorbidität und Komedikation in diesen Kohorten sein, die möglichweise zu erhöhten TDF-Wirkstoffspiegeln geführt haben. In größeren Real-World-Kohorten waren die renalen Nebenwirkungen von TDF jedoch gering (auch bei HIV-Kohorten). Aufgrund von Alternativen sollte TDF aber bei Patienten mit bereits bestehender Niereninsuffizienz (GFR $<60 \mathrm{ml} / \mathrm{min}$ ) oder Hypophosphatämie $<2 \mathrm{mg} / \mathrm{dl}$ nicht mehr eingesetzt werden. Mit Tenofovir Alafenamid (TAF) steht seit 2017 eine Alternative zur Verfügung, wenn Lamivudin, Telbivudin, Entecavir aufgrund der Resistenzlage nicht möglich sind. In den Phase-III-Zulassungsstudien kam es zu keiner Verschlechterung der GFR während 96 Wochen TAF-Therapie, während die GFR mit TDF leicht, aber signifikant stärker abgefallen war (Evidenz 1b) [135]. Es gibt Daten (v. a. aus der HIV-Behandlung), die die Sicherheit bei Patienten mit Niereninsuffizienz belegen. Eine Dosisanpassung ist erst bei einer GFR $<15 \mathrm{ml} / \mathrm{min}$ erforderlich ( $\triangleright$ Tab. 12).

Entecavir führt nicht oder nur minimal zu einer Reduktion der GFR. Eine Dosisreduktion sollte bei einer GFR $<50 \mathrm{ml} / \mathrm{min}$ vorgenommen werden. Es gibt keine Daten, ob die auch bei einer GFR $<50 \mathrm{ml} / \mathrm{min}$ weiterhin empfohlene doppelte ETV-Dosis bei Lamivudin-Resistenz ( $\triangleright$ Tab.12) zu vermehrten Nebenwirkungen führt.

Für Lamivudin liegen die längsten Erfahrungen bei Patienten mit Niereninsuffizienz vor. Wie unter 3.3.2 diskutiert, sollte Lami- vudin aufgrund der Resistenzentwicklung nicht mehr oder nur noch bei sehr niedriger Ausgangsviruslast eingesetzt werden.

Prinzipiell gilt die gleiche Empfehlung für Telbivudin. Allerdings ist Telbivudin die einzige Substanz, die zu einer Verbesserung der GFR (nach Cockroft-Gault) während der Therapie geführt hat [139, 140] (siehe auch 3.2.2). Der Mechanismus der potenziell nephroprotektiven Wirkung und der klinische Nutzen sind bislang unklar. Daher kann Telbivudin bei Niereninsuffizienz nicht generell als Therapiekonzept empfohlen werden.

Anmerkung: Telbivudin ist mittlerweile in Deutschland vom Markt genommen und daher nicht mehr in $>$ Tab. 12 aufgeführt.

\subsection{Welche Behandlungsempfehlungen werden für schwangere HBsAg-positive Patientinnen gegeben?}

\section{EMPFEHLUNG 3.12.1}

Bei HBsAg-positiven Patientinnen soll eine regelmäßige (mindestens alle 3 Monate) Bestimmung von ALT und HBV-DNA während der Schwangerschaft und mindestens bis 6 Monate nach Entbindung durchgeführt werden [3, A]

Konsens: 97,9\% (Delphi-Runde)

Geprüft 2020

NKLM

\section{Kommentar:}

In seltenen Fällen sind Aktivierungen der Hepatitis B während einer Schwangerschaft beschrieben worden, die in einzelnen Fällen zum akuten Leberversagen führten (Evidenz 3b) (keine Änderung zu [5]).

In der überwiegenden Mehrzahl der Fälle normalisieren sich hingegen die Transaminasen während einer Schwangerschaft (Evidenz 3a) (keine Änderung zu [5]).

Allerdings sind Schübe der Hepatitis in den ersten 3-6 Monaten nach der Entbindung nicht ungewöhnlich (Evdienz 3b) (keine Änderung zu [5]).

Eine neuere Studie hat festgestellt, dass die ALT-Flares postpartum mit der Höhe der HBV-DNA zu Beginn der Schwangerschaft korrelieren (Evidenz 2b) [197].

\section{EMPFEHLUNG 3.12.2}

Sollte eine Patientin während einer antiviralen Therapie schwanger werden, soll die Behandlungsindikation überprüft werden [1, A]. Eine bestehende Therapie mit Lamivudin (LAM), Telbivudin (TVD) oder Tenofovir (TDF) kann fortgesetzt werden [0, 2]. Eine bestehende Therapie mit pegyliertem Interferon alfa soll abgesetzt bzw. umgestellt werden [1, A]. Eine bestehende Therapie mit Entecavir oder Adefovir soll umgestellt werden [EK*]. Eine Umstellung sollte auf Tenofovir (TDF) erfolgen [EK ${ }^{*}$.

Konsens: $100 \%$ (Delphi-Runde)

Geprüft 2020

* Modifiziert 2020. 


\section{Kommentar:}

Bei der Abwägung von Nutzen und Risiken einer antiviralen Therapie während der Schwangerschaft sind potenzielle Gefährdungen für das Neugeborene und mögliche Risiken für die schwangere Patientin zu unterscheiden. In jedem Fall ist bei bereits bekannter oder neu diagnostizierter Hepatitis-B-Virusinfektion die Behandlungsindikation für die Schwangere zu überprüfen.

Lamivudin, Entecavir und Adefovir sind als sog. „C“-Drugs von der FDA klassifiziert, in Deutschland wird eine strenge Indikation zum Einsatz in der Schwangerschaft der Gruppe 6 angegeben. Demgegenüber werden Tenofovir und Telbivudin als „B“-Drug bzw. „Gruppe-4-Medikament“ klassifiziert. Die Klassifizierung als „B-Substanz/Klasse-4-Medikament“ bedeutet, dass sich aus Tierversuchen keine Hinweise auf eine Beeinträchtigung des Fötus ableiten ließen, ohne dass jedoch geeignete, kontrollierte Studien beim Menschen vorliegen. Die Klassifizierung als „C-Substanz/ Klasse-6-Medikament" bedeutet, dass sich in Tierversuchen Nebenwirkungen gezeigt haben. Ausreichende klinische Daten aus klinischen Studien und großen Schwangerschaftsregistern liegen bisher für Lamivudin, Telbivudin und Tenofovir (TDF) vor. Hierbei zeigte sich für diese Substanzen kein erhöhtes Risiko für fötale Missbildungen, auch wenn die Substanzen bereits im ersten Trimenon eingesetzt wurden (Evidenz 2a) [19, 20, 198].

Für TAF ist die Datenlage bislang noch unzureichend [199].

Bestehende Therapien mit Lamivudin, Telbivudin oder Tenofovir (TDF) brauchen bei eindeutiger Therapieindikation (fortgeschrittene Fibrose oder Zirrhose) nicht unterbrochen zu werden, da das potenzielle Risiko für den Fötus durch die Medikamentengabe nicht im Verhältnis zu dem Risiko eines Hepatitis-Flares nach Absetzen einer antiviralen Therapie steht. Therapien mit Adefovir und Entecavir sollten auf Tenofovir (TDF) umgestellt werden.

\section{EMPFEHLUNG 3.12.3}

Wurde bisher keine antivirale Therapie durchgeführt, soll eine Therapie während der Schwangerschaft angeboten werden bei:

a) aktiver Hepatitis, gemäß den Empfehlungen für nicht schwangere Frauen [EK],

b) Vorliegen einer HBV-DNA-Konzentration $>200000 \mathrm{IU} / \mathrm{ml}$, um das Risiko einer vertikalen Transmission (Mutter-KindÜbertragung) zu reduzieren $\left[1, A^{*}\right]$.

Konsens: 77,4\%* (Konsensuskonferenz) Modifiziert 2020

Evidenztabelle siehe Leitlinienreport Anhang III

NKLM

Klug Entscheiden

Die Gegenstimmen kritisierten die Formulierung „soll eine Therapie während der Schwangerschaft angeboten werden“. Die Formulierung wurde als zu schwach interpretiert. Die Formulierung „soll eine Therapie während der Schwangerschaft durchgeführt werden " wurde vorgeschlagen. Die Formulierung „angeboten werden“ wurde mehrheitlich beschlossen und soll auf die besondere Aufklärungspflicht einer medikamentösen Therapie bei Schwangeren hinweisen.

\section{Kommentar:}

Eine vertikale HBV-Transmission (Mutter-Kind-Übertragung) ist trotz adäquat durchgeführter aktiv-passiver Simultanimpfung des Neugeborenen (siehe 5.9) bei hochvirämischen Müttern möglich. In verschiedenen Kohorten betrug das Übertragungsrisiko bei Müttern mit einer HBV-Viruslast $>10^{7}-10^{8} \mathrm{IU} / \mathrm{ml}$ bis zu $32 \%$ (Evidenz 2b) (keine Änderung zu [5]).

Durch eine Reduktion der Viruslast $(<200000 \mathrm{IU} / \mathrm{ml})$ mittels antiviraler Therapie lässt sich dieses Risiko reduzieren (Evidenz 1a) $[19,20,22,25]$.

Bislang gibt es keine Evidenz, dass bei einer HBV-DNA $<200000 \mathrm{IU} / \mathrm{ml}$ eine vertikale Transmission auftritt (Evidenz 2a) [19].

Daher sollte bei einer HBV-DNA < $200000 \mathrm{IU} / \mathrm{ml}$ auch keine antivirale Therapie mit dem Ziel der perinatalen Transmissionsverhinderung begonnen werden [7].

Eine placebokontrollierte Studie mit jeweils 147 Patienten in jeder Gruppe (Placebo versus Tenofovir (TDF)) zeigte allerdings keinen signifikanten Unterschied bzgl. des Transmissionsrisikos. Allerdings ist bei keiner der mit Tenofovir (TDF) behandelten Mütter eine Infektion des Kindes aufgetreten. Alle (drei) Mutterzu-Kind-Übertragungen traten in der Placebogruppe auf [24].

Kontrovers ist die Antwort auf die Frage, ob eine Sectio das Risiko einer vertikalen Transmission reduzieren kann. Ein systematisches Review von 30 Datensätzen (9906 Fälle), mit allerdings sehr heterogener Datenlage, kam zum Schluss, dass das relative Risiko für die Entwicklung einer HBV-Infektion nach (elektiver) Sectio gegenüber einer vaginalen Geburt verringert ist (OR 0,51) (Evidenz 3a) [200].

Ein anderes systemisches Review (18 Studien, 11446 Fälle) konnte die Ergebnisse nicht bestätigen, wobei die Autoren darauf hinweisen, dass bei einer hohen HBV-DNA (> $200000 \mathrm{IU} / \mathrm{ml}$ ) die Ergebnisse vorsichtig zu interpretieren sind (Evidenz 3a) [201].

In der Tat deutet eine Studie mit 1409 Fällen darauf hin, dass die Sectio bei einer HBV-DNA > $200000 \mathrm{IU} / \mathrm{ml}$ einen Nutzen hat (Evidenz 3b) [202].

Die analysierten Studien waren meist aus China. Der Zeitpunkt der aktiven und passiven Impfung des Neugeborenen nach der Geburt spielt hier eine wichtige Rolle (optimal innerhalb der ersten 4-6 Stunden, siehe 5.9). Inwiefern die Ergebnisse daher auf Deutschland übertragen werden können, ist unklar.

Eine generelle Empfehlung zur Sectio kann daher nicht gegeben werden. Sollte die HBV-DNA zum Zeitpunkt der Geburt $>200000 \mathrm{IU} / \mathrm{ml}$ liegen, kann eine Sectio mit der Schwangeren (Nutzen/Risikoabwägung) besprochen werden.

\section{EMPFEHLUNG 3.12.4}

Eine Therapie zur Verhinderung der Mutter-Kind-Übertragung sollte möglichst früh, idealerweise vor der 32. Schwangerschaftswoche, aber nach dem 1 . Trimenon begonnen werden $\left[2, B^{*}\right]$.

Die Nukleos(t)idanaloga, die bei Schwangeren untersucht wurden, sind Lamivudin, Telbivudin und Tenofovir (TDF). Tenofovir (TDF) sollte bevorzugt eingesetzt werden [1b, $\mathrm{B}^{*}$ ]. 
Die Schwangere soll über die Vorteile und möglichen Risiken der NA-Therapie aufgeklärt werden [EK].

Konsens: $100 \%$ (2. Delphi-Runde)

Modifiziert 2020

* Evidenztabelle siehe Leitlinienreport Anhang III

\section{Kommentar:}

Wird eine Therapie nur zur Reduzierung des vertikalen Transmissionsrisikos durchgeführt, kann die Therapie prinzipiell in allen Phasen der Schwangerschaft (auch im 1. Trimenon) begonnen werden (Evidenz 2a) [19].

In den meisten Studien wurde die Therapie allerdings in der 28.-32. Schwangerschaftswoche gestartet (Evidenz 1b/2a) [19, $20,22,25]$.

In der Studie von Pan et al., wurde die Therapie in der 30.32. Woche begonnen; bei 31 von 97 behandelten Müttern war die HBV-DNA bei Geburt noch $\geq 200000 \mathrm{IU} / \mathrm{ml}$ und es gab 5 Fälle von HBV-Mutter-auf-Kind-Übertragungen. [22] Daher ist ein Beginn zwischen 1. Trimenon und 28. Schwangerschaftswoche ideal, wie in der WHO-Leitlinie empfohlen ist [23].

In Deutschland erfolgt gemäß den Mutterschaftsrichtlinien das Screening auf HBsAg allerdings erst nach der 32. Schwangerschaftswoche (https://www.g-ba.de/downloads/62-492-2130/ Mu-RL_2020-02-20_iK_2020-04-28.pdf), sodass eine Therapie erst frühestens nach diesem Zeitpunkt aufgenommen werden könnte. Der Erfolg einer späten Therapieeinleitung (Reduktion der HBV-DNA auf < $200000 \mathrm{IU} / \mathrm{ml}$ bis zur Geburt), insbesondere bei Patienten mit hoher Virämie, ist allerdings nicht bekannt. Daher sollte unbedingt die Mutterschaftsrichtlinie geändert werden. Die Untersuchung auf HBsAg sollte möglichst in der 12. Schwangerschaftswoche oder vorher erfolgen.

Real-World-Daten bestätigen den Erfolg und die Sicherheit von Tenofovir (TDF) zur Verhinderung der vertikalen Transmission [203].

Die Dauer der Therapie bei Schwangeren bzw. nach der Geburt ist bislang nicht gut definiert. Eine klare Empfehlung zur Therapiedauer kann nicht ausgesprochen werden. Die begonnene Therapie kann fortgeführt und entsprechend den Empfehlungen 3.8 beendet werden. Eine Beendigung kurz nach der Geburt kann ebenso erfolgen, wenn engmaschige Kontrollen gewährleistet sind. Das wird z. B. von der „Chinese Medical Association“ empfohlen [204].

In den Studien wurde die Therapie meist bis 4-12 Wochen post partum fortgeführt. Nach Abbruch der Therapie kam es in einigen Fällen zu ALT-Flares. Die Rate der Flares war etwas höher in den Behandlungsgruppen als in den unbehandelten Kontrollen. Die Flares waren meist mild und haben nicht zu einer fulminanten Hepatitis geführt (Evidenz 2a) [19, 20, 205].

Ein Argument für einen schnellen Abbruch der Therapie nach der Schwangerschaft kann die zuvor fehlende medizinische Indikation sein oder die Sorge der Mutter, dass beim Stillen potenziell für das Kind toxische Medikamente übertragen werden.

\section{EMPFEHLUNG 3.12.5}

Während der antiviralen Therapie mit den empfohlenen Nukleos(t)idanaloga kann das Kind gestillt werden [EK]. Die Mutter soll über die bislang wenig bekannten Risiken einer geringen Nukleos(t)idanaloga-Exposition der Kinder aufgeklärt werden [EK].

Konsens: 95,7\% (Delphi-Runde

Neu 2020

\section{Kommentar:}

Die Konzentrationen von Lamivudin oder Tenofovir (TDF) scheinen in der Muttermilch sehr gering zu sein. Die TDF-Exposition des Kindes beim Stillen wird im Vergleich zur Exposition in utero als niedriger erachtet (Evidenz 4) [206, 207].

Es gibt mittlerweile Daten zum Einsatz von TDF als HIV-Therapie bzw. Präexpositionsprophylaxe bei stillenden Frauen. Bislang gibt es keine Sicherheitsbedenken (Evidenz 3a) [208, 209].

Aufgrund der Datenlage sollte im Fall einer Fortführung der TDF-Therapie nicht vom Stillen abgeraten werden.

Sollte die Therapie direkt nach der Geburt dennoch abgesetzt werden, besteht vermutlich kein erhöhtes Risiko der Übertragung des HBV auf das Neugeborene durch das Stillen, sofern die Simultanimpfung des Neugeborenen lege artis (siehe 5.9) erfolgt ist. [203]

Unterstützt werden diese Daten durch die Ergebnisse eines systematischen Reviews. Die Auswertung von 10 Studien konnte bei direkt nach der Geburt geimpften Kindern keine Unterschiede hinsichtlich des HBsAg-Status der Kinder von HBsAg-positiven Müttern feststellen, unabhängig davon, ob sie gestillt wurden oder nicht. Die Autoren geben aber den Hinweis, dass das Stillen bei blutigen Verletzungen der Brustwarze pausiert werden sollte (Evidenz 3a) [210].

3.13 Wie kann eine Hepatitis-B-Reaktivierung unter Immunsuppression verhindert werden?

\section{EMPFEHLUNG 3.13.1}

Bei malignen Grunderkrankungen mit geplanter Chemotherapie oder vor Beginn einer immunsuppressiven Therapie sollen $\mathrm{HBsAg}$ und Anti-HBc bestimmt werden $[1, \mathrm{~A}]$.

Konsens: $100 \%$ (Delphi-Runde)

Modifiziert 2020

Leitlinienadaption EASL Clinical Practice Guideline HBV 2017

NKLM

Klug Entscheiden

\section{Kommentar:}

Die Reaktivierung einer HBV-Infektion ist eine potenziell lebensbedrohliche Komplikation einer Chemotherapie oder einer immunsuppressiven Therapie. Die Inzidenz einer Hepatitis-B-Reaktivierung während bzw. nach Chemotherapie beträgt bei 
HBsAg-positiven Trägern 15-50\% (Evidenz 2b), nach Knochenmarktransplantation über $75 \%$, wobei auch fulminante Verläufe und Todesfälle beschrieben wurden (Evidenz 3b) (keine Änderung zu [5]).

Bei HBsAg-negativen/Anti-HBc-positiven Patienten ist die Reaktivierung insgesamt seltener, jedoch kann in bestimmten Situationen das Reaktivierungsrisiko über $10 \%$ betragen (Evidenz 2a) (Evidenz 3b) (keine Änderung zu [5]).

Daher sollen alle Patienten, die eine immunsuppressive Therapie erhalten sollen, auf Anti-HBc und $\mathrm{HBsAg}$ getestet werden, idealerweise wird auch Anti-HBs bestimmt. Das entspricht internationalen Leitlinienempfehlungen. [6, 86, 87].

Bei Anti-HBc-positiven Patienten (unabhängig vom HBsAg-Status) sollte zusätzlich die HBV-DNA bestimmt werden, um eine okkulte HBV-Infektion auszuschließen (keine Änderung zu [5]).

\section{EMPFEHLUNG 3.13.2}

Die Einschätzung über die Notwendigkeit einer antiviralen Therapie zur Prophylaxe einer HBV-Reaktivierung soll abhängig von der vorliegenden Serologie $(\mathrm{HBsAg}+/ \mathrm{Anti}-\mathrm{HBc}+$ oder $\mathrm{HBsAg}-/ \mathrm{Anti}-\mathrm{HBC}+$ ) und der geplanten medikamentösen Therapie (Risikollasse) erfolgen ( $\bullet$ Abb. $\mathbf{3}$ )

- HBsAg+-Patienten mit hohem Risiko (Reaktivierungsrate $>10 \%$ ) sollen mit Nukleos(t)idanaloga antiviral behandelt werden $[1, A]$, Patienten mit moderatem Risiko (Reaktivierungsrate $1-10 \%$ ) sollten behandelt werden [2, B]; HBsAg+-Patienten mit niedrigem Risiko (<1\%) sollen mindestens alle 8 Wochen kontrolliert werden [1, A] und können ggfs. auch prophylaktisch antiviral behandelt werden $[0,3]$.

- HBsAg- und Anti-HBc+-Patienten sollten bei geplanter B-Zell depletierender Immunsuppression oder Stammzell-/ Knochenmarktransplantation antiviral behandelt werden [2, B]; bei Immunsuppression mit moderatem oder niedrigem Reaktivierungsrisiko sollen engmaschige Kontrollen erfolgen [2, A], oder es kann eine prophylaktische antivirale Therapie eingesetzt werden [0, 3].

- HBsAg- und Anti-HBc+-Patienten mit geplanter lokaler HCC-Therapie (TACE, perkutan/lokal ablative Verfahren, Resektion) sollten antiviral zur Prophylaxe einer HBV-Reaktivierung behandelt werden [2, B].

Konsens: 95,7\% (Delphi-Runde)

Modifiziert 2020

Leitlinienadaption EASL Clinical Practice Guideline HBV 2017

\section{Kommentar:}

Das Risiko einer HBV-Reaktivierung hängt vom serologischen Status des Patienten und von der eingesetzten immunsuppressiven Therapie ab und kann grob in hohes (>10\%), moderates (1-10\%) oder niedriges Risiko (<1\%) eingeteilt werden [86, 171].

Prinzipiell gilt, dass HBsAg-positive Patienten ein erheblich höheres Reaktivierungsrisiko verglichen mit HBsAg-negativen/AntiHBc-positiven Patienten aufweisen (keine Änderung zu [5]).
Selbstverständlich ist, dass neben dieser groben Einordnung auch individuelle Faktoren (Alter, Art der Grunderkrankung bzw. des Tumors, Komorbiditäten, Kombination von Immunsuppressiva, Dauer der Immunsuppression, eventuelle begleitende Lebererkrankung etc.) in der Risikoabschätzung berücksichtigt werden müssen.

Zur Einschätzung des Reaktivierungsrisikos in Abhängigkeit vom serologischen Status des Patienten und der Stärke der immunsuppressiven Therapie gibt es zahlreiche systematische Übersichtsarbeiten und Metaanalysen (Evidenz 1a) [171, 211-213].

Diese Übersichtsarbeiten bilden die Grundlage der in $\mathbf{A b b .} \mathbf{3}$ dargestellten Risikoklassen und werden in ähnlicher Form auch in internationalen Leitlinienempfehlungen verwendet [86, 214].

Dennoch muss darauf hingewiesen werden, dass für viele der teils neueren immunmodulierenden Therapien (z. B. Vedolizumab, Natalizumab, Nivolumab) teils noch sehr wenig Evidenz für das tatsächliche Reaktivierungsrisiko vorliegt. In anderen Fällen gibt es Hinweise, dass das tatsächliche Reaktivierungsrisiko in der Vergangenheit überschätzt wurde. Aus einer großen prospektiv beobachteten Real-World-Kohorte von Patienten mit rheumatologischen Erkrankungen und langfristiger Biologika-Therapie wird berichtet, dass bei $179 \mathrm{HBsAg} /$ Anti-HBc+-Patienten trotz verschiedener immunsuppressiver Substanzen (u. a. 146 Patienten erhielten Anti-TNF-Therapie) keine einzige HBV-Reaktivierung aufgetreten ist (Evidenz 3b) [215].

Im Fall von Methotrexat stuft eine hämatologisch-infektiologische Leitlinie das Reaktivierungsrisiko als „moderat“ ein, basierend auf einer einzelnen retrospektiven Arbeit mit bis zu $5 \%$ Reaktivierungen unter Methotrexat bei HBsAg-positiven Patienten [214].

Eine Metaanalyse ordnet Methotrexat allerdings recht klar der „niedrigen“ Risikostufe zu (Evidenz 2a) [171].

Schwierigkeiten bereitet auch die korrekte Zuordnung des Reaktivierungsrisikos für moderne personalisierte Krebstherapien. Eine Übersichtsarbeit konnte trotz Analyse aller verfügbaren Studien neuere Substanzen wie mTOR-Inhibitoren oder Multikinase-Inhibitoren nicht evidenzbasiert einordnen (Evidenz 2a) [213].

Für sehr neue Substanzklassen wie JAK1/2-Inhibitoren (Ruxolitinib) liegen bislang nur Einzelfallberichte vor (Evidenz 4) [216, 217].

Daher erscheint es aus Sicherheitsgründen sinnvoll, diese Substanzen zunächst als „mittlere Risikosubstanz“ sowohl für HBsAg +- als auch HBsAg-/Anti-HBc+-Patienten einzuordnen.

Das höchste Reaktivierungsrisiko besteht für HBsAg+- oder HBsAg-/Anti-HBc+-Patienten, die eine B-Zell depletierende Therapie (z. B. Rituximab) oder eine Knochenmark- bzw. Stammzelltransplantation erhalten (Evidenz 2a) (keine Änderung zu [5]).

In diesen Situationen soll vor Einleitung der Immunsuppression eine antivirale Therapie begonnen werden, weil dadurch effektiv patientenrelevante Endpunkte (Hepatitis, Dekompensation, Unterbrechung der Chemotherapie, Todesfälle) verhindert werden können (Evidenz 1a) (keine Änderung zu [5]).

Das entspricht auch den Empfehlungen internationaler Leitlinien $[6,86]$.

Für die neuen Immuncheckpointinhibitor(ICI)-Therapien (z. B. Nivolumab, Pembrolizumab, Atezolizumab, Ipilimumab u. a.) gibt es bislang nur Einzelfallberichte. Hier gibt es in einstelliger Patien- 


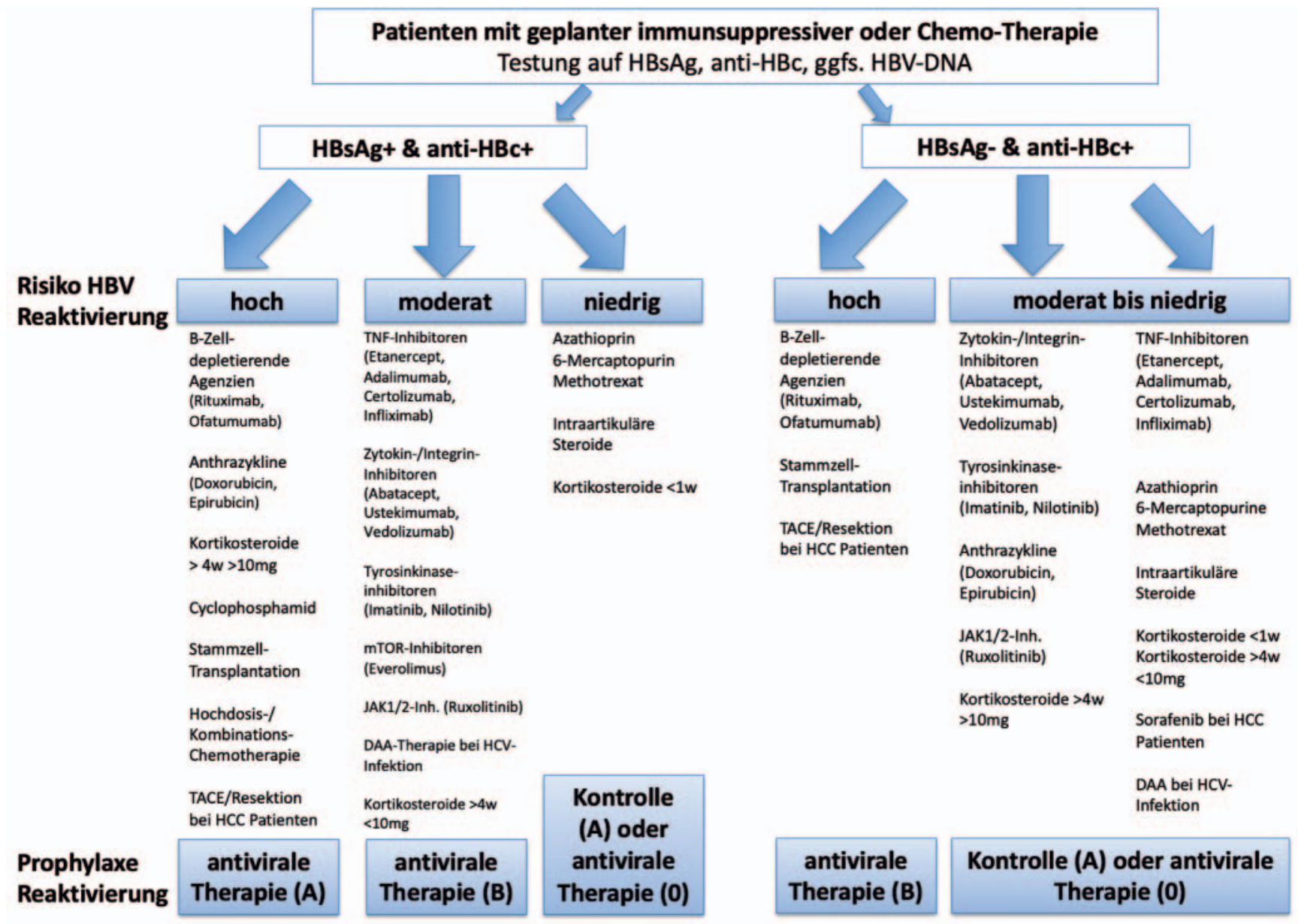

- Abb.3 Algorithmus zur Prävention der Hepatitis-B-Reaktivierung. Sonderfall HBV/HCV-koinfizierte Patienten (siehe auch AG6). Bei HBV/HCVkoinfizierten Patienten besteht das Risiko einer HBV-Reaktivierung nach erfolgreicher Behandlung der HCV-Infektion (siehe 6.2.2 und 6.2.3). [rerif]

tenzahl Berichte über Fälle von HBV-Reaktivierungen, aber auch von HBV-Suppression unter dieser Immuntherapie. [218-221] Es wird sogar überlegt, die Immuncheckpointinhibitoren in Zukunft zur Behandlung der chronischen Hepatitis B einzusetzen bzw. mit anderen neuen Medikamenten zu kombinieren, um Hepatitis-Bspezifische Immunantworten zu verbessern und somit die HBsAg-Verlustraten zu erhöhen [100, 221].

Eine prophylaktische HBV-Therapie sollte analog auch bei HBsAg-positiven Patienten mit moderatem Reaktivierungsrisiko durchgeführt werden (siehe Abbildung) (Evidenz 2a).

In $\mathrm{HBsAg}$-/Anti-HBc+-Patienten ist das Reaktivierungsrisiko, abgesehen von den genannten Hochrisikosituationen (B-Zell-Depletion, Stammzelltransplantation), sehr viel niedriger. Daher ist in diesen Konstellationen eine engmaschige Kontrolle ( $\mathrm{HBsAg}$, HBV-DNA und ALT alle 1-3 Monate) und „präemptive Therapie“, d. h. bei Auftreten von HBsAg oder HBV-DNA (vor Auftreten einer Hepatitis), gerechtfertigt (Evidenz 2a) (keine Änderung zu [5]).

In Sonderfällen, z. B. sehr langfristige Immunsuppression, unzureichende Adhärenz zur engmaschigen Kontrolle oder ungüns- tige Risikofaktoren (Alter, Tumorentität, begleitende Lebererkrankung o. Ä.), kann eine prophylaktische antivirale Therapie durchgeführt werden.

HCC-Therapie: Aktuelle lokale Therapiemodalitäten für das hepatozelluläre Karzinom (HCC) scheinen ein besonderes Risiko für HBV-Reaktivierungen darzustellen (Evidenz 2b). Retrospektive Analysen aus großen asiatischen Kohorten legen nahe, dass sowohl transarterielle Chemoembolisation (vor allem in Kombination mit Radiotherapie oder bei wiederholter Anwendung) als auch chirurgische Resektion ein erhebliches (> 10\%) Risiko für HBV-Reaktivierung haben, auch bei HBsAg-negativen (Anti-HBc-positiven) Patienten (Evidenz 2b). In diesen retrospektiven Analysen zeigten HCC-Patienten, die eine antivirale Therapie erhielten, weniger Reaktivierungen, weniger Dekompensationen und teilweise auch ein verbessertes Überleben (Evidenz 2b) [222-225]-

Daher ist bei Patienten mit (geplanter) ablativer HCC-Therapie (transarterielle Chemoembolisation, Radiofrequenzablation, Radiotherapie, Resektion) eine prophylaktische antivirale Therapie gerechtfertigt. 


\section{EMPFEHLUNG 3.13.3}

Zur Prophylaxe einer HBV-Reaktivierung sollten vorzugsweise hochpotente Nukleos(t)idanaloga (Entecavir oder Tenofovir (TAF oder TDF)) eingesetzt werden [EK]. Die antivirale Therapie sollte mindestens 6-12 Monate, bei B-Zell depletierenden Medikamenten mindestens 18 Monate nach Beendigung der immunsuppressiven Therapie fortgeführt werden [EK]. Konsens: 95,7\% (Delphi-Runde)

Neu 2020

\section{Kommentar:}

Prinzipiell ist eine prophylaktische antivirale Therapie auch mit Lamivudin möglich, wie es in vielen Kohorten erfolgreich beschrieben wurde (Evidenz 2a) [171, 211].

Allerdings ist aus der Primärtherapie mit Lamivudin bekannt, dass häufig Resistenzen auftreten, und zudem ist Lamivudin in Hochrisko-Reaktivierungssituationen Entecavir unterlegen (s. o., Evidenz 1b), sodass zur Prophylaxe der HBV-Reaktivierung eine hochpotente antivirale Substanz (Entecavir, Tenofovir) eingesetzt werden sollte. Ein systematisches Review kommt ebenso zu dem Ergebnis, dass Entevacir oder Tenofovir die effektivste Therapieoption zur Verhinderung der HBV-Reaktivierung darstellen [226, 227].

Auch bei HBsAg-/Anti-HBc+-Patienten gibt es Fallberichte von Lamivudin-Resistenzen, die zu einem Versagen der Therapie geführt haben (Evidenz 4) [228].

Daher sollte auch zur prophylaktischen und präemptiven Therapie ausschließlich Entecavir oder Tenofovir (TDF oder TAF) eingesetzt werden. Falls keine Therapie durchgeführt wird, sollen die Kontrollen der HBV-DNA alle 2-3 Monate erfolgen. Eine prospektive, randomisierte Studie zeigte, dass ein Kontrollintervall alle 8 Wochen alle HBV-Reaktivierungen bei HBsAg-negativen/Anti-HBc-positiven Patienten, die mit Rituximab behandelt wurden, rechtzeitig identifizieren konnte. Die präemptive Therapie mit TDF wurde im Anschluss durchgeführt, und kein Patient hatte eine HBsAg-Seroreversion (Evidenz 1b) [229].

Zur Dauer einer prophylaktischen antiviralen Therapie (für die oben geschilderten Indikationen) gibt es keine randomisierten, prospektiven Studien, sodass die aktuellen Leitlinien empfehlen, die Therapie 6-12 Monate nach Beendigung der immunsuppressiven Therapie fortzuführen [6, 86].

Es gibt allerdings Berichte, dass unter B-Zell depletierender Therapie (Rituximab und ähnliche Substanzen) auch noch nach etwas länger als einem Jahr nach Ende der Chemotherapie eine HBV-Reaktivierung auftreten kann (Evidenz 4) [230].

Da die antivirale Therapie sicher und gut verträglich ist, sollte bei B-Zell depletierender Chemotherapie und Hochrisikokonstellation aus Sicherheitsgründen die prophylaktische Therapie mindestens 18 Monate nach Abschluss der B-Zell-Depletion fortgeführt werden.

\section{Infektionen mit Hepatitis-B-Viren im Zusammenhang mit Organtransplantationen}

T. Berg, K. Herzer, C. Berg, M. Sterneck, B. Maasoumy, N. Aehling, E. Trowe (Selbsthilfe Lebertransplantierter), C. Strassburg, Bonn (DTG)

\subsection{Wie ist das Management von Patienten mit HBV-Infektion vor LTX?}

\section{EMPFEHLUNG 4.1.1}

Patienten mit HBV-induzierter Leberzirrhose und/oder HCC und nachweisbarer HBV-DNA sollen umgehend und dauerhaft mit einem hochpotenten NA (ETV, TDF, TAF) behandelt werden $[1, A]$.

Konsens: $100 \%$ (Delphi-Runde)

Geprüft 2020 (siehe 2.2.2, 2.2.3, 3.9.1)

\section{Kommentar:}

Die Prinzipien der antiviralen Therapie bei HBV-infizierten Patienten vor LTx unterscheiden sich nicht grundsätzlich von denen bei Patienten ohne Transplantationsindikation (siehe Empfehlungen und Kommentare der AG3) und entsprechen den Empfehlungen internationaler Leitlinien der EASL und der AASLD [6-8].

Sicherheit und Effektivität der Therapie mit potenten NA (Entecavir und Tenofovir) sind auch im Stadium der dekompensierten Erkrankung hoch. Eine Anpassung an die Nierenfunktion ist erforderlich ( $\triangleright$ Tab. 12), und bei Patienten mit einem MELD Score von $>22$ steigt das Risiko für die Entwicklung einer Laktatazidose unter NA. Aufgrund seines günstigen Nebenwirkungsprofils stellt TAF eine interessante Therapieoption für diese Patientengruppe dar. Allerdings liegen noch keine Daten zum Einsatz von TAF bei dekompensierter Zirrhose vor [6-8, 75, 76, 124, 125, 231].

\section{EMPFEHLUNG 4.1.2}

HBsAg-positive Patienten mit negativer HBV-DNA sollen engmaschige HBV-DNA-Kontrollen (ca. alle 3 Monate) erhalten [EK], eine antivirale Therapie ist in der Regel nicht erforderlich [EK]. Konsens: 95,6\% (Delphi-Runde) Geprüft 2020

\section{Kommentar:}

Eine regelmäßige Kontrolle ist wichtig, um Fluktuationen und Reaktivierungen der HBV-DNA rechtzeitig zu identifizieren (siehe 1.5.2). 


\section{EMPFEHLUNG 4.1.3}

Kommt es bei Patienten auf der Transplantationswarteliste im Verlauf der antiviralen Therapie zu einer Rekompensation der HBV-induzierten Leberzirrhose ins Stadium Child A und liegt kein hepatozelluläres Karzinom (HCC) vor, soll die Indikation zur LTx erneut überprüft werden [1, A].

Konsens: $100 \%$ (Delphi-Runde)

Geprüft 2020

\section{Kommentar:}

Die Zahl der Patienten, die jedoch aufgrund einer HBV-induzierten dekompensierten Leberzirrhose zur Lebertransplantation gelistet werden, ist als Folge der effektiven antiviralen Therapie in den letzten Jahrzehnten deutlich rückläufig (keine Änderung zu [5]).

Selbst bei dekompensierter Leberzirrhose führt die antivirale Therapie mit NA meist zu einer Stabilisierung des klinischen Verlaufs. Das transplantatfreie Überleben lag bei behandelten Patienten bei über $80 \%$. In bis zu einem Drittel der Fälle mit initial dekompensierter Zirrhose geht die Krankheit unter Therapie in ein kompensiertes Stadium über (Stadium Child A) (Evidenzgrad la) [75, 76, 232, 233].

Es soll dann im Einzelfall entschieden werden, ob weiterhin die Indikation zur LTx gegeben ist (keine Änderung zu [5]).

\section{EMPFEHLUNG 4.1.4}

Ein HCC-Screening soll mindestens alle 6 Monate durchgeführt werden [EK].

Konsens: $100 \%$ (Delphi-Runde)

Modifiziert 2020

\section{Kommentar:}

Obwohl die Rate neudiagnostizierter hepatozellulärer Karzinome durch die antivirale Therapie gesenkt werden kann, besteht gerade bei Patienten mit initial dekompensierter Zirrhose auch nach Rekompensation unter antiviraler Therapie ein signifikantes Risiko für die HCC-Entwicklung, sodass regelmäßige HCC-Screeninguntersuchungen erfolgen sollen (siehe AG 1) (keine Änderung zu [5]).

\subsection{Was versteht man unter einer HBV-Reinfektion?}

\section{DEFINITION 4.2.1}

Die HBV-Reinfektion des Lebertransplantats wird durch die Persistenz oder das Wiederauftreten von HBsAg im Serum angezeigt.

Konsens: 95,7\% (Delphi-Runde)

Geprüft 2020

\section{Kommentar:}

Bei Patienten mit replikativer, chronischer HBV-Infektion kommt es nach LTx ohne Prophylaxe regelhaft zur HBV-Reinfektion der transplantierten Leber (keine Änderung zu [5]).

Die HBV-Reinfektion ist durch die Persistenz oder das Wiederauftreten von HBsAg im Serum definiert. Meist findet sich in dieser Konstellation auch eine signifikante HBV-Replikation (HBVDNA positiv).

\section{DEFINITION 4.2.2}

Die HBV-Reinfektion geht in aller Regel mit einer histologisch nachweisbaren Transplantathepatitis einher.

Konsens: $100 \%$ (Konsensuskonferenz)

Geprüft 2020

\section{Kommentar:}

Die Reinfektionshepatitis verläuft unbehandelt in aller Regel schwer. Sie führt in der Mehrzahl der Patienten zum Verlust des Organs und ist mit einer hohen Letalität assoziiert (keine Änderung zu [5]).

Eine besonders rasch progrediente Verlaufsform ist die fibrosierend cholestatische Hepatitis B, die als Sonderfall auftreten kann (keine Änderung zu [5]).

Seit der Einführung der kombinierten HBV-Reinfektionsprophylaxe mit potenten NA plus Hepatitis-B-Immunglobulinen (HBIG) ist im Fall einer adäquaten Therapieadhärenz die HBV-Reinfektion jedoch eine Rarität geworden. [234]

\subsection{Wie ist das Management von Patienten mit HBV-Infekti-} on nach LTx? Wie erfolgt die Reinfektionsprophylaxe?

\section{EMPFEHLUNG 4.3.1}

Eine Reinfektionsprophylaxe ist bei Patienten mit HBV-Infektion obligat und soll initial mit einer Kombination aus einem hochpotenten Nukleos(t)idanalogon (NA) plus Hepatitis-BImmunglobulin (HBIG) erfolgen [2, A].

Konsens: 97,8\% (Delphi-Runde)

Geprüft 2020

Leitlinienadaption EASL Clinical Practice Guideline HBV 2017

\section{Kommentar:}

Primäres Ziel der Prophylaxe ist das Verhindern einer Reaktivierung der HBV-Replikation (Wiederauftreten von HBsAg und HBVDNA im Serum). Mit Einführung der Kombinationsprophylaxe konnten die Überlebensraten von Patienten mit HBV-Infektion deutlich gesteigert werden. HBV-infizierte Patienten erreichen heute ein 10-Jahres-Überleben nach LTx von bis zu $80 \%$ (keine Änderung zu [5]). 
Die Kombinationsprophylaxe, bestehend aus Hepatitis-B-Immunglobulin (HBIG) plus NA, führte im Vergleich zur früher eingesetzten HBIG-Monoprophylaxe zu einer deutlichen Senkung der Reinfektionsraten (keine Änderung zu [5]).

Diese Empfehlung entspricht den internationalen Leitlinien der EASL.

\section{EMPFEHLUNG 4.3.2}

Die Prophylaxe soll in der anhepatischen Phase der LTx beginnen und die HBIG-Dosierung anhand der Anti-HBs-Konzentrationen titriert werden. Ein Anti-HBs-Spiegel von $100 \mathrm{IU} / \mathrm{I}$ sollte nicht unterschritten werden [2, B].

Konsens: 95,6\% (Delphi-Runde)

Geprüft 2020

\section{Kommentar:}

Die HBIG-Prophylaxe beginnt in der anhepatischen Phase der Transplantation und wird nach Erreichen der HBsAg-Negativität mit einer Anti-HBs-Zielkonzentration von $\geq 100 \mathrm{U} / \mathrm{l}$ fortgesetzt. Das Standardschema umfasst die i. v. Applikation von 10000 Einheiten (IE) HBIG in der anhepatischen Phase, gefolgt von ca. 2000 IE HBIG an den Folgetagen bis zum Nachweis eines negativen HBsAg. Anschließend werden die Anti-HBs-Konzentrationen durch regelmäßige Gaben von 1000 bis 2000 IE HBIG i.v. etwa alle 4 Wochen auf einem Wert von $>100 \mathrm{U} / \mathrm{l}$ gehalten. Alternativ ist im Verlauf auch eine niedrig dosierte HBIG-Prophylaxe (z. B. 400-800 IE/Monat) bzw. die Applikation in größeren Intervallen (2000 IE alle 3 Monate i.v.) in Kombination mit einem NA für die meisten Patienten ausreichend (keine Änderung zu [5]).

Bei ausreichender Compliance sollte nach initialer i. v. Applikation die subkutane (s. c.) Applikation von HBIG zur HBV-Reinfektionsprophylaxe angestrebt werden. Die Dosierung erfolgt KGadaptiert (<75 kg 500 IE s. c. $1 \times$ wöchentlich, $\geq 75$ kg 1000 IE s. c.). Neuere Daten belegen, dass nach initialer i. v. Applikation und Erreichen einer stabilen Anti-HBs-Konzentration von > $100 \mathrm{U} / \mathrm{I}$ eine Umstellung auf wöchentliche Gaben der s.c. Formulierung zu jedem Zeitpunkt, auch bereits früh nach OLT, möglich ist (Evidenz 2b) [235].

\section{EMPFEHLUNG 4.3.3}

Bei Patienten mit NA-Resistenz zum Zeitpunkt der LTx soll die Prophylaxe mit einem gegen die resistente HBV-Variante wirksamen NA in Kombination mit HBIG durchgeführt werden [EK].

Konsens: $100 \%$ (Konsensuskonferenz)

Modifiziert 2020

\section{Kommentar:}

Die Wahl des NA erfolgt anhand individueller Faktoren wie der antiviralen Vorbehandlung, Resistenzsituation und Höhe der präoperativen Virusreplikation. Mittlerweile belegen zahlreiche Daten, dass unter Einsatz eines hochpotenten NA (Entecavir und
Tenofovir) das Risiko einer HBV-Reaktivierung auf bis zu $0 \%$ reduziert werden kann. Die bisherigen Studien mit limitierter Fallzahl schätzen hierbei Entecavir und Tenofovir im direkten Vergleich als gleichwertig ein [236-240].

Seit Januar 2017 ist Tenofovir alafenamide (TAF) zur Behandlung der chronischen Hepatitis B zugelassen. Im Gegensatz zu TDF muss beim Einsatz von TAF die Dosis nicht an die Nierenfunktion angepasst werden, und die Substanz hat auch keine signifikanten Effekte auf den Knochenstoffwechsel. In der 2017 veröffentlichten Leitlinie der EASL werden Indikationen definiert, in denen TAF oder ETV gegenüber TDF bevorzugt eingesetzt werden sollte. Diese Indikationen sind: Patienten älter als 60 Jahre, Erkrankungen des Knochenstoffwechsels (chronischer Steroidgebrauch oder anderer Medikamente, die die Knochendichte beeinträchtigen; Fragilitätsfrakturen in der Anamnese; Osteoporose), Einschränkung der Nierenfunktion (siehe 3.2.2) [6].

Patienten nach Transplantation haben durch die gleichzeitige Gabe von Calcineurininhibitoren und Steroiden ein erhöhtes Risiko für die Entwicklung einer Niereninsuffizienz und Osteopenie bzw. Osteoporose. Somit ist es rational, TDF nicht primär für die Reinfektionsprohylaxe bzw. Therapie der HBV-Reinfektion einzusetzen, sondern hier primär mit ETV oder TAF zu behandeln, wenngleich bisher nur wenige Daten zum Einsatz von TAF nach Transplantation vorliegen [241].

Die bei Niereninsuffizienz bestehenden Unsicherheiten in der Dosierung aller anderen NAs, um einen sicheren Wirkspiegel aufrechtzuhalten und das Risiko der HBV-Rekurrenz so gering wie möglich zu halten, können als ein weiteres Argument für den primären Einsatz von TAF in dieser Konstellation angesehen werden. Lamivudin, aber auch Adefovir und Telbivudin können aufgrund der deutlich höheren Rezidivraten nicht mehr empfohlen werden, weder als Monoprophylaxe noch in Kombination mit HBIG [6].

\section{EMPFEHLUNG 4.3.4}

Eine Umstellung auf eine alleinige orale Prophylaxe mit einem potenten NA unter Verzicht auf HBIG kann im Verlauf nach LTx bei ausreichender Adhärenz und stabil HBsAg-negativen Patienten mit niedrigem Rezidivrisiko (siehe Kommentar*) erfolgen [0, 2] ( Tab. 13).

* Voraussetzungen für eine alleinige NA Reinfektionsprophylaxe: keine hohe HBV-Replikation zum Zeitpunkt der LTx, keine HIV- oder HDV-Koinfektion und kein HCC vor Transplantation.

Konsens: 95,6\% (Delphi-Runde)

Modifiziert 2020

Leitlinienadaption EASL Clinical Practice Guideline HBV 2017

\section{Kommentar:}

Die Kombinationsprophylaxe mit HBIG plus NA wird zeitlich nicht mehr zwingend unbegrenzt empfohlen, da inzwischen belastbare Daten aus prospektiven Studien vorliegen, die belegen, dass nach initialer effektiver Kombinationsprophylaxe (HBsAg negativ, Anti-HBs positiv, HBV-DNA negativ) die Prophylaxe mit einer alleinigen oralen Therapie mit einem potenten NA ebenso 
- Tab.13 Empfehlung zur Prophylaxe der HBV-Reinfektion nach OLT.

\begin{tabular}{|c|c|c|c|c|}
\hline Vor LT & HBV-DNA positiv & Vor LT & \multicolumn{2}{|c|}{$\begin{array}{l}\text { Antivirale Vorbehandlung mit NA mit hoher Resistenzbarriere } \\
\text { (ETV, TDF, TAF*) }\end{array}$} \\
\hline \multirow[t]{5}{*}{ Nach LT } & Anhepatische Phase & Tag der LT & \multicolumn{2}{|l|}{ HBIG i.v. $10000 \mathrm{IU}$} \\
\hline & Woche 1 nach LT & Tag 1-7 post LT & \multicolumn{2}{|l|}{$\begin{array}{l}\text { HBIG i. v. } 2000 \text { IU Tag } 1-7 \\
\text { plus NA (ETV, TDF, TAF*) } \\
\text { Ziel: Anti-HBs > } 100 \mathrm{IU} / \mathrm{I}\end{array}$} \\
\hline & \multirow[t]{3}{*}{ Erhaltungsphase } & Bis Monat 12 post LT & \multicolumn{2}{|c|}{$\begin{array}{l}\text { HBIG i. v. } 1000-2000 \text { IU monatlich oder } 500 \mathrm{IU} \text { s. c. pro Woche bei KG } \\
<75 \mathrm{~kg} \text { bzw. } 1000 \mathrm{IU} \text { s. C. pro Woche bei } \mathrm{KG}>75 \mathrm{~kg} \\
\text { plus NA (ETV, TDF, TAF*) } \\
\text { Ziel: Anti-HBs }>100 \mathrm{IU} / \mathrm{I}\end{array}$} \\
\hline & & \multirow{2}{*}{$\begin{array}{l}\text { Nach Monat } 12 \text { post LT, indi- } \\
\text { viduelle Entscheidung zur Be- } \\
\text { endigung der HBIG-Therapie }\end{array}$} & Niedriges HBV-Reaktivierungsrisiko** & $\begin{array}{l}\text { Monoprophylaxe mit NA } \\
(\text { ETV, TDF, TAF*) }\end{array}$ \\
\hline & & & $\begin{array}{l}\text { Hohes HBV-Reaktivierungsrisiko** } \\
\text { oder eingeschränkte Therapieadhärenz }\end{array}$ & $\begin{array}{l}\text { HBIG i. v. oder s. c. weiterführen } \\
\text { plus NA (ETV, TDF, TAF*) }\end{array}$ \\
\hline
\end{tabular}

effektiv ist wie die bisher etablierte lebenslange Kombinationsprophylaxe (Evidenz 2b) [242-247].

Allerdings scheint die initiale zusätzliche HBIG-Gabe notwendig zu bleiben, wenn bei den Patienten zum Zeitpunkt der Transplantation noch ein positiver HBV-DNA-Status vorliegt, während sich bei negativer HBV-DNA zum LTx-Zeitpunkt kein Vorteil einer kombinierten Prophylaxe ableiten lässt [236, 240, 246].

Risikofaktoren für eine HBV-Reinfektion nach Absetzen der HBIG-Therapie mit Fortführen einer alleinigen NA-Therapie sind nach aktueller Datenlage vor allem eine hohe HBV-DNA zum Zeitpunkt der Transplantation (> $100000 \mathrm{IU} / \mathrm{ml}$ ), die HBV-HDV-Koinfektion, eine reduzierte NA-Dosierung bei eingeschränkter Nierenfunktion, ein HCC vor LTx mit erhöhtem HCC-Rekurrenzrisiko sowie eine verminderte Therapietreue (Adhärenz) [244, 248251].

Bei Vorliegen dieser Risikofaktoren sollte man derzeit von einem Absetzen der HBIG-Therapie Abstand nehmen. Diese Empfehlungen stützen sich unter anderem auf retrospektive Analysen von 338 Patienten, bei denen sowohl eine präoperative Lamivudin-Resistenz als auch ein HCC signifikant mit einem erhöhten HBV-Rekurrenzrisiko nach Beenden der kombinierten Prophylaxe assoziiert waren [247].

Eine Rekurrenz der Hepatitis Delta ist aufgrund des aggressiven Verlaufs der Infektion nach Transplantation unter Immunsuppression und der bisher fehlenden therapeutischen Optionen unbedingt zu vermeiden, sodass die alleinige Monoprophylaxe mit einem NA bei der HDV-Koinfektion nicht erfolgen soll, wenngleich zur Notwendigkeit einer lebenslangen kombinierten Prophylaxe widersprüchliche Daten existieren. Bis zum Vorliegen größerer prospektiver Fallserien bei Hepatitis Delta soll die Kombinationsprophylaxe nicht beendet werden [252].

Die kombinierte Prophylaxe hat sich in einer Studie auch gegenüber der Monoprophylaxe als überlegen erwiesen [249].
Wenn Patienten seit vielen Jahren stabil auf eine Kombinationstherapie mit Lamivudin plus HBIG eingestellt sind, muss bei Fortführung der Kombinationsprophylaxe nicht zwingend eine Umstellung auf ein potentes NA (ETV, TDF, TAF) erfolgen. Eine Beendigung der HBIG-Therapie soll aber nur unter Fortführung einer Monoprophylaxe mit einem potenten NA durchgeführt werden.

Eine ausreichende Adhärenz und regelmäßige Kontrollen (Abstand: inital alle 4-8 Wochen, dann alle 3 Monate, später alle 6 Monate) von HBsAg und HBV-DNA sind Voraussetzungen für den Verzicht auf eine kombinierte Immunprophylaxe.

Die AASLD-Empfehlungen empfehlen eine Fortführung der kombinierten Prophylaxe zusätzlich bei HIV-koinfizierten Patienten [8].

Begleiterkrankungen, insbesondere das Vorliegen einer Niereninsuffizienz, müssen bei der Dosierung der Substanzen berücksichtigt werden, und die Nierenfunktion sollte im Verlauf kontrolliert werden. Es ist bisher nicht ausreichend untersucht, ob der Wechsel auf eine Monoprophylaxe mit hochpotenten NA (Entecavir oder Tenofovir) auch bei Patienten mit Niereninsuffizienz im Stadium IV und V und reduzierter ETV- oder TDF-Dosis ausreichend sicher ist. Es muss in Studien geprüft werden, ob in dieser Konstellation der Einsatz von TAF ohne notwendige Dosisreduktion primär zu empfehlen ist.

Über den optimalen Zeitpunkt des Absetzens von HBIG (wenn keine Risikokonstellation vorliegt) gibt es unterschiedliche Daten. In vielen Studien wurde HBIG 12 Monate nach LTx abgesetzt. Es liegen aber auch Daten vor, die das erfolgreiche und sichere Absetzen von HBIG bereits 1 Woche oder 3 Monate nach LTx zeigen. Einige retrospektive Studien zeigten zudem die Sicherheit einer alleinigen NA-Prophylaxe vom Zeitpunkt der LTx an, unter vollständigem Verzicht auf HBIG [244, 253-255].

Die AASLD empfiehlt daher sogar eine sehr kurzfristige HBIGGabe für 5-7 Tage bzw. auch den kompletten Verzicht auf eine HBIG-Prophylaxe bei Patienten mit geringem Risiko. [8] 
Hierzu fehlen nach unserer Einschätzung bislang jedoch belastbare, prospektive Langzeitdaten, sodass zurzeit auch bei Patienten mit günstigen prognostischen Faktoren, zumindest eine initiale Kombinationstherapie für mindestens 6-12 Monate weiterhin empfohlen wird.

\section{EMPFEHLUNG 4.3.5}

Eine aktive HBV-Impfung kann unter Fortführung der Prophylaxe im Langzeitverlauf nach LTx versucht werden [3, 0].

Konsens: $95.6 \%$ (Delphi-Runde)

Geprüft 2020

\section{Kommentar:}

Eine aktive Hepatitis-B-Impfung nach LTx mit dem Ziel, eine dauerhafte Anti-HBs-Antwort zu induzieren, ist nur bei wenigen Patienten erfolgreich, kann aber unter Fortführung der Reinfektionsprohylaxe versucht werden (Evidenz 3b) [256-258].

Bei für mindestens 12 Monate stabilen Anti-HBs-Konzentrationen > $100 \mathrm{U} / \mathrm{l}$ nach letzter HBIG-Gabe kann eine Beendigung der oralen Prophylaxe mit NA erwogen werden. Engmaschige Kontrollen der Anti-HBs-Spiegel und des HBsAg sind dann im Verlauf notwendig. Bei Rückgang der Anti-HBs-Konzentrationen sollte erneut die orale Prophylaxe mit NA begonnen werden. Neue Hepatitis-B-Impfstoffe mit höherer Immunogenität befinden sich in der Entwicklung und könnten zu einer Steigerung des Impfansprechens bei Patienten nach LTx beitragen.

\section{EMPFEHLUNG 4.3.6}

Patienten mit Zustand nach HBV-Infektion (Anti-HBc-positiv) sollen auf HBV-DNA untersucht werden. Bei negativer HBV-DNA soll keine prophylaktische Therapie erfolgen. Eine HBV-Impfung sollte durchgeführt werden, sofern die AntiHBs-Konzentrationen < $100 \mathrm{IU}$ betragen [EK].

Konsens: $100 \%$ (Konsensuskonferenz)

\section{Kommentar:}

Die Empfehlungen entsprechen den Empfehlungen in 3.13 und 5.8.3.

\subsection{Wie ist das therapeutische Vorgehen bei nachgewiese- ner HBV-Reinfektion?}

\section{EMPFEHLUNG 4.4.1}

Bei bestätigter HBV-Reinfektion soll die HBIG-Therapie beendet und eine dauerhafte antivirale Therapie mit einem potenten NA (ETV, TDF, TAF) durchgeführt werden [1, A]. Konsens: 97,8\% (Delphi-Runde)

Geprüft 2020

\section{Kommentar:}

Aufgrund des hohen Risikos des Transplantatverlusts und der signifikanten Letalität besteht bei allen Patienten mit HBV-Reinfektion eine Behandlungsindikation unabhängig vom histologischen Fibrosestadium und der inflammatorischen Aktivität, der Höhe der Viruslast und der Transaminasen (keine Änderung zu [5]).

Da heutzutage die überwiegende Mehrzahl der Patienten eine Kombinationsprohylaxe aus HBIG plus NA erhält, sollte bei Rekurrenz von HBsAg ohne nachweisbare HBV-DNA HBIG beendet und die Therapie mit dem bisher verwendeten NA unter regelmäßigen HBV-DNA-Kontrollen alle 3 Monate fortgeführt werden. Bei Anstieg der HBV-DNA unter NA-Monoprophylaxe oder Kombinationsprophylaxe ist entweder von einer Nichtadhärenz zur Therapie oder einer Resistenzentwicklung auszugehen. Eine Resistenztestung kann erfolgen, wenn die Medikamentenadhärenz gesichert ist.

\section{EMPFEHLUNG 4.4.2}

Bei fehlendem Therapieansprechen oder Resistenzentwicklung soll eine Modifikation der Therapie entsprechend den Empfehlungen der AG3 erfolgen [1, A].

Konsens: 97,8\% (Delphi-Runde)

Geprüft 2020

\section{Kommentar:}

Heutzutage ist die HBV-Reinfektion mehrheitlich Folge von Resistenzentwicklungen gegenüber den verwendeten NA und seltener die Folge von HBIG-induzierten Selektionen von Resistenzmutationen im HBV-Surface-Gen (keine Änderung zu [5]).

Das Risiko ist insbesondere dann hoch, wenn bereits vor LTx eine Resistenz gegenüber dem zur Prophylaxe verwendeten NA vorhanden war. Die Wahl der antiviralen Therapie erfolgt in Abhängigkeit von der Vortherapie bzw. der Resistenzsituation. Der Einsatz hochpotenter nicht kreuzresistenter HBV-Polymerase-Inhibitoren (ETV, TAF bzw. TDF) wird empfohlen (siehe AG3).

\subsection{Wie ist das Management von HBV-infizierten Patienten mit kombinierter Organtransplantation (z. B. Leber plus Niere)?}

\section{STATEMENT 4.5.1}

Das Management vor und nach Leber-Nieren-Transplantation unterscheidet sich nicht von dem Vorgehen bei Patienten mit alleiniger LTx.

Konsens: $100 \%$ (Delphi-Runde)

Geprüft 2020

\section{Kommentar:}

Die 1985 erstmals durchgeführte kombinierte Leber-NierenTransplantation [259] ist eine selten angewandte, aber etablierte Behandlungsmethode zur Therapie von Patienten mit irreversibler terminaler Leber- und Niereninsuffizienz [260-262]. 


\section{EMPFEHLUNG 4.5.2}

Die Dosierung überwiegend renal eliminierter Medikamente soll an die Nierentransplantat-Funktion angepasst werden [1, A].

Konsens: $100 \%$ (Delphi-Runde)

Geprüft 2020

\section{Kommentar:}

Zur Berechnung der Dosierung von Medikamenten, die an die Nierentransplantat-Funktion angepasst werden muss, sollte zumindest die Cockroft-und-Gault-Formel oder besser eine der MDRD-Formeln herangezogen werden. Mit der MDRD6-Formel ist die genaueste Berechnung der Nierentransplantat-Funktion möglich; allerdings ist in diesem Fall (im Gegensatz zur Cockroftund-Gault- und zu anderen MDRD-Formeln) auch eine Untersuchung des Urins erforderlich, was die Prozedur erschwert [263].

Die Dosierung der NA sollte gemäß der Fachinformation an die Nierenfunktion angepasst werden (siehe auch AG3, > Tab. 12). Besondere Vorsicht ist generell bei zusätzlicher Applikation von nephrotoxischen Substanzen geboten. Zur Nephroprotektion und Prävention einer Osteoporose kann TAF gegenüber TDF bevorzugt werden (siehe auch 3.2.2) [6].

Häufig sind einer kombinierten Leber- und Nieren-Transplantation schon eine oder mehrere alleinige Nierentransplantationen vorausgegangen. Die hiermit in Einzelfällen verbundene starke Immunisierung des Patienten kann dazu führen, dass eine erneute alleinige Nierentransplantation nicht mehr oder nur unter einer sehr intensiven Immunsuppression möglich ist. Bei kombinierter Leber-Nieren-Transplantation wird das Nierentransplantat in der Regel durch das Lebertransplantat vor Abstoßungsreaktionen „geschützt“, sodass meist eine geringere immunsuppressive Therapie als bei alleiniger Nierentransplantation verabreicht werden kann und sollte [264, 265].

\subsection{Wie ist das Management von Patienten, die für eine Transplantation anderer solider Organe (nicht Leber) evaluiert werden?}

\section{EMPFEHLUNG 4.6.1}

Vor einer geplanten Organtransplantation sollen alle Patienten auf das Vorliegen einer aktuellen oder zurückliegenden HBV-Infektion untersucht werden [1, A].

Konsens: $100 \%$ (Delphi-Runde)

Geprüft 2020

\section{Kommentar:}

Unbehandelt zeigt die chronische HBV-Infektion nach Transplantation aufgrund der notwendigen immunsuppressiven Therapie meist einen progredienten Verlauf und ist mit einer signifikanten Letalität assoziiert. Das Risiko einer fulminanten Reaktivierung der HBV-Infektion unter Immunsuppression ist erhöht. Dieses Risiko besteht auch bei niedrig replikativer HBeAg-negativer HBV-Infektion (sogenannte HBsAg-Träger (siehe auch 3.13) (keine Änderung zu [5]).

\section{STATEMENT 4.6.2}

Die HBV-Infektion stellt bei entsprechender Prophylaxe bzw. antiviraler Therapie keine Kontraindikation für eine Organtransplantation dar.

Konsens: 97,8\% (Delphi-Runde)

Geprüft 2020

\section{Kommentar:}

Vor Einführung der NA-Therapie hatten HBV-infizierte Organtransplantationsempfänger im Vergleich zu HBV-negativen Patienten ein signifikant reduziertes Transplantat- und Gesamtüberleben (keine Änderung zu [5]).

Die chronische HBV-Infektion stellte damals bei potenziellen Organempfängern (nicht Leber) eine relative bzw. absolute Kontraindikation zur Transplantation dar. Seit Einführung einer konsequenten Therapie bzw. Prophylaxe mit hochpotenten NA bei HBsAg-positiven Organempfängern lassen sich keine wesentlichen Unterschiede mehr zwischen HBV-infizierten und HBV-naiven Organempfängern in Bezug auf das Transplantat- und Gesamtüberleben feststellen.

Das Vorliegen einer HBV-induzierten Leberzirrhose stellt jedoch einen potenziellen Risikofaktor für die leberbezogene Sterblichkeit nach der Transplantation dar. Bei Patienten mit Leberzirrhose sollte daher die Indikation zu einer kombinierten Organtransplantation geprüft werden bzw. bei dekompensierter Zirrhose eine kombinierte Transplantation erfolgen (keine Änderung zu [5]).

\section{EMPFEHLUNG 4.6.3}

Patienten mit isoliert positivem Anti-HBc-Antikörperstatus sollten auf HBV-DNA untersucht werden [EK].

Konsens: 97,9\% (Delphi-Runde)

Neu 2020

\section{Kommentar:}

Eine okkulte HBV-Infektion, definiert durch den Nachweis einer meist geringen HBV-Replikation (HBV-DNA positiv) bei gleichzeitig negativem HBsAg-Status, sollte ausgeschlossen werden, da unter dieser Konstellation ein signifikantes Risiko besteht, dass es unter der immunsuppressiven Therapie nach der Transplantation zu einer Reaktivierung der HBV-Infektion kommt (siehe 3.13).

\section{EMPFEHLUNG 4.6.4}

Bei Nachweis einer HBV-Infektion soll eine weitere Diagnostik entsprechend den üblichen diagnostischen Empfehlungen bei HBV-Infektion durchgeführt werden [EK].

Konsens: $100 \%$ (Delphi-Runde)

Neu 2020 


\section{Kommentar:}

Die HBV-Diagnostik wird analog zu den Empfehlungen in AG1 durchgeführt.

\section{EMPFEHLUNG 4.6.5}

Patienten mit chronischer Hepatitis B sollen entsprechend den aktuellen Empfehlungen antiviral behandelt werden [EK]. Konsens: $100 \%$ (Delphi-Runde)

Modifiziert 2020

\section{Kommentar:}

Die Therapieempfehlungen unterscheiden sich nicht von denen bei anderen Patienten mit HBV-Infektion. Komorbiditäten sollten für die Auswahl der antiviralen Therapie analog zu den Empfehlungen in AG3 berücksichtigt werden.

\subsection{Wie ist das Management von Patienten mit positiver} HBV-Serologie nach Transplantation anderer solider Organe (nicht Leber)? Wann, wie und bei wem wird eine Prophylaxe durchgeführt?

\section{EMPFEHLUNG 4.7.1}

Unabhängig vom Stadium und der Aktivität der HBV-Infektion sollen alle HBsAg- bzw. HBV-DNA-positiven Patienten eine dauerhafte antivirale Therapie mit hoch-potenten NA (ETV, TDF, TAF) erhalten. Der Beginn der Therapie erfolgt spätestens zum Zeitpunkt der Transplantation [2, A].

Konsens: $100 \%$ (Delphi-Runde)

Modifiziert 2020

Leitlinienadaption EASL Clinical Practice Guideline HBV 2017

\section{Kommentar:}

Ziel der antiviralen Therapie ist die rasche Suppression der HBV-Replikation unter die Nachweisgrenze sensitiver HBV-DNATests bzw. bei Patienten mit nicht replikativer, inaktiver HBV-Infektion (inaktiver HBsAg-Träger) die Prophylaxe der Hepatitis-BReaktivierung unter der immunsuppressiven Therapie. Bei allen HBsAg-positiven Patienten, die eine immunsuppressive Therapie erhalten, soll daher eine Prophylaxe bzw. Therapie mit einem hochpotenten NA durchgeführt werden. Bei niedrig virämischen HBsAg-Trägern kann die prophylaktische Therapie mit Lamivudin zwar häufig ausreichend sein, ETV und TDF bzw. TAF zeichnen sich jedoch durch eine höhere Effektivität und Resistenzbarriere aus und sollten daher bevorzugt werden, wie auch in den internationalen Leitlinien der EASL und AASLD empfohlen [6, 8].

Das Management erfolgt analog zu den Empfehlungen in AG3.

\section{EMPFEHLUNG 4.7.2}

Bei isoliert Anti-HBc-positiven bzw. Anti-HBc- plus Anti-HBspositiven Patienten (Zustand nach HBV-Infektion) soll ein regelmäßiges Monitoring auf HBsAg und HBV-DNA erfolgen. Eine prophylaktische antivirale Therapie braucht nicht regelhaft durchgeführt zu werden [EK].

Konsens: $100 \%$ (Delphi-Runde)

Modifiziert 2020

\section{Kommentar:}

Das Risiko einer Hepatitis-B-Reaktivierung bei isoliert AntiHBc-positiven ( \pm Anti-HBs) Patienten (HBsAg negativ und HBVDNA negativ) liegt unter einer immunsuppressiven Therapie (z. B. Chemotherapie) bei ca. 0,9-5\% [266] (keine Änderung zu [5]).

Bei Anti-HBc/Anti-HBs-positiven Empfängern (Z.n. HBV-Infektion) ist das Risiko niedriger [267].

Bei Anti-HBc-positiven und HBV-DNA negativen Organempfängern (nicht Leber) wird aufgrund dieses geringen Reaktivierungsrisikos keine generelle prophylaktische antivirale Therapie empfohlen, sofern keine B-Zell-Antikörper zur Immunsuppression eingesetzt werden [268].

Bei diesen Patienten sollten jedoch im Verlauf nach der Transplantation regelmäßig (im ersten Jahr alle 3 Monate, danach alle 3-6 Monate) HBV-DNA-Kontrollen durchgeführt und eine präemptive Behandlung begonnen werden, sobald die HBV-DNA positiv wird. Bei bestimmten Konstellationen, die mit einem erhöhten Risiko für eine Reaktivierung assoziiert sind, kann eine prophylaktische Therapie durchgeführt werden. Das sind z. B. $\mathrm{HBsAg}$-negative/Anti-HBc-positive Patienten mit nachweisbarer HBV-DNA (okkulte HBV-Infektion) oder einer Behandlung mit Immunsuppressiva mit hohem Risiko für eine HBV-Reaktivierung (z. B. Behandlung mit einem B-Zell-Antikörper, siehe auch 3.13). Das entspricht auch den internationalen Leitlinien der EASL [6].

Die AASLD-Leitlinien empfehlen ebenfalls, HBsAg-negative, Anti-HBc-positive Nicht-Leberempfänger auf eine HBV-Reaktivierung regelmäßig zu untersuchen, jedoch keine generelle prophylaktische Therapie. Alternativ kann eine antivirale Therapie für die ersten 6-12 Monate, die Zeitspanne maximaler Immunsuppression, in Betracht gezogen werden [8].

4.8 Wie ist das Management von Patienten vor und nach Stammzelltransplantation (SZT)? Wann, wie und bei wem wird eine antivirale Therapie bzw. Prophylaxe durchgeführt?

\section{EMPFEHLUNG 4.8.1}

Vor einer geplanten SZT sollen alle Patienten auf das Vorliegen einer HBV-Infektion mittels HBsAg-, Anti-HBc- und Anti-HBsTestung untersucht werden. Bei Nachweis einer HBV-Infektion (HBsAg-positiv) soll eine weitere Diagnostik entsprechend den Empfehlungen (siehe AG1) durchgeführt werden [2, A]. Konsens: $100 \%$ (Delphi-Runde)

Geprüft 2020 


\section{Kommentar:}

Eine virale Hepatitis stellt mit 7-15\% die dritthäufigste Leberkomplikation bei Patienten nach SZ-Transplantation dar (Graftversus-host-Reaktion 33-40\%, medikamentös-toxischer Schaden 19-30\%). Da effektive Therapiestrategien vorliegen, sollten alle Patienten vor SZT auf das Vorliegen einer HBV-Infektion mittels HBsAg-, Anti-HBc- und Anti-HBs-Testung untersucht werden (keine Änderung zu [5]).

\section{STATEMENT 4.8 .2}

Die HBV-Infektion stellt bei antiviraler Prophylaxe oder Therapie keine Kontraindikation zur SZT dar.

Konsens: $100 \%$ (Delphi-Runde)

Geprüft 2020

\section{Kommentar:}

Die HBV-Infektion kann effektiv verhindert bzw. behandelt werden und stellt daher keine Kontraindikation zur SZT dar (keine Änderung zu [5]).

\section{EMPFEHLUNG 4.8.3}

Patienten mit chronischer HBV-Infektion sollen entsprechend den aktuellen Empfehlungen antiviral mit NA behandelt werden [EK].

Konsens: $100 \%$ (Delphi-Runde)

Geprüft 2020

\section{Kommentar:}

Patienten vor und nach KMT/SZT werden ebenso entsprechend den Empfehlungen in AG3 behandelt. Komorbiditäten (Niereninsuffizienz) sollten berücksichtigt werden.

\section{EMPFEHLUNG 4.8.4}

Bei niedrig replikativer HBeAg-negativer HBV-Infektion soll zur Prophylaxe der Hepatitis-B-Reaktivierung nach SZT eine antivirale Therapie mittels NA durchgeführt werden [II, A]. Die Prophylaxe sollte spätestens mit Beginn der myeloablativen Chemotherapie erfolgen [EK]. Bei HBsAg-negativen Patienten mit Zustand nach HBV-Infektion (Anti-HBC \pm Anti-HBs positiv) sollte zur Prophylaxe der Hepatitis-B-Reaktivierung nach SZT ebenfalls eine antivirale Therapie mittels NA durchgeführt werden [II, B] (siehe auch 3.13).

Konsens: $100 \%$ (Delphi-Runde)

Modifiziert 2020

Leitlinienadaption EASL Clinical Practice Guideline HBV 2017

\section{Kommentar:}

NA sind für die Therapie und Prophylaxe einer Hepatitis-B-Reaktivierung geeignet (siehe 3.13). Die prophylaktische Gabe von Lamivudin im Rahmen prospektiver Studien bei HBsAg-positiven Patienten unter Chemotherapie konnte die Häufigkeit der Hepatitis-B-Reaktivierung erheblich vermindern (Evidenz 2a) (keine Änderung zu [5]).

Bei niedrig virämischer, HBeAg-negativer HBV-Infektion (sogenannter inaktiver HBsAg-Trägerstatus) soll daher zur Prophylaxe der Reaktivierung nach SZT eine antivirale Therapie mittels NA durchgeführt werden, wobei der Beginn der Prophylaxe 2 Wochen vor bzw. spätestens mit Beginn der knochenmarkablativen Chemotherapie erfolgen soll. In einer retrospektiven Studie mit 216 HBsAg-positiven Patienten, die Lamivudin oder Entecavir als Prophylaxe nach SZT erhielten, zeigten sich nach 6, 12 und 24 Monaten deutlich höhere Hepatitis-B-Reaktivierungsraten in der Lamivudin-Gruppe (3\%, 7\%, 24\%) im Vergleich zur EntecavirGruppe (0\%, $0 \%, 2 \%)$ [269].

Somit sollte, auch in Übereinstimmung mit internationalen Leitlinien, die prophylaktische Therapie der Hepatitis B nach SZT bevorzugt mit antiviralen Medikamenten mit einer hohen Resistenzbarriere (ETV oder TDF/TAF) durchgeführt werden [6, 8].

Hepatitis-B-Reaktivierungen nach SZT bei HBsAg-negativen und isoliert Anti-HBc-positiven Patienten bzw. Anti-HBc- und Anti-HBs-positiven Patienten sind in zahlreichen Einzelfällen und Fallserien beschrieben worden (keine Änderung zu [5]).

In einer neueren prospektiven Studie zeigte sich für unbehandelte HBsAg-negative, Anti-HBc-positive ( \pm Anti-HBs-positive) Patienten nach allogener SZT eine hohe Rate an HBV-Reaktivierungen von $41 \%$ innerhalb von 2 Jahren, wobei Patienten mit einem Alter $>50$ Jahre und mit chronischer Graft-versus-Host-Disease (GvHD) ein besonders hohes Reaktivierungsrisiko aufwiesen (Evidenz 2b) [270].

Diese Daten rechtfertigen den Einsatz einer primären antiviralen Prophylaxe mittels NA, vor allem in der Gruppe von Patienten mit einem hohen Risiko, die Hepatitis B zu reaktivieren (siehe auch 3.13). Bei Patienten mit einem Alter unter 50 Jahren ohne chronische GvHD kann gegebenenfalls auch ein engmaschiges Monitoring der HBV-DNA alle 4 Wochen alternativ zur primär prophylaktischen antiviralen Therapie durchgeführt werden.

\section{EMPFEHLUNG 4.8.5}

Die prophylaktische antivirale Therapie sollte mindestens 12 Monate über die Immunrekonstitution (Ende der Chemotherapie) hinaus fortgeführt werden [EK].

Konsens: 97,8\% (Delphi-Runde)

Geprüft 2020

\section{Kommentar:}

Zur Dauer der Prophylaxe existieren keine Daten. Da Reaktivierungen aber auch jenseits der Immunrekonstitution auftreten können, sollte die Prophylaxe für eine Dauer von mindestens 
12 Monaten über die Immunrekonstitution hinaus fortgeführt werden. Die Empfehlungen entsprechen den Empfehlungen 3.13.

\section{EMPFEHLUNG 4.8.6}

Der Versuch eines adoptiven Immuntransfers durch HepatitisB-Impfung des Spenders kann erwogen werden [0, 4]. Konsens: $100 \%$ (Delphi-Runde)

Geprüft 2020

\section{Kommentar:}

Ein adoptiver Immuntransfer durch Knochenmarksspende HBV-immuner, d. h. Anti-HBs-positiver Spender reduziert das Risiko der Hepatitis-B-Reaktivierung und kann in Einzelfällen sogar zu einer Ausheilung der chronischen HBV-Infektion des Empfängers führen (Evidenz 4) (keine Änderung zu [5]).

\section{EMPFEHLUNG 4.8.7}

Bei Anti-HBs-positivem Spender und isoliert Anti-HBc-positivem Empfänger kann auf eine prophylaktische antivirale Therapie verzichtet werden [EK]. Ohne Prophylaxe sollen jedoch nach SZT engmaschige Kontrollen der HBV-DNA (ca. alle 4 Wochen) und bei messbarer HBV-DNA umgehend eine antivirale Therapie mit NA erfolgen [EK].

Konsens: 95,6\% (Delphi-Runde)

Geprüft 2020

\section{Kommentar:}

Der protektive Effekt des adoptiven Immuntransfers ist bei der SZT durch Spender mit durchgemachter HBV-Infektion höher als bei Stammzellspendern, die ausschließlich eine Impfung gegen Hepatitis B erhalten haben. Da in beiden Kostellationen kein absoluter Schutz vor einer Hepatitis-B-Reaktivierung gegeben ist, werden engmaschige Kontrollen der HBV-DNA im Abstand von ca. 4 Wochen nach SZT empfohlen [270].

Bei Reaktivierung erfolgt die Therapie analog den Empfehlungen in AG3.

\subsection{Wie ist das Management von Patienten mit De-novo-HBV-Infektion nach Organtransplantation?}

\section{EMPFEHLUNG 4.9.1}

Bei Nachweis einer De-novo-HBV-Infektion nach Organtransplantation (HBsAg-positiv) soll unabhängig von der Aktivität der Erkrankung eine antivirale Therapie mit einem hochpotenten NA (ETV, TDF, TAF) begonnen werden [EK]. Konsens: $100 \%$ (Delphi-Runde)

Modifiziert 2020

\section{Kommentar:}

De-novo-HBV-Infektionen nach Lebertransplantation, d. h. Neuauftreten von HBsAg im Serum, werden in ca. 2 bis $5 \%$ beobachtet. Ein hoher Anti-HBs-Titer vor Transplantation (nach HBVImpfung) reduziert das Risiko der De-novo-HBV-Infektion (keine Änderung zu [5]).

Die Transplantation eines Anti-HBc( \pm Anti-HBs-)-positiven Organs bzw. ein Anti-HBc-positiver Serostatus des Empfängers stellen Risikofaktoren für die De-novo-HBV-Infektion dar (keine Änderung zu [5]).

Die De-novo-HBV-Infektion führt meist zu einer chronischen Hepatitis B und ist unbehandelt mit einer signifikanten Morbidität und Letalität assoziiert (keine Änderung zu [5]).

Aufgrund der vorhandenen immunsuppressiven Therapie sollen alle Patienten mit De-novo-HBV-Infektion nach Transplantation unabhängig von der Höhe der HBV-DNA antiviral mit einem NA mit hoher Resistenzbarriere (ETV, TDF oder TAF) behandelt werden (siehe 3.13).

\section{EMPFEHLUNG 4.9.2}

Eine PEG-IFN-Therapie soll nicht eingesetzt werden [EK]. Konsens: $100 \%$ (Delphi-Runde)

Geprüft 2020

\section{Kommentar:}

Der Einsatz von Interferon alfa ist nach Organtransplantation nicht zu empfehlen, da aufgrund der immunmodulatorischen Eigenschaften ein erhöhtes Risiko für eine Abstoßung oder auch eine Plasmazell-Hepatitis besteht [271].

\subsection{Wie ist das Management von Patienten, die ein Organ eines Anti-HBc-positiven Spenders erhalten?}

Transplantation einer Leber eines Anti-HBc-positiven/HBsAgnegativen Spenders:

\section{EMPFEHLUNG 4.10.1}

Bei Anti-HBs-negativem Empfänger soll eine Prophylaxe mit einem NA durchgeführt werden [EK]. Eine kombinierte Prophylaxe mit HBIG + NA sollte nicht erfolgen [EK]. Die Prophylaxe mit einem NA sollte dauerhaft durchgeführt werden [EK]. Sofern die Prophylaxe beendet wird, sollen regelmäßige Kontrollen von HBsAg und HBV-DNA erfolgen [EK].

Konsens: 95,7\% (Delphi-Runde)

Modifiziert 2020

\section{Kommentar:}

Bei HBsAg-negativen Patienten, die ein HBsAg-negatives, AntiHBc-positives Transplantat erhalten, liegt das Risiko einer HBV-Reaktivierung im Transplantat ohne antivirale Prophylaxe in Abhängigkeit vom HBV-Immunstatus des Empfängers bei 33-100\%. [5, 8, 272] 
Daher wird in dieser Konstellation eine HBV-Prophylaxe empfohlen.

Eine Kombinationsprophylaxe mit NA plus HBIG erscheint jedoch nicht erforderlich und wird auch von der Leitlinie der AASLD nicht empfohlen [8].

Die meisten Daten liegen für eine Monoprophylaxe mit Lamivudin vor. In Anbetracht der gut dokumentierten Effektivität und Sicherheit der Prophylaxe mit einer LAM-Monotherapie kann in dieser speziellen Konstellation auch der Einsatz von Lamivudin in einer Dosierung von $100 \mathrm{mg}$ einmal täglich erwogen werden $[273,274]$.

Für den Stellenwert zum Einsatz hochpotenter NA (ETV, TDF und TAF) zur Prophylaxe einer HBV-Reaktivierung bei einer Lebertransplantation Anti-HBc-positiver/HBsAg-negativer Organe existieren derzeit nur sehr wenige Daten [273, 275-277].

Die AASLD-Leitlinien weisen darauf hin, dass die Verwendung von Entecavir, TDF oder TAF bei Langzeitanwendung das geringste Risiko für Resistenzen aufweist [8].

Die notwendige Dauer einer NA-Prophylaxe ist bisher nicht definiert. Das Risiko der Reaktivierung ist in der Frühphase nach Transplantation bei starker Immunsuppression wahrscheinlich am höchsten und im Langzeitverlauf nach LTx bei niedriger Dosierung der Immunsuppressiva möglicherweise geringer. Bei AntiHBs-negativen Empfängern tritt die Reinfektion ohne Prophylaxe im Median 24 Monate nach LTX auf und nach zeitlich limitierter Prophylaxe im Median nach 35 Monaten, wie gepoolte Daten aus verschiedenen Serien zeigen. Auch Reaktivierungen nach mehr als 5 Jahren sind beschrieben (keine Änderung zu [5]).

Daher wird aufgrund der hohen Sicherheit und guten Verträglichkeit der NA-Therapie eine dauerhafte NA-Prophylaxe empfohlen. Die Wahl des NA sollte in Analogie zu den Empfehlungen der HBV-Reinfektionsprohylaxe bei HBsAg-positiven Empfängern erfolgen (siehe 4.3.3).

\section{EMPFEHLUNG 4.10.2}

Bei isoliert Anti-HBs-positiven Empfängern ist das Risiko der HBV-Reaktivierung geringer als bei Anti-HBs-negativen Empfängern. Dennoch sollte eine Prophylaxe mit einem NA auch bei diesen Patienten erfolgen [EK].

Die Prophylaxe (4.10.1 und 4.10.2) sollte mit dem Zeitpunkt der Transplantation beginnen [EK].

Konsens: 95,6\% (Delphi-Runde)

Modifiziert 2020

\section{Kommentar:}

Ein Anti-HBs-positiver Empfänger hat ein signifikant geringeres Risiko einer HBV-Reaktivierung nach Transplantation eines AntiHBc-positiven Spenderorgans (keine Änderung zu [5]).

Dabei korreliert das Risiko der Reaktivierung mit der Höhe der Empfänger-Anti-HBs-Konzentrationen und ist umso niedriger, je höher die Anti-HBs-Konzentrationen sind.

Daher sollen alle Patienten ohne ausreichende Immunisierung gegen HBV vor der Transplantation geimpft werden. Ohne zusätzliche Prophylaxe verbleibt bei Anti-HBs-positiven Empfängern im
Mittel ein Risiko von ca. 18 \% für eine HBV-Reaktivierung nach Transplantation eines Anti-HBc-positiven/HBsAg-negativen Organs [272].

In Analogie zu Anti-HBsAg-negativen Empfängern ist auch bei Anti-HBs-positivem Empfänger eine HBV-Prophylaxe mit einer NA-Monotherapie ausreichend (keine Änderung zu [5]) [272, 273].

Die notwendige Dauer der NA-Prophylaxe ist unklar. Eine Beendigung der NA-Prophylaxe kann unter engmaschiger Kontrolle (im ersten Jahr alle 3 Monate, danach alle 3-6 Monate) der HBsAgund HBV-DNA-Konzentrationen erwogen werden, wenn nach HBV-Impfung eine stabile Anti-HBs-Response mit Titern $>100 \mathrm{IU} / \mathrm{ml}$ induziert werden konnte [278-282].

\section{EMPFEHLUNG 4.10.3}

Bei kombiniert Anti-HBs- und Anti-HBc-positiven Empfängern ist das Risiko einer HBV-Reaktivierung besonders gering. Hier kann der Verzicht auf eine Prophylaxe erwogen werden und stattdessen können engmaschige Kontrollen von HBV-DNA und HBsAg erfolgen [EK]. Bei messbarer HBV-DNA- und/oder $\mathrm{HBsAg-Positivität} \mathrm{soll} \mathrm{dann} \mathrm{umgehend} \mathrm{eine} \mathrm{antivirale} \mathrm{Thera-}$ pie mit einem NA erfolgen [EK].

Konsens: 95,7\% (Delphi-Runde)

Neu 2020

\section{Kommentar:}

Besonders niedrig erscheint das Risiko einer HBV-Reaktivierung bei Anti-HBs-positiven/Anti-HBc-positiven-Empfängern (Z.n. Hepatitis B). Der Nutzen einer Prophylaxe ist hier nicht eindeutig belegt [273].

Die Rate an HBV-Reaktivierungen betrug bei einer Prophylaxe mit LAM \pm HBIG $3 \%(n=1 / 36)$ und ohne Prophylaxe $4 \%(n=3 / 70)$. Daher erscheint bei diesen Patienten auch der Verzicht auf eine Prophylaxe vertretbar zu sein. Unter diesen Umständen ist allerdings ein enges Monitoring von HBsAg und HBV-DNA erforderlich. Im ersten Jahr nach Transplantation sollte eine Kontrolle alle 3 Monate, im weiteren Verlauf alle 3-6 Monate erfolgen [272].

Transplantation anderer Organe (z. B. Niere, Herz, Lunge, Pankreas) oder Stammzelltransplantation eines Anti-HBc-positiven/HBsAg-negativen Spenders:

\section{EMPFEHLUNG 4.10.4}

Eine Prophylaxe mit HBIG und/oder einem NA sollte unabhängig vom Anti-HBs-Status des Transplantatempfängers aufgrund des insgesamt geringen Risikos der HBV-Infektion nicht erfolgen [EK]. Es sollten Kontrollen von HBV-DNA und HBsAg im Verlauf durchgeführt werden [EK]. Bei messbarer HBVDNA- und/oder HBsAg-Positivität soll umgehend eine antivirale Therapie mit einem NA erfolgen [EK].

Konsens: 97,8\% (Delphi-Runde)

Modifiziert 2020 


\section{Kommentar:}

Das Risiko einer HBV-Übertragung ist bei der Herz-, Lungenoder Nierenspende eines Anti-HBc-positiven/HBsAg-negativen Spenders im Vergleich zur Leberspende gering (<5\%). In einem systematischen Review, in dem 1385 Nierentransplantatempfänger mit Organen von Spendern analysiert wurden, die HBsAg-negativ, aber Anti-HBc-positiv waren, wurden im Verlauf nach Transplantation 0,3\% HBsAg-positiv und 2,3\% Anti-HBc-positiv getestet. Der Anti-HBc-Status des Spenders hat keinen Einfluss auf das Empfängerüberleben (keine Änderung zu [5]) [283, 284].

Eine erfolgreiche HBV-Impfung des Empfängers scheint das Risiko einer HBV-Transmission durch das Spenderorgan zusätzlich zu reduzieren und wird daher für alle Patienten empfohlen. Das Vorhandensein von Anti-HBc und/oder Anti-HBs bei den Empfängern ist mit einem Schutz gegen HBV-Übertragung und HBsAgSerokonversion verbunden [273, 285].

Aufgrund dieses geringen Risikos der HBV-Übertragung wird eine Prophylaxe in dieser Konstellation nicht generell empfohlen.

Anmerkung: Die AASLD-Leitlinien empfehlen allerdings, dass eine antivirale Therapie verabreicht werden sollte, um dieses geringe Risiko einer HBV-Infektion weiter zu verringern. Hier wird dann allerdings nur eine Therapie von 6-12 Monaten empfohlen [8].

Die Empfänger Anti-HBc-positiver/HBsAg-negativer Organe sollten zum Ausschluss einer Hepatitis-B-Reaktivierung bzw. HBV-Transmission regelmäßig auf HBsAg und HBV-DNA untersucht werden (alle 3 Monate im 1. Jahr nach Transplantation, im Verlauf alle 3-6 Monate). Bei positivem Nachweis von $\mathrm{HBsAg}$ und/oder HBV-DNA besteht die Indikation zur antiviralen Therapie (siehe 4.9).

Für das Risiko einer HBV-Transmission nach Stammzelltransplantation (SZT) eines Anti-HBc-positiven/HBsAg-negativen Spenders liegen nur unzureichende Daten vor. Es wird grundsätzlich dasselbe Vorgehen wie bei Herz-, Lungen- oder Nierenspende empfohlen. Es soll in jedem Fall eine engmaschige Kontrolle der HBV-Parameter nach SZT erfolgen. Eine okkulte HBV-Infektion (HBsAg negativ, HBV-DNA positiv) sollte bei Anti-HBc-positiven Stammzellspendern durch Bestimmung der HBV-DNA vor der Transplantation ausgeschlossen werden.

Der Nachweis von Anti-HBc-Antikörpern nach Organ-Tx bedeutet nicht in jedem Fall, dass eine HBV-Reaktivierung bzw. De-novo-HBV-Infektion stattgefunden hat, sondern kann auch durch eine Transfusion von Blut und Blutprodukten (z. B. Gabe von Immunglobulinen), die Anti-HBc-Antikörper enthalten, bedingt sein (keine Änderung zu [5]) ( Tab. 14).

\subsection{Wie ist das Management von Patienten, die ein Organ eines HBsAg-positiven Spenders erhalten?}

\section{EMPFEHLUNG 4.11.1}

Die Transplantation von Organen eines HBsAg-positiven Spenders kann in Einzelfällen bei Zustimmung des Empfängers erwogen werden [EK].

Konsens: 97,8\% (Delphi-Runde)

Neu 2020

\section{Kommentar:}

Die Lebertransplantation ist bei einem HBsAg-positiven Spender bisher nur in Ausnahmefällen durchgeführt worden. Unter einer effektiven antiviralen Prophylaxe mit hochpotenten NA zeigte sich jedoch ein vergleichbares Transplantatüberleben und Gesamtüberleben wie bei Patienten, die ein HBsAg-negatives Spenderorgan erhalten hatten [273, 286, 287].

In einer asiatischen Studie erhielten 42 Patienten eine HBsAgpositive Spenderleber. Es wurde nach der Transplantation eine Prophylaxe mit NA \pm HBIG durchgeführt. Das Transplantatüberleben und das Gesamtüberleben unterschieden sich nicht signifikant von den 327 Kontrollpatienten, die ein HBsAg-negatives Spenderorgan erhalten hatten [286].

Aufgrund des ausgeprägten Organmangels bestand bei den Mitgliedern ein hoher Konsens, auch die Transplantation HBsAgpositiver Organe in Einzelfällen und nach individueller Nutzen-Risiko-Abwägung bei expliziter Einwilligung des Empfängers und ausreichender Organqualität zu empfehlen.

\section{EMPFEHLUNG 4.11.2}

Alle Patienten, die eine Lebertransplantation eines HBsAg-positiven Spenders erhalten, sollen dauerhaft mit einem hochpotenten NA (ETV, TDF, TAF) behandelt werden [EK]. Konsens: $100 \%$ (Delphi-Runde)

Neu 2020

\section{Kommentar:}

Aufgrund der effektiven antiviralen Prophylaxe mit hochpotenten NA, wie unter 4.11 .1 beschrieben, soll bei allen Patienten, die ein $\mathrm{HBsAg-positives} \mathrm{Lebertransplantat} \mathrm{erhalten,} \mathrm{eine} \mathrm{lebenslange} \mathrm{Thera-}$ pie mit einem hochpotenten NA (ETV, TDF, TAF) erfolgen. Eine HBIGProphylaxe ist nicht erforderlich, da das Organ bereits mit HBV infiziert ist und eine Reinfektion nicht verhindert werden kann.

EMPFEHLUNG 4.11.3

Bei allen anderen Organtransplantationen (nicht Lebertransplantation, inkl. SZT) eines HBsAg-positiven Spenders soll die Prophylaxe initial kombiniert mit HBIG plus potentem NA erfolgen [EK] (siehe 4.3.1).

Konsens: $100 \%$ (Delphi-Runde)

Neu 2020

\section{Kommentar:}

Die Erfahrungen mit der Verwendung von Nierentransplantaten HBsAg-positiver Spender sind begrenzt. Nach bisherigen Daten ist die Transplantation der Niere eines HBsAg-positiven Spenders kein Risikofaktor für ein ungünstiges Transplantat- oder Gesamtüberleben, sofern zum Zeitpunkt der Transplantation ein ausreichender HBV-Impfschutz (Anti-HBs-Konzentration > 100 U/I) besteht. Sofern zum Zeitpunkt der Transplantation keine ausreichende Anti-HBs- 
- Tab. 14 Empfehlung bei Transplantation von Organen von Anti-HBc-positiven/HBsAg-negativen Spendern.

\begin{tabular}{|l|l|l|l|}
\hline $\begin{array}{l}\text { Anti-HBc-positives und HBsAg- } \\
\text { negatives Spenderorgan }\end{array}$ & \multicolumn{2}{|c|}{ Empfänger-Status } & Empfehlung \\
\hline & Anti-HBs & Anti-HBc & \\
\hline Leber & - & - & $\begin{array}{l}\text { Dauerhafte NA-Prophylaxe } \\
\text { (mind. bis Anti-HBs stabil > 100 IU/ml) }\end{array}$ \\
\hline & + & - & $\begin{array}{l}\text { Dauerhafte NA-Prophylaxe } \\
\text { (mind. bis Anti-HBs stabil > 100 IU/ml) }\end{array}$ \\
\hline Anderes Organ (nicht Leber) & $+/-$ & + & $\begin{array}{l}\text { Monitoring von HBsAg und HBV-DNA ausreichend } \\
\text { (alle 3 Monate im 1. Jahr, danach alle 3-6 Monate) }\end{array}$ \\
\hline & +- & $+/-$ & $\begin{array}{l}\text { Monitoring von HBsAg und HBV-DNA ausreichend } \\
\text { (alle 3 Monate im 1. Jahr, danach alle 3-6 Monate) }\end{array}$ \\
\hline
\end{tabular}

Konzentration (> $100 \mathrm{IU} / \mathrm{ml}$ ) vorliegt, soll initial zur NA-Therapie zusätzlich HBIG eingesetzt werden. Die Dauer der HBIG-Therapie ist nicht definiert. Eine Behandlung für 3 Monate scheint gemessen an kleinen Fallserien ausreichend zu sein (Dosierungen entsprechend $\triangleright$ Tab. 13) $[273,288,289]$.

Allerdings wurde ein Fall einer fulminanten, letztlich letal verlaufenden HBV-Infektion ein Jahr nach Nierentransplantation einer Niere eines HBsAg-positiven Spenders beschrieben. Hierbei lag eine HBsAg-„Escape“-Mutante vor. Eine Prophylaxe mit einem NA war in diesem Fall jedoch nicht durchgeführt worden [290].

Aufgrund des existierenden Organmangels bestand bei den Leitlinienmitgliedern ein hoher Konsens für die Empfehlung, die Transplantation HBsAg-positiver Nicht-Leber-Organe in Analogie zu der Empfehlung bei der Lebertransplatation nach gründlicher Prüfung von individuellen Risiken und Nutzen des Patienten in $\mathrm{Er}$ wägung zu ziehen. Über die Sicherheit und das Management von Herz- und Lungentransplantationen mit Organen von HBsAg-positiven Spendern liegen nur unzureichende Daten vor.

\section{EMPFEHLUNG 4.11.4}

Bei einer Stammzelltransplantation eines $\mathrm{HBsAg-positiven}$ Spenders soll zusätzlich der Spender möglichst frühzeitig vor der Transplantation mit einem hochpotenten NA behandelt werden [EK].

Konsens: $100 \%$ (Delphi-Runde)

Neu 2020

\section{Kommentar:}

Auch die Datenlage zur Sicherheit der Verwendung von HBsAgpositiven Stammzellspendern ist derzeit sehr begrenzt. Eine Verwendung von HBsAg-positiven Stammzellspendern kann im Falle fehlender anderer Optionen in Erwägung gezogen werden. Ohne Prophylaxe ist das Risiko einer HBV-Übertragung hoch (48-56\%) [291, 292].

Der Stammzellspender soll möglichst frühzeitig vor der Transplantation mit einem hochpotenten NA behandelt werden, um die Viruslast zu minimieren [293].

Der Empfänger soll eine langfristige Prophylaxe mit einem potenten NA erhalten. Die optimale Dauer der Prophylaxe ist nicht definiert. Es wird bei guter Verträglichkeit eine dauerhafte Prophylaxe empfohlen. Eine Beendigung der NA-Prophylaxe kann unter engmaschiger Kontrolle der HBsAg- und HBV-DNA-Konzentrationen erwogen werden, wenn nach HBV-Impfung eine stabile Anti-HBs-Response mit HBsAg-Konzentrationen $>100 \mathrm{lU} / \mathrm{ml}$ induziert werden konnte [292, 293].

\section{EMPFEHLUNG 4.11.5}

Patienten mit einer Hepatitis-Delta-Virusinfektion sollten keine HBsAg-positive Spenderleber erhalten [EK].

Konsens: 97,8\% (Delphi-Runde)

Neu 2020

\section{Kommentar:}

Bei Patienten mit einer Hepatitis Delta sollten keine HBsAg-positiven Spenderlebern verwendet werden. Ein Rezidiv der Hepatitis Delta ist wahrscheinlich und trat in einer kleinen Fallserie in beiden HDV-infizierten Patienten auf, die ein HBsAg-positives Organ erhielten. [294]

\subsection{Wer sollte vor einer Organtransplantation gegen HBV geimpft werden?}

\section{EMPFEHLUNG 4.12.1}

Patienten mit einem Anti-HBs-Spiegel < $100 \mathrm{U} / \mathrm{l}$ sollen so früh wie möglich vor einer geplanten Organ-Tx unter Ausnutzung aller Strategien zur Steigerung des Impfansprechens gegen Hepatitis B geimpft werden [EK].

Konsens: $100 \%$ (Delphi-Runde)

Modifiziert 2020

\section{Kommentar:}

Bisher ist die Schwelle der Anti-HBs-Konzentration, bei der von einem sicheren Impfschutz nach Transplantation ausgegangen werden kann, nicht bekannt. Die Höhe der Anti-HBs-Konzentra- 
tionen ist aber hinsichtlich der Prävention einer De-novo-HBV-Infektion nach Transplantation von Bedeutung [295, 296].

Die HBV-Impfung sollte so früh wie möglich erfolgen, da mit zunehmendem Progress der Lebererkrankung das Impfansprechen abnimmt. Das Impfansprechen bei Patienten mit Leberzirrhose vor Transplantation liegt bei einem konventionellen Impfschema $(20 \mu \mathrm{g}$ i.m. zu den Monaten 0, 1 und 6) bei etwa 16-28\% (keine Änderung zu [5]).

Zur Steigerung des Impfansprechens können höhere Dosierungen und/oder zusätzliche Impfapplikationen (Booster) zum Einsatz kommen (siehe auch 5.6 und 5.8) (keine Änderung zu [5]).

Eine Hochdosis-Hepatitis-B-Impfung mit ein- oder mehrmaligen Gaben von $80 \mu \mathrm{g}$ Vakzine führt bei Patienten mit chronischer Lebererkrankung, die nicht auf eine Impfung (mit $3 \times 40 \mu \mathrm{g}$ des HBV-Impfstoffs) angesprochen haben, zu einer signifikanten Steigerung des Impfansprechens (keine Änderung zu [5]).

Eine Wiederholung eines Impfzyklus mit $3 \times 40 \mu \mathrm{g}$ des HBVImpfstoffs nach initialem Nichtansprechen auf die Impfung (AntiHBs-Konzentration < $10 \mathrm{lU} / \mathrm{ml}$ ) führte in einer prospektiven Studie zu einem Impfansprechen von 51 \% mit einer medianen Anti-HBsKonzentration von IU/ml (Spannweite, 11 bis > $1000 \mathrm{IU} / \mathrm{ml}$ ) [297].

\section{EMPFEHLUNG 4.12.2}

Eine Booster-HBV-Impfung sollte bei Patienten mit Anti-HBsKonzentrationen $\geq 10$ und $<100 \mathrm{U} / \mathrm{I}$ durchgeführt werden [5, B]. Konsens: $100 \%$ (Delphi-Runde)

siehe siehe 5.7

\section{Kommentar:}

Da mit hoher Wahrscheinlichkeit die Höhe des Anti-HBs-Titers hinsichtlich der Prävention einer De-novo-HBV-Infektion nach Transplantation von Bedeutung ist und die Impfung sicher ist, wird bereits bei einem Abfall des Anti-HBs-Spiegel < $100 \mathrm{U} / \mathrm{l}$ bei vorher erfolgreich geimpften Patienten eine Boosterimpfung vor Transplantation empfohlen.

Auch bei Anti-HBc-positiven Patienten mit einem Anti-HBs-Spiegel < $100 \mathrm{U} / \mathrm{I}$ wird eine Boosterimpfung vor Transplantation empfohlen, wenngleich prospektive Studien zur Effektivität bzw. Notwendigkeit dieser Impfstrategie fehlen (keine Änderung zu [5]).

\section{Immunprophylaxe der Hepatitis B}

D. Glebe, W. Jilg, W. Gerlich, B . Kallinowski B, J. Schulze zur Wiesch, J. Verheyen, S. Wicker

\subsection{Wer soll gegen Hepatitis B geimpft werden?}

\section{EMPFEHLUNG 5.1}

Entsprechend den Empfehlungen der Ständigen Impfkommission am Robert Koch-Institut (STIKO) sollen geimpft werden [EK]:

5.1.1: alle Säuglinge ab dem vollendeten 2. Lebensmonat, Konsens: $100 \%$ (Delphi-Runde)
5.1.2: alle Neugeborenen HBsAg-positiver Mütter oder von Müttern mit unbekanntem $\mathrm{HBsAg}$-Status innerhalb von 12 Stunden,

Konsens: 97,9\% (Delphi-Runde)

5.1.3: alle noch nicht geimpften Kinder und Jugendlichen bis zum vollendeten 17. Lebensjahr, möglichst vor Beginn der Pubertät,

Konsens: $100 \%$ (Delphi-Runde)

NKLM

5.1.4: alle in der Indikationsliste der STIKO aufgeführten Personen mit erhöhtem Hepatitis-B-Risiko ( $\triangleright$ Tab. 15).

Konsens: 97,9\% (Delphi-Runde)

Modifiziert 2020

NKLM

5.2 Wann sollte die Impfung gegen Hepatitis B durchgeführt werden?

\section{EMPFEHLUNG 5.2}

Die Impfung sollte durchgeführt werden:

5.2.1: bei Säuglingen ab dem vollendeten 2. Lebensmonat [EK]

Konsens: $100 \%$ (Delphi-Runde)

5.2.2: bei Neugeborenen HBsAg-positiver Mütter oder von Müttern mit unbekanntem HBsAg-Status innerhalb von 12 Stunden nach Geburt (s. Postexpositionsprophylaxe) [EK] Konsens: $100 \%$ (Delphi-Runde)

5.2.3: bei noch nicht geimpften Kindern und Jugendlichen bis zum vollendeten 17. Lebensjahr möglichst vor Beginn der Pubertät [EK]

Konsens: $100 \%$ (Delphi-Runde)

5.2.4: bei Hepatitis-B-gefährdetem Personal im Gesundheitsund Rettungsdienst vor Aufnahme der Berufsausbildung [EK] Konsens: $100 \%$ (Delphi-Runde)

5.2.5: bei Medizin- und Zahnmedizinstudenten vor Beginn des Studiums bzw. des Krankenpflegediensts [EK]

Konsens: $100 \%$ (Delphi-Runde)

5.2.6: bei Patienten vor geplanter Transplantation [EK] Konsens: $100 \%$ (Delphi-Runde)

5.2.7: bei Patienten mit chronischer Nierenkrankheit vor Eintritt der Dialysepflichtigkeit [EK]

Konsens: $100 \%$ (Delphi-Runde)

5.2.8. bei Patienten mit HIV-Infektion möglichst frühzeitig nach Erstdiagnose; bei Nichtansprechen bereits immunsupprimierter Patienten sollte nach Erreichen einer Immunrekonstitution unter antiretroviraler Therapie die Impfung wiederholt werden [EK].

Konsens: $100 \%$ (Delphi-Runde)

5.2.9: bei Patienten in Gemeinschaftseinrichtungen (z. B. Pflegeheime, psychiatrische Einrichtungen) und Bewohnern von Fürsorgeeinrichtungen für Zerebralgeschädigte oder Verhaltensgestörte vor Aufnahme in die Einrichtung [EK] Konsens: 97,9\% (Delphi-Runde) 
> Tab. 15 Die Indikationsliste der Ständigen Impfkommission (STIKO) - Stand August 2020 [Robert Koch-Institut 2020].

1. Personen, bei denen wegen einer vorbestehenden oder zu erwartenden Immundefizienz bzw. -suppression oder wegen einer vorbestehenden Erkrankung ein schwerer Verlauf einer Hepatitis-B-Erkrankung zu erwarten ist, z. B. HIV-Positive, Hepatitis-C-Positive, Dialysepatienten/-innen

2. Personen mit einem erhöhten nichtberuflichen Expositionsrisiko, z. B. Kontakt zu HBsAg-Trägern in Familie/Wohngemeinschaft, Sexualverhalten mit hohem Infektionsrisiko, i. v. Drogenkonsumierende, Untersuchungshäftlinge und Strafgefangene, ggf. Patienten/-innen psychiatrischer Einrichtungen

3. Personen mit erhöhtem beruflichem Expositionsrisiko, einschließlich Auszubildender, Praktikanten/-innen, Studierender und ehrenamtlich Tätiger mit vergleichbarem Expositionsrisiko, z. B. Personal in medizinischen Einrichtungen (einschließlich Labor- und Reinigungspersonal), Sanitäts- und Rettungsdienst, betriebliche Ersthelfer/-innen, Polizisten/-innen, Personal von Einrichtungen, in denen eine erhöhte Prävalenz von Hepatitis-B-Infizierten zu erwarten ist (z. B. Gefängnisse, Asylbewerberheime, Einrichtungen für Menschen mit Behinderungen).

4. Reiseindikation

individuelle Gefährdungsbeurteilung erforderlich

zusätzlich werden noch erwähnt:

Personen nach Verletzungen mit möglicherweise HBV-haltigen Gegenständen (z. B. Nadelstich) oder Blutkontakt mit Schleimhaut oder nicht intakter Haut (s. 5.10).

Neugeborene HBsAg-positiver Mütter oder von Müttern mit unbekanntem HBsAg-Status (unabhängig vom Geburtsgewicht) (s. 5.9).

Literatur: [298-302].

5.2.10: bei Personen nach Verletzungen mit möglicherweise erregerhaltigen bzw. -kontaminierten Gegenständen (z. B. Nadelstichverletzung) oder nach Kontakt von Schleimhaut oder verletzter Haut mit erregerhaltigem Material so bald wie möglich (innerhalb von 48 Stunden nach Exposition) (s. Postexpositionsprophylaxe) [EK] Konsens: 97,9\% (Delphi-Runde)

5.2.11: bei allen anderen Personen zum Zeitpunkt ihrer Zuordnung zu einer Risikogruppe [EK]

Konsens: 97,9\% (Delphi-Runde)

Modifiziert 2020

\section{Kommentar:}

Bei allen im medizinischen Bereich Tätigen ist ein Vollschutz gegen Hepatitis B (Anti-HBs von $\geq 100$ IU/I 4-8 Wochen nach kompletter Grundimmunisierung) bereits vor Aufnahme der Ausbildung von größter Bedeutung. Da die Verletzungs- und damit die Infektionsgefahr bei Anfängern besonders groß ist, sollte darauf geachtet werden, dass vor den ersten berufsspezifischen Praktika (z. B. Krankenpflegedienst bei Medizinstudenten, der meist bereits vor Beginn des Studiums abgeleistet wird) die Hepatitis-B-Impfung durchgeführt wird. Personen, die eine HepatitisB-Impfung ablehnen und nicht immun sind, sollten Tätigkeiten mit Übertragungsgefahr nicht ausüben.

Hämodialysepatienten sprechen schlecht auf die Hepatitis-BImpfung an. Daher sollten diese Personen bereits geimpft werden, wenn erstmals die Diagnose einer chronischen Nierenerkrankung gestellt wird, die eine spätere Dialysebehandlung und/oder Transplantation notwendig erscheinen lässt (Evidenz 3b) (keine Änderung zu [5]).

Auch bei HIV-Infizierten ist die Wirksamkeit der Impfung bei bereits bestehendem Immundefekt vermindert, die Impfung sollte daher bereits in einem frühen Infektionsstadium bei noch normaler CD4-Zellzahl durchgeführt werden (Evidenz 2b) (keine Änderung zu [5]).

Bei Patienten, die aufgrund ihrer Immunsuppression nicht auf die Impfung angesprochen haben, sollte nach Einleitung einer antiretroviralen Therapie (ART) und Verbesserung oder Normalisierung der Zahl der CD4-positiven Zellen sowie Abnahme der Viruslast die Impfung erneut versucht werden (Evidenz 2b) (keine Änderung zu [5]).

\subsection{Ist es vor einer Hepatitis-B-Impfung notwendig zu tes-} ten, ob bereits Kontakt mit dem Hepatitis-B-Virus stattgefunden hat?

\section{STATEMENT 5.3.1}

Eine Testung auf Hepatitis-B-Marker vor der Impfung ist aus medizinischen Gründen nicht notwendig.

Konsens: 95,8\% (Konsensuskonferenz)

Geprüft 2020

NKLM

\section{Kommentar:}

Es besteht keine medizinische Indikation vor einer geplanten Hepatitis-B-Impfung abzuklären, ob die Person bereits Kontakt mit dem Hepatitis-B-Virus hatte. Eine Impfung von Personen mit (asymptomatischer) akuter, chronischer oder abgelaufener Hepatitis B kann gefahrlos durchgeführt werden, ist allerdings wirkungslos. Bei Nichtansprechen auf eine Grundimmunisierung sollte daher eine akute oder chronische HBV-Infektion ausgeschlossen werden, bevor eine erneute Impfung durchgeführt wird (s. 5.6). 


\section{EMPFEHLUNG 5.3.2}

Eine Untersuchung auf Anti-HBc kann bei Angehörigen von Risikogruppen (wie in der Liste der STIKO aufgeführt) und bei Personen oder deren Nachkommen aus hochendemischen Gebieten sinnvoll sein, wenn das erhöhte Risiko schon seit längerer Zeit (Jahren) besteht [0, 4].

Konsens: 97,9\% (Delphi-Runde)

Geprüft 2020

\section{Kommentar:}

Ob eine Vortestung kostengünstig ist, hängt von den Testkosten, von den Kosten für den Impfstoff und vom Anteil Immuner im geimpften Kollektiv ab. So wird bei einem Testpreis von $€ 20,11$ (Vollkosten für den Anti-HBc-Test nach GOÄ) und einem Impfstoffpreis von $€ 198,87$ bis $€ 207,30$ (für 3 Dosen) eine Vortestung kostengünstig bei einer Anti-HBc-Prävalenz eines zu impfenden Kollektivs von etwa $10 \%$. Ein derartiger Wert wird in der deutschen Normalbevölkerung nicht erreicht, sehr wohl aber in bestimmten Hochrisikogruppen wie z. B. Personen aus Hochendemiegebieten, u. U. auch bei Menschen, die glaubhaft über eine Hepatitis unbekannter Ursache berichten. [303, 304]

Zusatz zur HBV-Impfung bei medizinischem Personal, das Tätigkeiten mit erhöhter HBV-Übertragungsgefahr ausübt.

Medizinischem Personal ist gemäß der Verordnung zur Arbeitsmedizinischen Vorsorge (ArbMedVV) eine Impfung gegen Hepatitis B anzubieten.

Bei einer Einstellungsuntersuchung sollte bei medizinischem Personal eine eventuell vorliegende chronische oder okkulte HBV-Infektion ausgeschlossen und Immunität festgestellt werden (siehe 1.1.3, zur initialen Diagnostik siehe 1.1.1 und 1.2.2). Bei fehlender Immunität ist eine aktive Hepatitis-B-Impfung zu veranlassen (siehe 1.2.1) und deren Erfolg zu kontrollieren (Anti-HBs-Titer $\geq 100 \mathrm{IU} / \mathrm{L}$ ) (siehe 5.4.2). Personen, die sich weigern, ihren HBV-Status überprüfen zu lassen, sollten Tätigkeiten mit erhöhter Übertragungsgefahr nicht ausüben.

Bei Personen, die bereits eine HBV-Infektion haben, ist eine Impfung wirkungslos (s. o.). Welche Tätigkeiten von HBV-Trägern im medizinischen Bereich ausgeübt werden dürfen, regeln die „Empfehlungen der Deutschen Vereinigung zur Bekämpfung der Viruskrankheiten (DVV) zur Prävention der nosokomialen Übertragung von Hepatitis B (HBV) und Hepatitis C Virus (HCV) durch im Gesundheitswesen Tätige“. Zu Tätigkeitseinschränkungen von HBV-Infizierten im Gesundheitswesen siehe: 5.12 [89].

\subsection{Ist es nach einer Hepatitis-B-Impfung notwendig zu testen, ob die Impfung erfolgreich war?}

\section{EMPFEHLUNG 5.4.1}

Bei geimpften Personen, die keiner spezifischen Risikogruppe angehören, gesund und jünger als 40 Jahre sind, braucht eine Erfolgskontrolle nach der Impfung nicht durchgeführt zu werden [EK].

Konsens: $100 \%$ (Konsensuskonferenz)

Geprüft 2020

\section{Kommentar:}

Die Serokonversionsraten von geimpften Kindern und Jugendlichen liegen bei $>98 \%$, bei gesunden jüngeren Erwachsenen (<40 Jahren) bei über $95 \%$ (keine Änderung zu [5]).

Die Kontrolle des Impferfolgs erscheint daher bei diesen Personen nicht notwendig, solange sie keinem deutlich erhöhten Risiko unterliegen.

\section{EMPFEHLUNG 5.4.2}

Eine Testung auf Anti-HBs sollte bei allen in > Tab. 15 genannten Personen durchgeführt werden [EK].

Konsens: $100 \%$ (Konsensuskonferenz)

Modifiziert 2020

\section{Kommentar:}

Eine quantitative Testung auf Anti-HBs 4-8 Wochen nach der Beendigung der Grundimmunisierung (d. h. nach der dritten bzw. vierten Impfung) ist dagegen angezeigt bei allen in $>$ Tab. 15 aufgeführten Personen, also allen, bei denen wegen einer vorbestehenden oder zu erwartenden Immundefizienz bzw. -suppression oder wegen einer vorbestehenden Erkrankung ein schwerer Verlauf einer Hepatitis-B-Erkrankung zu erwarten ist, und bei allen Menschen mit erhöhtem beruflichem oder nichtberuflichem Hepatitis-B-Risiko. Insbesondere sollte der Impferfolg bei Personen überprüft werden, bei denen von einer erniedrigten Ansprechrate auf die Impfung auszugehen ist, wie den bereits erwähnten Immunsupprimierten, Personen mit ausgeprägter Adipositas und älteren Menschen.

\section{EMPFEHLUNG 5.4.3}

Eine Testung kann erwogen werden bei nicht in $>$ Tab. 15 aufgeführten Personen, die älter als 40 Jahre sind [EK].

Konsens: 95,6\% (Delphi-Runde)

Modifiziert 2020

\section{Kommentar:}

Ein schlechteres Ansprechen auf die Grundimmunisierung ist bereits bei Menschen $>40$ Jahre festzustellen (Evidenz 2a) (keine Änderung zu [5]).

\section{Zusatz}

Auch unmittelbar nach der Geburt geimpfte Neugeborene sprechen schlechter auf die Impfung an und sollten daher ebenfalls getestet werden (Evidenz 1b) (keine Änderung zu [5]).

Gründe für eine Testung sind, dass zum einen bei möglichst allen geimpften Personen ein belastbarer Schutz erzielt werden sollte, weshalb Non- bzw. Lowresponder nachgeimpft werden sollten, zum zweiten kann bei ausgebliebenem Impferfolg im Falle eines Kontakts mit HBV, etwa durch eine Nadelstichverletzung o. Ä., durch eine sofortige Gabe von Hepatitis-B-Immunglobulin (HBIG), in der Regel kombiniert mit einer aktiven Impfung, eine Infektion noch vermieden werden. 
5.5 Ist nach erfolgreicher Impfung gegen Hepatitis B eine Auffrischimpfung notwendig?

\section{STATEMENT 5.5.1}

Nach derzeitigem Wissenstand kann man nach einer erfolgreichen Grundimmunisierung (Anti-HBs 4-8 Wochen nach letzter Impfung $\geq 100 \mathrm{IU} / \mathrm{I}$ ) von einem langjährigen, möglicherweise sogar lebenslangen Schutz vor einer Hepatitis-BErkrankung ausgehen.

Konsens: 95,7\% (Delphi-Runde)

Modifiziert 2020

NKLM

\section{Kommentar:}

Die Hepatitis-B-Impfung induziert bei allen erfolgreich Geimpften die Bildung neutralisierender Antikörper, die in einer Konzentration von $\geq 10 \mathrm{lU} / \mathrm{I}$ Schutz vor einer Infektion verleihen [5, 305].

Da die Anti-HBs-Konzentration nach der Grundimmunisierung allerdings sehr rasch absinkt, gilt als Kriterium einer erfolgreichen Immunisierung in Deutschland wie in England, Irland, Österreich und der Schweiz ein Anti-HBs-Wert von wenigstens $100 \mathrm{IU} / \mathrm{L}$, gemessen 4-8 Wochen nach der dritten Impfung. (Dieser Wert wurde auch deshalb gewählt, weil mit unterschiedlichen Anti-HBsTests erhobene Ergebnisse speziell im niedrigen Bereich zwischen 0 und $20 \mathrm{IU} / \mathrm{I}$ stark divergieren können) [306].

Selbst nach einer derartigen erfolgreichen Impfung sinkt das Anti-HBs jedoch bei etwa 20-50\% auch immunologisch gesunder Impflinge nach 4-10 Jahren unter einen Wert von $10 \mathrm{IU} / \mathrm{I}$ ab (Evidenz 2a) (keine Änderung zu [5]).

Auch diese Menschen sind aber vor Erkrankung geschützt. Die Basis dafür bildet ein ausgeprägtes immunologisches Gedächtnis, das über das Vorhandensein von Anti-HBs hinaus persistiert. Im Falle eines Kontakts mit dem Erreger wird sehr rasch eine Immunreaktion in Gang gesetzt, die eine beginnende Infektion schnell beendet und eine Erkrankung oder eine chronische Infektion sicher verhindert (Evidenz 3a) (keine Änderung zu [5]).

Wiederimpfungen von Personen, die ihre Antikörper verloren haben, führen nach 3-7 Tagen zu einem ausgeprägten Antikörperanstieg (Evidenz 2b) (keine Änderung zu [5]) [5, 307].

Eine derartige „anamnestische“ Immunantwort konnte auch 15 bis 20 Jahre nach der Grundimmunisierung bei über $90 \%$ aller Personen festgestellt werden, deren Antikörper in der Zwischenzeit unter einen Wert von $10 \mathrm{IU} / \mathrm{l}$ abgesunken waren (Evidenz 2b) (keine Änderung zu [5]).

\section{EMPFEHLUNG 5.5.2}

Bei im Säuglings- oder Kleinkindalter Geimpften ohne besonderes Hepatitis-B-Risiko braucht eine Auffrischimpfung nicht zu erfolgen [EK].

Tritt im späteren Leben ein erhöhtes Risiko ein (z. B. Ausbildung bzw. Tätigkeit in einem medizinischen Beruf), sollten eine Auffrischimpfung und eine anschließende serologische Kontrolle durchgeführt werden [EK].

Konsens: 95,7\% (Delphi-Runde)

Modifiziert 2020

\section{Kommentar:}

Auch einzelne kontrollierte Studien bei im Kindesalter Geimpften zeigen eine über 95 \%ige Schutzwirkung der Impfung für über 15 Jahre (Evidenz 2a) (keine Änderung zu [5]).

Eine Metaanalyse zum Langzeitschutz der Hepatitis-B-Impfung im Säuglingsalter wies allerdings nach, dass auch die als „Boostability“ bezeichnete Fähigkeit zu einer anamnestischen Immunreaktion nach einer Auffrischimpfung in Abhängigkeit von der Impfdosis und dem zeitlichen Abstand zur Grundimmunisierung abnimmt (Evidenz 2a) [308].

15 Jahre nach Grundimmunisierung waren im Mittel etwa $25 \%$ der Geimpften nicht mehr zu einer anamnestischen Reaktion in der Lage, hatten also wahrscheinlich ihr immunologisches Gedächtnis verloren. Allerdings handelte es sich bei der Mehrzahl der analysierten Studien um Untersuchungen in Hochrisikoregionen wie Zentralafrika, Südostasien oder Alaska, deren Ergebnisse aufgrund der spezifischen epidemiologischen Situation wie auch der verwendeten Impfstoffe nur bedingt auf europäische bzw. deutsche Verhältnisse übertragbar sind. Neue Untersuchungen aus Europa und den USA belegen aber, dass 16-23 Jahre nach Grundimmunisierung mit den heute üblichen Impfstoffen auch nach dem Absinken des schützenden Anti-HBs auf Werte $<10 \mathrm{IU} / \mathrm{l}, 94-97 \%$ mit einer prompten Antikörperbildung auf eine Auffrischimpfung reagieren (Evidenz 2b) [309-311].

Daher erscheint eine Auffrischimpfung auch angesichts der epidemiologischen Situation in Deutschland gegenwärtig nicht notwendig. Unterstützt werden könnte diese Sicht durch eine aktuelle Studie aus Alaska, in der 243 Personen, die als Kinder, Jugendliche oder Erwachsene geimpft wurden, 30 Jahre nach Grundimmunisierung untersucht wurden. $51 \%$ der Teilnehmer wiesen noch AntiHBs-Werte $\geq 10 \mathrm{IU} / \mathrm{I}$ auf, $88 \%$ der Teilnehmer mit Werten $<10 \mathrm{IU} / \mathrm{I}$ sprachen auf eine Auffrischimpfung an. Innerhalb der Beobachtungszeit wurden keine Durchbruchsinfektionen beobachtet und nur 2 Personen waren Anti-HBc-positiv (Evidenz 3). Allerdings ist nicht klar, inwieweit diese Ergebnisse auf die Verhältnisse in Deutschland übertragbar sind, denn es handelt sich auch hier um eine Untersuchung in einem Hochendemiegebiet, und die Teilnehmer wurden nicht mit dem heute ausschließlich verwendeten rekombinanten Impfstoff geimpft, sondern hatten die aus Plasma chronischer HBV-Träger hergestellte Vakzine erhalten [312]. 
Ergibt sich für als Säuglinge geimpfte Jugendliche oder Erwachsene ein erhöhtes Infektionsrisiko, sollte eine Auffrischimpfung erfolgen und der Anti-HBs-Wert 4-8 Wochen später bestimmt werden. Zu nennen sind hier etwa durch Ausbildung oder Tätigkeit in einem Gesundheitsberuf, Tätigkeit als Ersthelfer, HBsAg-positive Sexualpartner oder längeren Aufenthalt in einem Hochendemiegebiet gefährdete Personen oder Personen, bei denen wegen einer vorbestehenden oder zu erwartenden Immundefizienz bzw. -suppression oder wegen einer vorbestehenden Erkrankung ein schwerer Verlauf einer Hepatitis B zu erwarten ist, z. B. HIV-Positive, Hepatitis-C-Positive und Dialysepatienten. Das ist insbesondere deswegen notwendig, weil der Impferfolg bei allen diesen als Säuglinge oder Kleinkinder geimpften Personen in der Regel nicht kontrolliert wurde und eventuelle Nonresponder daher nicht entdeckt werden konnten. Außerdem ist damit zu rechnen, dass bis zu $50 \%$ dieser Personen einen Anti-HBs-Spiegel unter der Schutzgrenze von $10 \mathrm{IU} / \mathrm{L}$ aufweisen (Evidenz 2b) [307].

\section{EMPFEHLUNG 5.5.3}

Für Personen, die wegen eines in der Indikationsliste der STIKO aufgeführten erhöhten Risikos ( $>$ Tab. 15) erfolgreich geimpft wurden (Anti-HBs 4-8 Wochen nach letzter Impfung $\geq 100 \mathrm{IU} / \mathrm{I}$ ), braucht vor dem Hintergrund der epidemiologischen Situation in Deutschland gegenwärtig eine generelle Auffrischimpfung nicht zu erfolgen [EK].

Bei besonders hohem Expositionsrisiko sollte allerdings nach 10 Jahren eine Kontrolle des Anti-HBs-Werts und gegebenenfalls (wenn Anti-HBs < 100 IU/I) eine Auffrischimpfung durchgeführt werden [EK].

Konsens: $100 \%$ (Konsensuskonferenz)

Modifiziert 2020

\section{Kommentar:}

Für Menschen, die aufgrund eines spezifischen Risikos gemäß der Indikationsliste der STIKO (5.1) geimpft wurden, galt bis 2013 in Deutschland die Empfehlung einer Auffrischimpfung nach 10 Jahren. Um deren Notwendigkeit zu überprüfen, wurde von Mitgliedern der STIKO und der STIKO-Geschäftsstelle eine systematische Literaturübersicht zur Frage der Impfschutzdauer erstellt (Evidenz 3) [313].

Als wichtigstes Kriterium zur Bewertung des Impferfolgs wurde ein Impfdurchbruch in Form einer akuten oder chronischen Hepatitis B, HBsAg- oder HBV-DNA-Positivität gewählt. Die Untersucher fanden allerdings nur 10 Studien, die in Industrienationen Europas und in den USA durchgeführt wurden und die die Einschlusskriterien erfüllten. Sie zeigten zusammenfassend, dass unter Expositionsbedingungen, die mit der Situation in Deutschland vergleichbar waren, innerhalb eines Zeitraums von 10 Jahren bei erfolgreich Geimpften keine Fälle von klinischer Hepatitis B oder einer HBsAg-Positivität auftraten; Anti-HBc-Positivität wurde in weniger als $1 \%$ der Studienteilnehmer beobachtet. Diese Ergebnisse veranlassten die STIKO, von einer generellen Empfehlung einer Auffrischimpfung abzusehen und eine Position einzunehmen, wie sie auch von verschiedenen internationalen Gremien wie der WHO, dem amerikanischen Advisory Committee on Immunization Practices (ACIP) und dem Viral Hepatitis Prevention Board (VHPB) vertreten wird [305, 314, 315].

Aufgrund der doch beschränkten Datenlage und der Tatsache, dass keine hinreichend verlässliche Aussage über 10 Jahre hinaus gemacht werden kann, sollte bei Menschen mit besonders hohem Expositionsrisiko, z. B. bei permanent anhaltendem bzw. ständig wiederkehrendem übertragungsrelevantem Blutkontakt im medizinischen Bereich, HBsAg-positiven Partnern oder längerem Aufenthalt in einem Hochendemiegebiet mit intensivem Kontakt zur einheimischen Bevölkerung, weiterhin nach 10 Jahren eine AntiHBs-Kontrolle durchgeführt werden, gefolgt von einer Auffrischimpfung, wenn Anti-HBs < 100 IU/I ist. Das entspricht auch den gegenwärtigen Empfehlungen der STIKO [313].

Beobachtungen an geimpften amerikanischen Blutspendern zeigen, dass bei niedrigem (<100 IU/L) oder völlig abgefallenem Anti-HBs und sexueller Exposition okkulte HBV-Infektionen ohne nachweisbares HBsAg, aber mit transienter Virämie möglich sind. Diese Infektionen sind völlig asymptomatisch und führen nach einigen Wochen oder Monaten zu einer Auffrischung der Anti-HBsTiter. Die beobachteten okkulten HBV-Infektionen wurden vorwiegend durch andere HBV-Genotypen als den sonst in den USA vorherrschenden und im Impfstoff verwendeten Genotyp A2 hervorgerufen (Evidenz 2b) (keine Änderung zu [5]).

Klinisch sind diese Infektionen irrelevant oder wegen der natürlich erfolgten Auffrischung der Immunität möglicherweise sogar vorteilhaft. Ob diese okkulten Infektionen bei dem betroffenen Personenkreis zu einer Persistenz oder gar einer Reaktivierung bei einer Einschränkung des Immunsystems führen, ist bislang ungeklärt.

Die Bedeutung der transienten okkulten Virämie für die HBVSicherheit im Blutspendewesen muss jedoch untersucht werden. Ähnliches dürfte für die kürzlich beschriebenen Infektionen bei Geimpften gelten, die nicht nur ohne klinische Erscheinungen, sondern auch ohne serologische Korrelate (Anti-HBc, HBsAg) ablaufen und nur durch das Auftauchen HBcAg- und HBV-Polymerase-spezifischer T-Zellen bemerkbar werden [316].

Diese beiden Beobachtungen weisen noch einmal darauf hin, dass unsere gegenwärtige Impfstrategie einkalkuliert, dass Infektionen stattfinden können (wenn auch klinisch unauffällig). Das gilt auch für den Fall, dass nach 10 Jahren eine Auffrischimpfung erfolgt, weil bei einem beträchtlichen Anteil der Geimpften der Anti-HBs-Spiegel innerhalb dieses Zeitraums unter die Schutzgrenze absinkt und Infektionen wieder möglich sind. Vermeiden ließe sich das nur (zumindest zum größten Teil), wenn der Anti-HBs-Spiegel kontinuierlich über $100 \mathrm{IU} / \mathrm{I}$ gehalten wird, was aber mit den gegenwärtigen Impfstoffen nur bei einem Teil der Impflinge möglich sein dürfte. 
5.6 Wie ist bei Nichtansprechen auf die Hepatitis-B-Impfung (Anti-HBs nach 3 Impfungen < $10 \mathrm{IU} / \mathrm{I}$ ) zu verfahren?

\section{EMPFEHLUNG 5.6}

Personen, deren Anti-HBs-Konzentrationen 4-8 Wochen nach der Grundimmunisierung < $10 \mathrm{IU} / \mathrm{I}$ betragen („Nonresponder“), sollen nach Ausschluss einer HBV-Infektion (HBsAg, Anti-HBc) erneut geimpft werden [EK].

Konsens: $100 \%$ (Delphi-Runde)

Modifiziert 2020

\section{Kommentar:}

Mehrere Studien konnten zeigen, dass mit bis zu 3 zusätzlichen Impfungen in Abständen von 1-3 Monaten 50-100\% der Nonresponder zur Serokonversion zu bringen sind (Evidenz 2b) (keine Änderung zu [5]).

Nonresponder sollen daher bis zu 3 weitere Impfungen (in Abständen von 1-3 Monaten) erhalten. Eine Reihe von Untersuchern beschreibt den Einsatz von intradermalen Impfungen bei Nonrespondern. Obwohl immunologisch einleuchtend, gibt es bis jetzt bei Immungesunden keinen eindeutigen Beweis für eine signifikant bessere Immunantwort auf diese Impftechnik (Evidenz 1a) (keine Änderung zu [5]) [317].

Sofern vor der Impfung kein HBsAg und Anti-HBc bestimmt wurde, sollte bei Nichtansprechen auf die Hepatitis-B-Impfung eine Bestimmung nachgeholt werden, weil es sich in diesem Fall um chronische Virusträger handeln könnte!

\subsection{Wie ist bei Personen zu verfahren, deren Anti-HBs-Kon- zentration 4-8 Wochen nach Grundimmunisierung 10-99 IU/I beträgt (gesunde Lowresponder)?}

\section{EMPFEHLUNG 5.7}

Personen, deren Anti-HBs-Konzentration 4-8 Wochen nach der Grundimmunisierung 10-99IU/I beträgt („Lowresponder“), sollten entsprechend den Empfehlungen der STIKO eine sofortige Wiederimpfung erhalten; Anti-HBs sollte nach 4-8 Wochen erneut bestimmt werden [5, B].

Konsens: 97,9\% (Delphi-Runde)

Geprüft 2020

\section{Kommentar:}

Die Notwendigkeit eines derartigen Vorgehens wurde niemals bewiesen. Der Wert von $\geq 100 \mathrm{IU} / \mathrm{I}$ als Kriterium für gutes Ansprechen auf die Impfung (nicht für Immunität!) wurde auf einer internationalen Konferenz im Jahr 1988 festgelegt (Expertenmeinung), auch aufgrund der mit verschiedenen Anti-HBs-Tests nicht selten stark differierenden Ergebnisse (keine Änderung zu [5]) [306].

Ein Wert von $\geq 100 \mathrm{IU} / \mathrm{l}$ Anti-HBs 1-2 Monate nach der 3. Impfung weist nach unserer heutigen Kenntnis auch auf das „Priming“ eines guten immunologischen Gedächtnisses und damit auf einen verlässlichen Langzeitschutz vor Erkrankung hin, ein niedrigerer Wert schließt das aber nicht aus (in den USA gilt ein Wert von $\geq 10$ IU/I 1-3 Monate nach der 3. Impfung als Beweis für eine erfolgreiche Impfung).

\subsection{Was ist bei der Impfung von Immunsupprimierten generell zu beachten?}

\section{EMPFEHLUNG 5.8.1}

Bei immunsupprimierten bzw. immundefizienten Personen sollte eine erhöhte Dosis (doppelte Dosis bzw. Dosis für Dialysepflichtige) verabreicht werden [2, B].

Konsens: 95,8\% (Delphi-Runde)

Geprüft 2020

\section{EMPFEHLUNG 5.8.2}

Bei Dialysepatienten sollte wie bei allen immunsupprimierten bzw. immundefizienten Personen die Gabe einer erhöhten Dosis (doppelte Dosis bzw. Dosis für Dialysepflichtige) bzw. ein speziell für diese Patientengruppe vorgesehener stärker adjuvantierter Impfstoff verabreicht werden [EK].

Konsens: 97,8\% (Delphi-Runde)

Modifiziert 2020

\section{Kommentar 5.8.1/5.8.2}

Für Dialysepatienten wurde das bessere Ansprechen auf eine erhöhte Dosis des Impfstoffs mehrfach gezeigt (Evidenz 2a), ebenso für immunsupprimierte bzw. immundefiziente Personen, z. B. HIVInfizierte mit eingeschränkter Immunfunktion (Evidenz 2b) und chronische Alkoholiker (keine Änderung zu [5]).

Studien bei Dialysepatienten mit intradermaler Impfung ergaben widersprüchliche Ergebnisse. Ebenso wie bei Immungesunden ließ sich in den meisten Untersuchungen an Dialysepatienten ein besseres Abschneiden der intradermalen Technik gegenüber der intramuskulären Injektion nicht feststellen (Evidenz 2a) (keine Änderung zu [5]).

Eine Studie fällt allerdings eindeutig positiv aus und lässt zumindest den Versuch mit dieser Technik bei Dialysepatienten, die bisher nicht auf die Impfung angesprochen haben, als sinnvoll erscheinen. Mehrere kleine Dosen scheinen hierbei von Vorteil zu sein $(2 \times 5 \mu \mathrm{g}$ in $250 \mu \mathrm{l}$ in die Volarseite des rechten und linken Unterarms, $1 \times$ pro Woche für 8 Wochen (Evidenz 2b) (keine Änderung zu [5]).

\section{EMPFEHLUNG 5.8.3}

Eine Kontrolle des Impferfolgs sollte erfolgen [2, B]. Besteht ein erhöhtes Hepatitis-B-Risiko, sollte Anti-HBs jährlich kontrolliert werden [2, B]. Bei Absinken von Anti-HBs auf Werte $<100 \mathrm{IU} / \mathrm{l}$ sollte eine Auffrischimpfung erfolgen [EK].

Konsens: $100 \%$ (Delphi-Runde)

Geprüft 2020 


\section{Kommentar:}

Über die Schutzdauer nach erfolgreicher Grundimmunisierung von immunsupprimierten Personen ist wenig bekannt. Im Gegensatz zur Situation bei Gesunden wurden klinisch manifeste HBVInfektionen bei geimpften Dialysepatienten beobachtet, deren Anti-HBs-Titer unter $10 \mathrm{lU} / \mathrm{l}$ abgefallen war (Evdienz Ila) (keine Änderung zu [5]).

Nach Meinung der meisten Autoren erschien es daher gerechtfertigt, diese Patienten in regelmäßigen Abständen auf Anti-HBs zu testen und durch Auffrischimpfungen einen Anti-HBs-Spiegel von > $10 \mathrm{IU} / \mathrm{l}$ aufrechtzuerhalten.

Auch wenn für andere immunsupprimierte Personen keine Daten dazu vorliegen, sollte bei ihnen genauso verfahren werden, sofern ein erhöhtes Hepatitis-B-Risiko besteht [315].

Allerdings hat die STIKO im Jahr 2013 den Anti-HBs-Wert, der in diesen Fällen nicht unterschritten werden sollte, auf $100 \mathrm{IU} / \mathrm{I}$ festgelegt [318].

Grund dafür war neben den mit verschiedenen Anti-HBs-Tests differierenden Ergebnissen auch die Vorstellung, dass mit höheren Anti-HBs-Werten auch Infektionen (und nicht nur Erkrankungen) besser verhindert werden [319].

\section{EMPFEHLUNG 5.8.4}

Patienten mit HIV-Infektion sollten bei noch intakter Immunfunktion normal geimpft werden. Der Impferfolg sollte kontrolliert werden; bei Nichtansprechen sollten weitere Impfungen durchgeführt werden [2, B].

Konsens: $100 \%$ (Delphi-Runde)

Geprüft 2020

\section{EMPFEHLUNG 5.8.5}

Bei HIV-Patienten mit Immundefekt sollte eine erhöhte Impfdosis verabreicht werden [2, B]. Bei Nonrespondern sollte nach Einleitung einer ART und Verbesserung der Zahl der CD4-positiven Zellen sowie Abnahme der Viruslast die Impfung erneut versucht werden [2, B].

Konsens: 95,7\% (Delphi-Runde)

Geprüft 2020

\section{Kommentar 5.8.4/5.8.5:}

Bei HIV-Patienten hängt das Vorgehen vom Immunstatus ab. Bei noch Immunkompetenten kann wie bei Gesunden geimpft werden, allerdings sollte der Impferfolg kontrolliert werden. Immundefiziente Patienten sollten wie alle Immunsupprimierten mit höheren Dosen geimpft werden. Eine französische Langzeitstudie zeigte deutlich bessere Ergebnisse bei einem Schema mit $4 \times 40 \mu \mathrm{g} \mathrm{HBsAg}$ gegenüber dem Normalschema mit $3 \times 20 \mu \mathrm{g}$ bzw. einer 4-maligen intradermalen Applikation von $4 \mu \mathrm{g}$ (Evidenz 2b) [320].

Bei Nonrespondern ist nach Einleitung einer ART und Verbesserung oder Normalisierung der Zahl der CD4-positiven Zellen sowie
Abnahme der Viruslast der Impferfolg deutlich erhöht (Evidenz 2b) (keine Änderung zu [5]).

\subsection{Wie ist die Postexpositionsprophylaxe bei Neugeborenen durchzuführen?}

\section{EMPFEHLUNG 5.9.1}

Neugeborene HBsAg-positiver Mütter sollen innerhalb von 12 Stunden nach Geburt aktiv-passiv (aktive Impfung plus Hepatitis-B-Immmunglobulin) immunisiert werden [1, A]. Konsens: $100 \%$ (Delphi-Runde)

Geprüft 2020

\section{Kommentar:}

Die Wirksamkeit der aktiv-passiven Postexpositionsprophylaxe bei Neugeborenen von HBsAg-positiven Müttern wurde vielfach demonstriert (Evidenz 1a) (keine Änderung zu [5]).

Dazu werden gleichzeitig mit dem Impfstoff 30-100 IU AntiHBs pro kg KG verabreicht, i. d. Regel $1 \mathrm{ml}$ eines i. m. zu applizierenden Anti-HBs-Präparats mit einer Anti-HBs-Konzentration von $200 \mathrm{IU} / \mathrm{ml}$. Vier bis acht Wochen nach der Grundimmunisierung soll der Impferfolg durch die Bestimmung von Anti-HBs überprüft werden. Um ein Impfversagen bzw. einen Virusdurchbruch zu erkennen, soll zusätzlich noch auf HBsAg und Anti-HBc getestet werden.

Auch die aktive Impfung allein verhütet mit großer Sicherheit eine Infektion; bei Neugeborenen von Müttern, deren HBsAg-Status nicht bekannt ist und bei denen eine serologische Kontrolle innerhalb von 12 Stunden nicht möglich ist, sollte daher unmittelbar post partum die Grundimmunisierung mit einem Hepatitis-BImpfstoff begonnen werden. Bei nachträglicher Feststellung einer HBsAg-Positivität kann beim Neugeborenen innerhalb von 7 Tagen postpartal die Gabe von Hepatitis-B-Immunglobulin nachgeholt werden (in erster Linie, um die Zeit bis zur Bildung „eigener“ schützender Antikörper beim Kind zu überbrücken) (keine Änderung zu [5]).

\section{EMPFEHLUNG 5.9.2}

Schwangeren mit einer HBV-DNA-Konzentration > 200000 IU/ $\mathrm{ml}$ soll eine antivirale Therapie angeboten werden, um das Risiko der Mutter-Kind-Übertragung zusätzlich zur Postexpositionsprophylaxe zu reduzieren [1, A] (siehe 3.12). Konsens: $100 \%$ (Konsensuskonferenz)

Neu 2020

Evidenztabelle siehe Leitlinienreport Anhang III

\section{Kommentar:}

Ein Versagen der Postexpositionsprophylaxe ist möglich, wenn

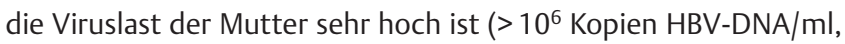
bzw. $2 \times 10^{5} \mathrm{IU} / \mathrm{ml}$ ). In diesen Fällen soll eine antivirale Therapie der Mutter zur Senkung der Viruslast erwogen werden (Details siehe 3.12). Dafür ist es notwendig, die Schwangere frühzeitig 
auf eine bestehende HBV-Infektion zu testen, damit noch ausreichend Zeit für ein Anschlagen der antiviralen Therapie bis zum Geburtstermin bleibt. Daher sollte bei Schwangeren mit erhöhtem Risiko für eine HBV-Infektion der Nachweis von HBsAg bereits in der Frühschwangerschaft erfolgen, um bei chronischer Infektion mit hoher Viruslast eine antivirale Therapie zur Transmissionsprophylaxe einzuleiten.

Die aktiv-passive Postexpositionsprophylaxe wird nach Geburt des Kindes wie üblich durchgeführt. Sollte bei hoher Viruslast der Mutter (HBV-DNA > $200000 \mathrm{lU} / \mathrm{ml}$ ) keine Therapie erfolgt sein, scheint eine besonders frühe aktiv-passive Postexpositionsprophylaxe (in den ersten 4 Stunden nach der Geburt) mit sehr geringen Transmissionsraten in dieser Situation verbunden zu sein. (Details siehe 3.12).

Allerdings kann die sehr frühe Impfung nicht immer sichergestellt sein und die Transmissionsrate ist nicht komplett bei $0 \%$. Daher sind Maßnahmen zur Reduktion der HBV-DNA bis zum Zeitpunkt der Geburt auf Werte $<200000 \mathrm{IU} / \mathrm{ml}$ wichtig.

\section{EMPFEHLUNG 5.9.3}

Eine Sectio ausschließlich zur Verhinderung der Mutter-KindÜbertragung soll nicht durchgeführt werden, wenn die HBVDNA-Konzentration der Mutter zum Zeitpunkt der Geburt $<200000 \mathrm{IU} / \mathrm{ml}$ ist und das Neugeborene aktiv-passiv geimpft wird [2, A].

Konsens: $100 \%$ (Konsensuskonferenz)

Neu 2020

Evidenztabelle siehe Leitlinienreport Anhang III

\section{Kommentar:}

Kontrovers ist die Antwort auf die Frage, ob eine Sectio das Risiko einer vertikalen Transmission reduzieren kann. Ein systematisches Review von 30 Datensätzen (9906 Fälle), mit allerdings sehr heterogener Datenlage, kam zum Schluss, dass das relative Risiko für die Entwicklung einer HBV-Infektion nach (elektiver) Sectio gegenüber einer vaginalen Geburt verringert ist (OR 0,51) (Evidenz 3a) [200].

Allerdings zeigte sich in der Subgruppe der Kinder mit Durchführung der postpartalen aktiven und passiven Immunisierung keine Risikoreduktion einer vertikalen Transmission durch eine elektive Sectio.

Ein anderes systematisches Review (18 Studien, 11446 Fälle) zeigte ebenfalls keinen Unterschied hinsichtlich einer Mutter-KindÜbertragung in Abhängigkeit vom Geburtsmodus bei Durchführung einer Immunoprophylaxe. Allerdings weisen die Autoren darauf hin, dass bei einer hohen HBV-DNA (> $200000 \mathrm{lU} / \mathrm{ml}$ ) die Ergebnisse vorsichtig zu interpretieren sind (Evidenz 2a) [201].

In der Tat deutet eine Studie mit 1409 Fällen darauf hin, dass die Sectio bei einer HBV-DNA > $200000 \mathrm{IU} / \mathrm{ml}$ einen Nutzen hat (Evidenz 3b) [202].

Die analysierten Studien waren meist aus China. Der Zeitpunkt der aktiven und passiven Impfung des Neugeborenen nach der Geburt spielt hier eine wichtige Rolle. Inwiefern die Ergebnisse daher auf Deutschland übertragen werden können, ist unklar.
Eine generelle Empfehlung zur Sectio kann daher nicht gegeben werden. Sollte die HBV-DNA zum Zeitpunkt der Geburt $>200000 \mathrm{lU} / \mathrm{ml}$ liegen, kann eine Sectio mit der Schwangeren (Nutzen-Risiko-Abwägung) besprochen werden.

\subsection{Wie ist bei nicht gegen Hepatitis B Immunen im Falle eines Kontakts mit HBV-haltigem Material zu verfahren?}

\section{EMPFEHLUNG 5.10}

Nach Viruskontakt sollte so früh wie möglich, auf jeden Fall innerhalb von 48 Stunden, eine aktiv-passive Immunisierung erfolgen [3, B].

Konsens: 97,8\% (Delphi-Runde)

Geprüft 2020

\section{Kommentar:}

Ein Infektionsrisiko besteht bei Stich- und Schnittverletzungen mit Instrumenten (insbesondere mit Hohlnadeln), die an einem Patienten mit akuter oder chronischer Hepatitis B verwendet wurden, bei dem eine Virämie nachgewiesen wurde (HBV-DNA-positiv) oder vermutet werden muss (HBsAg-positiv), sowie bei Kontakt mit Blut, Serum oder Gewebe oder blutkontaminierten Körperflüssigkeiten eines solchen Patienten mit Schleimhaut oder nicht intakter Haut.

In einer Untersuchung, in der Personen nach Verletzung mit einer mit HBsAg- und HBeAg-positivem Blut kontaminierten Kanüle eine aktiv-passive Immunisierung erhielten, konnte bei 22 (95,6\%) von 23 eine HBV-Infektion verhindert werden, gegenüber 22 von 33 (66,7\%), die in einer früheren Studie nur einmal passiv immunisiert worden waren. Die Simultanimpfung wurde innerhalb von 48 Stunden verabreicht, im Mittel nach 17 Stunden (Evidenz 3b) (keine Änderung zu [5]).

Eine aktiv-passive Immunisierung sollte daher so bald wie möglich, auf jeden Fall aber innerhalb von 48 Stunden nach dem Kontakt erfolgen. Das gilt auch für Menschen, deren Immunstatus unbekannt und nicht innerhalb von 48 Stunden abzuklären ist (s. STIKO-Empfehlung. [321]

Inwieweit spätere Gaben von Immunglobulin und Impfstoff noch sinnvoll sind, ist unklar; auf jeden Fall dürfte ihre Wirksamkeit deutlich geringer sein!

\subsection{Gibt es Sicherheitsbedenken oder Kontraindikationen gegen eine Hepatitis-B- Impfung?}

\section{STATEMENT 5.11.1}

Der Hepatitis-B-Impfstoff ist sehr gut verträglich. Schwere Nebenwirkungen oder Komplikationen, über die speziell aufgeklärt werden müsste oder weswegen bestimmte Personen nicht geimpft werden können, sind wissenschaftlich nicht belegt.

Konsens: 95,7\% (Delphi-Runde)

Geprüft 2020 


\section{Kommentar:}

Der Hepatitis-B-Impfstoff ist sehr gut verträglich (Evidenz 3a) (keine Änderung zu [5]).

Wie bei anderen Impfstoffen kann es innerhalb von 1-3 Tagen, selten länger anhaltend, an der Impfstelle zu Rötung, Schmerzhaftigkeit und Schwellung kommen, gelegentlich auch verbunden mit Beteiligung der zugehörigen Lymphknoten. Allgemeinsymptome wie beispielsweise leichte bis mäßige Temperaturerhöhung, Frösteln, Kopf- und Gliederschmerzen oder Müdigkeit sind selten. In der Regel sind diese Lokal- und Allgemeinreaktionen vorübergehender Natur und klingen rasch und folgenlos wieder ab. In Einzelfällen wird über anaphylaktische und allergische Reaktionen (Vaskulitis, Urtikaria, niedriger Blutdruck) nach Hepatitis-B-Impfung berichtet. Ungeklärt ist ein ursächlicher Zusammenhang der Impfung mit den sehr selten beobachteten neurologischen Störungen (Enzephalitis, Enzephalomyelitis, Myelitis, Opticusneuritis, Guillain-Barré-Syndrom) und Erkrankungen anderer Organe (Arthritiden, Angioödem, Erythema multiforme, Lupus erythematodes, Thrombozytopenie), die im zeitlichen Zusammenhang mit der Hepatitis-B-Impfung auftraten. In der Mehrzahl dieser Einzelfallberichte dürfte es sich um das zufällige zeitliche Zusammentreffen von miteinander nicht ursächlich verbundenen selbstständigen Ereignissen handeln (Evidenz 4) (keine Änderung zu [5]).

Die Verursachung oder die Auslösung eines akuten Schubs von Multipler Sklerose oder anderer demyelinisierender Erkrankungen durch die Hepatitis-B-Impfung wird immer wieder diskutiert (Evidenz nicht bewertet). Es gibt jedoch keine wissenschaftlichen Fakten, die einen solchen Zusammenhang beweisen. Eine Vielzahl qualifizierter Studien konnte keine Evidenz für einen kausalen Zusammenhang der postulierten Krankheit mit der Impfung finden (Evidenz 3a) [322].

Daran ändert auch das Urteil des Europäischen Gerichtshofs nichts, der einem Mann, der kurz nach der dritten Hepatitis-BImpfung eine Multiple Sklerose entwickelte, Schadensersatz zusprach [323, 324].

Aus wissenschaftlicher Sicht ist dieses Urteil nicht relevant, da es die verfügbaren Evidenzen zum medizinischen Sachverhalt nicht berücksichtigt.

\section{EMPFEHLUNG 5.11.2}

Personen mit hochfieberhaften und/oder behandlungsbedürftigen akuten Erkrankungen sollten nicht geimpft werden [2, B].

Konsens: 97,8\% (Delphi-Runde)

Geprüft 2020

\section{EMPFEHLUNG 5.11.3}

Personen, die nach einer vorangegangenen Impfung mit einem Hepatitis-B-Impfstoff Zeichen einer Überempfindlichkeit oder andere ungeklärte unerwünschte Wirkungen gezeigt haben, sollten nicht geimpft werden [EK].

Konsens: 95,7\% (Delphi-Runde)

Geprüft 2020

\section{Kommentar:}

Personen mit hochfieberhaften und/oder behandlungsbedürftigen Erkrankungen sollten frühestens 2 Wochen nach Genesung geimpft werden. Allergische Erscheinungen oder andere unerwünschte Arzneimittelwirkungen im zeitlichen Zusammenhang mit einer Hepatitis-B-Impfung stellen ein Impfhindernis gegen eine nachfolgende Hepatitis-B-Impfung dar, wenn aufgrund der besonderen Umstände ein Kausalzusammenhang angenommen werden muss [321].

Darüber hinausgehende Kontraindikationen gibt es nicht; Schwangere können gegen Hepatitis B geimpft werden (Evidenz $2 b$ ), allerdings sollte - wie für alle Impfungen in der Schwangerschaft - die Indikation streng gestellt sein [325].

\subsection{Gibt es Tätigkeitseinschränkungen von HBV-Infizierten im Gesundheitswesen (HCW, healthcare worker)?}

\section{EMPFEHLUNG 5.12.1}

Bei HBV-DNA-Konzentrationen $<200 \mathrm{IU} / \mathrm{ml}$ sind keine Einschränkungen der Tätigkeit und keine zusätzlichen Sicherheitsmaßnahmen erforderlich. Kontrollen der HBV-DNA sollen alle 3 Monate durchgeführt werden [EK].

Konsens: $100 \%$ (Konsensuskonferenz)

Geprüft 2020

\section{Kommentar:}

Eine Übertragung von HBV im Zusammenhang mit dem Tätigkeitsprofil von HCW wurde bislang bei HBV-DNA-Konzentrationen unter $200 \mathrm{IU} / \mathrm{ml}$ nicht beschrieben $(200 \mathrm{lU} / \mathrm{ml}$ entsprechen 1000 Genomen HBV/ml, bei einem Umrechnungsfaktor von $1 \mathrm{IU}=5 \mathrm{Ge}-$ nom HBV) und ist nach Stand der Kenntnis für diese spezielle Übertragungssituation sehr unwahrscheinlich. Daher werden für HBV-Konzentrationen $<200 \mathrm{IU} / \mathrm{ml}$ bei chronisch HBV-infizierten HCW keine Einschränkung der Berufstätigkeit und keine zusätzlichen Sicherheitsmaßnahmen für erforderlich gehalten. Da im Laufe einer chronischen HBV-Infektion die HBV-DNA-Konzentration im Blut auch ohne auffällig klinisches Bild stark variieren kann, sind serologische Kontrollen der HBV-DNA mit einer hochsensitiven Detektionsmethode alle 3 Monate angeraten. Bei einer Virämie $<200 \mathrm{IU} / \mathrm{ml}$ HBV-DNA sind in der Regel keine Einschränkungen oder besonderen Sicherheitsmaßnahmen erforderlich. Bei höherer Virämie sollte eine Kommission über die vertretbaren Tätigkeiten entscheiden. Bei Tätigkeiten mit Übertragungsgefahr muss die Virämie mittels einer sensitiven, quantitativen HBVDNA-Nachweistechnik engmaschig kontrolliert werden: alle 3 Monate, solange HBV-DNA im Serum nachweisbar ist; alle 6 Monate, solange bei nicht nachweisbarer HBV-DNA das HBsAg nachweisbar ist. Bei stabil negativen HBV-DNA-Werten sollten alle 6 Monate das HBsAg und Anti-HBs bestimmt werden; alle 12 Monate nach HBsAg-Verlust bzw. Serokonversion von HBsAg zu AntiHBs. Nach einem stabilen HBsAg-Verlust bzw. einer Serokonversion von HBsAg zu Anti-HBs ist von einer stabilen Remission auszugehen. Es besteht jedoch ein Risiko einer Reaktivierung, z. B. bei Immunsuppression [89]. 
Als HCW gelten alle medizinisch, zahnmedizinisch, pflegerisch, geburtshelferisch oder assistierend am Patienten Tätigen in unterschiedlichen Bereichen, z. B. Krankenhäusern, Ambulanzen, Arztpraxen, Dialyseeinrichtungen, Pflegeheimen und ambulant tätigen Pflegeeinrichtungen. Entscheidend bei o.g. Tätigkeiten ist die Existenz eines möglichen Übertragungsweges. Die Tätigkeit selbst muss nicht mit einer Anstellung verbunden sein und umfasst daher auch den Personenkreis der Belegärzte, Honorarärzte, Gastärzte, Praktikanten, Hospitanten und Famulanten.

\section{EMPFEHLUNG 5.12.2}

Bei Werten zwischen 200 und $20000 \mathrm{IU} / \mathrm{ml}$ soll eine individuelle Bewertung des Übertragungsrisikos je nach Tätigkeit erfolgen und ggf. sollen Maßnahmen zur Senkung der Übertragungsgefahr ergriffen werden [EK].

Konsens: 96,3\% (Konsensuskonferenz)

Neu 2020

\section{Kommentar:}

Annähernd 500 HBV-Übertragungen durch wenigstens $52 \mathrm{HCW}$ wurden bislang beschrieben, deren HBV-DNA-Konzentrationen zum Zeitpunkt ihrer Untersuchung alle erheblich über $2000 \mathrm{IU} / \mathrm{ml}$ lagen (Evidenz 3b) [326].

Bei Werten zwischen 200 und $20000 \mathrm{IU} / \mathrm{ml} \mathrm{HBV-DNA}$ ist das Risiko einer Übertragung bedingt z. B. durch die Verletzungsgefahr des HCW bei invasiven chirurgischen Tätigkeiten immer noch sehr gering, aber nicht mehr vernachlässigbar. Werden tatsächlich Tätigkeiten mit Übertragungsgefahr ausgeübt, sollte in diesem Fall eine Ad-hoc-Kommission prüfen, ob (1) eine besonders hohe Übertragungsgefahr vorliegt, (2) die Übertragungsgefahr durch zusätzliche Sicherheitsmaßnahmen verringert werden kann oder (3) diese Tätigkeiten zukünftig vermieden werden müssen (zu Einzelheiten und Vorgehensweisen siehe: [89]).

\section{STATEMENT 5.12.3}

Konstant hohe HBV-DNA-Konzentrationen von $>20000 \mathrm{IU} / \mathrm{ml}$ sind mit einer übertragungsträchtigen Tätigkeit gemäß Empfehlung der Deutschen Vereinigung zur Bekämpfung der Viruskrankheiten (DVV) nicht vereinbar.

Konsens: $100 \%$ (Konsensuskonferenz)

Neu 2020

\section{Kommentar:}

Institutionen und Fachgesellschaften aus den USA, Kanada und Australien benennen in ihren Empfehlungen teilweise andere Grenzwerte und Kategorien zur Vermeidung von HBV-Übertragungen bei medizinischen Eingriffen. Die in der DVV-Empfehlung ausgeführten Betrachtungen entsprechen diesen Empfehlungen; die empfohlenen Maßnahmen sind in der DVV-Empfehlung jedoch zum Teil strenger formuliert [89].

\section{Ausblick:}

Die Schutzdauer der HBV-Impfung ist nach wie vor nicht geklärt. Über die Persistenz schützender Antikörper liegt eine Vielzahl von Studien vor. Die Datenlage zur Persistenz des immunologischen Gedächtnisses, das nach dem Verschwinden der schützenden Antikörper für den Schutz vor Erkrankung im Falle einer Infektion verantwortlich ist, ist aber nach wie vor nicht ausreichend. Hier sind weitere Untersuchungen dringend notwendig, zumal bei 30-50\% der im Säuglingsalter geimpften Personen bereits nach 10-15 Jahren der Anti-HBs-Spiegel unter $10 \mathrm{IU} / \mathrm{I}$ abgesunken ist.

Die Wirksamkeit (vor allem auch die Dauer des Schutzes vor Infektion) und die Antigenzusammensetzung der in Deutschland verfügbaren Impfstoffe sollten insbesondere für spezielle Risikogruppen verbessert werden (z. B. Dialysepatienten, Non- bzw. Lowresponder, Personen über 40 Jahre etc.). Dies könnte durch Einschluss von weiteren viralen Epitopen, z. B. der PräS-Domänen der HBV-Oberflächenproteine, erreicht werden. Bereits getestete PräS-haltige Impfstoffe zeigen schnellere und bessere Ansprechraten bei Neugeborenen sowie Non- und Lowrespondern im Vergleich zu konventionellen Vakzinen [327].

\section{Management der relevanten HBV-Koinfektionen}

H. Wedemeyer, A. Wranke, L. Sandmann, H. Klinker, P. Ingiliz, S. Christensen

\subsection{Bei welchen Patienten mit HBV/HDV-Infektion soll eine} Therapie durchgeführt werden? Wie soll die antivirale Therapie durchgeführt werden?

\section{EMPFEHLUNG 6.1.1}

Der Einsatz von pegyliertem Interferon alfa (PEG-IFN) soll bei allen Patienten mit chronischer HBV/HDV-Koinfektion und einer kompensierten Lebererkrankung geprüft werden [2, A]. Konsens: $100 \%$ (Konsensuskonferenz)

Geprüft 2020

\section{Kommentar:}

Eine chronische HDV-Infektion ist im Vergleich zu Patienten, die nur mit HBV infiziert sind, mit einem höheren Risiko für die Entwicklung einer Leberzirrhose verbunden. Dies wurde in Kohortenanalysen aus den 1980er- und 1990er-Jahren gezeigt und kürzlich in mehreren systematischen Übersichten bestätigt (Evidenz 2a) [328-331].

Etwa $20 \%$ aller Leberzirrhosen bei HBsAg-positiven Patienten sind auf eine HDV-Koinfektion zurückzuführen. [331] Das relative Risiko für die Entwicklung einer Leberzirrhose war in einer Metaanalyse für Anti-HDV-positive Patienten 3,84-fach höher als bei HBV-Monoinfizierten (95\%-KI, 1,79-8,24) [330].

Die HDV-Infektion ist zudem ein unabhängiger Risikofaktor für die Entstehung eines hepatozellulären Karzinoms. Eine Metanalyse zeigte ein relatives HCC-Risiko bei mit HBV/HDV koinfizierten Patienten von 1,3. Ein besonders hohes HCC-Risiko besteht für 
HBV/HDV/HIV-infizierte Patienten (OR 7,1). Insgesamt ließ sich das erhöhte HCC-Risiko allerdings nur für asiatische Patientenkohorten nachweisen (Evidenz 2a) [332].

Die 5-Jahres-Mortalität ist bei Patienten mit chronischer Hepatitis $B / D$ gegenüber Patienten mit alleiniger Hepatitis B ungefähr verdoppelt (Evidenz 2b) [328, 329].

Unter den 8 bekannten HDV-Genotypen [333] scheint der in Deutschland vorherrschende HDV-Genotyp 1 mit einem schlechten Überleben bei chronischer Infektion assoziiert zu sein. [334] Bei Einwanderern aus Westafrika findet sich dagegen häufig der HDV-Genotyp 5, der mit einem besseren Ansprechen auf eine antivirale Therapie mit pegyliertem Interferon alfa vergesellschaftet zu sein scheint (Evidenz 3b) [335, 336].

Pegyliertes Interferon alfa (PEG-IFN) ist zur Therapie der Hepatitis B zugelassen und hat auch eine Wirkung gegen HDV. [337] Unter einer Interferon-alfa-Therapie (Standard Interferon oder PEG-IFN) zeigen sich HDV-RNA-Suppressionen von bis zu $47 \%$. Die höchsten Ansprechraten sind in kleineren Kohortenstudien dokumentiert.

In den 2 großen kontrollierten, prospektiven HIDIT-Studien betrug die Ansprechrate zum Therapieende 23-48\%, und 24 Wochen nach Therapieende wiesen nur etwa $25 \%$ der Patienten eine negative HDV-RNA auf (Evidenz 1b) [338, 339].

Im weiteren Langzeitverlauf hatten allerdings ca. $50 \%$ der untersuchten Patienten einen späten HDV-RNA Relapse (Evidenz 2b) [340].

Eine erfolgreiche Therapie mit Interferon alfa ist mit einem günstigeren Langzeitverlauf assoziiert. Das Risiko, klinische Komplikationen einer Leberzirrhose zu entwickeln, war bei Patienten, die mit pegyliertem Interferon alfa behandelt wurden, in Kohorten in Ankara [341], Hannover [342], Frankreich [336] und Schweden [343] geringer. Ein negatives Testergebnis für HDV-RNA war mit einem günstigeren klinischen Verlauf assoziiert (Evidenz 2b).

Wenn zusätzlich zur negativen HDV-RNA ein HBsAg-Verlust erreicht wurde, konnte ein sehr günstiger Langzeitverlauf beobachtet werden [342, 344].

Die Frage, ob ein relativer HDV-RNA-Abfall bei noch nachweisbarer HDV-RNA (zum Beispiel um das 100-Fache (2 Log-Stufen)) bereits die Prognose verbessert, wird kontrovers diskutiert [345].

Nukleosidanaloga und Nukleotidanaloga zur Behandlung der chronischen Hepatitis B haben keine direkte antivirale Wirksamkeit gegen HDV (Evidenz 1b). [338] Ein möglicher Nutzen der NA-Therapie bei der HBV/HDV-Koinfektion wird unter 6.1.3 diskutiert.

Die Bedeutung neuer antiviraler Therapien gegen HDV, die sich in klinischer Entwicklung befinden, wird derzeit in Phase-2und Phase-3-Studien untersucht [100]. Der Prenylierungsinhibitor Lonafarnib wird als Monotherapie über 48 Wochen und in Kombination mit PEG-Interferon alfa-2a untersucht. Der HBV-Eintrittshemmer Bulevirtid wird in 2 verschieden Dosen $(2 \mathrm{mg}$ und $10 \mathrm{mg}$ s. c. täglich) über 2 und 3 Jahre getestet. Eine vorläufige Zulassung von Bulevirtid ist im Juli 2020 für Hepatitis-D-Patienten mit kompensierter Lebererkrankung durch die EMA erfolgt. Fallberichte zur Therapie mit Bulevirtid zeigen eine Verbesserung der ALT auch bei Patienten mit Leberzirrhose (Evidenz 4) [346].

Für den Einsatz von Bulevirtid bei Patienten mit chronischer Hepatitis B/D wird zeitnah ein Addendum erstellt.
Anmerkung: Die Herstellerfirma des PEG-Interferon alfa-2a hat im Juli 2020 angekündigt, dieses weltweit vom Markt zu nehmen. Aktuelle Projektionen gehen von einer Verfügbarkeit in Deutschland bis zum Jahresende 2022 aus. Der Marktrückzug betrifft alle Handelsformen; es besteht kein Zusammenhang mit der Sicherheit oder Wirksamkeit des Produkts. Bis zur letzten Lieferung ist die bekannte Qualität gewährleistet. Der aktuelle Bestand des Arzneimittels wird abverkauft, eine Produktion findet nicht mehr statt (https://www.roche.de/medien/meldungen/Mittelfristig-la euft-Pegasys-aus-Alle-1-5163.html).

Wir werden rechtzeitig ein Addendum veröffentlichen.

\section{EMPFEHLUNG 6.1.2}

Die Therapiedauer mit PEG-IFN sollte mindestens 48 Wochen betragen [2, B]. Eine Therapieverlängerung kann bei einem Abfall des HBsAg und guter Verträglichkeit mit dem Ziel eines HBsAg-Verlustes erwogen werden [EK].

Konsens: 97,8\% (Konsensuskonferenz)

Modifiziert 2020

Evidenztabelle siehe Leitlinienreport Anhang III

\section{Kommentar:}

Die Mehrzahl der bisherigen Studien zur Therapie der Hepatitis D hat eine Therapiedauer von 48 Wochen untersucht [337].

Die HIDIT-1-Studie des Kompetenznetzes Hepatitis konnte zum Therapieende bei $23 \%$ bzw $24 \%$ der 60 mit PEG-IFNa-2a behandelten Patienten eine Unterdrückung der Viruslast mit oder ohne zusätzliche Gabe von Adefovir-Dipivoxil bei einer 48-wöchigen Behandlung mit PEG-Interferon alfa-2a erreichen. 24 Wochen nach Ende der Behandlung lag die Rate der Patienten mit negativer HDV-RNA bei $28 \%$ [338].

Therapiestudien, die eine kürzere Therapie als 48 Wochen untersucht haben, liegen nicht vor.

Derzeit gibt es auch keine Evidenz, dass eine Therapieverkürzung im Sinne einer „Response-guided“-Therapie auf der Basis einer HDV-RNA-Kinetik während der Behandlung (analog zur Hepatitis-C-Therapie mit PEG-IFN) sinnvoll ist. Zwar ist ein Abfall der HDV-RNA zu Therapiewoche 24 mit einem virologischen Ansprechen am Therapieende (Woche 48) assoziiert, allerdings ließen sich keine Stoppregeln identifizieren, die mit ausreichender Wahrscheinlichkeit ein Therapieversagen vorhersagen [347].

Eine weitere randomisierte Studie des Kompetenznetzes Hepatitis hat bei 120 Patienten eine verlängerte PEG-Interferon-alfa2a-Therapie von 96 Wochen untersucht, wobei die Hälfte der Patienten zusätzlich mit Tenofovir (TDF) behandelt wurde. Am Ende der Therapie waren 48 Patienten (40\%) HDV-RNA-negativ. Die meisten Patienten wurden in den ersten 48 Wochen der Therapie HDV-RNA-negativ; nur 2 Patienten erreichten dieses Ziel während der Therapieverlängerung bis Woche 96. Allerdings traten trotz der verlängerten Therapie bei $40 \%$ der Patienten (19/48), die zum Therapieende eine negative HDV-RNA aufwiesen, Virusrückfälle bis zur Nachbeobachtungswoche 24 auf. Das bedeutet, dass 26,7 \% der Patienten 24 Wochen nach Therapieende HDV-RNA-negativ waren. Damit konnte mit einer verlängerten 
Behandlung die Zahl der Patienten mit dauerhafter HDV-RNAUnterdrückung nicht relevant gesteigert werden, weshalb eine auf 96 Wochen verlängerte Therapie nicht generell gerechtfertigt ist (Evidenz 2b) [339].

Wird während einer Behandlung mit PEG-IFN jedoch ein Abfall des HBsAg beobachtet, so kann in diesen Fällen eine Fortsetzung der Behandlung über Therapiewoche 48 hinaus gerechtfertigt sein. In diesen Fällen kann das Ziel eines HBsAg-Verlusts bei einigen Patienten erreicht werden. Ein HBsAg-Verlust ist mit einem verbesserten klinischen Langzeitverlauf assoziiert. [100, 342] Damit wäre eine funktionelle Ausheilung der zugrunde liegenden HBV-Infektion erreicht, womit auch die HDV-Infektion ausgeheilt wäre. Die Dauer der Therapie sollte in diesem Fall individuell an den Abfall des HBsAg angepasst werden. Quantitative HBsAg-Bestimmungen alle 3-6 Monate unter einer verlängerten PEG-IFNTherapie sollten erfolgen. In Fallserien aus Italien und Deutschland [344], der Türkei [341] und den USA [348] sind HBsAg-Verluste nach Therapiedauern von bis zu 4 Jahren beschrieben (Evidenz 3b). Bei der verlängerten Therapie sollen aber die Verträglichkeit der Behandlung und das Risiko für schwerwiegende Nebenwirkungen berücksichtigt werden.

\section{EMPFEHLUNG 6.1.3}

Bei nachweisbarer HBV-Replikation können Nukleos(t)idanaloga (NA) gegen HBV eingesetzt werden [EK]. Konsens: 97,8\% (Konsensuskonferenz)

Neu 2020

\section{Kommentar:}

Nukleos(t)idanaloga (NA) gegen HBV haben keine direkte antivirale Wirksamkeit gegen HDV. Es liegen negative Studien für Famciclovir [349], Lamivudin [350], Entecavir (Evidenz 3b) [351] und Adefovir (Evidenz 1b) [338] vor.

Ebenso zeigte Tenofovir (TDF) in Kombination mit PEG-IFN keinen zusätzlichen Effekt im Vergleich zu PEG-IFN allein (Evidenz 1b) [339].

In einer spanischen Kohorte von HBV/HDV/HIV-infizierten Patienten wurde allerdings bei 10 von 19 Patienten während einer Langzeittherapie mit Tenofovir (TDF) eine Abnahme der HDV-RNA beobachtet (Evidenz 3b) [352].

In einer Kohorte von HBV/HDV/HIV-infizierten Patienten aus der Schweiz, die eine Tenofovir-haltige antiretroviale Therapie erhielten, zeigten nur $28,6 \%$ eine Reduktion der HDV-RNA von $\geq 2,0$ log, und $14,3 \%$ hatten innerhalb von 5 Jahren eine negative HDVRNA. Eine Reduktion des HBsAg konnte hier nicht dokumentiert werden (Evidenz 3b) [353].

Ob der Abfall der HDV-RNA bei einigen HBV/HDV/HIV-infizierten Patienten direkt durch TDF induziert ist oder durch Immunphänomene (z. B. Immunrekonstitution bei HIV), ist nicht klar. Es wurde gezeigt, dass TDF Interferon lambda induzieren kann [354].

Der klinische Verlauf von Patienten, die NA erhalten haben, wurde in retrospektiven Studien untersucht und hat im Vergleich zu PEG-IFN-Therapien schlechtere Verläufe für eine alleinige NATherapie gezeigt. Allerdings ist hier ein Bias zu berücksichtigen, da alleinige NA-Therapien in der Regel bei Patienten durchgeführt wurden, die Kontraindikationen für PEG-IFN aufwiesen (z. B. fortgeschrittene Zirrhosen) [342, 343].

Für die Therapie mit NA bei Patienten mit chronischer Hepatitis D und positiver HBV-DNA mit dem Ziel, den Progress der Lebererkrankung durch die Suppression der HBV-DNA zu senken, gibt es bislang wenig Evidenz. Dennoch ist davon auszugehen, dass die Therapieprinzipien, die bei der HBV-Monoinfektion empfohlen sind (siehe 2 und 3), auch bei der Koinfektion mit HDV einen klinischen Nutzen im Sinne einer Reduktion von Komplikationen der Lebererkrankung haben. In der Mehrzahl der Fälle haben Patienten mit einer Hepatitis D unabhängig vom HBeAg-Status niedrige HBV-DNA-Werte [355, 356].

\section{EMPFEHLUNG 6.1.4}

Patienten mit dekompensierter Leberzirrhose oder akuter fulminanter Hepatitis D sollen für eine Lebertransplantation evaluiert werden [EK]. Konsens: $100 \%$ (Konsensuskonferenz)

Modifiziert 2020

\section{Kommentar:}

Ist aufgrund einer fortgeschrittenen Leberzirrhose mit entsprechenden Komplikationen keine antivirale Therapie mit PEGIFN oder mit neuen antiviralen Therapien möglich, bleibt nur die Lebertransplantation als Therapieoption. Patienten, die aufgrund einer Hepatitis D lebertransplantiert werden müssen, haben im Vergleich zu anderen Indikationen eine sehr gute Prognose nach einer Lebertransplantation. [252] Reinfektionen mit HBV und HDV können mittels passiver Immunisierung gegen HBV und gleichzeitiger Gabe von NA gegen HBV verhindert werden (siehe 4.3).

6.2 Bei welchen Patienten mit HBV/HCV-Koinfektion soll eine Therapie durchgeführt werden? Wie soll die antivirale Therapie durchgeführt werden?

\section{EMPFEHLUNG 6.2.1}

Eine replikative Hepatitis C (HCV-RNA positiv) soll bei allen HBsAg-positiven Personen antiviral behandelt werden [2, $A^{*}$ ]. Die Auswahl des Therapieregimes erfolgt analog zur HCV-Monoinfektion. Die Indikation zur Therapie der HBV-Infektion erfolgt analog zur Therapieindikation bei der HBV-Monoinfektion (siehe 2.2).

Konsens: $100 \%$ (Konsensuskonferenz)

Modifiziert 2020

Leitlinienadaptation DGVS HCV-Leitlinie

Die S-3-Leitlinie Hepatitis C (2018) empfiehlt: „Eine antivirale Therapie der chronischen Hepatitis C bei HBV/HCV-Koinfektion sollte aufgrund der erhöhten Morbidität angestrebt werden (II/B). “ Im Addendum der Leitlinie (2020) wird empfohlen: „Alle Patienten mit einer replikativen HCV-Infektion (HCV-RNA nachweisbar) sollen antiviral behandelt werden (A)." Aufgrund der erhöhten Mortalität bei HCV/HBV-Koinfektion und sehr guter Verträglichkeit und Erfolgsrate einer DAA-Therapie zur HCV-Behandlung wurde der Empfehlungsgrad A ausgesprochen. 


\section{Kommentar:}

Analog der S3-Leitline zur Hepatitis C sollen alle Patienten mit replikativer Hepatitis C behandelt werden [12]. Dazu gehören auch HBV/HCV-koinfizierte Patienten.

Eine gleichzeitige, chronische Infektion mit HBV und HCV bedingt eine signifikant schlechtere Prognose der resultierenden Lebererkrankung. Bei der Behandlung bzw. Überwachung dieser Patienten sollen daher beide Infektionen berücksichtigt werden [12].

In Australien war die Wahrscheinlichkeit, an einer Lebererkrankung zu versterben, 32,9-fach erhöht für Patienten mit einer HBV/ HCV-Koinfektion (95\%-Konfidenzintervall 23,1-46,7). Das war deutlich erhöht im Vergleich zu Patienten mit den jeweiligen Monoinfektionen (12,2-fach für Hepatitis B bzw. 16,8-fach für Hepatitis C) (Evidenz 2b) [357].

Die HBV/HCV-Koinfektion führt zu einem höheren Risiko, im weiteren Verlauf ein Leberzellkarzinom (HCC) zu entwickeln, als die Infektion mit einem der beiden Hepatitisviren allein (Evidenz 2a) [358, 359].

Es gibt hier allerdings auch ein systematisches Review, das kein erhöhtes HCC-Risiko für HBV/HCV-Koinfizierte im Vergleich zu Patienten mit einer Monoinfektion nachweisen konnte [360].

Da das Risiko aber auch nicht vermindert ist und die meisten Daten ein erhöhtes HCC-Risiko dokumentieren, sollte bei fortgeschrittener Fibrose (Metavir F3 und F4) frühzeitig eine regelmäßige Tumorsurveillance mittels halbjährlicher Ultraschalluntersuchung der Leber eingeleitet werden [12].

Eine serologisch ausgeheilte Hepatitis B (HBsAg negativ/Anti$\mathrm{HBC}$ positiv) war in einigen, aber nicht allen Studien mit einem erhöhten Risiko für ein HCC bei Hepatitis-C-Patienten assoziiert. Allerdings variiert der Effekt sehr stark zwischen verschiedenen Kohorten, Regionen und Komorbiditäten [170, 361].

Bei HBV/HCV-koinfizierten Patienten ist in der Mehrzahl der Fälle das HCV dominant, die HBV-Virusreplikation ist häufig unterdrückt [362, 363]. Grundsätzlich wird die antivirale Wirksamkeit der Substanzen gegen HBV bzw. HCV nicht durch die jeweils andere Koinfektion beeinflusst. Für HBsAg-positive Patienten sind sehr hohe Ausheilungsraten einer HCV-Infektion mit neuen, direkt antiviralen Substanzen gegen HCV beschrieben, die sich nicht von HCV-Monoinfizierten unterscheiden. [364] Umgekehrt sind NA gegen HBV auch im Kontext einer HCV-Infektion effektiv [363]. Damit können die Substanzen analog zu jeweiligen Monoinfektion ausgewählt werden.

Die Indikationsstellung für eine antivirale Therapie der jeweiligen Infektion sollte analog zu den Monoinfektionen erfolgen. D.h., dass jeder HBsAg-positive Patient mit Nachweis einer HCVReplikation prinzipiell bezüglich einer antiviralen Therapie gegen HCV evaluiert werden sollte. Umgekehrt ist die Indikation für eine NA-Therapie gegen HBV bei HCV-koinfizierten Patienten, bei allen Patienten mit einer Leberzirrhose und nachweisbarer HBV-DNA und bei nicht zirrhotischen Patienten mit einer HBVDNA von > $2000 \mathrm{IU} / \mathrm{ml}$ zu prüfen.
EMPFEHLUNG: 6.2 .2

Bei allen HBsAg-positiven Patienten soll während und nach der HCV-Therapie eine Überwachung von HBV-DNA und ALT durchgeführt werden [2, A]. Eine prophylaktische Therapie zur Verhinderung einer HBV-Reaktivierung braucht i. d. R. nicht zu erfolgen [0, 2]. Eine antivirale Therapie der HBV-Infektion sollte bei einer klinisch relevanten Reaktivierung erfolgen [2, B].

Konsens: $100 \%$ (Konsensuskonferenz)

Neu 2020

Evidenztabelle siehe Leitlinienreport Anhang III

\section{Kommentar:}

Prinzipiell kann eine Ausheilung einer HCV-Infektion bei HBsAg-positiven Patienten zu einem Anstieg der HBV-DNA führen. Dies ist bereits im Kontext von Behandlungen mit PEG-IFN gezeigt worden [365].

Der Einsatz von direkt antiviralen Substanzen gegen HCV ist in Fallberichten mit einer Steigerung der HBV-Replikation assoziiert worden, die zu deutlichen Transaminasenanstiegen geführt hat. [366, 367] In Einzelfällen hat eine HBV-Reaktivierung zu Leberversagen mit der Notwendigkeit von Lebertransplantationen geführt [367].

Als klinische relevante Reaktivierung der Hepatitis B kann ein Anstieg der HBV-DNA angesehen werden, der eine Therapieindikation einer Monoinfektion nahelegen würde. Das bedeutet, dass für Anstiege auf $>2000 \mathrm{IU} / \mathrm{ml}$ bei nichtzirrhotischen Patienten und bei jedem Nachweis einer HBV-DNA bei Patienten mit Leberzirrhose eine NA-Therapie evaluiert werden sollte.

Eine prospektive Studie aus Taiwan hat eine Sofosbuvir/Ledipasvir-Behandlung bei HBsAg-positiven Patienten untersucht. Hier zeigte sich in 39 von 74 Fällen ein Anstieg der HBV-DNA im Verlauf der Therapie. Allerdings entwickelten in diesem Zusammenhang nur 5 Patienten einen ALT-Anstieg auf das 2-Fache des oberen Normwerts, von denen wurde bei 3 Patienten eine antivirale Therapie gegen Hepatitis B eingeleitet (Evidenz 2b) [364].

Diese Beobachtung ist in Übereinstimmung mit weiteren kleineren Fallserien. In einer Metaanalyse wurde das Risiko für eine HBV-Reaktivierung im Kontext einer interferonfreien Therapie gegen HCV analysiert. HBV-Reaktivierungen scheinen während oder nach einer inferferonfreien HCV-Therapie zeitlich früher aufzutreten als bei interferonhaltigen Therapien [366, 367]. Das Risiko für HBV-Reaktivierungen bei HBsAg-positiven Patienten wurde in einer anderen Metaanalyse mit 24\% angegeben (95\%Konfidenzintervall 19-30\%) (Evidenz 2a) [367].

Zusammenfassend besteht keine Notwendigkeit einer generellen prophylaktischen NA-Therapie gegen HBV, wenn bei HBsAgpositiven Patienten (ohne sonstige Therapieindikation) eine Hepatitis-C-Therapie durchgeführt wird. Allerdings sind Anstiege der HBV-DNA häufig, und in Einzelfällen können Transaminasenanstiege auftreten. Sollte eine Therapieindikation für die Hepatitis B bestehen, sollte die Anti-HBV-Therapie dann möglichst vor Beginn einer Hepatitis-C-Behandlung eingeleitet werden. 


\section{EMPFEHLUNG: 6.2 .3}

Wird eine antivirale Therapie der HCV-Infektion bei Anti-HBcpositiven/HBsAg-negativen Personen durchgeführt, soll eine HBV-DNA-Testung bei Verdacht auf eine HBV-Reaktivierung erfolgen [2, A].

Konsens: 97,8\% (Konsensuskonferenz)

Neu 2020

Evidenztabelle siehe Leitlinienreport Anhang III

\section{Kommentar:}

Einzelne Fallberichte von HBV-Reaktivierungen wurden im Zusammenhang mit einer direkt antiviralen Therapie von HCV-Infektionen bei HBsAg-negativen/Anti-HBc-positiven Patienten beschrieben. Andere Kohortenstudien haben keine oder nur sehr wenige HBV-Reaktivierungen beobachtet. Das Risiko für eine HBV-Reaktivierung bei HBsAg-negativen/Anti-HBc-positiven Patienten ist daraufhin in Metaanalysen untersucht worden. Insgesamt ist das Risiko für eine HBV-Reaktivierung gering und beträgt zwischen $1 \%$ und $2 \%$ während und nach einer HCV-Therapie bei HBsAg-negativen/Anti-HBc-positiven Patienten (Evidenz 2a) [366, 367].

Besteht ein klinischer Verdacht auf eine HBV-Reaktivierung, z. B. aufgrund einer fehlenden Normalisierung oder sogar eines Anstiegs der ALT- und/oder AST-Werte im Verlauf der HepatitisC-Therapie, soll eine Untersuchung auf HBV-DNA folgen, mit möglicherweise anschließender Einleitung einer antiviralen Therapie gegen Hepatitis B. Es gibt jedoch keine Evidenz für eine generelle prophylaktische Anti-HBV-Therapie, wenn bei HBsAg-negativen/Anti-HBc-positiven Patienten eine Hepatitis-C-Therapie eingeleitet wird.

\section{EMPFEHLUNG: 6.2 .4}

Bei Anti-HCV-positiven/HCV-RNA-negativen Personen soll die Indikationsstellung zur Therapie der HBV-Infektion analog zu Anti-HCV-negativen Personen erfolgen [EK]. Konsens: $100 \%$ (Konsensuskonferenz) Neu 2020

\section{Kommentar:}

Ein Zustand nach Hepatitis C (Anti-HCV-positiv/HCV-RNA-negativ) hat keinen Einfluss auf die Indikationsstellung und Durchführung einer antiviralen Therapie gegen Hepatitis B. Patienten, die die HCV-Infektion spontan ausgeheilt haben, haben kein signifikantes Rückfallrisiko und auch eine normale Lebenserwartung. [368] Rückfälle nach Ausheilung einer chronischen Hepatitis C mit neuen direkt antiviralen Substanzen gegen Hepatitis $C$ sind ebenfalls extrem selten mit einer Häufigkeit von $<1 \%$ nach mehr als 24 Wochen nach Therapieende. [369] Dementsprechend ist eine Einleitung einer Hepatitis-B-Therapie bei Patienten mit Zustand nach Hepatitis C unbedenklich. Es besteht kein Risiko für HCV-Reaktivierungen. Aufgrund der zuvor bestandenen Koinfek- tion und des damit verbundenen erhöhten Risikos für die Ausbildung von klinischen Komplikationen sollte eine HBV-Therapie in jedem Fall auch nach Ausheilung einer Hepatitis C erfolgen, um das Risiko für die Entwicklung einer Leberzirrhose und eines HCC zu reduzieren.

\subsection{Wie sollte die antivirale Therapie bei HBV/HCV/HDV- Dreifachinfektionen durchgeführt werden?}

\section{STATEMENT 6.3}

Die Therapie orientiert sich an der dominanten Virushepatitis und entspricht den bei HBV/HDV- und HBV/HCV-Doppelinfektionen etablierten Prinzipien.

Konsens: $100 \%$ (Konsensuskonferenz)

Geprüft 2020

\section{Kommentar:}

Bei einer HBV/HDV/HCV-Koinfektion dominierte in der Mehrzahl der Studien die HCV-Infektion oder HDV-Infektion (keine Änderung zu [5]).

Der virologische Status ist allerdings nicht stabil und kann einer dynamischen Entwicklung unterliegen. Daher sind sequenzielle Verlaufskontrollen für eine Charakterisierung des jeweiligen Infektionsmusters notwendig. Obgleich Querschnittuntersuchungen belegen, dass bei HIV-infizierten Patienten HBV und HDV inhibitorische Effekte auf die HCV-Replikation ausüben, ist die Gefahr einer HCV-Reaktivierung bei suffizienter HIV/HBV-Therapie gering (keine Änderung zu [5]).

6.4 Bei welchen Patienten mit HBV/HIV-Koinfektion soll eine Therapie durchgeführt werden? Wie soll die antivirale Therapie bei Patienten mit HBV/HIV-Koinfektion durchgeführt und überwacht werden?

\section{EMPFEHLUNG 6.4.1}

Die chronisch-replikative Hepatitis B (HBV-DNA positiv) soll bei HIV-Koinfizierten antiviral behandelt werden [2, A]. Konsens: $100 \%$ (Konsensuskonferenz)

Modifiziert 2020

Leitlinienadaptation EASL Clinical Practice Guideline HBV 2017

\section{Kommentar:}

Weltweit sind mehr als 3 Millionen Menschen mit HIV und HBV infiziert [370].

Die deutsch-österreichischen HIV-Leitlinien sowie die europäischen HIV- und EASL-Hepatitis-B-Leitlinien empfehlen eine antiretrovirale Therapie (ART) bei HBV/HIV-Koinfektion unabhängig von der CD4-Zellzahl im Blut aufgrund eines erhöhten Risikos einer Fibroseprogression bis zur Leberzirrhose und Entstehung eines hepatozellulären Karzinoms (HCC). Umgekehrt sollte gemäß diesen Leitlinien auch die HBV-Infektion entsprechend antiviral behandelt werden [6, 371, 372]. 


\section{EMPFEHLUNG: 6.4 .2}

Die HBV-Therapie soll im Rahmen einer antiretroviralen HIV-Therapie erfolgen [1, A]. Die antiretrovirale Therapie soll Tenofovir (TDF oder TAF) enthalten [1, A]. Konsens: $100 \%$ (Konsensuskonferenz)

Modifiziert 2020

Leitlinienadaptation EASL Clinical Practice Guideline HBV 2017

\section{Kommentar:}

Bei Personen mit HIV-Koinfektion soll die Behandlung von HBV mit der HIV-Therapie koordiniert werden, da mehrere HBV-Medikamente eine Anti-HIV-Wirkung haben [6, 7].

Eine Tenofovir (TDF oder TAF) enthaltende ART ist sowohl gegen HIV als auch gegen HBV wirksam. Mit Beginn der Behandlung sollten mögliche Nebenwirkungen überwacht werden (siehe 3.2.2). Eine Therapieumstellung von TDF auf TAF ist bei Nebenwirkungen (Niereninsuffizienz und Knochenstoffwechselstörungen) empfohlen.

Bei einem Wechsel der ART von einem TDF- auf ein TAF-haltiges ART-Regime bei Patienten mit supprimierter HIV- und HBVViruslast blieben mehr als $90 \%$ der Patienten virologisch für beide Infektionen supprimiert. Dabei verbesserten sich Surrogatmarker der Nierenfunktion und die Knochendichte nach Wechsel zu einer TAF enthaltenden ART [373].

Nach Einleitung einer ART bei schlechtem Immunstatus und einer Leberzirrhose kann ein Immunrekonstitutionssyndrom mit dem Risiko eines hepatitischen „flare“ und Leberdekompensation auftreten. Diese Patienten benötigen in den ersten Monaten eine engmaschige Überwachung. Eine Unterbrechung der Therapie mit TDF oder TAF sollte aufgrund einer möglichen Reaktivierung der HBV-Infektion mit dem Risiko eines hepatitischen „Flare“ und Leberdekompensation vermieden werden. Bei Kontraindikation gegen TDF oder TAF besteht die Möglichkeit der Gabe von Entecavir (ETV), das nur eine schwache antiretrovirale Wirksamkeit gegenüber HIV hat. Vorbehandlungen mit Lamivudin (3TC) oder Emtricitabin (FTC) müssen berücksichtigt werden. Bei Wechsel von TDF/TAF auf Wirkstoffe mit niedrigerer genetischer Barriere wie ETV besteht das Risiko eines viralen Durchbruchs, insbesondere bei Patienten mit einer 3TC/FTC-Vorbehandlung und Leberzirrhose.

Bei günstigen Voraussetzungen (HBV-Genotyp A, hohe ALT, niedrige HBV-DNA) kann eine Therapie mit pegyliertem Interferon alpha versucht werden (keine Änderung zu [5]).

\section{EMPFEHLUNG 6.4.3}

Therapieüberwachung und Therapieanpassungen sollten unter Beachtung der HIV-Koinfektion entsprechend den Empfehlungen bei HBV-Monoinfizierten durchgeführt werden [EK].

Konsens: $100 \%$ (Konsensuskonferenz)

Geprüft 2020

\section{Kommentar:}

Die Überwachung der HBV-Therapie unterscheidet sich bei HIV-Koinfizierten nicht von Patienten mit einer HBV-Monoinfektion. Sollte es zu einem Progress der Lebererkrankung kommen, kann auch die Lebertransplantation eine therapeutische Option sein (keine Änderung zu [5]).

\section{Hepatitis-B-Virusinfektion im Kindes- und Jugendalter}

S. Wirth , P. Gerner, G. Flemming, J. de Laffolie, T. Lang, M. Melter, W.D. Huber

\section{Vorbemerkung}

Die folgenden Ausführungen orientieren sich an den unter Abschnitt 9 ausgeführten Empfehlungen der von der AASLD 2016 publizierten Leitlinie zur Therapie der chronischen Hepatitis B. Es gibt keine wesentlichen Abweichungen in den Empfehlungen; es wurden allerdings die Zulassungskonditionen für die Medikamente an die europäischen Bedingungen angepasst [7].

Die akute Hepatitis B wird aufgrund häufig symptomarmer Verläufe bei Kindern relativ selten diagnostiziert. Die chronische Hepatitis B im Kindes- und Jugendalter ist eine seltene Erkrankung. Aufgrund einiger Unterschiede im klinischen Verlauf und in Bezug auf Therapiemöglichkeiten ist es sinnvoll, diese Altersgruppe in einem Kapitel separat zu betrachten.

Epidemiologie und Verlauf der HBV-Infektion im Kindes- und Jugendalter

Von der Gesamtzahl der ca. 400000 HBV-Träger in Deutschland werden nur etwa 5 \% für das Kindes- und Jugendalter geschätzt. Allerdings wird davon ausgegangen, dass fast $1 / 3$ der Träger die Infektion im Kindesalter erworben hat. Hiervon sind besonders Migrantenkinder betroffen. Die Zahl der akuten Infektionen steigt im Alter zwischen 15 und 19 Jahren vor allem bei Männern deutlich an. Die sexuelle Transmission und die horizontale Übertragung in Wohngemeinschaften sind die häufigsten Übertragungswege [374, 375].

Bei hoher Konzentration von HBV im Blut reichen für eine Infektion minimale Blutmengen von $0,1 \mu \mathrm{l}$ aus. Die Übertragung der Viren kann somit immer auch über Haut- und Schleimhautläsionen erfolgen. Das HBV kann durch medizinische und zahnärztliche Eingriffe, Tätowieren, Piercing etc. übertragen werden. Transfusionen und die Gabe von Blutprodukten (Gerinnungspräparate, Immunglobuline, Humanalbumin, tiefgefrorenes Frischplasma etc.) stellen kein nennenswertes Risiko mehr dar. Eltern können mit ihren Kindern ganz normalen zärtlichen Kontakt pflegen.

Bei der vertikalen Transmission erfolgt die Infektion des Kindes in der Regel sub partu. Bis zu $5 \%$ der Neugeborenen infizierter Mütter werden intrauterin infiziert. Bei diesen Kindern kann bereits am 1. Lebenstag im Venenblut (nicht Nabelschnurblut) HBsAg und meist auch HBV-DNA und Anti-HBc-IgM nachgewiesen werden. Die intrauterine Infektionswahrscheinlichkeit kann mit einer replikationsmindernden Behandlung im letzten Schwangerschaftstrimenon signifikant reduziert werden (siehe 3.12) [19, 20]. 
Die Infektionsrate sub partu der Neugeborenen HBeAg-positiver Mütter ohne perinatale aktiv-passive Immunprophylaxe beträgt 70-95\%. Die Infektionsrate ist niedriger, wenn die Mütter HBeAg-negativ (20-25\%) bzw. Anti-HBe-positiv (ca. 10\%) sind. Ist die Mutter Anti-HBe-positiv oder die HBeAg-Negativität mit der Präsenz einer Prä-Core-Mutante verbunden, kann bei einer Infektion beim Kind - typischerweise im Alter von 2-4 Monaten eine fulminante Hepatitis auftreten [376-378].

Die Mütter von vertikal infizierten Kindern sind meistens asymptomatische chronische HBsAg-Träger; eine akute Hepatitis $B$ liegt nur selten vor. Die Inkubationszeit beträgt etwa 90 Tage (40-180 Tage). In seltenen Fällen infizieren sich Kinder auch perinatal, wenn eine HBsAg-Mutante vorliegt, gegen die die Anti-HBsAntikörper des HBIG nicht neutralisierend wirken [379-381].

\section{Klinisches Bild}

Klinisch ist die chronische Hepatitis B von anderen Hepatitisformen nicht zu unterscheiden. Asymptomatische und subklinische Formen sind häufig. Das gilt besonders für das Neugeborenenalter. Extrahepatische Manifestationen wie Arthralgien, Exantheme (unter anderem Gianotti-Crosti-Syndrom), Myalgien, Vaskulitis, Kryoglobulinämie, Glomerulonephritis und Myo-Perikarditis können vorkommen [382].

\section{Prognose}

Die Letalität der fulminanten Hepatitis nach HBV-Übertragung von einer $\mathrm{HBeAg}$-negativen Mutter ist unbehandelt sehr hoch (bis $80 \%$ ). Die Chronifizierungsrate bei Übertragung von einer HBeAg-positiven Mutter ist altersabhängig. Sie beträgt bei Infektion im Neugeborenenalter bis zu 95\%, im Alter von 1-5 Jahren etwa 25-40\% und im Schulkind- und Erwachsenenalter ca. 5-10\%. Ein kleiner Teil der chronisch infizierten Kinder entwickelt schon vor dem Erwachsenenalter eine Leberzirrhose oder sehr selten ein hepatozelluläres Karzinom. Darüber hinaus sind Patienten mit einer HBV-Infektion einschließlich der HBsAg-Träger durch eine Superinfektion mit HDV und einer damit verbundenen Progredienz der Krankheit gefährdet [382].

Die chronische HBV-Infektion beginnt in der Regel mit einer „immuntoleranten“ HBeAg-positiven Phase mit normalen Transaminasen und sehr hoher Virämie (HBeAg-positive Infektion), die über viele Jahre stabil sein kann. Bei persistierendem HBeAg kann sie im Verlauf in die immunreaktive Phase mit erhöhten Transaminasen übergehen. Die Prognose der chronisch-aktiven Hepatitis B wird von der entzündlichen Aktivität bestimmt. Es gibt milde, progrediente Formen, die sich bessern, und Formen, bei denen bis zur Hälfte der Patienten eine Leberzirrhose mit weiteren Folgen wie Leberkoma und/oder primäres Leberzellkarzinom entwickelt. Nach Infektion in den ersten Lebensjahren dürfte das Leberzirrhoserisiko bis zum Erreichen des Erwachsenenalters in Deutschland kaum mehr als $5 \%$ betragen [383, 384].

Letztlich wird die Prognose der chronischen Hepatitis vom Zeitpunkt der Serokonversion von HBeAg zu Anti-HBe bestimmt, deren Eintritt meist aus der immunreaktiven Phase im Einzelfall nicht prognostizierbar ist. Die spontane jährliche Serokonversion beträgt bei Kindern etwa 8-10\%; sie ist aber bei Individuen mit einer vertikalen Transmission und nach einer immunsuppressiven
Therapie deutlich niedriger. Die ethnische Herkunft spielt dabei eine große Rolle. In einer umfangreichen kanadischen Untersuchung ergab sich bei rund $50 \%$ eine Anti-HBe-Serokonversion bis zum Alter von 19 Jahren im Langzeitverlauf. Die Serokonversionsrate war bei nicht asiatischen Patienten deutlich höher und lag bei ca. $70 \%$, bei den Patienten asiatischer Herkunft bei ca. $40 \%$ [385].

Eine spontane Serokonversion zu Anti-HBs und damit eine Heilung der chronischen Hepatitis wird bei weniger als 0,5\% der Kinder/Jahr beobachtet. In seltenen Fällen kann es bei serokonvertierten Kindern zu einer Reaktivierung von Anti-HBe zu HBeAg, meist mit Progredienz der Krankheit, kommen [7, 382].

Alkoholkonsum, hepatotoxische Medikamente und Drogen (Ecstasy) verschlechtern die Prognose der Erkrankung.

HBeAg-positive chronische HBsAg-Träger sollten im Kindesund Jugendalter habjährlich kontrolliert werden. Nach Serokonversion zu Anti-HBe sind jährliche Untersuchungen ausreichend.

\subsection{Wie wird die Diagnose gestellt?}

\section{EMPFEHLUNG 7.1}

Die Diagnostik der Hepatitis B im Kindesalter soll sich an der Diagnostik im Erwachsenenalter orientieren (siehe Kapitel 1) und mindestens die Bestimmung von $\mathrm{HBsAg}, \mathrm{HBeAg}$, AntiHBe, Anti-HBc und HBV-DNA sowie der Transaminasen umfassen [EK]. Eine Leberbiopsie braucht nicht durchgeführt zu werden $[0,4]$.

Konsens: 97,9\% (Delphi-Runde)

Geprüft 2020

NKLM

\section{Kommentar:}

Die Vorgehensweise zur Diagnose einer Hepatitis B unterscheidet sich im Kindes- und Jugendalter nicht wesentlich von der bei Erwachsenen (siehe AG1). In den ersten 3-6 Monaten können wiederholte HBV-DNA-Bestimmungen sinnvoll sein, da eine passagere Virämie vorkommen kann. Die für die Praxis wichtigsten Marker der aktiven Virusreplikation und damit der Infektiosität sind HBeAg und HBV-DNA. Die chronische Hepatitis B ist durch eine HBsAg-Trägerschaft von mehr als 6 Monaten gekennzeichnet. In der frühen HBeAg-positiven Phase ist die Rate der Virusreplikation mit häufig > $10^{9} \mathrm{HBV}$-Genomen pro ml Serum hoch. In der späteren Anti-HBe-positiven Phase ist die Virusreplikation mit HBV-DNA-Titern zwischen 10 und 104 Genomen/ml niedriger. Der Zeitpunkt der Serokonversion von HBeAg zu Anti-HBe ist individuell nicht prognostizierbar und gewöhnlich begleitet von einer Normalisierung der Transaminasen, einer auf unterhalb von 105 HBV-Genomen/ml liegenden HBV-DNA-Konzentration und einer reduzierten entzündlichen Aktivität im Lebergewebe (Evidenz 4) [384, 385].

In dieser Phase ist die Infektiosität deutlich niedriger als vor der Serokonversion. Bei Anti-HBe-positiven, HBeAg-negativen Kindern mit erhöhten Transaminasen oder mit ausgeprägter Virämie besteht der Verdacht auf das Vorliegen von Prä-Core- oder BasalCore-Promoter(„HBe-minus“)-Mutanten. Diese Patienten sind insgesamt selten, erkranken oft schwerer und zeigen manchmal 
eine rasche Progredienz zur Leberzirrhose. Eine „HBe-minus“-Mutante kann bei einem Patienten zusammen mit dem Wildvirus als Quasispezies gemeinsam vorkommen, sodass es - in dieser Altersgruppe allerdings ebenso selten - HBeAg-positive Konstellationen einer Infektion mit der Prä-Core-Mutante gibt (Evidenz 4) [386].

Die Kriterien zur Beurteilung der Histologie unterscheiden sich nicht von denen Erwachsener und berücksichtigen neben der entzündlichen Infiltration und dem Ausmaß der Leberzellnekrose den Fibrosegrad.

Bei vollständiger „Immuntoleranz“ (neue Definition: chronische HBeAg-positive HBV-Infektion) bestehen keine wesentlichen histologischen Veränderungen. Diese Kinder weisen in der Regel hohe HBV-DNA-Konzentrationen im Serum auf. Die Untersuchung von Lebergewebe ist nicht obligatorisch, sondern empfiehlt sich bei Verdacht auf einen progredienten Verlauf [7].

\subsection{Welche Therapiemöglichkeiten und -ziele bestehen bei einer Hepatitis B im Kindes- und Jugendalter?}

\section{EMPFEHLUNG 7.2.1}

Eine akute Hepatitis B im Kindes- und Jugendalter sollte nicht behandelt werden [EK]. Eine Ausnahme stellt die fulminante Hepatitis dar. Hier sollte eine Behandlung mit einem zugelassenen Nukleos(t)idanalogon erwogen werden [4, B*].

Konsens: 95,7\% (Delphi-Runde)

Modifiziert 2020

* Geprüft 2020

\section{Kommentar:}

Für eine antivirale Therapie der akuten Hepatitis B liegen keine Daten vor. Es wird keine Behandlung empfohlen (Evidenz 5) [382].

Sollte sich im frühen Säuglingsalter eine schwere bzw. fulminante Hepatitis B entwickeln, besteht eine lebensgefährliche Erkrankung mit hoher Letalität. Es gibt Einzelberichte und Expertenerfahrung, dass der Verlauf bei sofortiger Behandlung mit einem Nukleosidanalogon positiv beeinflusst werden kann (Evidenz 4) [378, 387-389].

\section{EMPFEHLUNG 7.2.2}

Bei chronischer Hepatitis B kann eine Behandlung erfolgen $\left[2,0^{*}\right]$. Das primäre Therapieziel bei der Behandlung der chronischen Hepatitis $B$ bei Kindern und Jugendlichen ist die Serokonversion zu Anti-HBe. In Europa sind Tenofovir (TDF) ab 12 Jahren und Entecavir ab 2 Jahren zugelassen. Mit pegyliertem Interferon (PEG-IFN) kann ab 3 Jahren behandelt werden. Die Indikationsstellung zur Behandlung und ihre Überwachung sollten durch einen in diesem Gebiet erfahrenen Kinder-Gastroenterologen oder -Infektiologen erfolgen [EK]. Konsens: 97,9\% (Delphi-Runde)

Modifiziert 2020

* Leitlinienadaptation AASLD Practice Guideline HBV 2016

\section{EMPFEHLUNG 7.2.3}

Bei wiederholt normaler ALT sollte keine Behandlung erfolgen $[4, \mathrm{~B}]$. Konsens: 96,9\% (Konsensuskonferenz)

Modifiziert 2020

* Leitlinienadaptation AASLD Practice Guideline HBV 2016

\section{Kommentar:}

Da es nach wie vor keine effektive kausale Therapie der chronischen Hepatitis B (mit dem Ziel einer funktionellen Heilung) gibt, müssen bei der Beurteilung oder Festlegung der Indikationen für die verfügbaren Behandlungsmöglichkeiten die Ziele in Kenntnis des spontanen Verlaufs in dieser Altersgruppe besonders berücksichtigt werden. Da die Erkrankung in den ersten beiden Lebensdekaden in der Regel keine ausgeprägte Progredienz bei sehr hoher Virusreplikation aufweist, ist die Behandlung mit Lamivudin allein über einen langen Zeitraum wenig hilfreich (Evidenz 4) [390].

Bei dieser Substanz ist mit einer hohen Resistenzrate zu rechnen, was die weiteren Behandlungsoptionen erschwert. Im Kindes- und Jugendalter muss das Therapieziel - wenn schon eine Serokonversion zu Anti-HBs kaum möglich ist - die Serokonversion von HBeAg zu Anti-HBe sein. Die wesentlichen prognostischen Parameter wie Höhe der Serumtransaminasen und das Virusreplikationsniveau müssen bei der Indikationsstellung berücksichtigt werden. Bei beiden Therapieoptionen, Interferon alfa und Nukleosid/Nukleotidanaloga, kann bei Behandlung in der immunreaktiven Phase und einer sehr hohen Virusreplikation mit einer Serokonversionsrate von 16-26\% pro Jahr gerechnet werden, bei einer Behandlungsdauer über 12 Monate zwischen 32 und $40 \%$ (Evidenz 1a) [391, 392].

Mit zunehmendem Anstieg der Transaminasen wird die Ansprechrate besser. Die spontane HBeAg/Anti-HBe-Serokonversionsrate steigt ebenso mit der Höhe der entzündlichen Aktivität. Bei einer erfolgreichen Behandlung wird die Serokonversion zeitlich vorgezogen, in einer aktuellen Studie wurde die absolute Serokonversionsrate erhöht (Evidenz 2b) [384, 393-396].

Auf lange Sicht wird die absolute spontane Remissionsrate durch die antivirale Therapie nicht erhöht. Es ist daher Konsens, nur Patienten mit einer höheren Serokonversionswahrscheinlichkeit zu behandeln und die Therapie bei Patienten mit erhöhten Transaminasen zu indizieren [7].

Bei Kindern und Jugendlichen liegen Therapieerfahrungen mit alfa-Interferon, mit PEG-alfa-Interferon-2a, Lamivudin, Adefovir, Tenofovir (TDF) und Entecavir vor.

Anmerkung: TAF hat bislang (2020) für die Altersgruppe noch keine Zulassung.

\section{Interferon alfa}

Man kann eine chronische Hepatitis B mit Interferon alfa behandeln. Indikationen für eine Behandlung sind: $\mathrm{HBeAg-positive} \mathrm{chronische}$ Hepatitis B mit Erhöhung der Serumtransaminasen sowie in Einzelfällen HBeAg-negative chronische Hepatitis B mit oder ohne Erhöhung der Serumtransaminasen und HBV-DNA > $20000 \mathrm{IU} / \mathrm{ml}$ (> 10 $0^{5} \mathrm{Ko}-$ pien/ml). Letztere Gruppe kann auch mit einem Nukleosid-/Nukleo- 
tidanalogon behandelt werden. Anti-HBe-positive Kinder mit normalen Transaminasen und DNA-Werten $<2000 \mathrm{IU} / \mathrm{ml}\left(<10^{4}\right.$ Kopien/ml) werden nicht behandelt. Als Kontraindikationen gelten Autoimmunerkrankungen, eine dekompensierte Leberzirrhose, ausgeprägte Thrombo-/Leukozytopenie und Gravidität. Die tägliche Dosis sollte 5 Mio. I.E./m² KOF, maximal 10 Mio. I.E./Tag s. c., an 3 Tagen der Woche betragen. Die Behandlung wurde mit einer Dauer von 6 Monaten durchgeführt. Die Serokonversion von HBeAg zu Anti-HBe ist abhängig von der entzündlichen Aktivität vor Therapie und anderen Faktoren und kann je nach Kontrollzeitraum mit 25-45\% veranschlagt werden. Eine Ausheilung, d. h. Serokonversion zu Anti-HBs, wird bei 6-10\% der Patienten erreicht [Ila] [391].

Die Behandlung von Kindern und Jugendlichen mit chronischer Hepatitis B mit Standard(nicht pegyliertem)-Interferon alfa wird als obsolet angesehen. Eine 2018 publizierte kontrollierte klinische Studie mit PEG-Interferon alfa-2a wurde über einen Therapiezeitraum von 48 Wochen durchgeführt. 24 Wochen nach Therapieende waren 25,7\% der Patienten zu Anti-HBe und $8 \%$ zu Anti-HBs serokonvertiert. Die Therapie wurde 2018 von der EMA ab dem Alter von 3 Jahren zugelassen. Die Dosierung beträgt je nach Körperoberfläche zwischen 65 und $180 \mu \mathrm{g}$ pro Woche über 48 Wochen (Evidenz 1b) [397].

Fast alle Kinder zeigen Nebenwirkungen. Meistens sind es grippeähnliche Symptome. Schwere Nebenwirkungen wie Neutropenie, Krämpfe und Epistaxis sind selten und klingen nach Absetzen von Interferon ab. Der Nachweis von Autoantikörpern ohne klinische Symptome einer Autoimmunkrankheit zwingt nicht zum Absetzen der Therapie. Auf die Schilddrüsenfunktion ist besonders zu achten; u. a. sollten TSH-Werte und Schilddrüsen-Autoantikörper wiederholt untersucht werden, da die Induktion einer Autoimmunthyreoiditis möglich ist. Unter der Behandlung kann es zu einer Reduktion der Wachstumsgeschwindigkeit kommen, die sich nach Absetzen der Medikation wieder normalisiert. Stimmungsschwankungen kommen häufiger vor, depressive Verstimmungen selten (Evidenz 4) [383].

Bei einer wirksamen Interferonbehandlung können die Transaminasen vorübergehend ansteigen. Danach folgt die Serokonversion von HBeAg zu Anti-HBe mit und ohne Verlust von HBsAg; Die HBV-DNA-Konzentration liegt in der Regel < $2000 \mathrm{IU} / \mathrm{ml}\left(10^{4} \mathrm{Ko}-\right.$ pien $/ \mathrm{ml}$ ), und es kommt zu einer histologischen Besserung. Bei einigen Patienten tritt die Serokonversion erst mehrere Monate nach Beendigung der Therapie ein (Evidenz 4) [398].

Kinder mit einer vertikalen Transmission von HBV, geringer entzündlicher Aktivität im Lebergewebe, Patienten mit einer zusätzlichen HDV-Infektion und Kinder mit Immundefizienz sprechen schlechter auf die Therapie an (Evidenz 4) [380, 381].

Nach Beendigung der Interferontherapie kann es zu einer Reaktivierung (Wahrscheinlichkeit ca. 5\%) kommen. Eine Zweitbehandlung mit einer auf Interferon alfa basierenden Therapie ist von geringerer Effektivität (Evidenz 4) [399].

\section{Nukleosid-/Nukleotidanaloga}

Von den 6 für Erwachsene zugelassenen Nukleos(t)idanaloga sind für Kinder oder Jugendliche Lamivudin, Entecavir, Adefovir und Tenofovir Disoproxil Fumarat (TDF) von der FDA und Entecavir und Tenofovir (TDF) von der EMA in Europa zugelassen. Telbivudin ist in Deutschland nicht mehr erhältlich. Zu Tenofovir Alafenamid (TAF) gibt es noch keine publizierten Daten bei Kindern und Jugendlichen. Eine Studie läuft (NCT02 932150 ). Lamivudin wurde bei Kindern $(1 \times 3 \mathrm{mg} / \mathrm{kg} / \mathrm{KG} / \mathrm{Tag}$ per os, max. $100 \mathrm{mg} / \mathrm{Tag})$ in Europa „off label“ angewendet. Die Serokonversion zu Anti-HBe lag nach einem Jahr bei $23 \%$ (Evidenz 1b) [393].

Bei einem Viertel der behandelten Patienten kam es innerhalb von 12-18 Monaten zur Resistenzentwicklung (Evidenz 1b) [400]. Lamivudin gilt daher heute als obsolet.

Adefovir dipivoxil ist von der FDA ab 12 Jahren zugelassen, wird aber wie bei Erwachsenen nicht mehr empfohlen (siehe auch 3.2.3). Bei den jüngeren Kindern gab es keine signifikante Wirksamkeit im Vergleich zum Spontanverlauf. Bei den Jugendlichen lag die Anti-HBe-Serokonversionsrate nach 48 Wochen bei 15,9\%. In der angeschlossenen Langzeitbeobachtung serokonvertierten nach weiteren 4,5 Jahren 34\% der 162 eingeschlossenen Patienten (Evidenz 1b) [401, 402].

Entecavir ist ein hochpotentes Nukleosidanalogon mit sehr geringer Resistenzentwicklung. Es ist von der EMA ab dem Alter von 2 Jahren zugelassen. In einer Studie mit 180 Kindern waren in der Verumgruppe nach 48 Wochen $24 \%$ zu Anti-HBe serokonvertiert. Nach 96 Wochen waren es 35,8\% im Vergleich zu 18 \% im Spontanverlauf (Evidenz 1b) [392].

Tenofovir (TDF) ist ein Nukleotidanalogon mit ebenfalls niedriger Resistenzentwicklung. Es ist ab 12 Jahren zugelassen. Von 52 behandelten Jugendlichen waren $21 \%$ nach 72 Wochen HBeAgnegativ; in der Kontrollgruppe waren es $15 \%$, womit ein signifikantes Resultat verfehlt wurde (Evidenz 1b). [403] Tenofovir alafenamid (TAF) ist für die Altersgruppe bislang (2020) noch nicht zugelassen.

Grundsätzlich wird die Therapieindikation für Kinder und Jugendliche in der immunreaktiven Phase der chronischen Hepatitis B gesehen. Die meisten Studien definierten dieses Einschlusskriterium mit einer Transaminasenerhöhung über das 1 1/2-Fache des oberen Normalwerts. Nach Abschluss der Studien waren nur 16-24\% der behandelten Kinder und Jugendlichen HBeAg-negativ, bei Verlängerung wurde der Anteil deutlich höher mit 34$36 \%$. Die Therapiedauer ist bisher nicht definiert, da es keine Langzeitdaten für Entecavir und Tenofovir über den Zeitraum von mehr als 2 Jahren gibt. Aus Sicht erfahrener Behandler muss die Behandlungsdauer mindestens 3-5 Jahre betragen, um eine deutlich höhere Serokonversionswahrscheinlichkeit zu erreichen. Dies muss mit den Patienten und Eltern besprochen werden, damit die Bereitschaft zur Compliance vor Therapiebeginn geklärt ist.

\section{Kombinationstherapien}

Verschiedene Studien haben die Kombination eines Nukleosidanalogons mit PEG-Interferon alfa v. a. bei Kindern und Jugendlichen mit chronischer HBV-Infektion und immuntoleranten Merkmalen untersucht und hoffnungsvolle Ergebnisse dokumentiert. Eine Pilotstudie mit der Kombinationsbehandlung Lamivudin/Alfa-Interferon dokumentierte eine Anti-HBs-Serokonversionsrate von 5/23 (23\%) (Evidenz 2b) [404].

Eine weitere Pilotstudie mit der gleichen Kombination zeigte bei 11/28 (39\%) immuntoleranten Patienten eine Serokonversion zu Anti-HBe und bei 6/28 (21\%) eine Serokonversion zu Anti-HBs (Evidenz 2b) [405]. 
Die antivirale Behandlung mit einer sequenziellen Kombination von Alfa-Interferon/Lamivudin führte zu einer signifikanten Verbesserung der Raten der nicht nachweisbaren Serum-HBV-DNA (74\%), der Serokonversion zu Anti-HBe (33\%) und des HBsAg-Verlusts (22\%) bei 46 Kindern mit chronischer HBV-Infektion und immuntoleranten Merkmalen. In der Kontrollgruppe erreichte nur ein Patient (4\%) eine spontane Serokonversion zu Anti-HBe und keiner einen HBsAg-Verlust (Evidenz 2b) [406].

Es wurde eine kontrollierte, randomisierte klinische Studie mit Lamivudin/Entecavir in Kombination mit PEG-Interferon alfa-2a bei immuntoleranten Kindern und Jugendlichen durchgeführt, mit dem Ziel, die Therapieindikation im Fall eines positiven Ergebnisses um die immuntoleranten Patienten zu erweitern (An Open-label Study of Pegasys in Combination With Lamivudine in Children With HBeAg-positive Chronic Hepatitis B in the Immune-Tolerant Phase; ClinicalTrials.gov Identifier: NCT02263079). Im Einzelfall könnte auch bei immuntoleranten Kindern eine antivirale Behandlung sinnvoll sein (z. B. Reduktion des Transmissionsrisikos, Vermeidung einer Stigmatisierung). Die Studie wurde 2018 abgebrochen, da sich keine höhere Anti-HBe-Serokonversion gegenüber der Kontrollgruppe ergab (Evidenz 1b) [407]. Aufgrund dieser Studie hat sich an der Empfehlung, Kinder mit HBeAg-positiver Infektion (immuntolerant) nicht zu behandeln, bislang nichts geändert.

Die Diskrepanz der Studiendaten kann durch das Studiendesign, die Auswahl der Patienten (unterschiedliches Alter) begründet sein, aber möglichweise könnte auch die Sequenz der Kombinationstherapie (zuerst IFN oder zuerst NA oder gleichzeitig) einen Einfluss haben.

\section{EMPFEHLUNG 7.2.4}

Kinder und Jugendliche mit gleichzeitiger immunsuppressiver Therapie können im Indikationsfall mit einem Nukleos(t)idanalogon behandelt werden [EK].

Konsens: 97,9\% (Delphi-Runde)

Neu 2020

\section{Kommentar:}

Kinder und Jugendliche mit gleichzeitiger immunsuppressiver Therapie können im Indikationsfall z. B. zur Verringerung eines Reaktivierungsrisikos mit einem Nukleosid-/Nukleotidanalogon (Entecavir oder Tenofovir (TDF) entsprechend der Zulassung) behandelt werden (Evidenz 4) [380], siehe 5.13.

\subsection{Welche prophylaktischen Maßnahmen sind sinnvoll?}

\section{EMPFEHLUNG 7.3.1}

Eine Zulassung zu Gemeinschaftseinrichtungen oder eine Berufsausbildung/Berufsausübung (unter Berücksichtigung der Empfehlungen AG 5) soll im Regelfall nicht eingeschränkt oder verwehrt werden [EK]. Konsens: $100 \%$ (Konsensuskonferenz)

Neu 2020

\section{Kommentar:}

Hygienische Maßnahmen verhindern die perkutane oder mukokutane Übertragung. Gefährdete Kinder sind daher frühzeitig zu einer sorgfältigen persönlichen Hygiene zu erziehen. Eine Isolierung des Patienten ist nicht notwendig. HBsAg-positive Kinder können Kindereinrichtungen besuchen. Ihre Ausgrenzung ist nicht zu tolerieren. Empfohlen wird, alle Gruppenmitglieder gemäß den STIKO-Empfehlungen aktiv zu immunisieren. Bei Kindern mit mangelnder Hygiene, Kindern mit aggressiven Verhaltensweisen (Beißen, Kratzen), immunsupprimierten Kindern und Kindern mit einer vermehrten Blutungsneigung und entzündlichen Hautkrankheiten kann eine individuelle Entscheidung durch das Gesundheitsamt getroffen werden. Eltern und Betreuer sollten über ein bekanntes Infektionsrisiko gegebenenfalls informiert und auf die Wichtigkeit der Impfung besonders hingewiesen werden. Der Schulbesuch HBsAg-positiver Kinder ist in der Regel uneingeschränkt möglich (Evidenz 4) (keine Änderung zu [5]).

\section{EMPFEHLUNG 7.3.2}

Im Fall einer HBV-Infektion soll [1, A]

- eine Aufklärung zu Transmissionsrisiko und Übertragungswegen erfolgen.

- eine aktive Immunisierung der in Gemeinschaftseinrichtungen lebenden Gruppenmitglieder und des Betreuungspersonals gemäß STIKO-Empfehlungen erfolgen.

- bei HBsAg-positiven Müttern die aktive und passive Immunisierung des Neugeborenen innerhalb von 12 Stunden nach der Entbindung erfolgen.

- eine aktive Immunisierung von Personen (und Sexualpartnern), die im gemeinsamen Haushalt leben, und von engen Freunden durchgeführt werden.

Konsens: $100 \%$ (Konsensuskonferenz)

Geprüft 2020

\section{Kommentar:}

\section{Passive Immunprophylaxe}

Die präexpositionelle Immunprophylaxe hat durch die Möglichkeit der Impfung erheblich an Bedeutung verloren.

Die postexpositionelle Immunprophylaxe sollte bei empfänglichen Personen immer sofort, spätestens innerhalb von 48 Stunden nach einer Inokulation mit virushaltigem Material erfolgen, so z. B. bei Blutkontakt der Schleimhäute (Auge, Verschlucken von Blut), bei Blutkontakt einer verletzten Haut (Beißen, Kratzen, Ekzem), nach Nadelstich oder Schnittverletzung, nach Sexualkontakt oder bei einer vermuteten vertikalen Transmission. Verwendet wird ein spezifisches Hepatitis-B-Immunglobulin, 0,06 ml/kg KG (maximal $5 \mathrm{ml}$ ) i. m. oder 0,12-0,2 ml bzw. 6-12 IE/ kg KG (Neugeborene $0,4 \mathrm{ml} / \mathrm{kg} \mathrm{KG}$ ) i. v. Gleichzeitig sollte aktiv geimpft werden.

Im Falle einer Exposition bei früher geimpften Kindern (perkutaner oder mukokutaner Kontakt mit HBsAg-positivem Material) sollte die Anti-HBs-Konzentration bestimmt werden. Ist die Konzentration < $10 \mathrm{IE} / \mathrm{l}$, wird nachgeimpft, obwohl wahrscheinlich 
auch bei dieser Konstellation eine Immunität vorliegen dürfte. Ist die Immunreaktion nach der Impfung unbekannt oder ist eine Bestimmung des Anti-HBs-Gehalts nicht innerhalb von 12 Stunden möglich, sollte das Kind ein Hepatitis-B-Immunglobulin entweder i. v. (0,6-2 ml/kg KG, maximal $5 \mathrm{ml}$, z. B. Hepatect R) oder i. m. (30-100 IE/kg (üblicherweise $1 \mathrm{ml}$ ), z. B. Hepatitis-B-Immunglobulin Behring), erhalten. Überflüssiges Immunserum sollte nicht verworfen, sondern kann bis zu einer Dosis von 0,5 ml/kg KG injiziert werden. Bekannte Hypo- und Nonresponder erhalten das Hepatitis-B-Immunglobulin sofort.

\section{Aktive Immunprophylaxe}

Hierzulande werden vorwiegend Gen-H-B-Vax-K ( $5 \mu \mathrm{g} \mathrm{HBsAg/}$ $0,5 \mathrm{ml})$ und Engerix-B Kinder ( $10 \mu \mathrm{g} \mathrm{HBsAg} / 0,5 \mathrm{ml})$ verwendet. Die Grundimmunisierung besteht aus 3 Impfungen, die i. m. in den Oberarm oder bei Säuglingen in den lateralen Anteil des Oberschenkels verabreicht werden. Der Impfstoff darf nicht ins Fettgewebe und nicht intradermal injiziert werden. Deshalb ist die Glutaealregion als Impfort nicht geeignet. Außerdem gibt es einen Kombinationsimpfstoff gegen Hepatitis A und B (Twinrix Kinder $^{\circledR}$ ) für Kinder nach dem 1. Lebensjahr. Die HBV-Impfung ist in den Routineimpfplan für Säuglinge und Kleinkinder integriert und wird im Rahmen einer 6-fach-Impfung im ersten Lebensjahr verabreicht. Bei den Schuleingangsuntersuchungen des Jahres 2018 hatten 87,2\% (78,4 in Baden-Würtemberg bis 94,1\% in Sachsen-Anhalt) der Kinder eine vollständige Grundimmunisierung [408].

Postvakzinale Titerbestimmungen sind nur bei Risikopatienten indiziert. Bei über 95 \% der Kinder und Erwachsenen tritt eine Serokonversion mit einem Anti-HBs-Antikörperspiegel > 10 IE/I ein. Der Impfschutz hält im Regelfall über 10 Jahre an und wird auch von der zellulären Immunität getragen. Bei Hypo- oder Nonrespondern ist entweder von vornherein die Einzeldosis zu verdoppeln, so z. B. bei immundefizienten Kindern und Hämodialysepatienten, oder eine zusätzliche Impfung vorzunehmen. Kinder, die Antikörperspiegel zwischen 10 und $100 \mathrm{IE} / \mathrm{l}$ entwickeln, sollten eine weitere Impfung erhalten. Kinder, die keine Antikörper bilden, können bis zu 3-mal zusätzlich geimpft werden. Nach der Impfung sind bei Hyporespondern die Antikörpertiter etwa jährlich zu untersuchen. Bei Werten von $<10 \mathrm{IE} / \mathrm{ml}$ sollte nachgeimpft werden.

Nebenwirkungen der Impfung treten bei etwa 5\% der geimpften Kinder auf. Sie sind gewöhnlich leicht: Temperaturerhöhung, Unwohlsein, lokale Reaktionen. Ein Kausalzusammenhang zwischen Hepatitis-B-Impfung und demyelinisierenden Krankheiten einschließlich Multipler Sklerose und Erblindung ist nicht bewiesen (siehe 5.11).

\section{Impfindikation}

Die Hepatitis-B-Impfung ist eine empfohlene Impfung für alle Kinder und Jugendlichen. Darüber hinaus sind Risikogruppen zu impfen (siehe Empfehlungen der STIKO, siehe 5.1). Die Immunisierung bereits immuner Kinder oder Individuen mit einer nicht bekannten chronischen HBV-Infektion ist nutzlos, aber unschädlich. Eine Schwangerschaft ist keine Kontraindikation.

Die aktiv-passive Simultanimpfung sollte immer dann vorgenommen werden, wenn eine passive Immunprophylaxe unumgänglich erscheint. Neugeborene HBsAg-positiver Mütter erhalten sofort nach der Geburt (siehe 5.9), am besten noch im
Kreißsaal bzw. innerhalb von 12 Stunden postnatal, ein spezielles Immunglobulin, $1 \mathrm{ml}$ (bzw. 0,5 ml/kg KG) i. m. oder 0,4 ml/kg KG i. v., und kontralateral die 1. Impfdosis. Darüber hinaus sollten bei jedem Neugeborenen einer HBsAg-positiven Mutter HBsAg und $\mathrm{HBeAg}$ untersucht werden, um eine intrauterine Infektion auszuschließen. Die alleinige passive Immunisierung Neugeborener von HBsAg-positiven Müttern ist obsolet (Evidenz 1a) [409].

Eine akute Hepatitis B in der Frühschwangerschaft stellt für Mutter und Kind kein erhöhtes Risiko hinsichtlich der Schwangerschaft dar. Eine akute Erkrankung in der Spätschwangerschaft kann die Frühgeburtenrate erhöhen und ebenso wie eine chronische Hepatitis B zu einer vertikalen Transmission der Viren führen.

Bei Frühgeborenen ist die Serokonversionsrate niedriger als bei Reifgeborenen. Durch Anwendung eines Impfschemas mit 4 Dosen (Zeitpunkt: 0-1 - 5-9 Monate) konnte die Erfolgsrate von 76 auf $90 \%$ gesteigert werden. Nach Abschluss der Grundimmunisierung sollte eine Kontrolle von Anti-HBs und Anti-HBc erfolgen. Ist der HBsAg-Status der Mutter bei der Geburt nicht bekannt, sollten immer sofort, spätestens innerhalb von 12 Stunden post natum, das Neugeborene aktiv immunisiert und der HBsAg-Status der Mutter bestimmt werden. Fällt der Befund positiv aus, wird dem Kind nachträglich so bald wie möglich Hepatitis-B-Immunglobulin verabreicht. Geimpfte Neugeborene können gestillt werden.

Patienten mit einer chronischen Hepatitis B und fehlender Immunität gegen Hepatitis A sollten gegen Hepatitis A geimpft werden.

\section{Interessenkonflikte}

siehe Leitlinienreport

\section{Literatur}

[1] World Health Organization. Hepatitis B. 2019. Im Internet: https://www. who.int/news-room/fact-sheets/detail/hepatitis-b

[2] Robert Koch-Institut. Infektionsepidemiologisches Jahrbuch meldepflichtiger Krankheiten für 2018. 2019. Im Internet: https://www.rki.de/DE/Con tent/Infekt/Jahrbuch/Jahrbuch_2018.pdf?_blob=publicationFile

[3] Stahmeyer JT, Becker H, Heidelberger S et al. Kosten einer leitliniengerechten Versorgung von Hepatitis-B-Patienten in Deutschland. Z Gastroenterol 2012; 50: 745-752

[4] Cornberg M, Protzer U, Dollinger MM et al. Prophylaxe, diagnostik und therapie der hepatitis-B-virus-(HBV-)infektion: „Upgrade“ der leitlinie, AWMF-register-Nr.: 021/011. Z Gastroenterol 2007; 45: 525-574

[5] Cornberg M, Protzer U, Petersen J et al. Prophylaxis, diagnosis and therapy of hepatitis B virus infection the German guideline. Z Gastroenterol 2011; 49: 871-930

[6] European Association for the Study of the Liver (EASL). EASL 2017 Clinical Practice Guidelines on the management of hepatitis B virus infection. J Hepatol 2017; 67: 370-398

[7] Terrault NA, Bzowej NH, Chang KM et al. AASLD Guidelines for Treatment of Chronic Hepatitis B. Hepatology 2016; 63: 261-283

[8] Terrault NA, Lok ASF, McMahon BJ et al. Update on prevention, diagnosis, and treatment of chronic hepatitis B: AASLD 2018 hepatitis B guidance. Hepatology 2018; 67: 1560-1599

[9] Greten TF, Malek NP, Schmidt S et al. Diagnostik und Therapie des hepatozellulären Karzinoms. Z Gastroenterol 2013; 51: 1269-1326 
[10] Castera L, Yuen Chan HL, Arrese M et al. EASL-ALEH Clinical Practice Guidelines: Non-invasive tests for evaluation of liver disease severity and prognosis. J Hepatol 2015; 63: 237-264

[11] Sarrazin C, Zimmermann T, Berg T et al. Prophylaxis, diagnosis and therapy of hepatitis-C-virus (HCV) infection: the German guidelines on the management of HCV infection. Z Gastroenterol 2018; 56: 756 doi:10.1055/a-0599-1320

[12] Sarrazin C, Zimmermann T, Berg T et al. Prophylaxe, Diagnostik und Therapie der Hepatitis-C-Virus(HCV)- Infektion. Z Gastroenterol 2020; 58: 1110-1131

[13] Lynen Jansen P, Preiß JC, Muche-Borowski C et al. Das Leitlinienprogramm der DGVS. Z Gastroenterol 2013; 51: 643-650

[14] Muche-Borowski C, Selbmann H, Nothacker M et al. Das AWMF-Regelwerk Leitlinien. 2013

[15] Blümle A, Sow D, Nothacker M et al. Manual Systematische Recherche für Evidenzsynthesen und Leitlinien. Cochrane Deutschl Stift Inst für Evidenz der Medizin, Inst für Medizinische Biometrie und Stat Freiburg, Arbeitsgemeinschaft der Wissenschaftlichen Medizinischen Fachgesellschaften - Inst für Medizinisches Wissensmanagement, Är 2019, 2. Auflage: 1-63

[16] Scheiblauer H, Soboll H, Nick S. Evaluation of 17 CE-marked HBsAg assays with respect to clinical sensitivity, analytical sensitivity, and hepatitis B virus mutant detection. J Med Virol 2006; 78: S66-S70

[17] Westhoff TH, Jochimsen F, Schmittel A et al. Fatal hepatitis B virus reactivation by an escape mutant following rituximab therapy. Blood 2003; 102: 1930

[18] Awerkiew S, Däumer M, Reiser M et al. Reactivation of an occult hepatitis $B$ virus escape mutant in an anti-HBs positive, anti-HBc negative lymphoma patient. J Clin Virol 2007; 38: 83-86

[19] Brown RS, McMahon BJ, Lok ASF et al. Antiviral therapy in chronic hepatitis B viral infection during pregnancy: A systematic review and metaanalysis. Hepatology 2016; 63: 319-333

[20] Li W, Jia L, Zhao X et al. Efficacy and safety of tenofovir in preventing mother-to-infant transmission of hepatitis B virus: A meta-analysis based on 6 studies from China and 3 studies from other countries. BMC Gastroenterol 2018; 18: 121

[21] Hyun MH, Lee YS, Kim JH et al. Systematic review with meta-analysis: the efficacy and safety of tenofovir to prevent mother-to-child transmission of hepatitis B virus. Aliment Pharmacol Ther 2017; 45: 1493-1505

[22] Pan CQ, Duan Z, Dai E et al. Tenofovir to prevent hepatitis B transmission in mothers with high viral load. N Engl J Med 2016; 374: 2324-2334

[23] World Health Organization. Prevention of mother-to-child transmission of hepatitis B virus: Guidelines on antiviral prophylaxis in pregnancy. Geneva World Heal Organ. 2020. Licence: CC BY-NC-SA 3.0 IGO. Im Internet: https://apps.who.int/iris/bitstream/handle/10665/333391/ 9789240002708-eng.pdf?sequence=1\&isAllowed=y

[24] Jourdain G, Ngo-Giang-Huong N, Harrison L et al. Tenofovir versus Placebo to Prevent Perinatal Transmission of Hepatitis B. N Engl ] Med 2018; 378: 911-923

[25] Lin Y, Liu Y, Ding G et al. Efficacy of tenofovir in preventing perinatal transmission of HBV infection in pregnant women with high viral loads. Sci Rep 8, 15514 (2018)

[26] Walz A, Wirth S, Hucke J et al. Vertical Transmission of Hepatitis B Virus (HBV) from Mothers Negative for HBV Surface Antigen and Positive for Antibody to HBV Core Antigen. J Infect Dis 2009; 200: 1227-1231

[27] Robert Koch-Insitut. Zur Situation bei wichtigen Infektionskrankheiten in Deutschland: Virushepatitis B, C und D im Jahr 2009. Epidemiol Bull 2009; 20: 177-190

[28] Ganem D, Prince AM. Hepatitis B Virus Infection - Natural History and Clinical Consequences. N Engl ] Med 2004; 350: 1118-1129

[29] McMahon B]. Natural history of chronic hepatitis B. Clin Liver Dis 2010; 14: $381-396$
[30] Veldhuijzen IK, Toy M, Hahné SJM et al. Screening and Early Treatment of Migrants for Chronic Hepatitis B Virus Infection Is Cost-Effective. Gastroenterology 2010; 138: 522-530

[31] Colloredo Mels G, Bellati G, Leandro G et al. Role of IgM antibody to hepatitis B core antigen in the diagnosis of hepatitis B exacerbations. Arch Virol Suppl 1993; 8: 203-211

[32] Chen C], Yang HI, Su J et al. Risk of hepatocellular carcinoma across a biological gradient of serum hepatitis B virus DNA Level. J Am Med Assoc 2006; 295: 65-73

[33] Iloeje UH, Yang HI, Su J et al. Predicting cirrhosis risk based on the level of circulating hepatitis B viral load. Gastroenterology 2006; 130: 678-686

[34] Chen G, Lin W, Shen F et al. Past HBV viral load as predictor of mortality and morbidity from HCC and chronic liver disease in a prospective study. Am J Gastroenterol 2006; 101: 1797-1803

[35] Yang HI, Lu SN, Liaw YF et al. Hepatitis B e Antigen and the Risk of Hepatocellular Carcinoma. N Engl J Med 2002; 347: 168-174

[36] Cornberg M, Wong VWS, Locarnini S et al. The role of quantitative hepatitis B surface antigen revisited. J Hepatol 2017; 66: 398-411

[37] Tseng TC, Liu C], Yang HC et al. Serum hepatitis B surface antigen levels help predict disease progression in patients with low hepatitis B virus loads. Hepatology 2013; 57: 441-450

[38] Wedemeyer H, Manns MP. Epidemiology, pathogenesis and management of hepatitis D: Update and challenges ahead. Nat Rev Gastroenterol Hepatol 2010; 7: 31-40

[39] Bremer B, Anastasiou OE, Ciesek S et al. Automated nucleic acid isolation methods for HDV viral load quantification can lead to viral load underestimation. Antivir Ther 2019; 24: 117-123

[40] Heese F, Görg C. Diagnostische wertigkeit einer internistischen referenzsonografie (DEGUM-Stufe 3). Ultraschall der Medizin 2006; 27: 220 224

[41] Sheu JC, Sung JL, Chen DS et al. Growth rate of asymptomatic hepatocellular carcinoma and its clinical implications. Gastroenterology 1985 89: 259-266

[42] Barbara L, Benzi G, Gaiani S et al. Natural history of small untreated hepatocellular carcinoma in cirrhosis: A multivariate analysis of prognostic factors of tumor growth rate and patient survival. Hepatology 1992; 16 : $132-137$

[43] Trinchet JC, Chaffaut C, Bourcier V et al. Ultrasonographic surveillance of hepatocellular carcinoma in cirrhosis: A randomized trial comparing 3and 6-month periodicities. Hepatology 2011; 54: 1987-1997

[44] Wang JH, Chang KC, Kee KM et al. Hepatocellular carcinoma surveillance at 4-vs. 12-month intervals for patients with chronic viral hepatitis: A randomized study in community. Am J Gastroenterol 2013; 108: 416424

[45] Sarri G, Westby M, Bermingham S et al. Diagnosis and management of chronic hepatitis B in children, young people, and adults: summary of NICE guidance. BMJ 2013; 346: f3893

[46] Singal A, Volk ML, Waljee A et al. Meta-analysis: Surveillance with ultrasound for early-stage hepatocellular carcinoma in patients with cirrhosis. Aliment Pharmacol Ther 2009; 30: 37-47

[47] Sarin SK, Kumar M, Lau GK et al. Asian-Pacific clinical practice guidelines on the management of hepatitis B: a 2015 update. Hepatol Int 2016; 10: $1-98$

[48] Korean Association for the Study of the Liver. KASL clinical practice guidelines: management of chronic hepatitis B. Clin Mol Hepatol 2016; 22: $18-75$

[49] Park JW, Lee JH, Suh KS et al. 2014 Korean Liver Cancer Study GroupNational Cancer Center Korea practice guideline for the management of hepatocellular carcinoma. Korean J Radiol 2015; 16: 465-522

[50] Thiele M, Gluud LL, Fialla AD et al. Large variations in risk of hepatocellular carcinoma and mortality in treatment Naïve hepatitis B patients: Systematic review with Metaanalyses. PLoS One 2014; 9: e107177 
[51] Galle PR, Forner A, Llovet JM et al. EASL Clinical Practice Guidelines: Management of hepatocellular carcinoma. J Hepatol 2018; 69: 182-236

[52] Trevisani F, D’Intino PE, Morselli-Labate AM et al. Serum $\alpha$-fetoprotein for diagnosis of hepatocellular carcinoma in patients with chronic liver disease: Influence of HBsAg and anti-HCV status. J Hepatol 2001; 34 : 570-575

[53] Papatheodoridis G, Dalekos G, Sypsa V et al. PAGE-B predicts the risk of developing hepatocellular carcinoma in Caucasians with chronic hepatitis B on 5-year antiviral therapy. J Hepatol 2016; 64: 800-806

[54] Wong GLH, Wong VWS, Choi PCL et al. Development of a non-invasive algorithm with transient elastography (Fibroscan) and serum test formula for advanced liver fibrosis in chronic hepatitis B. Aliment Pharmacol Ther 2010; 31: 1095-1103

[55] Wong GLH, Chan HLY, Choi PCL et al. Non-invasive algorithm of enhanced liver fibrosis and liver stiffness measurement with transient elastography for advanced liver fibrosis in chronic hepatitis B. Aliment Pharmacol Ther 2014; 39: 197-208

[56] Wong GLH, Wong VWS, Choi PCL et al. Increased liver stiffness measurement by transient elastography in severe acute exacerbation of chronic hepatitis B. J Gastroenterol Hepatol 2009; 24: 1002-1007

[57] Papatheodoridis GV, Manolakopoulos S, Liaw YF et al. Follow-up and indications for liver biopsy in $\mathrm{HBeAg}$-negative chronic hepatitis $\mathrm{B}$ virus infection with persistently normal ALT: A systematic review. J Hepatol 2012; 57: 196-202

[58] Kumar M, Satapathy S, Monga R et al. A randomized controlled trial of lamivudine to treat acute hepatitis B. Hepatology 2007; 45: 97-101

[59] Yu JW, Sun L], Zhao YH et al. The study of efficacy of lamivudine in patients with severe acute hepatitis B. Dig Dis Sci 2010; 55: 775-783

[60] Wiegand J, Wedemeyer $\mathrm{H}$, Franke A et al. Treatment of severe, nonfulminant acute hepatitis $B$ with lamivudine vs placebo: A prospective randomized double-blinded multicentre trial. J Viral Hepat 2014; 21: 744750

[61] Mantzoukis K, Rodríguez-Perálvarez M, Buzzetti E et al. Pharmacological interventions for acute hepatitis B infection: An attempted network meta-analysis. Cochrane Database Syst Rev 2017; 3: CD011645

[62] Tillmann HL, Hadem J, Leifeld L et al. Safety and efficacy of lamivudine in patients with severe acute or fulminant hepatitis $B$, a multicenter experience. J Viral Hepat 2006; 13: 256-263

[63] Jochum C, Maischack F, Anastasiou OE et al. Therapie der akuten fulminanten Hepatitis B mit Nucleos(t)id-Analogen ist sicher und führt nicht zur Chronifizierung der Hepatitis B. Z Gastroenterol 2016; 54: 13061311

[64] Yu JW, Sun LJ, Yan BZ et al. Lamivudine treatment is associated with improved survival in fulminant hepatitis B. Liver Int 2011; 31: 499-506

[65] Brunetto MR, Oliveri F, Coco B et al. Outcome of anti-HBe positive chronic hepatitis $B$ in alpha-interferon treated and untreated patients: A long term cohort study. J Hepatol 2002; 36: 263-270

[66] Kumar M, Sarin SK, Hissar S et al. Virologic and Histologic Features of Chronic Hepatitis B Virus-Infected Asymptomatic Patients With Persistently Normal ALT. Gastroenterology 2008; 134: 1376-1384

[67] Lai M, Hyatt B], Nasser I et al. The clinical significance of persistently normal ALT in chronic hepatitis B infection. J Hepatol 2007; 47: 760-767

[68] Tsang PSY, Trinh H, Garcia RT et al. Significant Prevalence of Histologic Disease in Patients With Chronic Hepatitis B and Mildly Elevated Serum Alanine Aminotransferase Levels. Clin Gastroenterol Hepatol 2008; 6: 569-574

[69] Papatheodoridis GV, Manesis EK, Manolakopoulos S et al. Is there a meaningful serum Hepatitis B virus DNA cutoff level for therapeutic decisions in hepatitis $B$ e antigen-negative chronic hepatitis $B$ virus infection? Hepatology 2008; 48: 1451-1459
[70] Wu IC, Lai CL, Bui Han SH et al. Efficacy of entecavir in chronic hepatitis b patients with mildly elevated alanine aminotransferase and biopsyproven histological damage. Hepatology 2010; 51: 1185-1189

[71] Chen JD, Yang HI, lloeje UH et al. Carriers of Inactive Hepatitis B Virus Are Still at Risk for Hepatocellular Carcinoma and Liver-Related Death. Gastroenterology 2010; 138: 1747-1754

[72] Kim JH, Sinn DH, Kang W et al. Low-level viremia and the increased risk of hepatocellular carcinoma in patients receiving entecavir treatment. Hepatology 2017; 66: 335-343

[73] Sinn DH, Lee J, Goo J et al. Hepatocellular carcinoma risk in chronic hepatitis B virus-infected compensated cirrhosis patients with low viral load. Hepatology 2015; 62: 694-701

[74] Zoutendijk R, Reijnders JG, Zoulim F et al. Virological response to entecavir is associated with a better clinical outcome in chronic hepatitis $B$ patients with cirrhosis. Gut 2013; 62: 760-765

[75] Singal AK, Salameh H, Kuo YF et al. Meta-analysis: The impact of oral anti-viral agents on the incidence of hepatocellular carcinoma in chronic hepatitis B. Aliment Pharmacol Ther 2013; 38: 98-106

[76] Lok ASF, McMahon BJ, Brown RS et al. Antiviral therapy for chronic hepatitis $B$ viral infection in adults: A systematic review and meta-analysis. Hepatology 2016; 63: 284-306

[77] Huang G, Li P, Lau WY et al. Antiviral therapy reduces hepatocellular carcinoma recurrence in patients with low HBV-DNA levels: A randomized controlled trial. Ann Surg 2018; 268: 943-954

[78] Chen VL, Yeh ML, Le AK et al. Anti-viral therapy is associated with improved survival but is underutilised in patients with hepatitis B virusrelated hepatocellular carcinoma: real-world east and west experience. Aliment Pharmacol Ther 2018; 48: 44-54

[79] He L, Liu X, Zhao Y et al. Efficacy of Nucleot(s)ide Analogs Therapy in Patients with Unresectable HBV-Related Hepatocellular Carcinoma: A Systematic Review and Meta-Analysis. Dis Markers 2017; 2017: 7075935

[80] Yuan P, Chen P, Qian Y. Evaluation of antiviral therapy performed after curative therapy in patients with HBV-related hepatocellular carcinoma: An updated meta-analysis. Can J Gastroenterol Hepatol 2016; 2016: 5234969

[81] Xia BW, Zhang YC, Wang J et al. Efficacy of antiviral therapy with nucleotide/nucleoside analogs after curative treatment for patients with hepatitis B virus-related hepatocellular carcinoma: A systematic review and meta-analysis. Clin Res Hepatol Gastroenterol 2015; 39: 458-468

[82] Huang G, Lau WY, Wang ZG et al. Antiviral therapy improves postoperative survival in patients with hepatocellular carcinoma. Ann Surg 2015; 261: 56-66

[83] Zhou Y, Zhang Z, Zhao Y et al. Antiviral therapy decreases recurrence of hepatitis b virus-related hepatocellular carcinoma after curative resection: A meta-analysis. World J Surg 2014; 38: 2395-2402

[84] Yin J, Li N, Han Y et al. Effect of antiviral treatment with nucleotide/nucleoside analogs on postoperative prognosis of hepatitis $B$ virus-related hepatocellular carcinoma: A two-stage longitudinal clinical study. J Clin Oncol 2013; 31: 3647-3655

[85] Wong JSW, Wong GLH, Tsoi KKF et al. Meta-analysis: The efficacy of antiviral therapy in prevention of recurrence after curative treatment of chronic hepatitis B-related hepatocellular carcinoma. Aliment Pharmacol Ther 2011; 33: 1104-1112

[86] Reddy KR, Beavers KL, Hammond SP et al. American Gastroenterological Association Institute guideline on the prevention and treatment of hepatitis B virus reactivation during immunosuppressive drug therapy. Gastroenterology 2015; 148: 215-219

[87] Sarmati L, Andreoni M, Antonelli G et al. Recommendations for screening, monitoring, prevention, prophylaxis and therapy of hepatitis $B$ virus reactivation in patients with haematologic malignancies and patients who underwent haematologic stem cell transplantation a position paper. Clin Microbiol Infect 2017; 23: 935-940 
[88] Chen JZJQ, Liao ZW, Huang FL et al. Efficacy and safety of tenofovir disoproxil fumarate in preventing vertical transmission of hepatitis $B$ in pregnancies with high viral load. Sci Rep 2017; 7: 4132

[89] Glebe D, van Bömmel F, Dudareva S et al. Prävention der nosokomialen Übertragung von Hepatitis-B-Virus (HBV) und Hepatitis-C-Virus (HCV) durch im Gesundheitswesen Tätige: Empfehlungen der Deutschen Vereinigung zur Bekämpfung der Viruskrankheiten (DVV) e. V. Bundesgesundheitsblatt Gesundheitsforschung Gesundheitsschutz 2020; 63: 218-225

[90] Mazzaro C, Dal Maso L, Urraro T et al. Hepatitis B virus related cryoglobulinemic vasculitis: A multicentre open label study from the Gruppo Italiano di Studio delle Crioglobulinemie - GISC. Dig Liver Dis 2016; 48: 780-784

[91] Wang WN, Wu MY, Ma FZ et al. Meta-analysis of the efficacy and safety of nucleotide/nucleoside analog monotherapy for hepatitis B virusassociated glomerulonephritis. Clin Nephrol 2016; 85: 21-29

[92] Yang Y, Ma YP, Chen DP et al. A meta-Analysis of antiviral therapy for hepatitis b virus-Associated membranous nephropathy. PLoS One 2016; 11: e0160437

[93] Hui CK, Leung N, Yuen ST et al. Natural history and disease progression in Chinese chronic hepatitis B patients in immune-tolerant phase. Hepatology 2007; 46: 395-401

[94] Andreani T, Serfaty L, Mohand D et al. Chronic Hepatitis B Virus Carriers in the Immunotolerant Phase of Infection: Histologic Findings and Outcome. Clin Gastroenterol Hepatol 2007; 5: 636-641

[95] Chu CM, Hung SJ, Lin J et al. Natural history of hepatitis B e antigen to antibody seroconversion in patients with normal serum aminotransferase levels. Am J Med 2004; 116: 829-834

[96] You SL, Yang HI, Chen CJ. Seropositivity of hepatitis B e antigen and hepatocellular carcinoma. Ann Med 2004; 36: 215-224

[97] Manno M, Cammà C, Schepis F et al. Natural history of chronic HBV carriers in Northern Italy: Morbidity and mortality after 30 years. Gastroenterology 2004; 127: 756-763

[98] Tseng TC, Liu C], Yang HC et al. High levels of hepatitis B surface antigen increase risk of hepatocellular carcinoma in patients with low HBV load. Gastroenterology 2012; 142: 1140-1149.e3

[99] Tseng TC, Liu C], Chen CL et al. Risk stratification of hepatocellular carcinoma in hepatitis B virus e antigen-negative carriers by combining viral biomarkers. J Infect Dis 2013; 208: 584-593

[100] Cornberg M, Suk-Fong Lok A, Terrault NA et al. Guidance for design and endpoints of clinical trials in chronic hepatitis B - Report from the 2019 EASL-AASLD HBV Treatment Endpoints Conferenceł. J Hepatol 2020; 72: 539-557

[101] Kim GA, Lim YS, An J et al. HBsAg seroclearance after nucleoside analogue therapy in patients with chronic hepatitis b: Clinical outcomes and durability. Gut 2014; 63: 1325-1332

[102] Yuen MF, Wong DKH, Fung J et al. HBsAg Seroclearance in Chronic Hepatitis B in Asian Patients: Replicative Level and Risk of Hepatocellular Carcinoma. Gastroenterology 2008; 135: 1192-1199

[103] Yip TCF, Wong GLH, Chan HLY et al. HBsAg seroclearance further reduces hepatocellular carcinoma risk after complete viral suppression with nucleos(t)ide analogues. J Hepatol 2019; 70: 361-370

[104] Wong GLH, Chan HLY, Mak CWH et al. Entecavir treatment reduces hepatic events and deaths in chronic hepatitis B patients With liver cirrhosis. Hepatology 2013; 58: 1537-1547

[105] Arends P, Sonneveld M], Zoutendijk R et al. Entecavir treatment does not eliminate the risk of hepatocellular carcinoma in chronic hepatitis B: Limited role for risk scores in Caucasians. Gut 2015; 64: 1289-1295

[106] Papatheodoridis GV, Lampertico P, Manolakopoulos S et al. Incidence of hepatocellular carcinoma in chronic hepatitis $B$ patients receiving nucleos(t)ide therapy: A systematic review. J Hepatol 2010; 53: 348356
[107] Kim SS, Hwang JC, Lim SG et al. Effect of virological response to entecavir on the development of hepatocellular carcinoma in hepatitis B viral cirrhotic patients: Comparison between compensated and decompensated cirrhosis. Am J Gastroenterol 2014; 109: 1223-1233

[108] Marcellin P, Gane E, Buti M et al. Regression of cirrhosis during treatment with tenofovir disoproxil fumarate for chronic hepatitis B: A 5-year open-label follow-up study. Lancet 2013; 381: 468-475

[109] Chang TT, Liaw YF, Wu SS et al. Long-term entecavir therapy results in the reversal of fibrosis/cirrhosis and continued histological improvement in patients with chronic hepatitis B. Hepatology 2010; 52: 886893

[110] Niederau C, Heintges T, Lange $\mathrm{S}$ et al. Long-term follow-up of HBeAgpositive patients treated with interferon alfa for chronic hepatitis B. N Engl J Med 1996; 334: 1422-1427

[111] Lin SM, Yu ML, Lee CM et al. Interferon therapy in HBeAg positive chronic hepatitis reduces progression to cirrhosis and hepatocellular carcinoma. J Hepatol 2007; 46: 45-52

[112] Yuen MF, Hui CK, Cheng CC et al. Long-term follow-up of interferon alfa treatment in Chinese patients with chronic hepatitis B infection: The effect on hepatitis B e antigen seroconversion and the development of cirrhosis-related complications. Hepatology 2001; 34: 139145

[113] Jacobson IM, Washington MK, Buti M et al. Factors Associated With Persistent Increase in Level of Alanine Aminotransferase in Patients With Chronic Hepatitis B Receiving Oral Antiviral Therapy. Clin Gastroenterol Hepatol 2017; 15: 1087-1094.e2

[114] Liang KH, Hsu CW, Chang ML et al. Peginterferon Is Superior to Nucleos (t)ide Analogues for Prevention of Hepatocellular Carcinoma in Chronic Hepatitis B. J Infect Dis 2016; 213: 966-974

[115] Lau GKK, Piratvisuth T, Kang XL et al. Peginterferon Alfa-2a, lamivudine, and the combination for HBeAg-positive chronic hepatitis B. N Engl J Med 2005; 352: 2682-2695

[116] Marcellin P, Lau GKK, Bonino F et al. Peginterferon Alfa-2a alone, lamivudine alone, and the two in combination in patients with $\mathrm{HBeAg}$ negative chronic hepatitis B. N Engl J Med 2004; 351: 1206-1217

[117] Sonneveld M], Zoutendijk R, Hansen BE et al. Pegylated interferon results in higher serological, but not virological, response rates when compared to continuous entecavir. Antivir Ther 2012; 17: 1605-1608

[118] Van Nunen AB, Hansen BE, Suh D] et al. Durability of HBeAG seroconversion following antiviral therapy for chronic hepatitis B: Relation to type of therapy and pretreatment serum hepatitis B virus DNA and alanine aminotransferase. Gut 2003; 52: 420-424

[119] Papatheodoridis GV, Chan HLY, Hansen BE et al. Risk of hepatocellular carcinoma in chronic hepatitis B: Assessment and modification with current antiviral therapy. J Hepatol 2015; 62: 956-967

[120] Dave S, Park S, Murad MH et al. Comparative Effectiveness of Entecavir vs Tenofovir for Preventing Hepatocellular Carcinoma in Patients with Chronic Hepatitis B: a Systematic Review and Meta-analysis. Hepatology 2021; 73: 68-78

[121] Choi WM, Choi J, Lim YS. Effects of Tenofovir vs Entecavir on Risk of Hepatocellular Carcinoma in Patients With Chronic HBV Infection: A Systematic Review and Meta-analysis. Clin Gastroenterol Hepatol 2021; 19: 246-258.e9

[122] Papatheodoridis GV, Dalekos GN, Idilman R et al. Similar risk of hepatocellular carcinoma during long-term entecavir or tenofovir therapy in Caucasian patients with chronic hepatitis B. J Hepatol 2020; 73: 1037-1045

[123] Voulgaris T, Papatheodoridi M, Lampertico P et al. Clinical utility of hepatocellular carcinoma risk scores in chronic hepatitis B. Liver Int 2020; 40: 484-495

[124] Liaw YF, Raptopoulou-Gigi M, Cheinquer $\mathrm{H}$ et al. Efficacy and safety of entecavir versus adefovir in chronic hepatitis $B$ patients with hepatic decompensation: A randomized, open-label study. Hepatology 2011; 54: $91-100$ 
[125] Shim JH, Lee HC, Kim KM et al. Efficacy of entecavir in treatment-naïve patients with hepatitis B virus-related decompensated cirrhosis. J Hepatol 2010; 52: 176-182

[126] Chan HLY, Chen YC, Gane EJ et al. Randomized clinical trial: Efficacy and safety of telbivudine and lamivudine in treatment-naïve patients with HBV-related decompensated cirrhosis. J Viral Hepat 2012; 19: 732-743

[127] Liaw YF, Sung JJY, Chow WC et al. Lamivudine for patients with chronic hepatitis B and advanced liver disease. N Engl J Med 2004; 351: 1521-1531

[128] Papatheodoridis GV, Dimou E, Dimakopoulos K et al. Outcome of hepatitis B e antigen-negative chronic hepatitis B on long-term nucleos (t)ide analog therapy starting with lamivudine. Hepatology 2005; 42: 121-129

[129] Zoulim F, Locarnini S. Hepatitis B Virus Resistance to Nucleos(t)ide Analogues. Gastroenterology 2009; 137: 1593-608.e1-2

[130] Warner N, Locarnini S. Mechanisms of hepatitis B virus resistance development. Intervirology 2014; 57: 218-224

[131] Berg T, Zoulim F, Moeller B et al. Long-term efficacy and safety of emtricitabine plus tenofovir DF vsß. tenofovir DF monotherapy in adefovirexperienced chronic hepatitis B patients. J Hepatol 2014; 60: 715-722

[132] Lim YS, Yoo BC, Byun KS et al. Tenofovir monotherapy versus tenofovir and entecavir combination therapy in adefovir-resistant chronic hepatitis B patients with multiple drug failure: Results of a randomised trial. Gut 2016; 65: 1042-1051

[133] Tenney DJ, Rose RE, Baldick C] et al. Two-year assessment of entecavir resistance in lamivudine-refractory hepatitis B virus patients reveals different clinical outcomes depending on the resistance substitutions present. Antimicrob Agents Chemother 2007; 51: 902-911

[134] Cathcart AL, Lik-Yuen Chan H, Bhardwaj N et al. No resistance to tenofovir alafenamide detected through 96 weeks of treatment in patients with chronic hepatitis b infection. Antimicrob Agents Chemother 2018; 62: e01064-18

[135] Agarwal K, Brunetto M, Seto WK et al. 96 weeks treatment of tenofovir alafenamide vs. tenofovir disoproxil fumarate for hepatitis B virus infection. J Hepatol 2018; 68: 672-681

[136] Buti M, Gane E, Seto WK et al. Tenofovir alafenamide versus tenofovir disoproxil fumarate for the treatment of patients with $\mathrm{HBeAg}$-negative chronic hepatitis $B$ virus infection: a randomised, double-blind, phase 3, non-inferiority trial. Lancet Gastroenterol Hepatol 2016; 1: 196-206

[137] Chan HLY, Fung S, Seto WK et al. Tenofovir alafenamide versus tenofovir disoproxil fumarate for the treatment of $\mathrm{HBeAg}$-positive chronic hepatitis B virus infection: a randomised, double-blind, phase 3, noninferiority trial. Lancet Gastroenterol Hepatol 2016; 1: 185-195

[138] Lampertico P, Chan HLY, Janssen HLA et al. Review article: long-term safety of nucleoside and nucleotide analogues in HBV-monoinfected patients. Aliment Pharmacol Ther 2016; 44: 16-34

[139] Gane EJ, Deray G, Liaw YF et al. Telbivudine improves renal function in patients with chronic hepatitis b. Gastroenterology 2014; 146: 138146.e 5

[140] Cholongitas E, Vasiliadis T, Goulis I et al. Telbivudine is associated with improvement of renal function in patients transplanted for HBV liver disease. J Viral Hepat 2015; 22: 574-580

[141] Ha NB, Ha NB, Garcia RT et al. Renal dysfunction in chronic hepatitis B patients treated with adefovir dipivoxil. Hepatology 2009; 50: 727-734

[142] Buti M, Fung S, Gane E et al. Long-term clinical outcomes in cirrhotic chronic hepatitis B patients treated with tenofovir disoproxil fumarate for up to 5 years. Hepatol Int 2015; 9: 243-250

[143] Chang TT, Lai CL, Yoon SK et al. Entecavir treatment for up to 5 years in patients with hepatitis b e antigen-positive chronic hepatitis B. Hepatology 2010; 51: 422-430

[144] Tenney DJ, Rose RE, Baldick C] et al. Long-term monitoring shows hepatitis $B$ virus resistance to entecavir in nucleoside-naïve patients is rare through 5 years-of therapy. Hepatology 2009; 49: 1503-1514
[145] Hui AY, Chan HLY, Cheung AYK et al. Systematic review: Treatment of chronic hepatitis B virus infection by pegylated interferon. Aliment Pharmacol Ther 2005; 22: 519-528

[146] Liaw YF, Jia JD, Chan HLY et al. Shorter durations and lower doses of peginterferon alfa-2a are associated with inferior hepatitis $B$ e antigen seroconversion rates in hepatitis B virus genotypes B or C. Hepatology 2011; 54: 1591-1599

[147] Sonneveld MJ, Hansen BE, Piratvisuth T et al. Response-guided peginterferon therapy in hepatitis B e antigen-positive chronic hepatitis B using serum hepatitis B surface antigen levels. Hepatology 2013; 58: 872-880

[148] Chan HLY, Messinger D, Papatheodoridis GV et al. A baseline tool for predicting response to peginterferon alfa-2a in $\mathrm{HBeAg}$-positive patients with chronic hepatitis B. Aliment Pharmacol Ther 2018; 48: 547 555

[149] Rijckborst V, Hansen BE, Ferenci P et al. Validation of a stopping rule at week 12 using HBsAg and HBV DNA for HBeAg-negative patients treated with peginterferon alfa-2a. J Hepatol 2012; 56: 1006-1011

[150] Colombatto P, Oliveri F, Leandro G et al. Platelet and white blood cell counts during therapy with different types of alpha interferon in patients with chronic viral hepatitis. Ital J Gastroenterol Hepatol 1997; 29: 441-447

[151] de Andrade LJO, D’Oliveira A, Silva CAC et al. A meta-analysis of patients with chronic hepatitis $C$ treated with interferon-alpha to determine the risk of autoimmune thyroiditis. Acta Gastroenterol Latinoam 2011; 41: 104-110

[152] ter Borg MJ, Hansen BE, Bigot G et al. ALT and viral load decline during PEG-IFN alpha-2b treatment for $\mathrm{HBeAg-positive} \mathrm{chronic} \mathrm{hepatitis} \mathrm{B.} \mathrm{J}$ Clin Virol 2008; 42: 160-164

[153] Wong GLH, Wong VWS, Chan HLY. Combination therapy of interferon and nucleotide/nucleoside analogues for chronic hepatitis B. J Viral Hepat 2014; 21: 825-834

[154] Marcellin P, Ahn SH, Ma X et al. Combination of Tenofovir Disoproxil Fumarate and Peginterferon $\alpha$-2a Increases Loss of Hepatitis B Surface Antigen in Patients with Chronic Hepatitis B. Gastroenterology 2016; 150: 134-144.e10

[155] Qiu K, Liu B, Li SY et al. Systematic review with meta-analysis: combination treatment of regimens based on pegylated interferon for chronic hepatitis B focusing on hepatitis B surface antigen clearance. Aliment Pharmacol Ther 2018; 47: 1340-1348

[156] Hongthanakorn C, Chotiyaputta W, Oberhelman K et al. Virological breakthrough and resistance in patients with chronic hepatitis $B$ receiving nucleos(t)ide analogues in clinical practice. Hepatology 2011; 53: 1854-1863

[157] Yeo YH, Ho HJ, Yang HI et al. Factors Associated With Rates of HBsAg Seroclearance in Adults With Chronic HBV Infection: A Systematic Review and Meta-analysis. Gastroenterology 2019; 156: 635-646.e9

[158] Sheppard-Law S, Zablotska-Manos I, Kermeen M et al. Factors associated with HBV virological breakthrough. Antivir Ther 2017; 22: 53-60

[159] van Vlerken LG, Arends P, Lieveld Fl et al. Real life adherence of chronic hepatitis B patients to entecavir treatment. Dig Liver Dis 2015; 47: 577-583

[160] Lim YS, Gwak GY, Choi ] et al. Monotherapy with tenofovir disoproxil fumarate for adefovir-resistant vs. entecavir-resistant chronic hepatitis B: A 5-year clinical trial. J Hepatol 2019; 71: 35-44

[161] Shirvani-Dastgerdi E, Winer BY, Celià-Terrassa T et al. Selection of the highly replicative and partially multidrug resistant rtS78T HBV polymerase mutation during TDF-ETV combination therapy. J Hepatol 2017; 67: 246-254

[162] Park ES, Lee AR, Kim DH et al. Identification of a quadruple mutation that confers tenofovir resistance in chronic hepatitis $B$ patients. J Hepatol 2019; 70: 1093-1102 
[163] Lin Y, Pan F, Wang Y et al. Adefovir dipivoxil-induced Fanconi syndrome and its predictive factors: A study of 28 cases. Oncol Lett 2017; 13: 307-314

[164] Seto WK, Asahina Y, Brown TT et al. Improved Bone Safety of Tenofovir Alafenamide Compared to Tenofovir Disoproxil Fumarate Over 2 Years in Patients With Chronic HBV Infection. Clin Gastroenterol Hepatol 2018 Jun 20: S1542-3565(18)30633-5

[165] Fong TL, Lee BT, Tien A et al. Improvement of bone mineral density and markers of proximal renal tubular function in chronic hepatitis B patients switched from tenofovir disoproxil fumarate to tenofovir alafenamide. J Viral Hepat 2019; 26: 561-567

[166] Grossi G, Loglio A, Facchetti F et al. Tenofovir alafenamide as a rescue therapy in a patient with HBV-cirrhosis with a history of Fanconi syndrome and multidrug resistance. J Hepatol 2018; 68: 195-198

[167] Lim SG, Wai CT, Rajnakova A et al. Fatal hepatitis B reactivation following discontinuation of nucleoside analogues for chronic hepatitis B. Gut 2002; 51: 597-599

[168] Papatheodoridis G, Vlachogiannakos I, Cholongitas E et al. Discontinuation of oral antivirals in chronic hepatitis B: A systematic review. Hepatology 2016; 63: 1481-1492

[169] Chang ML, Liaw YF, Hadziyannis SJ. Systematic review: Cessation of long-term nucleos(t)ide analogue therapy in patients with hepatitis B e antigen-negative chronic hepatitis B. Aliment Pharmacol Ther 2015; 42: $243-257$

[170] Raimondo G, Locarnini S, Pollicino T et al. Update of the statements on biology and clinical impact of occult hepatitis B virus infection. J Hepatol 2019; 71: 397-408

[171] Perrillo RP, Gish R, Falck-Ytter YT. American Gastroenterological Association Institute technical review on prevention and treatment of hepatitis b virus reactivation during immunosuppressive drug therapy. Gastroenterology 2015; 148: 221-244.e3

[172] Yip TCF, Wong GLH, Wong VWS et al. Durability of hepatitis B surface antigen seroclearance in untreated and nucleos(t)ide analogue-treated patients. J Hepatol 2018; 68: 63-72

[173] Stelma F, van der Ree MH, Jansen L et al. HBsAg loss after peginterferon-nucleotide combination treatment in chronic hepatitis B patients: 5 years of follow-up. J Viral Hepat 2017; 24: 1107-1113

[174] Roushan MRH, Mohammadpour M, Baiany M et al. Time to seroconversion of $\mathrm{HBsAg}$ to anti-HBs in individuals who lost $\mathrm{HBsAg}$ during follow-up. Epidemiol Infect 2016; 144: 2648-2653

[175] Chaung KT, Ha NB, Trinh HN et al. High frequency of recurrent viremia after hepatitis B e antigen seroconversion and consolidation therapy. J Clin Gastroenterol 2012; 46: 865-870

[176] Fung J, Lai CL, Tanaka Y et al. The duration of lamivudine therapy for chronic hepatitis b: Cessation vs. continuation of treatment after HBeAg seroconversion. Am J Gastroenterol 2009; 104: 1940-1946

[177] Qiu YW, Huang LH, Yang WL et al. Hepatitis B surface antigen quantification at hepatitis $B$ e antigen seroconversion predicts virological relapse after the cessation of entecavir treatment in hepatitis B e antigen-positive patients. Int J Infect Dis 2016; 43: 43-48

[178] Chi H, Hansen BE, Yim C et al. Reduced risk of relapse after long-term nucleos $(\mathrm{t})$ ide analogue consolidation therapy for chronic hepatitis $\mathrm{B}$. Aliment Pharmacol Ther 2015; 41: 867-876

[179] Chen YC, Peng CY, Jeng WJ et al. Clinical outcomes after interruption of entecavir therapy in $\mathrm{HBeAg-negative} \mathrm{chronic} \mathrm{hepatitis} \mathrm{B} \mathrm{patients} \mathrm{with}$ compensated cirrhosis. Aliment Pharmacol Ther 2015; 42: 1182-1191

[180] Jung KS, Park JY, Chon YE et al. Clinical outcomes and predictors for relapse after cessation of oral antiviral treatment in chronic hepatitis B patients. J Gastroenterol 2016; 51: 830-839

[181] Berg T, Simon KG, Mauss S et al. Long-term response after stopping tenofovir disoproxil fumarate in non-cirrhotic HBeAg-negative patients - FINITE study. J Hepatol 2017; 67: 918-924
[182] Jeng W], Chen YC, Sheen IS et al. Clinical Relapse After Cessation of Tenofovir Therapy in Hepatitis B e Antigen-Negative Patients. Clin Gastroenterol Hepatol 2016; 14: 1813-1820.e1

[183] Höner zu Siederdissen C, Hui AJ, Sukeepaisarnjaroen W et al. Contrasting timing of virological relapse after discontinuation of tenofovir or entecavir in Hepatitis B e antigen-negative patients. J Infect Dis 2018; 218: $1480-1484$

[184] Su TH, Yang HC, Tseng TC et al. Distinct Relapse Rates and Risk Predictors after Discontinuing Tenofovir and Entecavir Therapy. J Infect Dis 2018; 217: 1193-1201

[185] Kuo MTe, Hu TH, Hung CH et al. Hepatitis B virus relapse rates in chronic hepatitis B patients who discontinue either entecavir or tenofovir. Aliment Pharmacol Ther 2019; 49: 218-228

[186] Höner Zu Siederdissen C, Rinker F, Maasoumy B et al. Viral and host responses after stopping long-term Nucleos(t)ide analogue therapy in HBeAg-negative chronic Hepatitis B. J Infect Dis 2016; 214: 1492-1497

[187] Hadziyannis S], Sevastianos V, Rapti I et al. Sustained responses and loss of $\mathrm{HBsAg}$ in $\mathrm{HBeAg}$-negative patients with chronic hepatitis B who stop long-term treatment with adefovir. Gastroenterology 2012; 143: 629-636.e1

[188] Papatheodoridis GV, Rigopoulou El, Papatheodoridi M et al. Daring-B: Discontinuation of effective entecavir or tenofovir disoproxil fumarate long-term therapy before HBsAg loss in non-cirrhotic HBeAg-negative chronic hepatitis B. Antivir Ther 2018; 23: 677-685

[189] van Bömmel F, Stein K, Heyne R et al. Response to discontinuation of long-term nucleos(t)ide analogue treatment in $\mathrm{HBeAg}$ negative patients: Results of the Stop-NUC trial. J Hepatol 2020; 73: S118-S119

[190] Zimmer CL, Rinker F, Höner Zu Siederdissen C et al. Increased NK Cell Function after Cessation of Long-Term Nucleos(t)ide Analogue Treatment in Chronic Hepatitis B Is Associated with Liver Damage and HBsAg Loss; Journal of Infectious Diseases. Oxford University Press; 2018: 1656-1666

[191] Rinker F, Zimmer CL, Höner zu Siederdissen C et al. Hepatitis B virusspecific $T$ cell responses after stopping nucleos(t)ide analogue therapy in HBeAg-negative chronic hepatitis B. J Hepatol 2018; 69: 584-593

[192] Buster EHC], Hansen BE, Buti M et al. Peginterferon alpha-2b is safe and effective in $\mathrm{HBeAg-positive} \mathrm{chronic} \mathrm{hepatitis} \mathrm{B}$ patients with advanced fibrosis. Hepatology 2007; 46: 388-394

[193] Charatcharoenwitthaya P, Sukeepaisarnjaroen W, Piratvisuth T et al. Treatment outcomes and validation of the stopping rule for response to peginterferon in chronic hepatitis B: A Thai nationwide cohort study. J Gastroenterol Hepatol 2016; 31: 1874-1881

[194] Campistol JM, Esforzado N, Martínez J et al. Efficacy and tolerance of interferon- $\alpha 2 b$ in the treatment of chronic hepatitis $C$ virus infection in haemodialysis patients. Pre- and post-renal transplantation assessment. Nephrol Dial Transplant 1999; 14: 2704-2709

[195] Chan TM, Ho SKN, Tang CSO et al. Pilot study of pegylated interferonalpha $2 a$ in dialysis patients with chronic hepatitis $C$ virus infection. Nephrology 2007; 12: 11-17

[196] Coppolino G, Simeoni M, Summaria C et al. The case of chronic hepatitis B treatment with tenofovir: an update for nephrologists. J Nephrol 2015; 28: 393-402

[197] Liu J, Wang J, Qi C et al. Baseline hepatitis B virus titer predicts initial postpartum hepatic flare. J Clin Gastroenterol 2018; 52: 902-907

[198] Shang J, Wen Q, Wang CC et al. Safety and efficacy of telbivudine for chronic hepatitis B during the entire pregnancy: Long-term follow-up. J Viral Hepat 2017; 24: 43-48

[199] Antiretroviral Pregnancy Registry Interim Report for 1 January 1989 31 January 2020*. http://www.apregistry.com. 2020

[200] Yang M, Qin Q, Fang Q et al. Cesarean section to prevent mother-tochild transmission of hepatitis B virus in China: A meta-analysis. BMC Pregnancy Childbirth 2017; 17: 303 
[201] Chen HL, Cai JY, Song YP et al. Vaginal delivery and HBV mother to child transmission risk after immunoprophylaxis: A systematic review and a meta-analysis. Midwifery 2019; 74: 116-125

[202] Pan CQ, Zou HB, Chen Y et al. Cesarean section reduces perinatal transmission of hepatitis B virus infection from hepatitis b surface antigen-positive women to their infants. Clin Gastroenterol Hepatol 2013; 11: 1349-1355

[203] Wang M, Bian Q, Zhu Y et al. Real-world study of tenofovir disoproxil fumarate to prevent hepatitis $B$ transmission in mothers with high viral load. Aliment Pharmacol Ther 2019; 49: 211-217

[204] Hou J, Wang G, Wang F et al. Guideline of Prevention and Treatment for Chronic Hepatitis B (2015 Update). J Clin Transl Hepatol 2017; 5: 297-318

[205] Hou J, Cui F, Ding Y et al. Management Algorithm for Interrupting Mother-to-Child Transmission of Hepatitis B Virus. Clin Gastroenterol Hepatol 2019; 17: 1929-1936.e1

[206] Ehrhardt S, Xie C, Guo N et al. Breastfeeding while taking lamivudine or tenofovir disoproxil fumarate: A review of the evidence. Clin Infect Dis 2015; 60: 275-278

[207] Hu X, Wang L, Xu F. Guides concerning tenofovir exposure via breastfeeding: A comparison of drug dosages by developmental stage. Int ] Infect Dis 2019; 87: 8-12

[208] Mofenson LM, Baggaley RC, Mameletzis I. Tenofovir disoproxil fumarate safety for women and their infants during pregnancy and breastfeeding. Aids 2017; 31: 213-232

[209] Mugwanya KK, John-Stewart G, Baeten J. Safety of oral tenofovir disoproxil fumarate-based HIV pre-exposure prophylaxis use in lactating HIV-uninfected women. Expert Opin Drug Saf 2017; 16: 867-871

[210] Shi Z, Yang Y, Wang $\mathrm{H}$ et al. Breastfeeding of newborns by mothers carrying hepatitis B virus: A meta-analysis and systematic review. Arch Pediatr Adolesc Med 2011; 165: 837-846

[211] Paul S, Dickstein A, Saxena A et al. Role of surface antibody in hepatitis $B$ reactivation in patients with resolved infection and hematologic malignancy: A meta-analysis. Hepatology 2017; 66: 379-388

[212] Pérez-Alvarez R, Díaz-Lagares C, García-Hernández F et al. Hepatitis B Virus (HBV) Reactivation in Patients Receiving Tumor Necrosis Factor (TNF)-Targeted Therapy. Medicine (Baltimore) 2011; 90: 359-371

[213] Voican CS, Mir O, Loulergue P et al. Hepatitis B virus reactivation in patients with solid tumors receiving systemic anticancer treatment. Ann Oncol 2016; 27: 2172-2184

[214] Mallet V, van Bömmel F, Doerig C et al. Management of viral hepatitis in patients with haematological malignancy and in patients undergoing haemopoietic stem cell transplantation: Recommendations of the 5th European Conference on Infections in Leukaemia (ECIL-5). Lancet Infect Dis 2016; 16: 606-617

[215] Barone M, Notarnicola A, Lopalco G et al. Safety of Long-Term Biologic Therapy in Rheumatologic Patients With a Previously Resolved Hepatitis B Viral Infection. Hepatology 2015; 62: 40-46

[216] Caocci G, Murgia F, Podda L et al. Reactivation of hepatitis B virus infection following ruxolitinib treatment in a patient with myelofibrosis. Leukemia 2014; 28: 225-227

[217] Kirito K, Sakamoto M, Enomoto N. Elevation of the hepatitis b virus dna during the treatment of polycythemia vera with the JAK kinase inhibitor ruxolitinib. Intern Med 2016; 55: 1341-1344

[218] Godbert B, Petitpain N, Lopez A et al. Hepatitis B reactivation and immune check point inhibitors. Dig Liver Dis 2021; 53: 452-455

[219] Lee PC, Chao Y, Chen MH et al. Risk of HBV reactivation in patients with immune checkpoint inhibitor-treated unresectable hepatocellular carcinoma. J Immunother Cancer 2020; 8: 1072

[220] Ekpanyapong S, Reddy KR. Hepatitis B Virus Reactivation: What Is the Issue, and How Should It Be Managed? Clin Liver Dis 2020; 24: 317-333
[221] Gane E, Verdon D], Brooks AE et al. Anti-PD-1 blockade with nivolumab with and without therapeutic vaccination for virally suppressed chronic hepatitis B: A pilot study. J Hepatol 2019; 71: 900-907

[222] Jang JW, Kim YW, Lee SW et al. Reactivation of hepatitis B virus in HBsAg-negative patients with hepatocellular carcinoma. PLoS One 2015; 10: e0122041

[223] Lao XM, Luo G, Ye LT et al. Effects of antiviral therapy on hepatitis B virus reactivation and liver function after resection or chemoembolization for hepatocellular carcinoma. Liver Int 2013; 33: 595-604

[224] Huang S, Xia Y, Lei Z et al. Antiviral Therapy Inhibits Viral Reactivation and Improves Survival after Repeat Hepatectomy for Hepatitis B VirusRelated Recurrent Hepatocellular Carcinoma. J Am Coll Surg 2017; 224 283-293.e4

[225] Yoo SH, Jang JW, Kwon JH et al. Preemptive antiviral therapy with entecavir can reduce acute deterioration of hepatic function following transarterial chemoembolization. Clin Mol Hepatol 2016; 22: 458-465

[226] Huang H, Li X, Zhu J et al. Entecavir vs lamivudine for prevention of hepatitis $B$ virus reactivation among patients with untreated diffuse large B-cell lymphoma receiving R-CHOP chemotherapy: A randomized clinical trial. JAMA - J Am Med Assoc 2014; 312: 2521-2530

[227] Zhang MY, Zhu GQ, Shi KQ et al. Systematic review with network metaanalysis: Comparative efficacy of oral nucleos(t)ide analogues for the prevention of chemotherapy-induced hepatitis $B$ virus reactivation. Oncotarget 2016; 7: 30642-30658

[228] Grossi G, Viganò M, Facchetti F et al. Failure of long-term lamivudine prophylaxis in patients with resolved hepatitis B infection undergoing chemotherapy and allogenic hematopoietic stem cell transplantation for hematological malignancies: Two case reports. Haematologica 2017; 102: e423-e426

[229] Buti M, Manzano ML, Morillas RM et al. Randomized prospective study evaluating tenofovir disoproxil fumarate prophylaxis against hepatitis B virus reactivation in anti-HBc-positive patients with rituximab-based regimens to treat hematologic malignancies: The Preblin study. PLoS One 2017; 12: e0184550

[230] Nakaya A, Fujita S, Satake A et al. Delayed HBV reactivation in rituximab-containing chemotherapy: How long should we continue anti-virus prophylaxis or monitoring HBV-DNA? Leuk Res 2016; 50: 46-49

[231] Liaw YF, Sheen IS, Lee CM et al. Tenofovir disoproxil fumarate (TDF), emtricitabine/TDF, and entecavir in patients with decompensated chronic hepatitis B liver disease. Hepatology 2011; 53: 62-72

[232] Jang JW, Choi JY, Kim YS et al. Long-term effect of antiviral therapy on disease course after decompensation in patients with hepatitis B virusrelated cirrhosis. Hepatology 2015; 61: 1809-1820

[233] Peng CY, Chien RN, Liaw YF. Hepatitis B virus-related decompensated liver cirrhosis: Benefits of antiviral therapy. J Hepatol 2012; 57: 442450

[234] Burra P, Germani G, Adam R et al. Liver transplantation for HBV-related cirrhosis in Europe: An ELTR study on evolution and outcomes. J Hepatol 2013; 58: 287-296

[235] De Simone P, Romagnoli R, Tandoi F et al. Early introduction of subcutaneous hepatitis B immunoglobulin following liver transplantation for hepatitis $B$ virus infection: A prospective, multicenter study. Transplantation 2016; 100: 1507-1512

[236] Zheng JN, Zou TT, Zou H et al. Comparative efficacy of oral nucleotide analogues for the prophylaxis of hepatitis B virus recurrence after liver transplantation: a network meta-analysis. Expert Rev Anti Infect Ther 2016; 14: 979-987

[237] Fernández I, Loinaz C, Hernández O et al. Tenofovir/entecavir monotherapy after hepatitis B immunoglobulin withdrawal is safe and effective in the prevention of hepatitis $B$ in liver transplant recipients. Transpl Infect Dis 2015; 17: 695-701 
[238] Choudhary NS, Saraf N, Saigal S et al. Low-dose short-term hepatitis B immunoglobulin with high genetic barrier antivirals: The ideal posttransplant hepatitis B virus prophylaxis? Transpl Infect Dis 2015; 17: 329-333

[239] Cholongitas E, Papatheodoridis GV. High genetic barrier nucleos(t)ide analogue(s) for prophylaxis from hepatitis b virus recurrence after liver transplantation: A systematic review. Am J Transplant 2013; 13: 353-362

[240] Manini MA, Whitehouse G, Bruce M et al. Entecavir or tenofovir monotherapy prevents HBV recurrence in liver transplant recipients: A 5-year follow-up study after hepatitis B immunoglobulin withdrawal. Dig Liver Dis 2018; 50: 944-953

[241] Sripongpun P, Mannalithara A, Kwo PY et al. Potential Benefits of Switching Liver Transplant Recipients to Tenofovir Alafenamide Prophylaxis. Clin Gastroenterol Hepatol 2020; 18: 747-749

[242] Weber NK, Forman LM, Trotter JF. HBIg discontinuation with maintenance oral anti-viral therapy and $\mathrm{HBV}$ vaccination in liver transplant recipients. Dig Dis Sci 2010; 55: 505-509

[243] Wong SN, Chu C], Wai CT et al. Low risk of hepatitits B virus recurrence after withdrawal of long-term hepatitis B immunoglobulin in patients receiving maintenance nucleos(t)ide analogue therapy. Liver Transplant 2007; 13: 374-381

[244] Fung J, Chan SC, Cheung C et al. Oral nucleoside/nucleotide analogs without hepatitis $b$ immune globulin after liver transplantation for hepatitis b. Am J Gastroenterol 2013; 108: 942-948

[245] Terrault N. Editorial: Prophylaxis in hbv-infected liver transplant patients: End of the HBIG era? Am J Gastroenterol 2013; 108: 949-951

[246] Wang P, Tam N, Wang $\mathrm{H}$ et al. Is hepatitis B immunoglobulin necessary in prophylaxis of hepatitis B recurrence after liver transplantation? A meta-analysis. PLoS One 2014; 9: e104480

[247] Lens S, García-Eliz M, Fernández I et al. Shorter hepatitis B immunoglobulin administration is not associated to hepatitis $B$ virus recurrence when receiving combined prophylaxis after liver transplantation. Liver Int 2018; 38: 1940-1950

[248] Idilman R, Akyildiz M, Keskin O et al. The long-term efficacy of combining nucleos(t)ide analog and low-dose hepatitis B immunoglobulin on post-transplant hepatitis B virus recurrence. Clin Transplant 2016; 30: 1216-1221

[249] Cholongitas E, Goulis I, Antoniadis N et al. Nucleos(t)ide analog(s) prophylaxis after hepatitis B immunoglobulin withdrawal against hepatitis $B$ and D recurrence after liver transplantation. Transpl Infect Dis 2016; 18: 667-673

[250] Fox AN, Terrault NA. Individualizing hepatitis B infection prophylaxis in liver transplant recipients. J Hepatol 2011; 55: 507-509

[251] Karlas T, Hartmann J, Weimann A et al. Prevention of lamivudine-resistant hepatitis B recurrence after liver transplantation with entecavir plus tenofovir combination therapy and perioperative hepatitis B immunoglobulin only. Transpl Infect Dis 2011; 13: 299-302

[252] Roche B, Samuel D. Liver transplantation in delta virus infection. Semin Liver Dis 2012; 32: 245-255

[253] Kasraianfard A, Watt KD, Lindberg L et al. HBIG Remains Significant in the Era of New Potent Nucleoside Analogues for Prophylaxis Against Hepatitis B Recurrence After Liver Transplantation. Int Rev Immunol 2016; 35: 312-324

[254] Radhakrishnan K, Chi A, Quan DJ et al. Short course of postoperative hepatitis B immunoglobulin plus antivirals prevents reinfection of liver transplant recipients. Transplantation 2017; 101: 2079-2082

[255] Teperman LW, Poordad F, Bzowej N et al. Randomized trial of emtricitabine/tenofovir disoproxil fumarate after hepatitis B immunoglobulin withdrawal after liver transplantation. Liver Transplant 2013; 19: 594-601

[256] Stärkel P, Stoffel M, Lerut J et al. Response to an experimental HBV vaccine permits withdrawal of $\mathrm{HBIg}$ prophylaxis in fulminant and selected chronic HBV-infected liver graft recipients. Liver Transplant 2005; 11: 1228-1234
[257] Sanchez-Fueyo A, Rimola A, Grande L et al. Hepatitis B immunoglobulin discontinuation followed by hepatitis B virus vaccination: A new strategy in the prophylaxis of hepatitis $B$ virus recurrence after liver transplantation. Hepatology 2000; 31: 496-501

[258] Rosenau J, Hooman N, Rifai K et al. Hepatitis B virus immunization with an adjuvant containing vaccine after liver transplantation for hepatitis B-related disease: Failure of humoral and cellular immune response. Transpl Int 2006; 19: 828-833

[259] Margreiter R, Kramar R, Huber C et al. Combined Liver and Kidney Transplantation. Lancet 1984; 323: 1077-1078

[260] Ruiz R, Kunitake H, Wilkinson AH et al. Long-term analysis of combined liver and kidney transplantation at a single center. Arch Surg 2006; 141: 735-741

[261] Kirchner Gl, Rifai K, Cantz T et al. Outcome and quality of life in patients with polycystic liver disease after liver or combined liver-kidney transplantation. Liver Transplant 2006; 12: 1268-1277

[262] Jalanko H, Pakarinen M. Combined liver and kidney transplantation in children. Pediatr Nephrol 2014; 29: 805-814

[263] Pöge U, Gerhardt T, Palmedo H et al. MDRD equations for estimation of GFR in renal transplant recipients. Am J Transplant 2005; 5: 1306-1311

[264] Neumann UP, Lang M, Moloenhauer A et al. Significance of a T-lymphocytotoxic crossmatch in liver and combined liver-kidney transplantation. Transplantation 2001; 71: 1163-1168

[265] Olausson M, Mjörnstedt L, Nordén G et al. Successful combined partial auxiliary liver and kidney transplantation in highly sensitized crossmatch positive recipients. Am J Transplant 2007; 7: 130-136

[266] Hwang JP, Lok ASF. Management of patients with hepatitis B who require immunosuppressive therapy. Nat Rev Gastroenterol Hepatol 2014; 11: 209-219

[267] Kanaan N, Kabamba B, Maréchal C et al. Significant rate of hepatitis B reactivation following kidney transplantation in patients with resolved infection. J Clin Virol 2012; 55: 233-238

[268] Loomba R, Liang TJ. Hepatitis B Reactivation Associated With Immune Suppressive and Biological Modifier Therapies: Current Concepts, Management Strategies, and Future Directions. Gastroenterology 2017; 152: 1297-1309

[269] Shang J, Wang H, Sun J et al. A comparison of lamivudine vs entecavir for prophylaxis of hepatitis $B$ virus reactivation in allogeneic hematopoietic stem cell transplantation recipients: A single-institutional experience. Bone Marrow Transplant 2016; 51: 581-586

[270] Seto WK, Chan TSY, Hwang YY et al. Hepatitis B reactivation in occult viral carriers undergoing hematopoietic stem cell transplantation: $\mathrm{A}$ prospective study. Hepatology 2017; 65: 1451-1461

[271] O'Grady ]. The immunoreactive patient: Rejection and autoimmune disease. Liver Transplant 2011; 17 (Suppl. 3): S29-S33

[272] Skagen CL, Jou JH, Said A. Risk of de novo hepatitis in liver recipients from hepatitis-B core antibody-positive grafts - a systematic analysis. Clin Transplant 2011; 25: E243-E249

[273] Huprikar S, Danziger-Isakov L, Ahn J et al. Solid organ transplantation from hepatitis B virus-positive donors: Consensus guidelines for recipient management. Am J Transplant 2015; 15: 1162-1172

[274] Wright AJ, Fishman JA, Chung RT. Lamivudine compared with newer antivirals for prophylaxis of hepatitis B core antibody positive livers: A cost-effectiveness analysis. Am J Transplant 2014; 14: 629-634

[275] Chang MS, Olsen SK, Pichardo EM et al. Prevention of de novo hepatitis $B$ in recipients of core antibody-positive livers with lamivudine and other nucleos(t)ides: A 12-year experience. Transplantation 2013; 95 960-965

[276] Chotiyaputta W, Pelletier S], Fontana RJ et al. Long-term efficacy of nucleoside monotherapy in preventing HBV infection in HBsAg-negative recipients of anti-HBc-positive donor livers. Hepatol Int 2010; 4: $707-715$ 
[277] Leong J, Coty P, Isabel Fiel M et al. Lamivudine resistance leading to de novo hepatitis B infection in recipients of hepatitis B core antibody positive liver allografts. Hepatol Res 2014; 44: 1248-1252

[278] Yamashiki N, Yoshizawa A, Ueda Y et al. The use of hepatitis B immunoglobulin with or without hepatitis $B$ vaccine to prevent de novo hepatitis $B$ in pediatric recipients of anti-HBc-positive livers. Pediatr Transplant 2018; 22: e13227

[279] Yang A, Guo Z, Ren Q et al. Active immunization in patients transplanted for hepatitis B virus related liver diseases: A prospective study. PLoS One 2017; 12: e0188190

[280] Wang SH, Loh PY, Lin TL et al. Active immunization for prevention of De novo hepatitis B virus infection after adult living donor liver transplantation with a hepatitis B core antigen-positive graft. Liver Transplant 2017; 23: 1266-1272

[281] Yoshizawa A, Yamashiki N, Ueda Y et al. Long-term efficacy of hepatitis $B$ vaccination as post-transplant prophylaxis in hepatitis $B$ surface antigen $(\mathrm{HBsAg})$ positive recipients and $\mathrm{HBsAg}$ negative recipients of antihepatitis B core positive grafts. Hepatol Res 2016; 46: 541-551

[282] Verna EC. Vaccination to prevent de novo hepatitis B: Are there patients who do not need antiviral prophylaxis? Liver Transplant 2017; 23: 1253-1254

[283] Mahboobi N, Tabatabaei SV, Blum HE et al. Renal grafts from anti-hepatitis B core-positive donors: A quantitative review of the literature. Transpl Infect Dis 2012; 14: 445-451

[284] Manickam P, Krishnamoorthi R, Kanaan Z et al. Prognostic implications of recipient or donor hepatitis $B$ seropositivity in thoracic transplantation: Analysis of 426 hepatitis B surface antigen-positive recipients. Transpl Infect Dis 2014; 16: 597-604

[285] Satterthwaite R, Ozgu I, Shidban $\mathrm{H}$ et al. Risks of transplanting kidneys from hepatitis B surface antigen- negative, hepatitis B core antibodypositive donors. Transplantation 1997; 64: 432-435

[286] Yu S, Yu J, Zhang W et al. Safe use of liver grafts from hepatitis B surface antigen positive donors in liver transplantation. J Hepatol 2014; 61: 809-815

[287] Saidi RF, Jabbour N, Shah SA et al. Liver transplantation from hepatitis B surface antigen-positive donors. Transplant Proc 2013; 45: 279-280

[288] Chancharoenthana W, Townamchai N, Pongpirul K et al. The outcomes of kidney transplantation in hepatitis B surface antigen ( $\mathrm{HBsAg}$ )-negative recipients receiving graft from $\mathrm{HBsAg-positive} \mathrm{donors:} \mathrm{A} \mathrm{retro-}$ spective, propensity score-matched study. Am J Transplant 2014; 14 : 2814-2820

[289] Jiang H, Wu J, Zhang X et al. Kidney transplantation from hepatitis B surface antigen positive donors into hepatitis B surface antibody positive recipients: A prospective nonrandomized controlled study from a single center. Am J Transplant 2009; 9: 1853-1858

[290] Magiorkinis E, Paraskevis D, Pavlopoulou ID et al. Renal transplantation from hepatitis B surface antigen ( $\mathrm{HBsAg}$ )-positive donors to $\mathrm{HBsAg}$ negative recipients: A case of post-transplant fulminant hepatitis associated with an extensively mutated hepatitis $B$ virus strain and review of the current literature. Transpl Infect Dis 2013; 15: 393-399

[291] Giaccone L, Festuccia M, Marengo A et al. Hepatitis B Virus Reactivation and Efficacy of Prophylaxis with Lamivudine in Patients Undergoing Allogeneic Stem Cell Transplantation. Biol Blood Marrow Transplant 2010; 16: 809-817

[292] Lau GKK, Lie AKW, Kwong YL et al. A case-controlled study on the use of HBsAg-positive donors for allogeneic hematopoietic cell transplantation. Blood 2000; 96: 452-458

[293] Hui CK, Lie A, Au WY et al. Effectiveness of prophylactic anti-HBV therapy in allogeneic hematopoietic stem cell transplantation with $\mathrm{HBsAg}$ positive donors. Am J Transplant 2005; 5: 1437-1445

[294] Franchello A, Ghisetti V, Marzano A et al. Transplantation of hepatitis B surface antigen-positive livers into hepatitis B virus-positive recipients and the role of hepatitis delta coinfection. Liver Transplant 2005; 11: 922-928
[295] Su W], Ho MC, Ni YH et al. High-titer antibody to hepatitis b surface antigen before liver transplantation can prevent de novo hepatitis b infection. J Pediatr Gastroenterol Nutr 2009; 48: 203-208

[296] Kim KH, Sang HA, Hyo YC et al. Hepatitis B virus infection after renal transplantation in the presence of antibody to hepatitis B surface antigen immunity. J Gastroenterol Hepatol 2004; 19: 847-853

[297] Gutierrez Domingo I, Pascasio Acevedo JM, Alcalde Vargas A et al. Response to vaccination against hepatitis $B$ virus with a schedule of four 40- $\mu$ g doses in cirrhotic patients evaluated for liver transplantation: Factors associated with a response. In: Transplantation Proceedings 2012: 1499-1501

[298] Robert Koch-Institut. Empfehlungen der Ständigen Impfkommission (STIKO). Epidemiol Bull 2020; 34. Im Internet: https://www.rki.de/DE/ Content/Infekt/EpidBull/Archiv/2020/Ausgaben/34_20.pdf? _blob=publicationFile

[299] Hilgendorf I, Freund M, Jilg W et al. Vaccination of allogeneic haematopoietic stem cell transplant recipients: Report from the International Consensus Conference on Clinical Practice in chronic GVHD. Vaccine 2011; 29: 2825-2833

[300] Kim DK, Riley LE, Harriman KH et al. Advisory Committee on Immunization Practices Recommended Immunization Schedule for Adults Aged 19 Years or Older - United States, 2017. MMWR Morb Mortal Wkly Rep 2017; 66: 136-138

[301] Sawyer MH, Hoerger T], Murphy TV et al. Use of hepatitis B vaccination for adults with diabetes mellitus: Recommendations of the advisory committee on immunization practices (ACIP). Morb Mortal Wkly Rep 2011; 60: 1709-1711

[302] World Health Organization. Global health sector strategy on viral hepatitis 2016-2021. Glob Hepat Program Dep HIV/AIDS. 2016: 56

[303] Poethko-Müller C, Zimmermann R, Hamouda O et al. Die Seroepidemiologie der Hepatitis A, B und C in Deutschland: Ergebnisse der Studie zur Gesundheit Erwachsener in Deutschland (DEGS1). Bundesgesundheitsblatt - Gesundheitsforsch - Gesundheitsschutz 2013; 56: 707-715

[304] Heidrich B, Cetindere A, Beyaz M et al. High prevalence of hepatitis markers in immigrant populations: A prospective screening approach in a real-world setting. Eur J Gastroenterol Hepatol 2014; 26: 1090-1097

[305] Centers for Disease Control and Prevention. Immunization of HealthCare Personnel Recommendations of the Advisory Committee on Immunization Practices (ACIP) Morbidity and Mortality Weekly Report. Mmwr 2011; 60: 1-46. Im Internet: http://www.cdc.gov/mmwr/cme/ conted.html

[306] Huzly D, Schenk T, jilg W et al. Comparison of nine commercially available assays for quantification of antibody response to hepatitis $B$ virus surface antigen. J Clin Microbiol 2008; 46: 1298-1306

[307] Brunskole Hummel I, Huber B, Wenzel JJ et al. Markers of protection in children and adolescents six to fourteen years after primary hepatitis $B$ vaccination in real life: A pilot study. Pediatr Infect Dis ] 2016; 35: 286-291

[308] Schönberger K, Riedel C, Rückinger S et al. Determinants of long-term protection after hepatitis b vaccination in infancy: A meta-analysis. Pediatr Infect Dis J 2013; 32: 307-313

[309] Chiara F, Bartolucci GB, Mongillo M et al. Hepatitis B vaccination at three months of age: A successful strategy? Vaccine 2013; 31: 1696-1700

[310] Middleman AB, Baker C], Kozinetz CA et al. Duration of protection after infant hepatitis B vaccination series. Pediatrics 2014; 133: e1500-e1507

[311] Dini G, Toletone A, Barberis I et al. Persistence of protective anti-HBs antibody levels and anamnestic response to HBV booster vaccination: A cross-sectional study among healthcare students 20 years following the universal immunization campaign in Italy. Hum Vaccines Immunother 2017; 13: 440-444

[312] Bruce MG, Bruden D, Hurlburt D et al. Antibody Levels and Protection after Hepatitis B Vaccine: Results of a 30-Year Follow-up Study and Response to a Booster Dose. J Infect Dis 2016; 214: 16-22 
[313] Harder T, Remschmidt C, Falkenhorst G et al. Background paper to the revised recommendation for hepatitis $B$ vaccination of persons at particular risk and for hepatitis B postexposure prophylaxis in Germany. Bundesgesundheitsblatt - Gesundheitsforsch - Gesundheitsschutz 2013; 56: 1565-1576

[314] FitzSimons D, Hendrickx G, Vorsters A et al. Hepatitis B vaccination: A completed schedule enough to control HBV lifelong?. Milan, Italy, 17-18 November 2011. Vaccine 2013; 31: 584-590

[315] World Health Organization. Weekly epidemiological record. Wkly Epidemiol Rec 2009; 84, 40: 405-420

[316] Werner JM, Abdalla A, Gara $\mathrm{N}$ et al. The hepatitis B vaccine protects reexposed health care workers, but does not provide sterilizing immunity. Gastroenterology 2013; 145: 1026-1034

[317] David MC, Ha SH, Paynter S et al. A systematic review and meta-analysis of management options for adults who respond poorly to hepatitis B vaccination. Vaccine 2015; 33: 6564-6569

[318] Robert Koch-Institut. Epidemiologisches Bulletin. Epidemiol Bull 2013; 36/37: 371-381. Im Internet: https://www.rki.de/DE/Content/Infekt/ EpidBull/Archiv/2013/Ausgaben/36_37_13.pdf?_blob=publicationFile

[319] Stramer SL, Wend U, Candotti D et al. Nucleic acid testing to detect HBV infection in blood donors. N Engl ] Med 2011; 364: 236-247

[320] Launay O, Rosenberg AR, Rey D et al. Long-term Immune Response to Hepatitis B Virus Vaccination Regimens in Adults With Human Immunodeficiency Virus 1 Secondary Analysis of a Randomized Clinical Trial. JAMA Intern Med 2016; 176: 603-610

[321] Robert Koch-Institut. Empfehlungen der Ständigen Impfkommission (STIKO) am Robert Koch-Institut. Epidemiol Bull 2017; 34: 333-376

[322] Mouchet J, Salvo F, Raschi E et al. Hepatitis B vaccination and the putative risk of central demyelinating diseases - A systematic review and meta-analysis. Vaccine 2018; 36: 1548-1555

[323] Vogel G. Europe's top court alarms vaccine experts. Science (80-) 2017; 356: 1320

[324] Mertens T. GfV-Stellungnahme zum EU-Urteil HBV-Impfung-MS-32017-06-23. Online 2017; Im Internet: https://www.g-f-v.org/node/ 716

[325] Sheffield JS, Hickman A, Tang J et al. Efficacy of an accelerated hepatitis b vaccination program during pregnancy. Obstet Gynecol 2011; 117: 1130-1135

[326] Raven SFH, De Heus B, Wong A et al. Fluctuation of Viremia in Hepatitis B Virus-Infected Healthcare Workers Performing Exposure-Prone Procedures in the Netherlands. Infect Control Hosp Epidemiol 2016; 37 : 655-660

[327] Gerlich WH. Prophylactic vaccination against hepatitis B: achievements, challenges and perspectives. Med Microbiol Immunol 2015; 204: 39-55

[328] Fattovich G, Boscaro S, Noventa F et al. Influence of Hepatitis Delta Virus Infection on Progression to Cirrhosis in Chronic Hepatitis Type B. J Infect Dis 1987; 155: 931-935

[329] Fattovich G, Giustina G, Christensen E et al. Influence of hepatitis delta virus infection on morbidity and mortality in compensated cirrhosis type B. Gut 2000; 46: 420-426

[330] Miao Z, Zhang S, Ou X et al. Estimating the Global Prevalence, Disease Progression, and Clinical Outcome of Hepatitis Delta Virus Infection. Infect Dis 2020; 221: 1677-1687

[331] Stockdale AJ, Kreuels B, Henrion MYR et al. The global prevalence of hepatitis D virus infection: Systematic review and meta-analysis. J Hepatol 2020; 73: 523-532

[332] Alfaiate D, Clément S, Gomes D et al. Chronic hepatitis D and hepatocellular carcinoma: A systematic review and meta-analysis of observational studies. J Hepatol 2020; 73: 533-539
[333] Le Gal F, Brichler S, Drugan T et al. Genetic diversity and worldwide distribution of the deltavirus genus: A study of 2,152 clinical strains. Hepatology 2017; 66: 1826-1841

[334] Su CW, Huang YH, Huo TI et al. Genotypes and Viremia of Hepatitis B and D Viruses Are Associated With Outcomes of Chronic Hepatitis D Patients. Gastroenterology 2006; 130: 1625-1635

[335] Spaan M, Carey I, Bruce M et al. Hepatitis delta genotype 5 is associated with favourable disease outcome and better response to treatment compared to genotype 1. J Hepatol 2020; 72: 1097-1104

[336] Roulot D, Brichler S, Layese R et al. Origin, HDV genotype and persistent viremia determine outcome and treatment response in patients with chronic hepatitis delta. J Hepatol 2020; 73: 1046-1062

[337] Wranke A, Wedemeyer H. Antiviral therapy of hepatitis delta virus infection - progress and challenges towards cure. Curr Opin Virol 2016; 20: $112-118$

[338] Wedemeyer H, Yurdaydìn C, Dalekos GN et al. Peginterferon plus adefovir versus either drug alone for hepatitis delta. N Engl ] Med 2011; 364: 322-331

[339] Wedemeyer H, Yurdaydin C, Hardtke S et al. PEG-Interferon alfa-2a plus tenofovir disoproxil fumarate for hepatitis D (HIDIT-II): a randomised, placebo controlled, phase 2 trial. Lancet Infect Dis 2019; 19: 275-286

[340] Heidrich B, Yurdaydin C, Kabaçam G et al. Late HDV RNA relapse after peginterferon alpha-based therapy of chronic hepatitis delta. Hepatology 2014; 60: 87-97

[341] Yurdaydin C, Keskin O, Kalkan Ç et al. Interferon Treatment Duration in Patients with Chronic Delta Hepatitis and its Effect on the Natural Course of the Disease. Journal of Infectious Diseases 2018; 217: 1184 1192

[342] Wranke A, Serrano BC, Heidrich B et al. Antiviral treatment and liverrelated complications in hepatitis delta. Hepatology 2017; 65: 414425

[343] Kamal H, Westman G, Falconer K et al. Long-Term Study of Hepatitis Delta Virus Infection at Secondary Care Centers: The Impact of Viremia on Liver-Related Outcomes. Hepatology 2020; 72: 1177-1190

[344] Niro GA, Smedile A, Fontana R et al. HBsAg kinetics in chronic hepatitis $D$ during interferon therapy: on-treatment prediction of response. Aliment Pharmacol Ther 2016; 44: 620-628

[345] Yurdaydin C, Abbas Z, Buti M et al. Treating chronic hepatitis delta: The need for surrogate markers of treatment efficacy. J Hepatol 2019; 70: 1008-1015

[346] Loglio A, Ferenci P, Uceda Renteria SC et al. Excellent safety and effectiveness of high-dose myrcludex-B monotherapy administered for 48 weeks in HDV-related compensated cirrhosis: A case report of 3 patients. J Hepatol 2019; 71: 834-839

[347] Keskin O, Wedemeyer H, Tüzün A et al. Association Between Level of Hepatitis D Virus RNA at Week 24 of Pegylated Interferon Therapy and Outcome. Clin Gastroenterol Hepatol 2015; 13: 2342-2349.e2

[348] Heller T, Rotman Y, Koh C et al. Long-term therapy of chronic delta hepatitis with peginterferon alfa. Aliment Pharmacol Ther 2014; 40: 93-104

[349] Yurdaydin C, Bozkaya H, Gürel S et al. Famciclovir treatment of chronic delta hepatitis. J Hepatol 2002; 37: 266-271

[350] Niro GA, Ciancio A, Tillman HL et al. Lamivudine therapy in chronic delta hepatitis: A multicentre randomized-controlled pilot study. Aliment Pharmacol Ther 2005; 22: 227-232

[351] Kabaçam G, Önder FO, Yakut M et al. Entecavir treatment of chronic hepatitis D. Clin Infect Dis 2012; 55: 645-650

[352] Soriano V, Vispo E, Sierra-Enguita R et al. Efficacy of prolonged tenofovir therapy on Hepatitis delta in HIV-infected patients. Aids 2014; 28: 2389-2394 
[353] Béguelin C, Friolet N, Moradpour D et al. Impact of tenofovir on hepatitis delta virus replication in the Swiss Human Immunodeficiency Virus Cohort Study. Clin Infect Dis 2017; 64: 1275-1278

[354] Murata K, Asano M, Matsumoto A et al. Induction of IFN- $\lambda$ as an additional effect of nucleotide, not nucleoside, analogues: A new potential target for HBV infection. Gut 2018; 67: 362-371

[355] Heidrich B, Deterding K, Tillmann HL et al. Virological and clinical characteristics of delta hepatitis in Central Europe. J Viral Hepat 2009; 16: 883-894

[356] Sureau C, Negro F. The hepatitis delta virus: Replication and pathogenesis. J Hepatol 2016; 64: S102-S116

[357] Amin J, Law MG, Bartlett M et al. Causes of death after diagnosis of hepatitis B or hepatitis C infection: a large community-based linkage study. Lancet 2006; 368: 938-945

[358] Donato F, Boffetta P, Puoti M. A meta-analysis of epidemiological studies on the combined effect of hepatitis $B$ and $C$ virus infections in causing hepatocellular carcinoma. Int J Cancer 1998; 75: 347-354

[359] Shi ], Zhu L, Liu S et al. A meta-analysis of case-control studies on the combined effect of hepatitis $B$ and $C$ virus infections in causing hepatocellular carcinoma in China. Br J Cancer 2005; 92: 607-612

[360] Cho LY, Yang J], Ko KP et al. Coinfection of hepatitis B and C viruses and risk of hepatocellular carcinoma: Systematic review and meta-analysis. Int J Cancer 2011; 128: 176-184

[361] Mak LY, Ka-Ho Wong D, Pollicino T et al. Occult hepatitis B infection and hepatocellular carcinoma: epidemiology, virology, hepatocarcinogenesis and clinical significance. J Hepatol 2020; 73: 952-964

[362] Wiegand SB, Jaroszewicz ], Potthoff A et al. Dominance of hepatitis C virus $(\mathrm{HCV})$ is associated with lower quantitative hepatitis B surface antigen and higher serum interferon- $y$-induced protein 10 levels in HBV/HCV-coinfected patients. Clin Microbiol Infect 2015; 21: 710.e1710.e9

[363] Sagnelli E, Sagnelli C, Macera M et al. An update on the treatment options for HBV/HCV coinfection. Expert Opin Pharmacother 2017; 18: 1691-1702

[364] Liu C], Chuang WL, Sheen IS et al. Efficacy of Ledipasvir and Sofosbuvir Treatment of HCV Infection in Patients Coinfected With HBV. Gastroenterology 2018; 154: 989-997

[365] Potthoff A, Berg T, Wedemeyer H. Late hepatitis B virus relapse in patients co-infected with hepatitis $B$ virus and hepatitis $C$ virus after antiviral treatment with pegylated interferon-a2b and ribavirin. Scand J Gastroenterol 2009; 44: 1487-1490

[366] Chen G, Wang C, Chen J et al. Hepatitis B reactivation in hepatitis B and $C$ coinfected patients treated with antiviral agents: A systematic review and meta-analysis. Hepatology 2017; 66: 13-26

[367] Mücke MM, Backus LI, Mücke VT et al. Hepatitis B virus reactivation during direct-acting antiviral therapy for hepatitis C: a systematic review and meta-analysis. Lancet Gastroenterol Hepatol 2018; 3: 172-180

[368] Omland LH, Christensen PB, Krarup H et al. Mortality among patients with cleared hepatitis $C$ virus infection compared to the general population: A danish nationwide cohort study. PLoS One 2011; 6: e22476

[369] Sarrazin C, Isakov V, Svarovskaia ES et al. Late relapse versus hepatitis C virus reinfection in patients with sustained virologic response after sofosbuvir-based therapies. Clin Infect Dis 2017; 64: 44-52

[370] Leumi S, Bigna J], Amougou MA et al. Global Burden of Hepatitis B Infection in People Living With Human Immunodeficiency Virus: A Systematic Review and Meta-analysis. Clin Infect Dis 2020; 71: 27992806

[371] Deutsch-österreichische Leitlinien zur antiretroviralen Therapie der HIV-Infektion. 2003

[372] European AIDS Clinical Society, (EACS). Treatment Guidelines 2016. 2016. Im Internet: http://www.eacsociety.org
[373] Gallant ], Brunetta J, Crofoot G et al. Brief Report: Efficacy and Safety of Switching to a Single-Tablet Regimen of Elvitegravir/Cobicistat/Emtricitabine/Tenofovir Alafenamide in HIV-1/Hepatitis B-Coinfected Adults. J Acquir Immune Defic Syndr 2016; 73: 294-298

[374] Robert Koch-Institut. Zur Situation bei wichtigen Infektionskrankheiten in DeutschlandVirushepatitis B und D im Jahr 2014. Epidemiol Bull 2015; 29: 271-288

[375] Gunardi H, Iskandar MY et al. Hepatitis B virus infection in children of HBV-related chronic liver disease patients: a study of intra-familial HBV transmission. Hepatol Int 2017; 11: 96-104

[376] Chen JC, Chang ML, Lin JN et al. Comparison of childhood hepatic malignancies in a hepatitis B hyper-endemic area. World J Gastroenterol 2005; 11: 5289-5294

[377] Ranger-Rogez S, Denis F. Hepatitis B mother-to-child transmission. Expert Rev Anti Infect Ther 2004; 2: 133-145

[378] Tseng YR, Wu JF, Kong MS et al. Infantile hepatitis B in immunized children: Risk for fulminant hepatitis and long-term outcomes. PLoS One 2014; 9: e111825

[379] Tabor E. Infections by hepatitis B surface antigen gene mutants in Europe and North America. J Med Virol 2006; 78 (Suppl. 1): S43-S47

[380] Gigliotti AR, Fioredda F, Giacchino R. Hepatitis B and C infection in children undergoing chemotherapy or bone marrow transplantation. J Pediatr Hematol Oncol 2003; 25: 184-192

[381] Lackner H, Moser A, Benesch M et al. Serological and molecular response on combined antiviral treatment in children with chronic hepatitis B after pediatric malignancy. Journal of Clinical Virology 2002; 25 (Suppl. 3): S73-S79

[382] Thomas HC, Lok ASF, Locarnini SA et al. (Hrsg). Viral Hepatitis. Wiley. Wiley-Blackwell. 2013

[383] Kelly D. Viral hepatitis in children. Boston, MA: Springer. 2004

[384] Bortolotti F, Guido M, Bartolacci S et al. Chronic hepatitis B in children after e antigen seroclearance: Final report of a 29 -year longitudinal study. Hepatology 2006; 43: 556-562

[385] Popalis C, Yeung LTF, Ling SC et al. Chronic hepatitis B virus (HBV) infection in children: 25 years' experience. J Viral Hepat 2013; 20: e20e26

[386] Wintermeyer P, Gerner P, Gehring $S$ et al. Prevalence of hepatitis B virus precore stop codon mutations in chronically infected children. World J Gastroenterol 2006; 12: 2235-2238

[387] Chen CY, Ni YH, Chen HL et al. Lamivudine treatment in infantile fulminant hepatitis B. Pediatr Int 2010; 52: 672-674

[388] Laubscher B, Gehri M, Roulet M et al. Survival of infantile fulminant hepatitis B and treatment with lamivudine. J Pediatr Gastroenterol Nutr 2005; 40: 518-520

[389] Diamanti A, Sartorelli MR, Alterio A et al. Successful tenofovir treatment for fulminant hepatitis B infection in an infant. Pediatr Infect Dis ] 2011; 30: 912-914

[390] Hartman C, Berkowitz D, Eshach-Adiv O et al. Long-term lamivudine therapy for chronic hepatitis b infection in children unresponsive to interferon. J Pediatr Gastroenterol Nutr 2006; 43: 494-498

[391] Jonas MM, Lok ASF, Mcmahon B] et al. Antiviral therapy in management of chronic hepatitis B viral infection in children: A systematic review and meta-analysis. Hepatology 2016; 63: 307-318

[392] Jonas MM, Chang MH, Sokal E et al. Randomized, controlled trial of entecavir versus placebo in children with hepatitis B envelope antigenpositive chronic hepatitis B. Hepatology 2016; 63: 377-387

[393] Jonas MM, Kelley DA, Mizerski J et al. Clinical trial of lamivudine in children with chronic hepatitis B. N Engl J Med 2002; 346: 1706-1713

[394] Diem HVT, Bourgois A, Bontems P et al. Chronic hepatitis B infection: Long term comparison of children receiving interferon alpha and untreated controls. J Pediatr Gastroenterol Nutr 2005; 40: 141-145 
[395] Hom X, Little NR, Gardner SD et al. Predictors of Virologic Response to Lamivudine Treatment in Children with Chronic Hepatitis B Infection. Pediatr Infect Dis J 2004; 23: 441-445

[396] Bortolotti F, lorio R, Pace $M$ et al. Long term effect of alpha interferon in children with chronic hepatitis B. Gut 2000; 46: 715-718

[397] Wirth S, Zhang H, Hardikar W et al. Efficacy and Safety of Peginterferon Alfa-2a (40KD) in Children With Chronic Hepatitis B: The PEG-B-ACTIVE Study. Hepatology 2018; 68: 1681-1694

[398] Sobaniec-Lotowska ME, Lebensztejn DM. Histological outcome of chronic hepatitis B in children treated with interferon alpha. World J Gastroenterol 2005; 11: 7179-7182

[399] Saltik-Temizel IN, Koçak N, Demir H. Lamivudine and high-dose interferon- $\alpha$ combination therapy for naive children with chronic hepatitis $B$ infection. J Clin Gastroenterol 2005; 39: 68-70

[400] Defresne F, Sokal E. Chronic hepatitis B in children: Therapeutic challenges and perspectives. J Gastroenterol Hepatol 2017; 32: 368-371

[401] Jonas MM, Kelly D, Pollack H et al. Efficacy and safety of long-term adefovir dipivoxil therapy in children with chronic hepatitis B infection. Pediatr Infect Dis J 2012; 31: 578-582

[402] Jonas MM, Kelly D, Pollack H et al. Safety, efficacy, and pharmacokinetics of adefovir dipivoxil in children and adolescents (age 2 to $<18$ years) with chronic hepatitis B. Hepatology 2008; 47: 1863-1871
[403] Murray KF, Szenborn L, Wysocki ] et al. Randomized, placebo-controlled trial of tenofovir disoproxil fumarate in adolescents with chronic hepatitis B. Hepatology 2012; 56: 2018-2026

[404] Carey I, D’Antiga L, Bansal S et al. Immune and Viral Profile from Tolerance to Hepatitis B Surface Antigen Clearance: a Longitudinal Study of Vertically Hepatitis B Virus-Infected Children on Combined Therapy. J Virol 2011; 85: 2416-2428

[405] Poddar U, Yachha SK, Agarwal ] et al. Cure for immune-tolerant hepatitis B in children: Is it an achievable target with sequential combo therapy with lamivudine and interferon? J Viral Hepat 2013; 20: 311-316

[406] Zhu S, Zhang H, Dong Y et al. Antiviral therapy in hepatitis B virus-infected children with immune-tolerant characteristics: A pilot open-label randomized study. J Hepatol 2018; 68: 1123-1128

[407] Rosenthal P, Ling SC, Belle SH et al. Combination of Entecavir/Peginterferon Alfa-2a in Children With Hepatitis B e Antigen-Positive Immune Tolerant Chronic Hepatitis B Virus Infection. Hepatology 2019; 69: 2326-2337

[408] Robert Koch-Institut. Impfstatus der Kinder und Jugendlichen in Deutschland, STIKO: Influenzaimpfungen in der COVID-19-Pandemie. Epidemiol Bull 2020; 32/33: 12

[409] Lee C, Gong Y, Brok J et al. Effect of hepatitis B immunisation in newborn infants of mothers positive for hepatitis B surface antigen: Systematic review and meta-analysis. Br Med J 2006; 332: 328-332 